\title{
BARRIERS AND CATALYSTS OF SUCCESSFUL AGING FOR LGBTQ+ OLDER ADULTS: A PHOTOVOICE STUDY
}

\author{
A Dissertation \\ presented to \\ the Faculty of the Graduate School \\ at the University of Missouri-Columbia
}

\author{
In Partial Fulfillment \\ of the Requirements for the Degree \\ Doctor of Philosophy
}

by

STEFFANY KERR

Dr. Jacquelyn Benson, Dissertation Supervisor

JULY 2021 
The undersigned, appointed by the dean of the Graduate School, have examined the dissertation entitled

\section{BARRIERS AND CATALYSTS OF SUCCESSFUL AGING FOR LGBTQ OLDER ADULTS: A PHOTOVOICE STUDY}

presented by Steffany (Sloan) Kerr,

a candidate for the degree of Doctor of Philosophy of Human and Environmental

Sciences,

and hereby certify that, in their opinion, it is worthy of acceptance.

Dr. Jacquelyn Benson, Associate Professor

Dr. Michelle Teti, Associate Professor

Dr. Chris Proulx, Associate Professor and Interim Chair

Dr. Lawrence Ganong, Chancellor's Professor and Emeritus Professor 
This dissertation is dedicated to my Nan, Mary Eugenia Simpson, my mom, Kelly Simpson, and my Pop, Bob Gene Simpson. 


\section{ACKNOWLEDGMENTS}

I would like to acknowledge and thank each member of my committee for your time, effort, and emotional resources along this journey, and in particular, during such unprecedented and stressful times. Thank you Dr. Ganong, for your vast wisdom and expertise in the field of family science. Dr. Proulx, thank you for your gentleness, while also holding high expectations. You are an expert at pointing out blind spots in my work, and pushing me to perfect the articulation of my arguments. Thank you Dr. Teti, for taking me on and mentoring me through the learning of Photovoice methods, and your guidance and expertise in working with marginalized populations. Last but not least, thank you Dr. Benson, for taking me on as a student, being my advocate and my mentor, and shaping me as an academic. I truly would not have made it to this point if it weren't for your patience, support in pushing the envelope, and your high expectations.

I would also like to thank Lilah, Miles, Violet, and August, who slept on my lap at night while I completed coursework, and showed me patience while I was working long days. You supported me even though I'm not a "real scientist" (because I don't use test tubes and beakers.) I am forever grateful to be on this life journey with you, my chaotic posse.

Finally, I would like to thank the generations of LGBTQ+ folks that paved the way. I want to acknowledge the freedom fighters, community organizers, and advocates that keep pushing for LGBTQ+ rights. I want to acknowledge those within the LGBTQ+ community that still do not benefit from equality - BIPOC queers, Black trans women who are murdered at alarming rates, and trans youth who are under constant legislative attack. Our work continues. 


\section{TABLE OF CONTENTS}

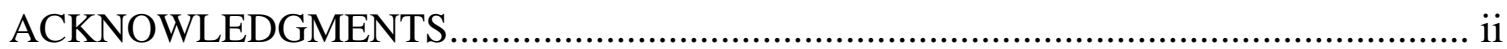

LIST OF

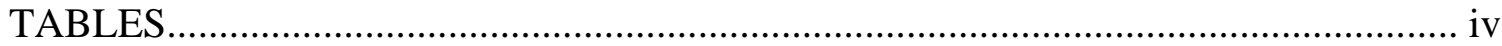

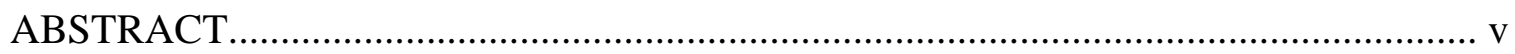

\section{CHAPTER}

1. BACKGROUND AND

SIGNIFICANCE

Literature Review

Theoretical Frameworks

2. METHODS.

Photovoice: A Visual Participatory Method

Significance of Study, Study Aims, \& Research Questions

Sample

Study Procedure

Data Analysis

3. RESULTS.

Focus Group Demographics

Photovoice Results

The Relational Landscape

Re-Writing the Narrative

Key Stakeholder Demographics

Key Stakeholder Survey Results

Images Brought Stories to Light

Nature of Identity

4. DISCUSSION

Implications for Theory and Practice

Implications for Professionals

Study Limitations

Conclusions

REFERENCES

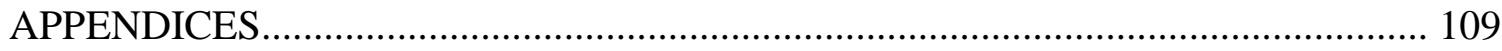

VITA 


\section{LIST OF TABLES}

FOCUS GROUP CODE

STRUCTURE

STAKEHOLDER SURVEY CODE

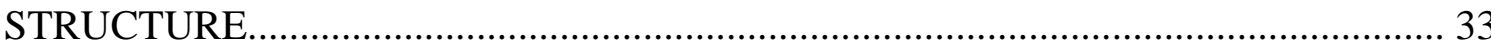

FOCUS GROUP PARTICIPANT

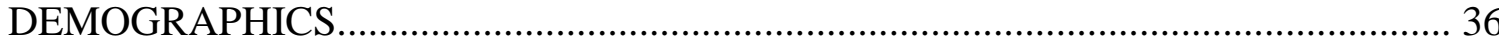

KEY STAKEHOLDER PARTICIPANT

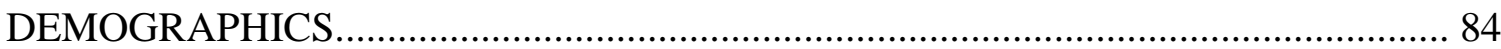




\begin{abstract}
For LGBTQ+ older adults, the intersecting influence of sexuality, gender expression, and sociocultural factors result in a distinct aging experience. The concept of successful aging is often utilized by professionals to guide policy and practice for aging populations, yet LGBTQ+ older adults are frequently absent from dominant perspectives on aging. To examine barriers and catalysts for successful aging from a queer perspective, Photovoice - a visual participatory research method — was utilized to engage participants $(n=9)$ in visually and verbally expressing their lived experience about barriers and catalysts of successful aging and overall aging experiences. The Photovoice exhibit was utilized as an educational tool for key stakeholders including health, legal, social welfare, and business professionals $(n=38)$. After viewing the virtual exhibit, stakeholders completed an online survey about the potential impact of the exhibit and reactions to the content. Drawing from interview data collected from the LBBTQ+ Photovoice participants, two primary themes were identified pertaining to what it means to age successfully as an LGBTQ+ individual: The Relational Landscape and Re-Writing the Narrative. Themes highlighted the centrality of the relationship with oneself, queer identity, and one's support network. Further, these themes articulated the importance of advocacy and representation as salient to feeling successful in later life. The key stakeholder survey yielded two themes pertaining to the educational impact of the Photovoice exhibit: Images Brought Stories to Light and Nature of Identity. These themes illustrated the ways in which professionals connected emotionally to the stories and images, and their learning about the importance of identity and timing of coming out for LGBTQ+ individuals.
\end{abstract}




\section{CHAPTER 1 -- BACKGROUND AND SIGNIFICANCE}

Sexual and gender minority older adults are a growing population, consisting of over two million individuals that identify as lesbian, gay, bisexual, transgender, nonbinary, and queer (LGBTQ+) (Fredricksen-Goldsen, Kim, Emlet, Muraco, Erosheva, Hoy-Ellis, Goldsen, \& Petry, 2011). Despite growing societal acceptance for sexual and gender diversity, LGBTQ+ older adults have been uniquely impacted by a history of discrimination and stigmatization, leading to significant health, economic, and social disparities (Jablonski, Vance, \& Beattie, 2013). Despite facing adversity across the life course, LGBTQ+ older adults demonstrate significant resilience in later life as evidenced by forging thriving social networks and fostering a positive self-concept (Hughes, Luz, Hall, Gardner, Hennessey, \& Lammers, 2016; Fredricksen-Goldsen, Jen, \& Muraco, 2019).

The complex and intersecting influence of sexuality, gender expression, and social and cultural contexts result in a distinct and nuanced aging experience (Fredricksen-Goldsen et al., 2011). It is necessary to consider how the trajectory of aging is uniquely shaped by one's queerness, and the unique aging experiences of sexual and gender minorities as compared to heterosexual and cis-gendered persons (King \& Cronin, 2010). Older LGBTQ+ adults, in particular, have benefitted least from growing acceptance of queer identities, resulting in a greater degree of exposure to minority stress. Yet, evidence suggests that older adults might uniquely benefit from later life as an opportunity to experience loosening identity constraints (Fabbre, 2015; Sloan \& Benson, 2020). The intersection of constraints and opportunities for LGBTQ+ individuals in later life can shed light on what it means to age successfully for sexual and gender minorities, 
and the ways in which queer aging is distinct from heterosexual and cis-normative populations. To consider what it means to age successfully as an LGBTQ+ person requires a queer framing to examine barriers and catalysts that influence the process of growing older (Fredricksen-Goldsen, Jen, \& Muraco, 2019).

As a foundation for exploring successful aging using a queer lens, the following literature review is framed around common barriers and catalysts that influence the aging experience. These barriers and catalysts were informed by the notion that life experiences of LGBTQ+ older adults have been significantly impacted by stress from stigma and discrimination, while also possessing inter-personal strengths, resilience, and coping (Meyer, 2003; Meyer, 2019). Given that LGBTQ+ individuals have historically been viewed through over-pathologizing and deficits-based perspectives, the dual analysis of difficulties and resilience within the aging queer community seeks to highlight a balanced perspective that encapsulates the spectrum of the lived experience (Fredricksen-Goldsen at al., 2014).

\section{Literature Review}

\section{Successful Aging}

The concept of successful aging, while used considerably in gerontological research and practice, often lacks definition consensus in the field (Rowe \& Kahn, 2015). While some define successful aging in terms of disease risk and functioning across cognitive, physical, and social domains, others argue that rigid definitions of successful aging that emphasize health are a poor fit for minority populations (Lehman, David \& Gruber, 2017). While there have been updates to models such as the Bio-Psycho-Social model to consider the broader ecological context, there remains a dearth of studies 
examining successful aging for LGBTQ+ populations (Fredricksen-Goldsen, Jen, \& Muraco, 2019). As such, barriers and catalysts of successful aging for this study are framed by the growing body of literature on LGBTQ+ older adult populations as a whole.

\section{Barriers to Successful Aging}

For the purpose of a queer-perspective analysis of factors that impact the aging experience for LGBTQ+ populations, the term barriers refer to experiences of minority stress that potentially hinder or complicate the aging experience (i.e., stigma, discrimination, violence, and rejection) (Meyer, 2003; Meyer 2010; Meyer, 2019). LGBTQ+ individuals are currently and historically impacted by hostile social environments and institutional prejudice. These experiences result in unique life course stressors that are not faced by heterosexual, cis-gender older adults, and therefore have the potential to drastically affect older adulthood. Elements of minority stress such as violence, discrimination, and stigma that are unique to LGBTQ+ individuals not only influence the physical and cognitive aging process, but create unique environmental and social challenges as well.

\section{Violence and Discrimination}

As a result of lacking societal acceptance and hostile social conditions for sexual and gender minorities, LGBTQ+ older adults have often experienced a significant number of adverse life experiences (Brown, 2009; Meyer, 2003). For instance, LBGTQ+ individuals have often endured verbal and physical assault, workplace discrimination, refusal of services and support, and legal discrimination (Cloyes, 2016). According to the Aging and Health Report survey of LGBTQ+ older adults age 50+ (Fredricksen-Goldsen et al., 2011), 68\% of all participants reported having been a victim of verbal assault. In 
addition to direct verbal or physical violence, LGBTQ+ older adults have also experienced cumulative impacts of discrimination, resource disparities, and stigma, which have been found to result in a variety of adverse physical and mental health outcomes. (Fredricksen-Goldsen, Jen, \& Muraco, 2019; Testa, Habarth, Peta, \& Basalm, 2015). For instance, Fredricksen et al. (2015) found a significant negative association between total lifetime victimization and discrimination and evaluations of quality of life. Moreover, long term exposure to violence is associated with poor mental health conditions and decreased engagement with social supports (Fredricksen-Goldsen, CookDaniels, Kim, Erosheva, Emlet, Hoy-Ellis, Goldsen, \& Muraco, 2013).

Research over the last two decades has highlighted that in terms of discrimination and violence, not all LGBTQ+ older adults are affected equally (Fredricksen-Goldsen et al., 2011). Despite growing acceptance for sexual and gender minority identities, older cohorts of LGBTQ+ individuals have benefitted least from changing societal acceptance of sexual and gender minorities. For example, the oldest LGBTQ+ individuals have been impacted most significantly by adverse social conditions. This age cohort also demonstrates higher numbers of chronic mental and physical health conditions as compared to younger LGBTQ+ cohorts (Jenkins-Morales, King, Hiler, Coopwood, \& Wayland, 2014). Further, in comparison to younger age cohorts, the oldest age group (age 80+) were found to have the most significant association of discrimination and victimization on mental and physical health as a result of spending the greatest amount of one's life course in hostile socio-cultural conditions (Fredricksen-Goldsen et al., 2015). 


\section{Stigma}

Stigma, in reference to LGBTQ+-specific minority stress, refers to the internalization of negative attitudes and perceptions, and also the anticipation of hostile social conditions (Meyer, 2003; Meyer 2010; Meyer 2019). Internalization of negative societal attitudes pertaining to one's gender identity and/or sexual orientation is associated with increased depression, anxiety, and suicidal behaviors. Moreover, hypervigilance, or stress induced by anticipating discrimination or victimization, is also associated with higher levels of suicide ideation, self-harm, and mental health conditions (Cloyes, 2016; Jenkins-Morales et al., 2013; Zelle \& Arms, 2015). While the implications of stigma are often present in those across the gender and sexual identity spectrum to some degree, transgender individuals are often at the greatest risk for negative effects of stigma. $71 \%$ of transgender older adults represented in the Aging and Health Survey reported considering or trying suicide, and $48 \%$ experience depression (FredricksenGoldsen et al., 2011). Further, bisexual older adults are also at increased risk of mental health challenges as a result of stigma, with $35 \%$ of bisexual women and $36 \%$ of bisexual men reporting depression, as compared to $31 \%$ of the overall LGBTQ+ older adult population.

In addition to greatly impacting mental health, internalized stigma also contributes to identity-hiding. "Coming out" or publicly proclaiming one's sexual or gender identity, is a process found to contribute to positive identity development (Fabbre, 2015). Further, being able to outwardly express one's identity promotes access to meaningful social connections, and decreases the likelihood of loneliness in later life (Fredricksen-Goldsen et al., 2011; Fredricksen-Goldsen et al., 2015). A fear of exposing 
one's gender or sexual identity can often manifest as fear-based avoidance of the health care system, barriers to accessing needed social services, and disruptions in social support (Yarns et. al., 2016). As such, cumulative effects of anticipated hostility, hypervigilance, and hiding of one's identity can have serious consequences in later life, and create significant barriers in the aging process (Kuyper \& Fokkema, 2010).

\section{Catalysts for Successful Aging}

Catalysts refer to cultivated resilience and elements of joy present in the face of minority stress, that can manifest as enjoyable aging experiences or mechanisms to buffer stress for LGBTQ+ older adults (Meyer, 2010). Catalysts also refer to pathways to thriving, which can manifest through personal expression, enjoying activities, or healthy support systems. For older LGBTQ+ adults, experiencing minority stress across the life course can also serve as a catalyst for developing coping mechanisms or protective strategies through positive identity development and pride (Meyer, 2003).

\section{Positive Identity}

While the process of publicly expressing one's sexual or gender identity can be stressful, the ability to express one's identity also serves as a protective mechanism (Meyer, 2003). For instance, in a cross-sectional study, Fredricksen-Goldsen et al. (2015) found a positive association between self-esteem and quality of life, which often increased as LGBTQ+ adults aged. Furthermore, in a longitudinal, comparison study of older and younger gay men, perception of life mastery increased with age, and was shown to contribute to positive identity in later life (Wright, LeBlanc, de Vries, \& Detels, 2012). Evidence suggests that for transgender individuals, who are more heavily stigmatized than their sexual minority counterparts, gender transition and identity 
expression can promote quality of life in later years. For instance, in a qualitative study, Fabbre (2015) found that for transgender women who transitioned in later life, shedding heteronormative ideals about older adulthood, and developing a positive sense of self facilitated a feeling of success as an older adult. Confidence and shedding of internalized stigma allowed transgender older adults to feel a sense of purpose in later life, and illuminated the role of positive identity and expression as a form of resilience.

\section{Agency and Advocacy}

The well-documented history of Stonewall, during which time LGBTQ+ individuals rioted against police brutality and discrimination, highlights that queer older adults have been asserting their personal agency through advocacy endeavors for decades (Butler, 1993). This is not only a historical phenomenon in the face of oppression, rather it continues to serve as a component of fostering quality of life and promoting feelings of success. For $\mathrm{LGBTQ}_{+}$older adults, self-efficacy and asserting personal agency can also promote resilience. In a study examining the role of theater to communicate challenging life experiences of older sexual and gender minorities, findings highlighted the positive impact on identity and feelings of resilience associated with sharing stories with the public (Hughes, Hall, Gardner, Walker, Hennessey, \& Lammers, 2016). Further, for LGBTQ+ older adults living with HIV, advocacy activities were found to be central to one's positive identity, as uplifting, caring for, and working toward equity for others experiencing HIV facilitated feeling a sense of purpose (Fabbre, 2015; FredricksenGoldsen et al., 2011). 


\section{Social Support and Networks}

A large body of evidence has illuminated the connection between social relationships and positive health outcomes ranging from encouraging healthy behaviors, to providing instrumental support necessary for accessing health services and navigating the health system (Benson, Sloan, \& Halt, 2018; Cohen, 2004; Fredricksen-Goldsen et al., 2011). Further, social supports have been found to be key to facilitating resilience and coping for LGBTQ+ older adults (Fredricksen-Goldsen et al., 2013; Fredricksen-Goldsen et al., 2015). While some evidence suggests that LGBTQ+ older adults are at higher risk for social isolation and loneliness, they have also been found to have thriving social networks (Fredricksen-Goldsen et al., 2011). Nearly 90\% of LGBTQ+ older adults report being connected with a social network, and $60 \%$ report having supportive family (Fredricksen-Goldsen et al., 2011). Moreover, a study conducted by Croghan et al. (2014) found that $69.2 \%$ of transgender women and $43.8 \%$ of transgender men were partnered at the time of data collection, and that $69.6 \%$ of transgender women and $73.3 \%$ of transgender men reported having family of choice. Additionally, social network size and quality have been found to buffer stress resulting from discrimination and stigmatization (Erosheva et al., 2017). This finding is especially pertinent, as it demonstrates that while LGBTQ+ older adults may experience higher levels of minority stress in comparison to heterosexual and cis-gendered individuals, social supports can counter effects of negative experiences. In a cross-sectional investigation of social networks in a sample of LGBTQ+ older adults, findings suggest that across the life course, social networks are effectively used to mobilize existing and future access to resources, particularly for individuals with diverse social networks (Erosheva, Kim, Emlet, \& Fredricksen-Goldsen, 2016). 


\section{Theoretical Frameworks}

As a means to apply a queer lens to considering successful aging for LGBTQ+ older adults, queer theory and life course perspective serve as foundational guiding frameworks. These theories frame the intersection of sexual orientation and/or gender identity and socio-historical context as salient to the aging experience for LGBTQ+ older adults, and provide theoretical insight to how sexual and gender minorities describe successful aging in later life.

\section{Queer Theory}

Queer theory focuses on the ways in which sexual and gender identities are fluid and attends to the ways in which identities are uniquely impacted by power imbalances and social disparities (King \& Cronin, 2010). Queer theory also serves to critique the notion that traditional values, heteronormative assumptions, and cis-gendered status are disproportionately applied as the lens through which we seek to understand human behavior. To apply queer theory is to attend to the notion that sexual orientation and gender identity are salient factors in one's identity development and life experiences, and that our method and approach of inquiry should be inherently influenced by perspectives outside of the gender and sexual binary (King \& Cronin, 2010). Further, the application of queer theory - in gerontology in particular-recognizes the intersection of queerness and aging for a more holistic examination of the spectrum of barriers and catalysts that influence later life for the LGBTQ+ older adult population (Brown, 2009).

Queer theory terminology originated from the LGBTQ+ activist movement in the wake of the HIV/AIDS crisis as a means to reclaim the word "queer" that was historically used as a slur toward gays and lesbians (Halperin, 2003). Although there is lack of 
consensus about how to precisely define the term queer, the expression has persisted as the means by which scholars illustrate the LGBTQ+ lived experience (Butler, 1993). At its essence, queer theory challenges power dynamics and highlights the importance of considering gender and sexual identity as salient to, and intertwined with, the lived experience. Current iterations of queer theory within family science place further emphasis on the spectrum of identities, and the importance of viewing gender identities and sexual orientations as distinct from each other, and critique power dynamics that perpetuate social hierarchies within the LGBTQ+ community (Oswald, Kuvalanka, Blume, \& Berkowitz, 2013).

\section{Iridescent Life Course Perspective}

For LGBTQ+ older adults, the complex and intersecting forces of sexuality, gender expression, social, and cultural contexts result in distinct aging experiences. The iridescent life course perspective was developed to interject a queer lens to the traditional life course theory and to better understand life course factors unique to LGBTQ+ individuals across the socio-historical landscape (Fredricksen-Goldsen, Jen, \& Muraco, 2019; Elder, 1994).

The iridescent life course perspective (Fredricksen-Goldsen, Jen, \& Muraco, 2019) adheres to the traditional tenants of life course theory, which focus on four primary themes: 1) Lives and historical times (i.e., historical effects, cohort effects, impacts of social change), 2) Timing of lives (i.e., timing and sequence of roles, intersection of events and age, normative and non-normative development, focus on life stage), 3) Linked lives (i.e., intersections between individual and social lives, influence of social networks, socialization, intergenerational trajectories), and 4) Human agency (i.e., 
interactions with environmental constraints, choice, personal efficacy, resilience) (Elder, 1994). By applying a queer lens, however, the iridescent life course perspective recognizes more fluidity in the process of aging and identity development over time.

Further, this perspective balances the framing of constraints due to life-long stigma and marginalization with unique protective factors prevalent within the LGBTQ+ aging community. In particular, the iridescent life course perspective allows for better insight pertaining to cohort factors, shifting socio-political contexts, and impacts of social conditions. 


\section{CHAPTER 2 - METHODS}

\section{Photovoice: A Visual Participatory Methodology}

The socio-cultural landscape of LGBTQ+ individuals has been disproportionately impacted by discrimination, violence, and marginalization. As a result, this population can be rightfully mistrusting of dominant culture given the history of harm done by those in power (Halperin, 2003; Muhammad, Wallerstein, Sussman, Avila, Belone, \& Duran, 2015). Historically, research on LGBTQ+ individuals has been littered with oppression and harm. For instance, The American Psychological Association has routinely pathologized sexual and gender minorities as plagued by mental illness and social deviance. Given the deep history of oppressive relationships between academics and sexual and gender minority populations, research must be approached using methods designed to dismantle the disproportionate power dynamic that exists between researcher and participant (Mitchell, 2011; Wang \& Burris, 1997). Further, for populations with a history of trauma and oppression, dominant discourse is often insufficient at capturing the lived experience, as it is rooted in the oppressive power structures. When the goal is to articulate the lived experience outside of cis-gender and heteronormative perspectives, tools of inquiry must have the appropriate capacity to operate outside the confines of dominant culture (Lorde, 1979, as cited in Lorde \& Gay, 2020).

Participatory action research methods were designed to dismantle power structures inherent to academic research by including participants in the data collection, analysis, and dissemination processes, while also serving as a tool for social empowerment and advocacy (Mitchell, 2011; Wang \& Burris, 1997). Specifically, Photovoice, a visual participatory research method, was developed to engage participants in visually 
documenting and reflecting on their experiences. The use of photos to convey the lived experience, especially for historically oppressed populations, has the potential to articulate constructs outside of the dominant social and cultural discourse, while also incorporating the use of other qualitative data generated through focus groups and interviews (Burles \& Thomas, 2014). Moreover, the process of generating visual data can serve as a particularly transformative experience for participants, especially with promoting self-efficacy and positive identity development (Teti, Pichon, Kabel, Farnan, \& Binson, 2013).

Photovoice methods are distinct from other qualitative and visual methods in that they are action-oriented, and designed to promote socio-cultural change (Wang, 1999). Data are intended to bring attention to and promote dialogue about individual and community issues, while also serving to disseminate research directly to key stakeholders and policy makers (Wang et al., 1998; Wang, 1999). For Photovoice in particular, data are disseminated via an exhibit consisting of participant-generated visual data for the purpose of amplifying marginalized participant perspectives and affecting social policies and practices (Fine, 2006; Wang, 1999).

For older LGBTQ+ individuals, Photovoice has the potential to be uniquely powerful for illuminating aspects of the aging experience that might otherwise remain invisible. Visual data can serve to promote exploration and meaning-making of the queer aging experience - to capture challenges and resilience inherent to the LGBTQ+ life course (Carlson, Engebretson, \& Chamberlain, 2006). Although the definition and concept of successful aging has been debated within the gerontology literature (Fredricksen-Goldsen et al., 2015; Lehman, David, \& Gruber, 2017; Martin, Kelly, 
Kahana, Wilcox, \& Poon, 2015), Photovoice methods have the potential to accommodate flexible definitions of aging successfully, and communicate lived experiences outside of cis-normative and heterosexual perspectives. This process can be especially validating for LGBTQ+ older adults who are often absent from dominant perspectives on aging, as well as underrepresented in queer communities (Brown, 2009; Walker, Powers, \& Witten, 2017). As such, the present study utilizes Photovoice methods to explore the concept and experience of aging successfully among the LGBTQ+.

\section{Ethics and Reflexivity}

When applying visual participatory methods, it is necessary to consider that while the voices and experiences of marginalized populations are amplified, so is the risk to participants wellbeing. Historically stigmatized or marginalized populations are more vulnerable to exploitation and harm, which serves as the impetus for using participatory methods (Buckingham, 2009; Mohammad et al., 2015; Mitchell, 2011). Given that photovoice methods include participants in data collection and analysis, the method inherently decentralizes the role of the researcher, leading to empowerment of participants and reducing the likelihood of unintentional harm to participants (Leach, 2006).

In order to fully address challenges related to power imbalance between researcher and participants, it necessary to build trust to foster equitable researcher and participant relationships (Wang, 1999). Facilitating conversations amongst participants about risk, visibility, and privacy allows for a more transparent informed consent process. Moreover, engaging in reflexivity helps to prevent over or under interpretation of the data, and appropriately attune to the messages and priorities of the participants (Leach, 
2006; Stoudt, Fox, \& Fine, 2012). Reflexivity is the process by which a researcher engages in self-reflection and analysis in relation to the ways in which the researcher's identity and experiences influence inquiry and data interpretation (Finlay, 2008). Engaging participants in dialogue about one's positionality and advocacy goals throughout the data generation and analysis process promotes researcher reflexivity as well as the facilitation of participant checking (de Vries \& Croghan, 2014). Participant checking occurs when the researcher engages participants in discussion about the accuracy of findings, and is a vital part of the participatory research process (Israel, Eng, Schulz, \& Parker, 2013). Transparency about aspects of positionality such as researcher interests, roles, goals, and privilege can also support the reflexivity process and encourage equitable researcher-participant dynamics (Muhammad et al., 2015).

\section{Action-Oriented Dissemination}

Photovoice methods are distinct from other qualitative and visual methods in that they are action-oriented, and designed to stimulate community advocacy (Wang, 1999). To that end, Photovoice includes an integral component as a means to disseminate findings, a community-based exhibit (Wang, Yi, Tao, \& Carovano, 1998). Visual methods are evocative, and can yield unique emotional reactions, making visual data especially effective for driving change with service providers and key stakeholders (Joffe, 2007). Such action-oriented dissemination of research findings has the potential to shift dominant-culture perspectives, and promote ongoing change-making for marginalized populations. 


\section{Significance of Study, Study Aims, \& Research Questions}

Notions of successful aging often shape approaches to service delivery for older adults by influencing assumptions about aging trajectories. What it means to age successfully, however, is generally influenced by dominant culture (i.e., white, middle class, heterosexual, cisgender). For aging LGBTQ+ populations, however, norms pertaining to successful aging can lead to a deficits-based perspective of those whose life course has been disproportionately impacted by stigma, marginalization, discrimination, health disparities, and poor environmental or economic conditions. As such, the primary aim of this study is to investigate notions of successful aging; particularly barriers and catalysts that contribute to aging successfully for older LGBTQ+ individuals. Further, this study used participatory action research methods to explore this topic, specifically Photovoice. While Photovoice as a method has demonstrated efficacy as a methodological approach, little is known about the impact of viewing the exhibit, and the level of influence these methods might have on systems, practices, and policy. To address this gap in the research literature, the secondary aim of this study is to assess a Photovoice exhibit as a means to educate service providers who might serve LGBTQ+ older adults. In sum, the following research questions were addressed:

1. What are the primary barriers and catalysts for successful aging for $L G B T Q+$ older adults?

2. What is the impact of using the Photovoice exhibit as a community education tool for service providers? 


\section{Sample}

\section{LGBTQ+ Older Adult Participants}

I recruited a total of nine LGBTQ+ older adults (age 50+) using theoretical sampling within a mid-sized midwestern city. This sample size reflects that of similar studies utilizing Photovoice, and accounts for facilitating intimate, critical dialogue within the discussion groups, as well as the collection of data from multiple sources (Teti et al., 2013; Wang \& Burris, 1997).

Recruitment took place via LGBTQ+ service organizations, social and health service providers, and local LGBTQ+ social media groups. To participate, individuals were required to be age 50 or older and identify as a sexual and/or gender minority (i.e., lesbian, gay, bisexual, transgender, queer, gender non-binary, asexual, intersex, etc.). Although older adults are typically defined as those age 65 and older, LGBTQ+ adults represent a population in which life expectancy has been significantly affected and altered by the AIDS epidemic, as well as numerous health disparities. Given those sociohistorical factors, it has been customary in queer gerontology studies to broaden the definition of older adult to include those 50 and older (Fredricksen-Goldsen et al., 2011).

\section{Sampling Procedure}

LGBTQ+ older adults are a seldom seen, seldom heard population, meaning that they are often lacking visible representation. As such, I used snowball sampling to reach potential participants. Participants were recruited via social media (i.e., Facebook, Twitter, and Instagram) ads that were posted and shared to pages and groups that pertained to LGBTQ+ individuals. The recruitment ad invited interested individuals to contact me via phone, text, or email to learn more about the study and eligibility. While 
the majority of recruitment was centralized within a mid-sized midwestern city, interested participants from other parts of the United States were also considered, given the virtual data collection approach. As such, the recruitment ad was shared to social media pages and groups that included individuals from across the United States.

Screening. Interested participants contacted me via email, text, or via phone using the information provided on the study ad. To determine fit for the study, I used a screening protocol that included asking participants for their age, date of birth, LGBTQ+ identity associations, comfort level with the necessary technology, and ability to provide informed consent. I also provided the interested party information about the time commitment of the study and focus group procedures.

Inclusion Criteria. In addition to the aforementioned age requirement, participants were required to self-determine that they possess the cognitive capacity to provide informed consent, reside in the United States, and have the ability to fulfill the time and technology requirements of the study. Due to risks related to Covid-19, particularly for older adults, I conducted this Photovoice study utilizing a virtual approach (i.e., Zoom). In order to participate in the study, individuals needed technology necessary for utilizing Zoom, and to possess the technological skills to fully operate the equipment (i.e., a wifi-enabled smartphone or computing device equipped with a camera and microphone; access to a stable internet connection.) Further, participants were required to hold an identity within the LGBTQ+ spectrum, including but not limited to: Lesbian, gay, bisexual, transgender, queer, intersex, asexual, or non-binary. Given the wide range of queer identities, participants self-identified as a fit for the queer focus of the Photovoice study. 


\section{Informed Consent}

IRB approval was obtained prior to recruitment, and participants were required to provide informed consent prior to participation. Those interested in participating in the study were invited to contact me via email, text, or telephone for screening. Interested individuals were provided information about what to expect with participation, including focus group procedures, picture taking, time requirements, and potential risks. They were also informed that this study was intended to better understand getting older as an LGBTQ+ individual, including challenges and resilience. Upon ensuring that inclusion criteria were met and receiving verbal or written confirmation of interest to opt into the study, participants were asked to complete the consent form and a brief demographic survey. Individuals were provided a copy of the informed consent for their records. Prior to the start of each focus group, participants were reminded that participation in the study was voluntary and that they could withdraw at any time. In addition, I read aloud a script (see Appendix) at the start of each focus group to remind individuals of their rights as a participant.

Given that this study includes photos taken by participants, there is a possibility of other individuals appearing in the photos presented for this project. As such, it is necessary to also include processes for obtaining informed consent from any individual included in photos submitted by participants. Upon engaging in the study, participants were briefed on how to obtain informed consent from individuals included in photos generated for this project, instructed about the importance of ensuring consent, and provided with a form to obtain written consent. 


\section{Key Stakeholder Participants}

A total of 38 key stakeholder participants were asked to view the virtual Photovoice exhibit of the Photovoice data generated during the photo-taking and interviews with the LGBTQ+ participants. I recruited key stakeholder participants using a convenience sample, through social media, as well as direct contact using a list of commonly used service providers from a local LGBTQ+ community center. Email communication was used to invite stakeholders to participate in the study, which included viewing the online exhibit and completing a follow-up survey about their reactions. Inclusion criteria for key stakeholder participants required that they work in a relevant health, social service, advocacy, non-profit, commerce, or legal position that serves either LGBTQ+ individuals or the aging population. Due to the small number of LGBTQ+ older adult services that exist, key stakeholders were not required to serve the older LGBTQ+ population specifically, as they could serve the general population of older adults or serve LGBTQ+ populations of other age cohorts. To participate in the exhibition and survey, stakeholders were required to possess necessary technology to access the internet and complete the online survey. Stakeholder participants were engaged in the study anonymously, however, they were invited to "opt in" to share their identifying information, if willing for the purposes of participating a more extensive interview or focus group regarding the exhibit in the future.

\section{Sampling Procedure}

Service professionals represented education, social work, LGBTQ+, healthcare, financial services, non-profit, or advocacy group professionals. I initiated direct contact with these professionals via email, providing information about the study and the time 
requirement. Interested individuals were invited to respond to the inquiry email. Given that only service providers that met the criteria for participation were contacted and invited to participate, no additional screening was necessary.

\section{Protection of Human Subjects}

While there were no anticipated risks for participating in this study, participants were informed that there was a potential to discuss subject matter that could be upsetting, such as stigma, violence, discrimination, or rejection. In order to ensure protection of human subjects, participants were briefed on these potential risks in advance, and were regularly informed that they did not have to discuss topics or ideas that made them uncomfortable. Further, participants were briefed on aspects of protecting their privacy prior to photo-taking. I provided one-on-one photo ethics and privacy briefs, which included avoiding pictures with identifying or personal information (i.e., names, addresses, social security numbers, etc.). Participants were also educated on the importance of obtaining informed consent from others included in their photos, and provided forms for obtaining consent.

The Photovoice exhibit, consisting of photos and excerpts created as a result of the Photovoice focus groups, was organized on a private website for viewing. Privacy was ensured by establishing privacy settings on the exhibit website, which limited viewing to only individuals provided with the link and password. I removed all participant names and instead applied a pseudonym for each participant to ensure anonymity. Participants were provided a unique password to access the exhibit. This measure was taken to protect the privacy of focus group participants and prevent sharing of the website to non-participants. 


\section{Study Procedure}

\section{Photovoice Discussion Groups}

I conducted a total of two, two-hour long virtual focus groups with three older adult LGBTQ+ participants each. Focus groups were kept intentionally small in order to maintain a level of intimacy necessary for participants to share photos and thoughts freely (Mitchell, 2011; Wang \& Burris, 1997). Participants were assigned to focus groups based on availability and order of recruitment, with new focus groups opening as needed after others reached capacity. Prior to the start of each focus group, I held one-on-one briefing sessions via phone. Briefing sessions consisted of an introduction to the project, discuss project guidelines, photograph tutorials, and photo-taking ethics (Teti, Koegler, Conserve, Handler, \& Bedford, 2018). I also briefed participants on strategies to ensure anonymity, risks and benefits of choosing to include intimate or private topics in photos, and general photo-taking ethics. After the briefing session, each participant was asked to take or gather photos using the following guiding questions:

What is it like growing older as an LGBTQ+ person?

How do you express your identity?

What brings you joy?

What are some challenges you face?

What do you wish others better understood about you?

Once photos were taken and selected, participants were instructed to electronically send a selection of 3-10 photos to me that they would like to present to their focus group. As the sole facilitator of the Photovoice focus groups, I used Miro, a software designed to facilitate visual collaboration, to organize photos submitted by each 
participant as well as guiding questions to serve as a visual aid to guide discussion. Photos were grouped by participant and hosted on the facilitator's screen, which was displayed via screen-share for the duration of the focus group. At the start of each focus group, I read aloud an informed consent script to gain verbal consent from participants to begin recording the session. Next, participants were invited one-by-one to present and discuss their photos. A semi-structured interview protocol was used to guide discussion, which included, but was not limited to the questions above (see Appendix C). As each participant discussed their photos, I utilized Miro to zoom into and navigate throughout the photos as discussion progressed.

During the process of conducting focus groups, I documented the process in a series of field notes to guide the reflexivity process and decision-making about focus group structure, pace, and possible changes to the semi-structured protocol. For instance, field notes were written to document the process of determining effective group size, making adaptations to the semi-structured protocol, and document ideas about more effective group facilitation approaches. Field notes were then used to inform improvement to and reflexivity throughout the process of conducting focus groups.

\section{Creation of the Photovoice Exhibit}

After each focus group, the recordings were used to transcribe each session verbatim. Transcripts were used to identify and select pertinent quotes to accompany each photo in the exhibit. I used Miro and an additional visual tool, Canva, to organize participant photos and excerpts. Canva provides a variety of free templates, backgrounds, and visual website builder tools that were used to arrange photos on a visually appealing background, along with quotes from the focus group. The Photovoice exhibit was 
organized and displayed on a private Wordpress site, using the slideshow feature. The exhibit used a home page with one button for each participant, which enabled viewers to view photos and excerpts as a slideshow for each individual participant (see Appendix A). After generating a mock-up of the photo and excerpt slideshow, I sent the slideshow to each participant as an email attachment for the purpose of participant-checking and validation. Participants were asked to review their slideshow and offer any feedback, corrections, or suggestions for creative or visual display. I also asked participants to provide final approval for their slideshow before officially adding it to the Photovoice exhibit website. All participants provided their final approval to include their slideshow in the Photovoice exhibit.

Once the Photovoice exhibit was fully constructed and the website was complete, focus group participants were invited to attend a final virtual focus group to view and discuss the exhibit. The virtual exhibit was attended by the majority of participants $(n=7)$. Participants not able to attend provided consent for the facilitator to display and discuss their photos during the exhibit in their absence. The final exhibit focus group consisted of each participant presenting and describing their photos and excerpts to the group, which was followed by a group discussion guided by a semi-structured protocol. This final focus group took place prior to sending the virtual exhibit to key stakeholders to provide focus group participants with the opportunity to view and discuss the final exhibit. During this virtual focus group, I also provided an opportunity to offer suggestions or changes before the Photovoice exhibit was distributed to key stakeholders for viewing. 


\section{Key Stakeholder Exhibit Viewing}

After providing focus group participants with the opportunity to virtually gather and discuss the Photovoice exhibit, it was then distributed to key stakeholders. In order to protect the privacy of focus group participants, key stakeholders were provided with a unique password required to view the exhibit. Further, the password was set to expire after 72 hours to prevent sharing of the exhibit to non-participants. Key stakeholders were asked to view the exhibit, consisting of viewing each participant's slide show with photos and excerpts, and complete an open-ended written survey to better understand the potential impact of using a Photovoice exhibit as a community education tool (see Appendix K ). An email was sent to each individual key stakeholder participant providing the link and password for the Photovoice exhibit, along with a link to the Qualtrics survey.

\section{Data Analysis}

\section{Focus Groups}

During the process of conducting focus groups, I created analytic memos to guide the reflexivity process and decision-making. For instance, memos were written to document the process of determining effective group size, making adaptations to the semi-structured protocol, and promote more effective group facilitation approaches. Focus groups were recorded and transcribed verbatim, with additional analytical memos created during the transcription process to reflect upon facilitation skills, pertinent questions, and surprising or intriguing responses. Focus group transcripts and analytical memos were imported into MAXQDA software. Thematic analysis was used to guide the process, which consisted of reviewing transcripts, creating further analytical memos, and 
organizing photo data. (Braun \& Clarke, 2012). Given that MAXQDA has the capacity to include digital media data, participant photos were also imported for analysis.

\section{Survey Responses}

Survey responses obtained via key stakeholders invited to view and reflect on the virtual exhibit were imported into a separate MAXQDA project and analyzed independently of the focus group and photo artifacts. While it was anticipated that some themes and concepts would overlap between the Photovoice data and survey responses, I approached the analytical process assuming the need for two separate code structures. As such, survey responses were exported via Qualtrics and imported into a separate and unassociated MAXQDA project to maintain independence across the data analysis process.

\section{Focus Group Data Coding Procedure}

Initial Coding. The analytical procedure for coding focus group data was guided by the use of thematic analysis (Braun \& Clark, 2012) to identify themes and meaning within and across the data. The coding process began with becoming familiar with the data, which occurred by listening to the focus group recordings several times, reviewing and ensuring accuracy of the transcripts, and reviewing each photo artifact. Throughout this initial data familiarization stage, I created analytical memos to document observations and noted points of interest, curiosity, and inquiry that might guide the coding process. After becoming familiar with the data, all transcripts and photos were imported into MAXQDA software to prepare for initial coding. I then began the coding process by highlighting and annotating salient words, phrases, topics, and patterns within the transcript data. Given that individuals referenced specific photos within the focus 
group transcripts, I created a code label for each photo, which also corresponded to the photo artifacts. The purpose of this process was to associate which photo was being described within the focus group transcript, while also having the ability to tag photo artifacts using the emerging code structure for the purpose of associating photos with the sections of the transcript in which they were referenced. Further, this ensured that both focus group transcripts and photo artifacts were linked within the transcripts and labeled with codes assigned to corresponding portions of text. For example, the example below shows the coded documents/artifacts on the left, and the corresponding codes on the right.
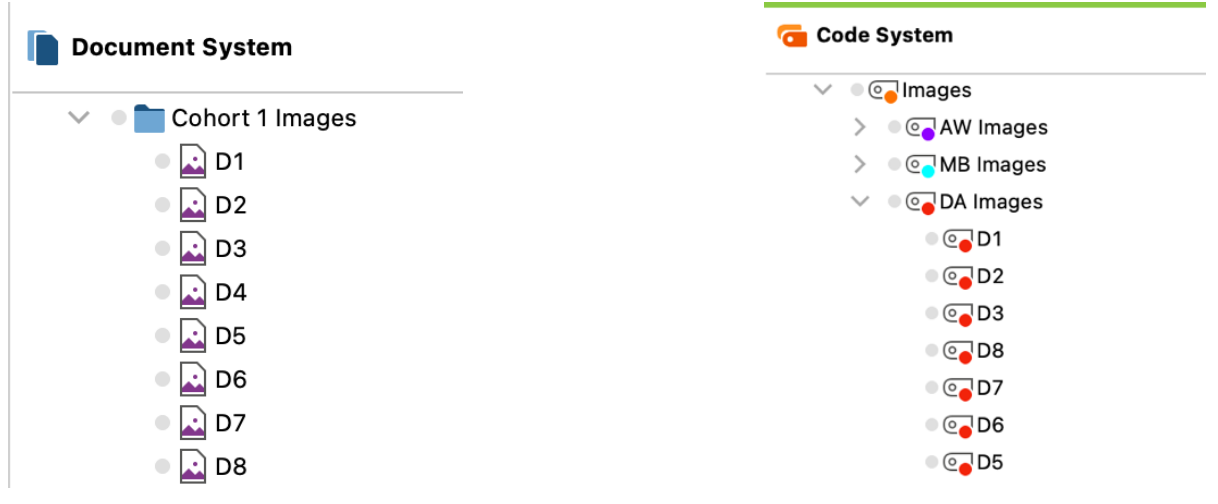

Searching for Themes. Next, I identified words and phrases generated from focus group transcripts and photos, and created analytical memos to identify and describe initial descriptive code labels informed by the initial coding process. Patterns and themes were identified within the initial descriptive codes, which informed the initial code hierarchy. I then conducted a second round of analysis, applying the first iteration of the code structure to each focus group transcript and photo artifact. Analytical memos were created to document the process of expanding and collapsing codes, as greater meaning and patterns were identified within the data. For instance, the initial codes recognizing 
identity and denying identity were collapsed into a single code of coming

out/transitioning as the broader themes related to identity became clear. The following excerpt provides an example of how the code book shifted as the code book was refined:

\begin{tabular}{|l|c|c|}
\hline \multicolumn{1}{|c|}{ Excerpt } & Initial Coding & Searching for Themes \\
\hline $\begin{array}{l}\text { It stripped a lot of things away } \\
\text { including the boy facade that I wore } \\
\text { for many years. I knew at age 6 that } \\
\text { something wasn't right, but because I } \\
\text { grew up in a fairly strict household...I } \\
\text { had to pretend for a long long time } \\
\text { that everything was normal. Which, it } \\
\text { absolutely wasn't. }\end{array}$ & $\begin{array}{c}\text { denying identity } \\
\text { grappling with identity } \\
\text { recognizing identity }\end{array}$ & $\begin{array}{c}\text { Coming } \\
\text { Out/Transitioning }\end{array}$ \\
\end{tabular}

Reviewing Potential Themes. As the code book was refined, I then began the process of reviewing for theme quality, coherence, and salience. First, I reviewed the code frequency chart to help shape the prioritization of themes. I considered opportunities for eliminating themes that were not well supported, or determined whether themes needed to be collapsed or re-organized. Themes that were not broadly applied across transcripts were considered for elimination or re-organization. For instance, the theme of retirement was not frequently applied and only present within one participant. That theme was instead collapsed into the theme living at a slower pace, which was more frequently applied. Theme coherence was determined by revisiting the research questions and the overarching story told within the data, as I considered broader barriers and catalysts for LGBTQ+ older adults, and the ways in which they exemplified successful aging. I also considered salience of each theme, which required the theme to pertain to the research question in a significant way.

Defining and Naming Themes. After reviewing the quality, coherence, and salience of themes, I then revisited the broader names of themes and ensuring that each 
theme could be clearly defined in a way that clearly addressed the study aims. Through the process of constructing and reviewing analytical memos, I grappled with different approaches for articulating barriers and catalysts of successful aging. While barriers and catalysts were evident throughout the data, and were guiding forces in the identification of successful aging for LGBTQ+ older adults, they were not, in and of themselves, the best way to articulate and define successful aging. Therefore, this reflection resulted in some re-naming and re-defining of the code structure to better capture the elements of aging successfully that were articulated by participants in their photos and narratives. For example, after reflecting upon the research question and the full picture of the data, it became clear that what participants were articulating actually went beyond the typical ways of describing successful aging. The theme that was initially called successful queer aging became Rewriting the Narrative of Growing Older, as participants routinely articulated that they were, in many ways, carving their own path that is not visible or reflected in society from the perspective of a seldom seen, seldom heard population. After this coding phase, the code book was considered to be in its final iteration. As such, each focus group transcript and photo were then coded a third and final time to ensure consistent application of the thematic structure.

\section{Focus Group Code Structure}

\section{Theme 1: The Relational Landscape}

Code

Frequency

\section{Relationship with Self \\ Barriers to Reckoning With and Relishing in One's Self}


Coming Out/Transitioning $\quad 52$

Grappling with/questioning identity 26

Denying identity 24

$\begin{array}{lr}\text { Closeted } & 7\end{array}$

$\begin{array}{ll}\text { Childhood reflections } & 13\end{array}$

Religion $\quad 10$

Not just a Phase $\quad 6$

Coming out in later life $\quad 59$

Differences based on marginalization $\quad 2$

$\begin{array}{ll}\text { Coping with assumptions } & 25\end{array}$

Physical decline 19

Body changes 16

HRT 6

Health system $\quad 19$

Covid-19 9

Chronic Pain 4

Catalysts for Identity Liberation
Self-discovery of authentic self

$\begin{array}{ll}\text { Sexuality } & 10\end{array}$

$\begin{array}{ll}\text { Courage to come out } & 13\end{array}$

Relishing in identity $\quad 27$

$\begin{array}{ll}\text { Gender identity expression } & 14\end{array}$

Passing $\quad 3$

Gender euphoria 4

Relationship with Others

Barriers to Relationship with Others

Stigma/Marginalization/Discrimination/Violence 27

Being outed 2

Rejection 16

Feeling misunderstood $\quad 15$

Lacking support $\quad 9$

$\begin{array}{lr}\text { Transphobia } & 14\end{array}$

Homophobia $\quad 7$

Discrimination within LGBTQ+ community 8

Where do I fit? $\quad 9$

Lacking support/visibility $\quad 5$

$\begin{array}{lr}\text { Strain and pain } & 12\end{array}$

Death, grief, loss 19

Catalysts for Thriving Social Support Networks

Chosen Family $\quad 66$

$\begin{array}{ll}\text { Being out as a pathway } & 27\end{array}$

13

Emotional support $\quad 22$

Unconditional love $\quad 17$ 
Theme 2: Rewriting the Narrative (of Growing Older)

Code

Frequency

Our Stories Need to Be Heard

Representation

Role Models

Filling the gap

Being queer in hetero spaces

Living authentically to show others

Paving the way for others

Increased confidence

Success beyond Outness

Staying healthy and active

Feeling younger

Nature

18

Travel

Reveling in accomplishments

New ways of seeing the world

Autonomy/Independence

Pursuing passions

What it's NOT

Feeling hope for the future

Happiness

Quality of life

Kindness

Resilience

Self-discovery

Advocacy

LGBTQ+ history

Paving the way for future generations

Educating others

Life's purpose 
Stakeholder Survey Coding Procedure. The above process of using thematic analysis (Braun \& Clarke, 2012) was also applied independently to the stakeholder survey responses, starting first with initial coding to identify pertinent words, phrases, and concepts. Initial codes were determined, followed by the process of searching for themes. Once themes were identified, I reviewed each theme for quality, coherence, and salience, which then included the process of examining the code frequency chart to determine whether each theme was sufficiently represented across the survey data. Finally, theme names and definitions were refined. Similar to the focus group data, survey data were coded three times to ensure accurate and consistent application of the code book. Figure 1 illustrates the coding process which resulted in the code structure shown below:

\section{Figure 1. Coding Procedures Flow Chart}

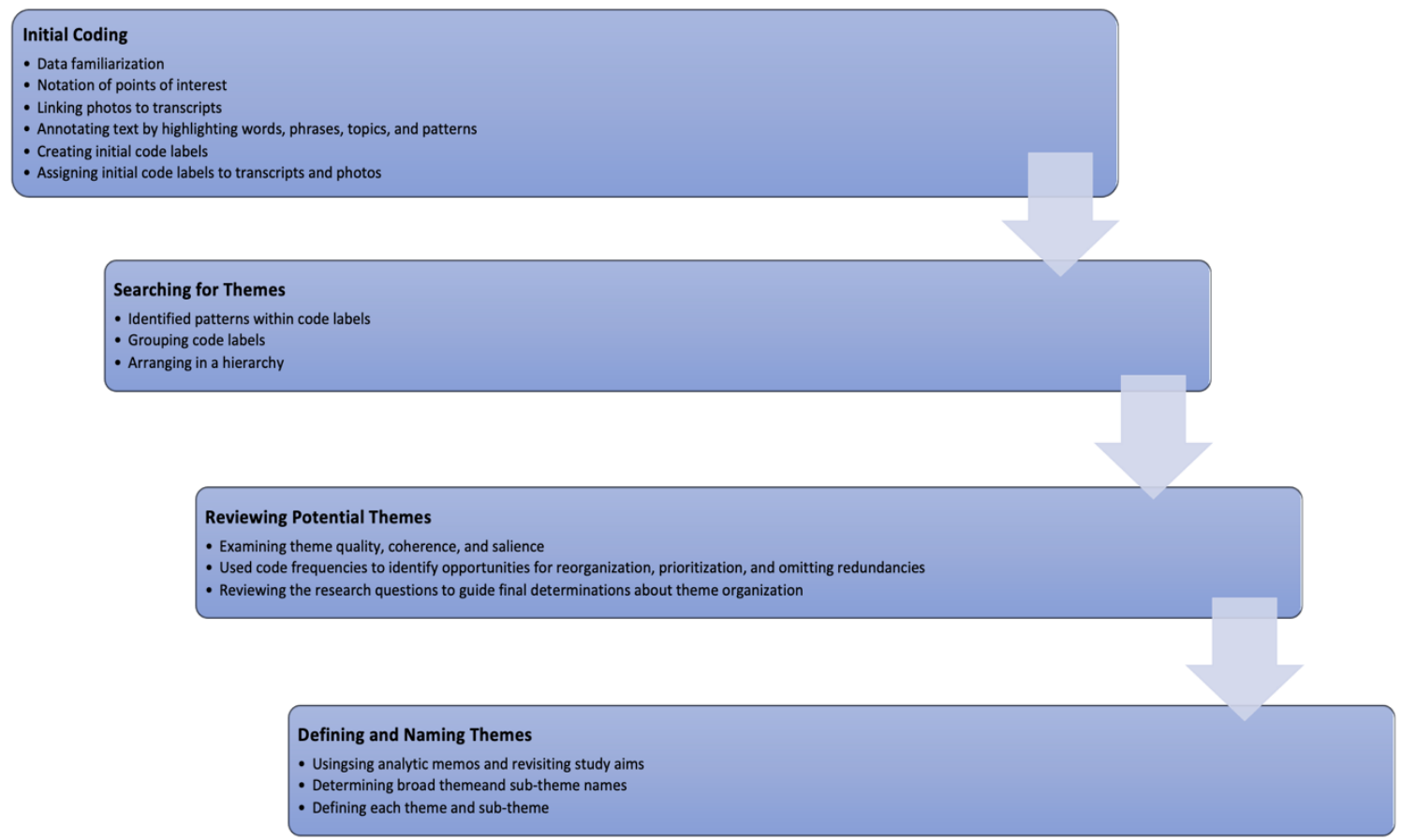




\section{Stakeholder Survey Code Structure}

\section{Theme 1: Images Brought Stories to Light}

Code

Frequency

Deeper meaning/insight

Empathy

Emotional connection

Detracting from educational content

Text format

Learning tool

Effective communication

Representation

Pictures made stories better

Compelling

\section{Theme 2: Nature of Identity}

Code

Frequency

Intersection of LGBTQ+ and Aging

Surprised to learn

Coming out in later life

Sexuality

HRT insights

How I can help

How do I ask?

Desire for training

Elicited curiosity

Unsure how to apply

\section{Data Trustworthiness}

I applied strategies to ensure validity of the data through using multiple sources of data. Focus group data consisted of both focus groups and photo data, which were coded 
both separately and together, and equally informed the code book. I considered whether themes were evident in both photos and focus groups, which ensured the validity of themes. Further, given that Photovoice is a participatory action method, participants were included in the process of ensuring data trustworthy and accuracy. As the focus group and photo data were organized into the Photovoice exhibit, participants were invited to review their individual slideshow consisting of photos and accompanying excerpts. Participants provided approval of their individual portion of the Photovoice exhibit, and provided feedback and thoughts about the photo and excerpts selected.

Finally, reflexivity was utilized to identify and reflect upon my position as the researcher, and consider the influence of my own perspective and assumptions in the data analysis process (Merriam \& Tisdell, 2016). To engage in reflexivity I wrote analytic memos to chronicle my thoughts and thematic ideas about the data, the patterns I saw in the data, and my interpretations of the themes and patterns being uncovered. Importantly, these memos were dated and timestamped so that I could review how my thoughts evolved over time as new data were collected and coding progressed throughout the data analysis process. I also used analytic memos to document and reflect upon negative cases, to consider the ways in which alternate experiences were present in the data, and how those negative cases influenced my analysis and interpretation of themes. 


\section{CHAPTER 3 -- RESULTS}

\section{Focus Group Demographics}

\section{Photovoice}

A total of nine LGBTQ+ older adults participated in the focus group portion of the study, consisting of three focus groups total. Participants ranged in age from 50-83 ( $M$ $=56.4 ; S D=10.71)$. Seven participants identified as female, and two participants identified as male. Of the seven who identified as female, three identified as cisgender and three identified as transgender (Male-to-Female). Both males identified as cisgender. Participants were also asked to describe their sexual orientation. Five participants identified as lesbian, one participant identified as gay, two participants identified as bisexual, and one participant described their sexual orientation as queer/questioning. Of the nine participants, eight were employed full time and one was retired. Notably, three participants were employed as gerontology healthcare providers - two in gerontological psychiatry/psychology, and one in hospice care. Other occupations described by participants included real estate, social security administration, marketing, engineering, and general healthcare. Of the nine participants, four described their relationship status as single, three were married, and two were engaged. One participant described their marriage as "open," and polyamorous. The remainder of partnered participants were monogamous. One participant identified their race as Hispanic, while the remainder of the participants were white. Six participants had children, all of whom were adults. ST was the only participant who described being out about her LGBTQ+ identity earlier in her life course, whereas the rest of the participants described coming out in later life. Further information about participant demographics are available in Table 1. 


\section{Table 1. Focus Group Participant Demographics}

\begin{tabular}{|c|c|c|c|c|c|}
\hline \multirow{2}{*}{$\begin{array}{l}\text { Participant } \\
\text { Status } \\
1\end{array}$} & \multirow{2}{*}{$\begin{array}{l}\text { Age } \\
50\end{array}$} & Gender Identity & Sexual Orientation & \multirow{2}{*}{$\begin{array}{l}\text { Race } \\
\text { White }\end{array}$} & \multirow{2}{*}{$\begin{array}{c}\text { Relationship } \\
\text { Single }\end{array}$} \\
\hline & & Female (Trans-MTF) & Lesbian & & \\
\hline 2 & 52 & Female (Trans-MTF) & Lesbian & White & Single \\
\hline 3 & 52 & Female (Cisgender) & Lesbian & White & Married \\
\hline 4 & 83 & Male (Cisgender) & Gay & White & Single \\
\hline 5 & 63 & Female (Trans-MTF) & Bisexual & White & \\
\hline \multicolumn{6}{|c|}{ Married/Poly } \\
\hline 6 & 51 & Female (Cisgender) & Lesbian & Hispanic & Single \\
\hline 7 & 50 & Female (Cisgender) & Lesbian & White & Married \\
\hline 8 & 54 & Male (Cisgender) & Bisexual & White & Engaged \\
\hline 9 & 53 & Female (Cisgender) & Questioning & White & Engaged \\
\hline
\end{tabular}

\section{Photovoice Results}

The primary aim of this study was to explore barriers and catalysts of successful aging for LGBTQ+ older adults through Photovoice, with the goal of learning more about how this population defines and conceptualizes the notion of successful aging.

Participants described forces that impact successful aging for LGBTQ+ older adults, particularly life experiences that have a positive or negative effect on participants' perception and experience of aging. Two primary themes emerged to articulate barriers and catalysts of successful aging for LGBTQ+ older adults: The Relational Landscape and Rewriting the Narrative. Within the theme of The Relational Landscape, two subthemes emerged to describe the centrality of Relationship with Self and Relationship with 
Others. The theme of Rewriting the Narrative also resulted in three sub-themes: Our Stories Need to Be Heard, Success Beyond Outness, and Advocacy. The final sub-theme described the ways in which visibility and representation in society, activities that aided in feeling successful, and the desire to advocate are salient to feeling as though they were aging successfully. Notably, barriers and catalysts of successful aging were a salient and fluid part of all the focus group discussions and photos. Thus, the barriers and catalysts to successful aging that were described by participants and represented in participant photos are discussed within a theme or sub-theme when relevant to the development of that theme.

\section{The Relational Landscape}

Through focus group discussions and photo artifacts, participants described barriers and catalysts pertaining to developing thriving relationship with self and with others. These experiences were articulated as central to feeling success in later life, and were heavily influenced by the coming out process. This overall theme encompasses the complex and intertwined nature of relationships, and the ways in which the relationship with one's self and others within the social network support and hinder successful aging.

\section{Relationship with Self}

Participants frequently described the significance of the relationship with one's self as pertinent to a feeling of success or challenge in later life. In particular, the relationship with one's self took shape through reflecting upon identity development, the coming out process, and re-establishing a more authentic relationship with themselves. This sub-theme also captured the ways in which participants denied and grappled with their identities, and processed internalized stigma. Participants frequently equated the 
coming out experience to successful aging, yet coming out also resulted in unique barriers for aging successfully. Notably, with the exception of one participant (ST), nearly all participants described having come out or initiated gender transition in later life. For many, this was something that required struggle across the life course, as they came to terms with themselves and learned to flourish as their authentic selves. For example, HV described the process of experimenting and grappling with gender identity: I've cross dressed my entire life but always in secret, in private. But (wife) I'm not going to go into how she found me, but one day I came out of our room in one of her dresses. This was after I went out in public, I looked like a man in a dress, but being in a dress just felt right. So I started cross dressing more frequently. I identified as bi-gender for a while because I really felt both male and female. The more I dressed as a woman, it was like, I'm a woman. I'm not bi-gender. I'm a woman. I was able to experiment and do different things. Put on make up which I'd never been able to do. Wear women's clothes. Sometimes I dressed androgynous. Sometimes I dressed male. I wasn't out yet. I was experimenting with who I am. I said, I don't know who I am. There's something missing. I was able to experiment and find a way in. (HV, Age 63)

\section{Barriers to Reckoning with and Relishing in One's Self. Participants}

commonly described significant barriers to becoming and living as one's authentic self, and feeling able to fully relish in their identity in later life. Individuals often found themselves reflecting on earlier points in the life course, in which they were required to suppress or deny themselves. For instance, the majority of participants described the process of facing barriers while reckoning with identity and relationship to one's self. Specifically, participants described challenges to discovering and accepting their identity, such as religion, unsupportive societal climate, and internalized stigma. Participants frequently reflected upon their childhood and young adulthood, during which they began to recognize their identity, yet felt forced to suppress or hide their sexuality or gender expression. For example, DA described the process of navigating her religious 
upbringing and fear of maltreatment in order to come out. She articulated knowing at an

early age that she was transgender, yet not able to be out.

Before I came out I was still kind of trapped into the narrative that I was brought up with. I came from a long family tradition of Mormanism, and they are very strict with the narrative and what to expect. It's extremely limited on the outlook on life. It's like, very rigid. You're only supposed to do certain things. Before [coming out] they had me pigeon-holed into a patriarchal society that just didn't make any sense to me. I've really become aware of the strict narrative my family has. I've always identified [as female] since I can remember. I was essentially an actor trying to avoid the wrath of not following their, the way I should be. Nothing seemed intuitive. They had a plan for my life. It just felt crushing. It felt like I was dying. When I was younger, I wanted so bad to come out. It was very hurtful. I had to hide it. I could not tell anybody because anybody that did come out at my age back then, they were pretty much institutionalized. They had electric shocks to the head. They didn't survive. I had to hide it because I wouldn't have had opportunities. I had to be an actor and try to learn how to go forth, become independent, where I could make decisions, and it was extremely difficult. It was very painful, very stressful. It was constant awareness, like it just felt like death. This was all growing up. When I came out, they didn't believe me. After coming out, things just fell in place. I feel like I'm free. There is no more closet. It's gone. There is no more darkness. I'm now with other people that are incredibly supportive, and they treat me as I see myself. It's like my past has been just a really drab dream, like I just escaped from prison. (DA, Age 52)

Another participant described religion as a barrier for living as their authentic self, specifically being brought up in a highly religious Southern Baptist family. MC (age 50) explained delaying coming out as a result of avoiding family rejection from her highly religious parents.

There was a lot of conflict with family. I waited until after my parents had passed before I came out because I'm sure that if I would have said, "Hi, I'm a Transbian" they would be like, "yeah, we're never ever going to talk to you again."

While there were many similarities across participants pertaining to barriers such as religion, stigma, or fear pertaining to coming out in later life, each participant articulated a highly complex process for recognizing and reckoning with their LGBTQ+ identity, which continued to reverberate even after choosing to come out. Some participants described denying their identity out of fear, while others felt that the lack of 
LGBTQ+ visibility in society and in particular, their specific community, affected their ability to acknowledge their queerness. AE reflects on her religious upbringing as a barrier for recognizing her queerness, yet also the lack of knowledge about lesbian women as a barrier to discovering her identity. She also articulated the path toward leaving her marriage of 30 years after discovering her sexuality. In addition, AE selected a photo of this time in her life to contribute to the Photovoice exhibit, as she reflected upon the importance of this moment in her coming out journey. AE described the importance of her photo as she reflected on her journey. She stated "In this photo, I had just bought my first car. It was the first time I ever bought anything with my own money. It was the first step of many that brought me to figuring out who I actually was!" She went on to explain the process of liberation:

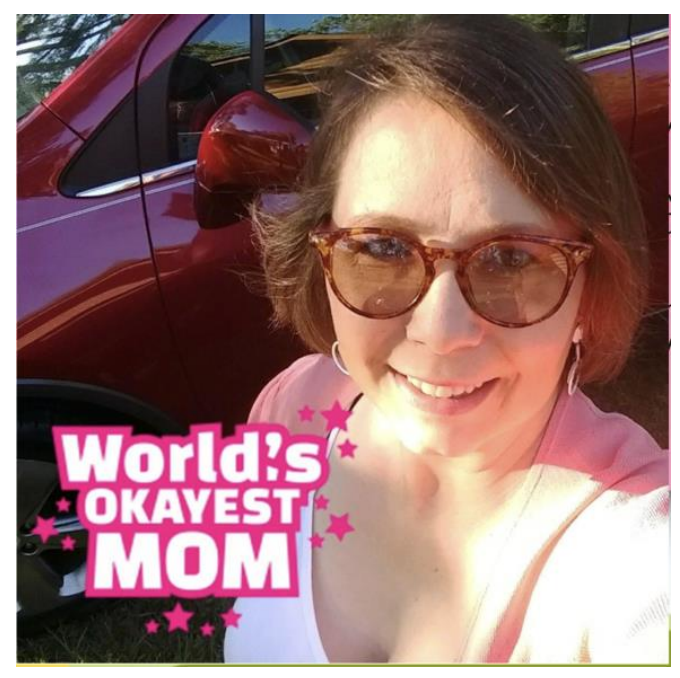

In that [Evangelical Christian] culture, God hates divorce. You don't divorce unless you're being physically abused and even then you work it out. Part of what upsets me to talk about is like that was 30 years of my life I gave! I also didn't know I could leave. I didn't know I was allowed to leave. And I didn't know that I could stand up and leave. I was reading a book on purity culture. I was reading stories of women who grew up like I did. They married a man, had kids, and then started thinking they were asexual. Then in their process they realized, no, I'm just not attracted to men. I sat there and I had looked at the book. Sitting in my living room, finishing up pain pills after shoulder surgery, I'm reading this book and I'm crying and I'm backing up and I'm reading it again. And I just sat down and thought oh god, it's me. It makes so much made sense! Like, I just sat there 
and had an epiphany. I am so gay! No wonder, all of this other stuff. I didn't have a catalyst like a lot of people. I didn't fall in love with a woman. I tell people, yeah I left my husband for a woman! Me! I left for me. (AE, Age 53)

AW went on to describe how her religious upbringing made it difficult to know that she might be queer.

People are like, 'how can you not know you're gay?' You can really not know you were gay in that kind of culture, the evangelical Christianity, purity culture! How could you not know? Well, how could I know? Let's flip it around. How could I know when it was literally not an option?

ML also described a lack of societal representation as a barrier for discovering her sexual orientation earlier in the life course, yet for her, she specifically described not feeling like she fit the Lesbian stereotype, and lacking diverse queer representation. ML also included the photo of the poster she described, as she felt that it was so pertinent to her coming out experience.

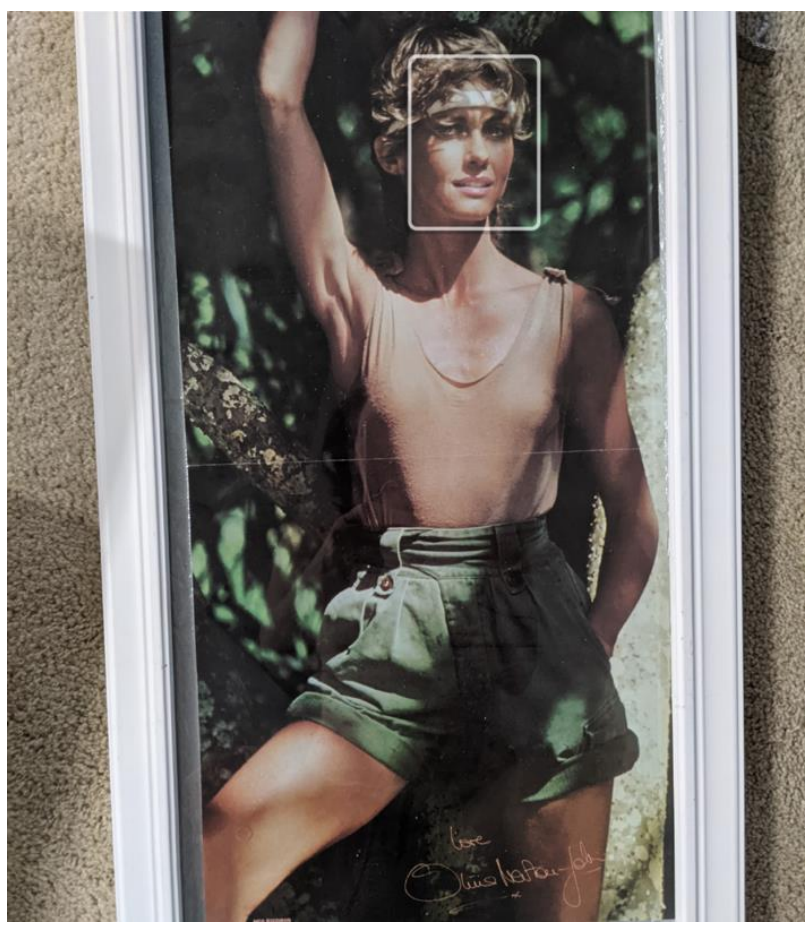

I didn't know I was a lesbian until...I guess I didn't tell myself I was until a few years ago. I didn't quite recognize it. But the poster was on my wall of Olivia Newton John - my best friends sister heard that I had this poster on my wall and was covered with Olivia pictures and told everyone that I was a lesbian. Hahahahah! It was like, no I'm not! It 
didn't feel like I fit the profile of the lesbians working at my dad's company in his cabinet shop so I was like, no. And I didn't have anyone else to look at. There was no Ellen at that time or anyone else. (ML, Age 52)

B expressed barriers for coming out as bisexual due to a lack of courage, but also went on to describe a lack of representation, especially for bisexual men in the LGBTQ+ community:

For me I did never really have the courage. It was typically a dark hidden type of a secret. I mean, I knew that I was, I knew what I felt inside but never had the courage thinking it would be acceptable to anybody. It was a discovery. Also bi people, they are hidden. Especially us men. It's hard to find anyone in the same situation coming out as bi as a guy. And at this age! (B, Age 54)

For K, the only participant that described her sexual orientation as questioning, she describes the difficulty of not knowing where she fits in the LGBTQ+ community, but in particular where to find other individuals also questioning their sexual orientation.

I know I'm not straight, but I don't know what letter in the alphabet soup $[L G B T Q+]$ I belong to. I joined some Facebook groups but a lot of them are for nonmonogamous people, and B and I are monogamous. I don't know anybody who is personally in the same situation [of questioning their sexual orientation]. (K, Age 53)

Participants articulated feeling disconnected from their authentic selves prior to coming out, and the ways in which being closeted had consequences for feeling a sense of thriving in later life. Even after coming out, some individuals described emotional challenges related to feeling as though they had wasted so many years of their life. Internalized stigma, in many instances, manifested as shame around delayed coming out. For those who had prior long-term heterosexual marriages, in particular, there was a lingering sense of regret that clouded some of their newfound joy after coming out. After experiencing a positive relationship with one's authentic self, participants commonly 
described feeling frustration for having waited so long to be able to fully enjoy one's self and feel a sense of thriving. For instance, AW stated:

I've got no time to waste! But damn, I sat somewhere for 30 years I didn't want to be. Now I'm where I want to be now and yeah we did wait seven months to U-haul it! I'm not trying to mess around with another 30 years of my life. (AW, age 53)

For others, there was a continual revisiting of their own barriers to coming out, as internalized stigma and shame continued to impact participants. For example, MB reflected upon his fears about coming out earlier due to his career, while also describing difficulty in making sense of his fears:

I was with Nestle 39 years. [My company] relocated me to California, with my partner at the time. And I never came out. I don't know why I just had this strong gut feeling that I shouldn't come out. And then when I moved to California, I knew that was the safest state in the country in which to live as a gay person. But I still felt uncomfortable. (MB, age 83)

In addition to the emotional consequences of internalized stigma and shame, participants described barriers related to physical decline that interfered with, or required a shift in identity. For transgender participants in particular, starting Hormone Replacement Therapy (HRT) in later-life specifically resulted in unique physical challenges that posed barriers to gender identity expression. For instance, HV, a transgender woman, described the irreversible hair loss as a result of waiting to start HRT in later life. While HV cringed at the photo as she presented it, she also stated "This photo shows how far I have made it! I would have never felt comfortable showing this picture earlier on in my transition!" For HV, showing the photo of her hair loss was a vulnerable act, which helped her articulate the implications of starting hormone replacement therapy later in life. 


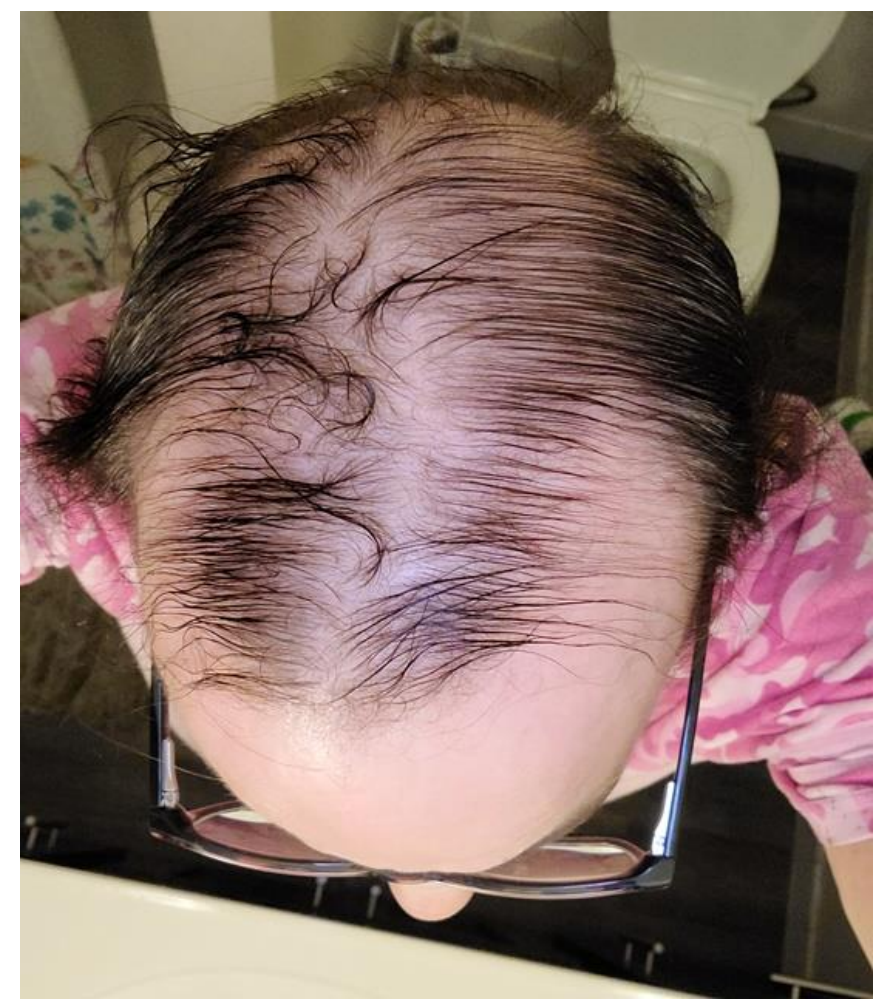

At least about my hair, you can see I'm bald on top, how thin it is. That's the problem with coming out late in life as trans. That male pattern baldness. I like to call it testosterone poisoning. If I would have come out earlier, the estrogen would have kept me from going this bald. Now I use wigs. (HV, age 63)

HV also described the physical consequences of HRT that further complicated the aging process, due to the timing of physical decline and the start of estrogen, as starting HRT at the time of active physical decline exacerbates muscle and tissue deterioration.

Lifting things, heavy things because of my pain increased, the muscles tighten more, head movement because my pain increased, it means I can't carry things like I used to.

Between not being able to pick up things because of the pain, and the hormones, I'm a lot weaker than I was four years ago. Male to female hormones, you tend to lose...unless you work out.. 10-25\% of your muscle mass. That's the challenge I have. (HV, age 63)

Catalysts for Identity Liberation. The intertwined relationship between pain, challenge, life experience, and joy associated with being out was articulated nearly all participants. While many described barriers to reckoning with and relishing in one's identity, many noted that the barriers in and of themselves cultivated internal change 
necessary to coming to know and live as their authentic self. Being out opened the doors to experiences that facilitated success in later life. For instance, MC's photo poignantly articulated the grueling but liberating process of coming to terms with one's self. This photo set the stage for MC's personal reflection about how she has changed over time.

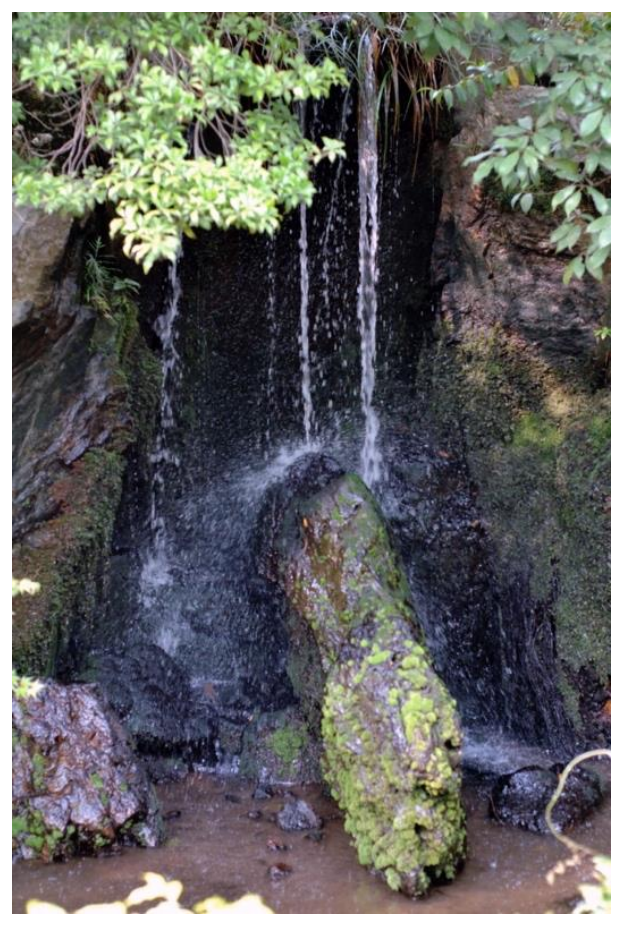

We're the rock that you see there in the middle and time is the water, and no matter how resilient, no matter how long we have, that water's gonna win. Just looking at the effect of the water on the rock is an absolutely beautiful thing. It stripped a lot of things away, including the boy facade that I wore for many, many years. (MC, age 50)

The ability to come out facilitated a healthy relationship with one's self, which also served as a catalyst for greater life fulfillment overall. For many, they reflected positively on their former self, and how far they have come along the journey of becoming their authentic selves. Participants not only expressed that sentiment verbally, but visually as well. The power of photos to articulate the vast importance of being out was described by several participants, and served as a powerful visual articulation of the coming out process through the use of color. 


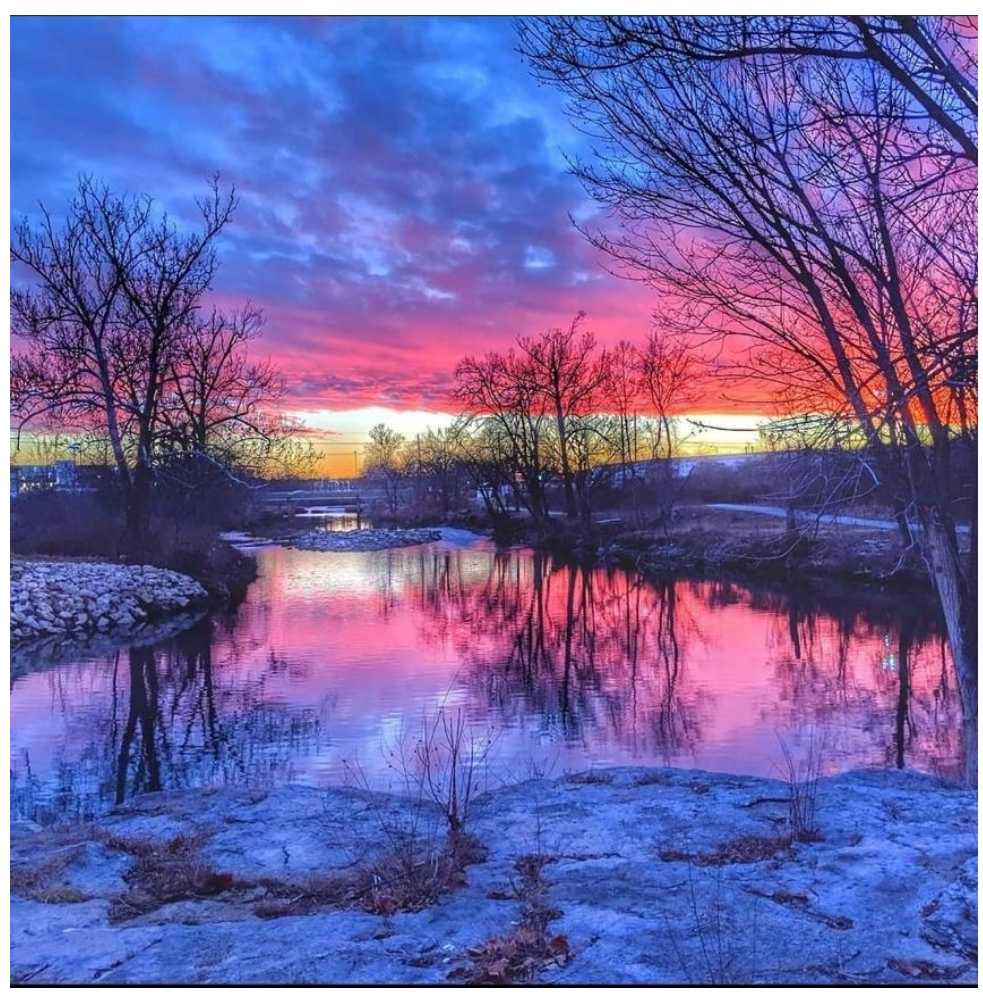

Before I came out, my pictures were mostly themed with kind of drab brutalism themes, construction, industrial, kind of cyber-punk. It was kind of depressing. When I came out, everything changed. My photography became much more vibrant, full of colors. (DA, age 52)

Similar to DA, ML also described the ability to see the world in a new way after coming out as a Lesbian. She also discussed the ways in which coming out has allowed her to experience a greater sense of enjoyment in life, but also a newfound appreciation of herself. During the focus group discussion, ML articulated her journey while presenting her photo of a Pride flag crosswalk. She stated, "I took this picture of the pride flag on the street and how it said Misfits. I thought, yeah, that's how I feel. Like a misfit for being gay sometimes." She went on to state: 


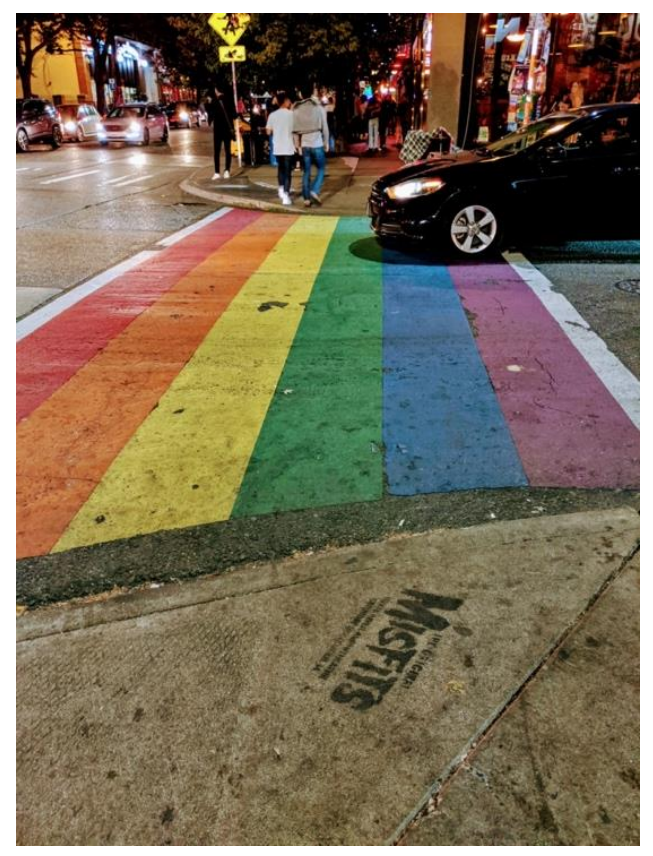

It's kind of like being reborn. Before I came out even when I had happy things I couldn't enjoy them. I remember being on a beach in Hawaii, thinking this sucks! What's wrong with me? I was at these really nice places but I couldn't appreciate it or love it. And now I'm like, you know what? Everything's fun! We're going to live the fun, we're going to be the fun people! I don't think that would have been my life beforehand. Sometimes people may think I'm being immature at this point or just being all, you know, weird or crazy. It's like, I enjoy the idea of just enjoying life. You know? Hiking, and riding bikes, and kayaking. I used to run. I remember listening to podcasts about people that run a lot, that ran ultras like I did. They do that because they're out running something. Something's chasing them. I think I was. I didn't know what it was, but I would have these revelations every now and then while running. What is wrong with me? What makes me run for 20 miles in a day? Why would I do this to myself? I know now that I was running away from my true self, but after coming out I just want to appreciate everything. And now I feel right with myself. (ML, Age 52)

MC also reflected upon her former self and they joy she experiences being able to live her life authentically. She used photos to describe her journey to self-discovery, while honoring her former selves, and feeling a sense of pride for having arrived: 


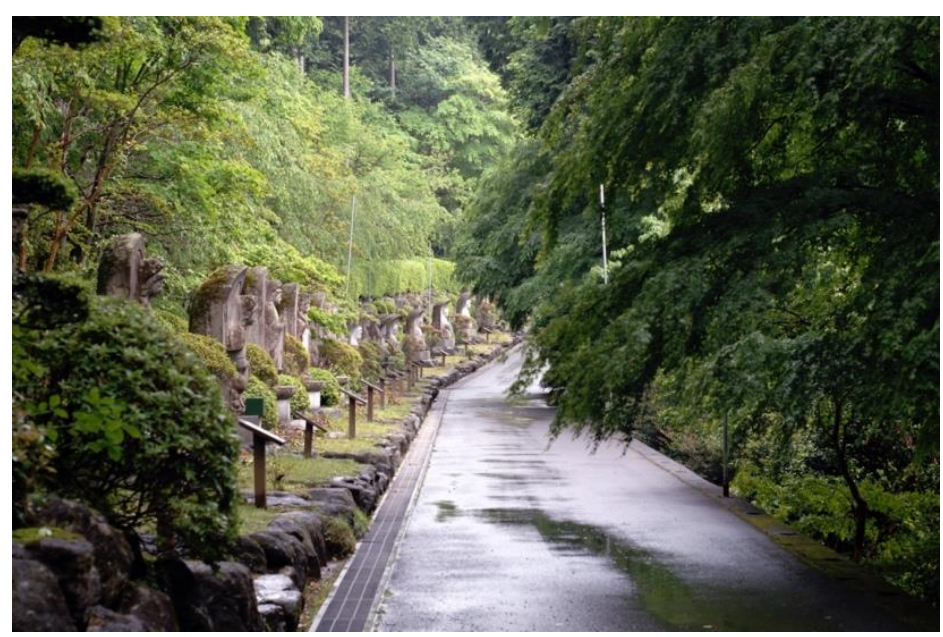

I saw all of these statues of my former selves. These are all where you've been. And now I have arrived. (MC, age 50)

For MB, who earlier articulated his trepidation associated with coming out, described the ways in which coming provided access to greater self-expression. He describes his public coming out, and also the ways in which it helped him find his voice.

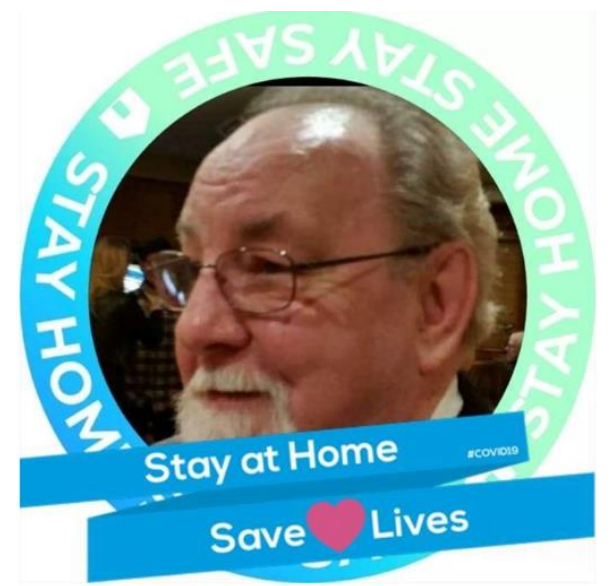

I talked to this friend of mine who worked for the local newspaper and I said, 'have I got a story for you!' The story was two thirds of the page. And I came out in the newspaper! And everybody was shocked! The world heard about it...heard about me. And it was kind of just kind of amazing. So after, this guy came up to me that I knew casually. He created a TV show on the public access TV. He said, I've been watching you carefully and I just love the way you are with people! I find you fascinating and intelligent. So, he told me about the show, and he wanted me to be on it. And I said, You've got to be kidding!? I went on to be the on-air host, and one of the producers of the Creative Connection with $\mathrm{MB}$ on our public access station It was really was, it was really incredible! (MB, Age 83) 
However, for ST — the only participant to come out earlier in the life course - the relationship with oneself was not associated with the coming out process, rather more so in settling down and finding comfort in herself. She described her journey through a number of partnerships and long-term relationships, and identified her newfound satisfaction in being alone and unpartnered as key to her identity in later life.

One thing also that I've learned as I have gotten older, is that being alone and being lonely are two completely different things. I am perfectly content with being alone with myself. When I was younger being alone was boring and kind of lonely. After spending time with various people, and having, you know, certain relationship issues, I'm perfectly content with being alone. It's not lonely for me. If I get lonely all I have to do is call up one of my friends and say hey you want to hang out or even just chat for five minutes? I've learned to enjoy the solitude. (ST, Age 51)

In addition to describing the difficult but necessary journey to self-discovery, participants frequently described the ways in which they relish in and celebrate their identity. For some, celebrating identity manifested as living the life they always wanted to live. Others described immense joy at being able to simply navigate the world as their authentic selves. For example, HV describes being able to vote for the first time after her legal name change.

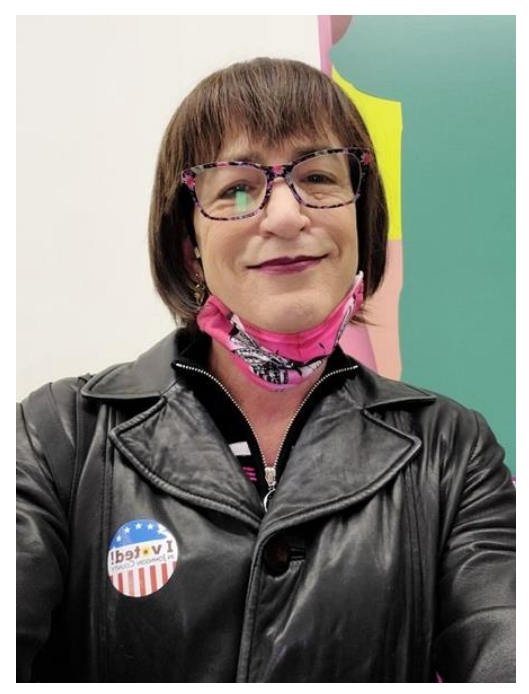

It was the first time I voted as [chosen name]. My name was legally changed. Two years ago I think it was. It was the first time I was able to vote as [chosen name]. Before I had 
to dress androgynous because my ID still had me as my male name. Once my name got changed, my ID, I was able to go dressed as female with the name [chosen name]. (HV, age 63)

B (Age 54) described the ways in which coming out and growing older has allowed him to experience greater self-confidence and feel more secure in himself:

I'm really not too concerned about what people think of me, as far as judgment stuff goes. As long as I'm okay with me, that's something I think is a whole lot different. The self confidence I think, is a benefit.

Part of celebrating the positive relationship with one's identity also included owning and describing vulnerable parts of themselves. Recognizing one's own sexuality, and honoring their sexual self in later life was a valuable part of the process. Several participants noted the taboo nature of sexuality in later life, and described frustration with lack of conversation and acceptance around sexuality in older adulthood. Further, participants noted the intertwined nature of sexuality and self-expression as positive force for celebrating the self, and as a catalyst overall for feeling a sense of happiness in later life. For instance, one participant used her photos to articulate the intersection of sexual submissiveness, queerness, and self-expression as pertinent to her identity. The photo referenced in the quote as "the middle picture" is displayed below: 


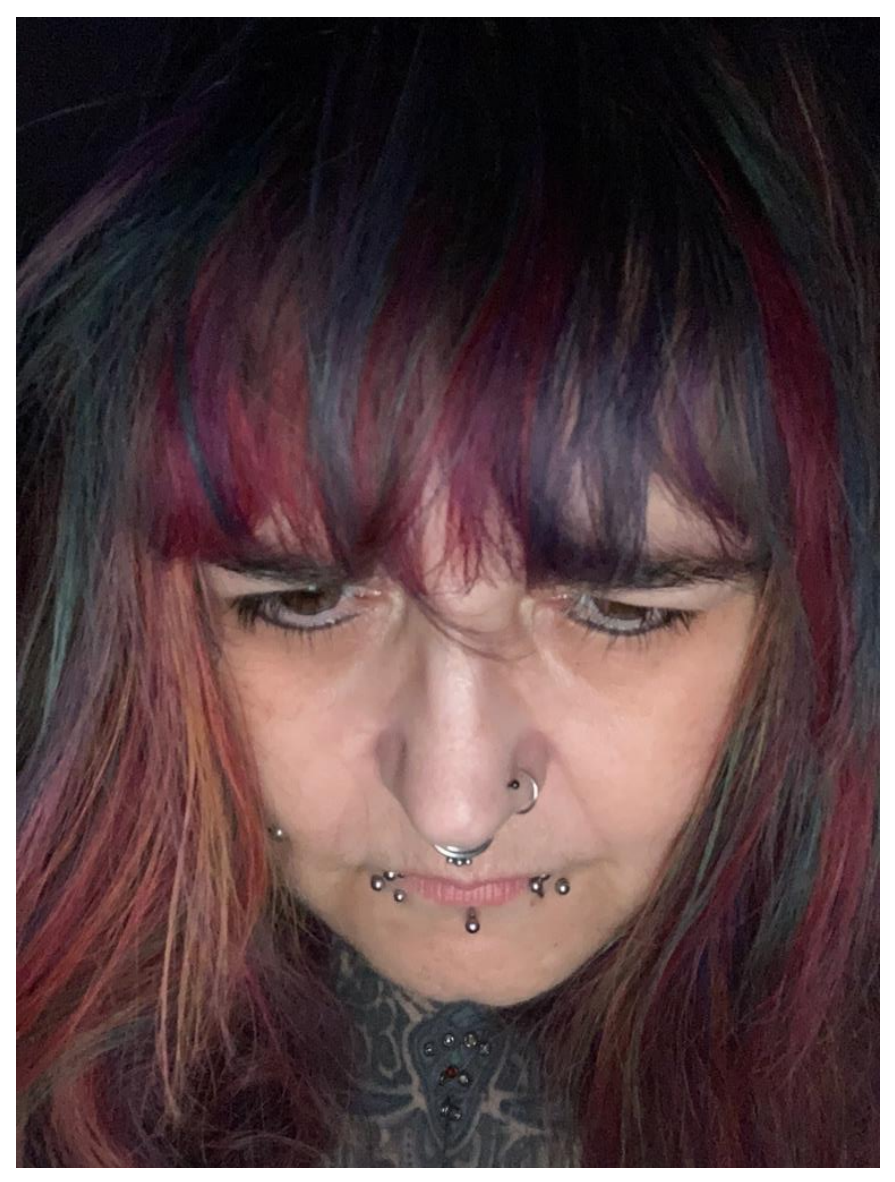

So, being queer, being older being heavily tattooed and pierced, liking to wear my hair in younger hairstyles. I feel like I exude that youthfulness that I'm never going to let age bring me down. And in the middle picture I was trying to show that just because we get older, it doesn't mean that we're not a sexual being. That's more of a kind of submissive sexual type picture I guess if I'm being truthful about it. And so all those pictures all really speak to my youthfulness and my playfulness and my alternativeness. (ST, Age 51)

$\mathrm{HV}$, a transgender woman who described enjoying an open marriage with her wife, articulated the process of being able to relate to her body sexually and with comfort, after much trial and error. Being able to find ways of relating to herself as a sexual being allowed her to participate more fully in activities to express her gender identity.

We enjoy walking through the woods especially without clothes on because you want to feel one with the world, one with the powers to be. It kind of challenged my transition since I hadn't had my surgery yet. I was embarrassed about what's between my legs. I've learned... hormones shrunk everything about 1/3 of the size I used to be. I've learned how to hide it so I can go [to the nudist camp] with a bikini bottom, so instead of being nude, I just go topless. (HV, Age 63) 


\section{Relationship with Others}

In addition to the relationship with one's self, participants frequently articulated that relationships with others proved to both hinder and support feeling successful in later life. Participants noted barriers such as navigating coming out to their support systems, experiencing discrimination, and feeling misunderstood by others.

Barriers to Relationship with Others. Commonly, participants described difficulties with support system or community, and experiences related to navigating rejection and feeling misunderstood. Coming out in later life, for the majority of participants, provided unique and difficult barriers to navigating one's support system. For instance, some participants were married upon coming out. For some, prior marriages resulted in divorce, while for others, it required a difficult adjustment process for the spouse. One participant described that upon coming out as transgender, she not only had to navigate her own transition process, but also had to cope with her wife's complicated feelings of grief and loss. HV was the only transgender participant to include photos of herself prior to her gender transition, which she highlighted as an important part of reflecting on her journey and the difficulties faced along the way. She described these challenges as she presented the following picture of her pre-coming out self and her wife. 


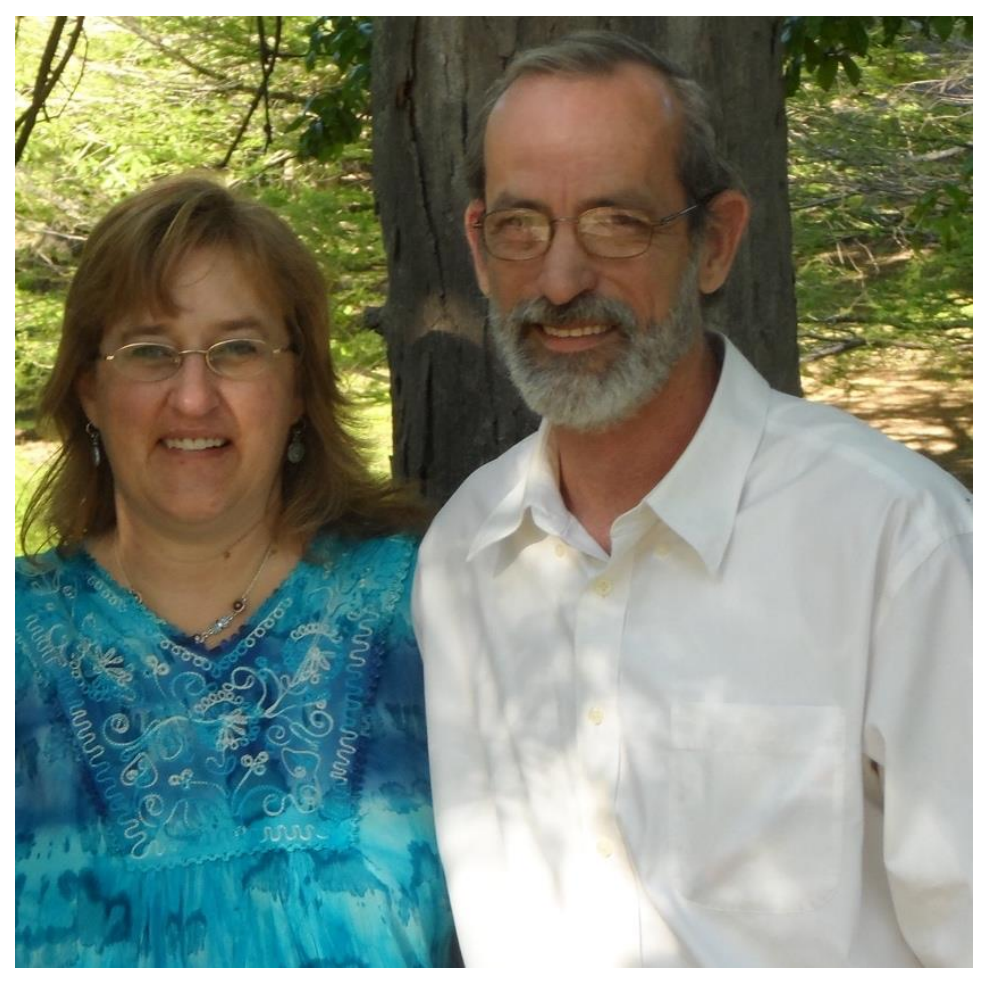

We're talking about difficulty. My wife said she had a hard time. Finally one day in the car she said "I forgive you." I said "for what?" She said "for taking away my husband!" (HV, age 63)

For two participants that participated in the study together as a couple, B coming out as bisexual actually resulted in K grappling with her own identity as well. Prior to B coming out, $\mathrm{K}$ identified as straight, however, over time she realized that she was questioning her own sexual orientation. B described the effects of his coming out process on $\mathrm{K}$ : 


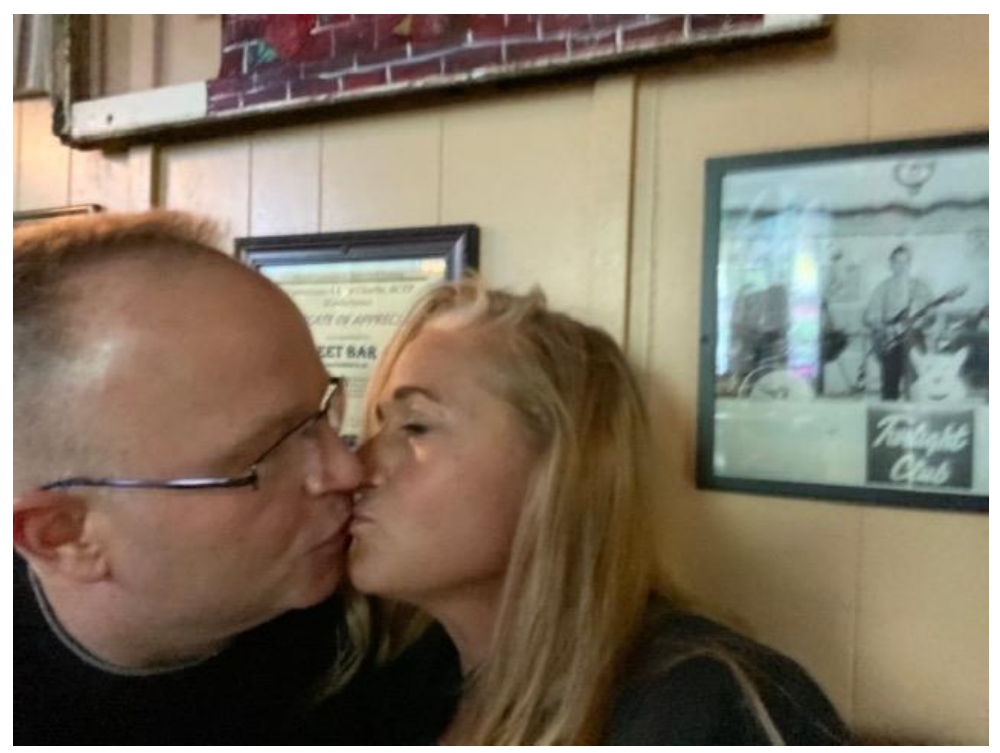

It was discovered, but then owning that, owning that part of identity has been a big huge relief and growing type of a thing for me. It's been really nice. It's been tough on $K$ because it's not necessarily what she signed up for in the beginning but we're working through all those pieces of course. (B, Age 54)

$\mathrm{K}$ then responded with:

"Yeah, it was definitely more than I bargained for! It brought up lots of questions within me and my own identity [sexual orientation]" (K, Age 53)

Participants also described challenges related to coming out to family and friends. While some noted that not all family members were rejecting, there were often some strained friend and family relationships and growing pains after coming out. While some were supportive at first, they described struggles as members of their social support system struggled to feel complete acceptance. MC's experience illustrated that while the initial reaction to her coming out was positive, her brother's level of acceptance fluctuated over time.

He was very accepting at that moment, and then a couple of months later I get this crazy, rant message from him about how I don't approve of the way you act, I don't approve of the way you dress. He still has his moments where he will say things like that, and then a week or two later he'll apologize. It just makes me wonder...I know that when people do things like that it's letting some things that are deep seated in their personality that 
they've covered up, come out. So I honestly have to wonder sometimes if he really is supportive of me.

- (MC, age 50)

Several participants also noted losing close friends as a result of coming out, which was an opportunity to remove unsupportive individuals from her social support network, yet also painful. For instance, ML stated:

I mean, I've lost some friends, which hurts. Ones that would have commented before about anything I did and now they don't even say anything. It's like, I have to deal with that a little bit. In my head I know who I am and I feel like the person I was when they wanted to be my friend, that wasn't really who I was. (ML, Age 52)

For MB, however, the primary barrier to having a thriving support system was related to impacts from the AIDS crisis, which resulted in the early deaths of over 100,000 gay men between the 80 's and 90 's, and has drastically affected the numbers of older gay men still living. When asked what his biggest challenges were as a gay man in later life, he stated:

Losing friends. I have no friends, no, no gay friends. Some moved away but most have died. I've worked on both coasts as a volunteer for people with AIDS, and I still talk about it as you know. In a year...just about a year we've got three vaccines for Covid. AIDS has been going on for 40 years. And there's no cure. (MB, age 83)

While the immediate social support network of spouse's, family and friends was affected by coming out or transitioning, many participants described experiencing barriers at the community-level. All participants articulated experiences of transphobia and homophobia. Commonly, transgender participants routinely described being misgendered, which was a painful and difficult experience. In addition to experiencing transphobia, individuals also communicated sentiments of feeling misunderstood or rejected. For instance, HV described these sentiments when describing her experiences at the beginning of her transition process. 
When I first came out, it was hard because people misgendered me, They don't do it on purpose, but they still sometimes use my old name. I had to deal with being the odd person out, not fitting in. Even in stores and whatnot. (HV, age 63)

MC also described being harassed and misgendered, in particular by co-workers and individuals out in the community. Notably, $\mathrm{MC}$ was not the only participant to mention being called a "dude in a dress" or "crossdresser" as a form of harassment. I think there's a lot of people out there who don't understand transgender whatsoever. Before at a couple of other jobs, you're just a dude in a dress. I can't even begin to express how much anger that fills me with, when somebody would say something like that. (MC, age 50)

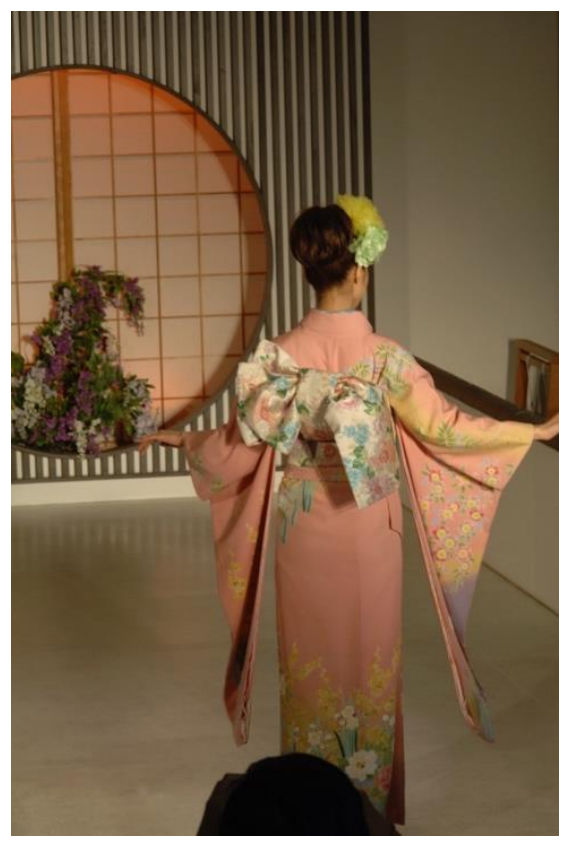

MC articulated this story while presenting this photo of a woman in a Kimono, and described that while others might see her as a "dude in a dress," she actually sees herself as this woman depicted in the photo. She stated, "This photo is of a woman wearing a Kimono that only unmarried women wear. The bow in the back is so complicated to tie that you have to have more than one person help you tie it. This is how I see myself. I'm saving up to buy a Kimono just like this one." The juxtaposition between presenting the photo of how MC sees herself, and the ideal of her gender expression, and articulating 
experiences of being misgendered, highlighted the complicated nature of negotiating one's gender identity with outside others.

ST, who came out earlier in her life course, also described several incidents of discrimination, harassment, and violence as a result of her sexual orientation. She described the shifting social climate as reducing the frequency of homophobic incidents, yet also stated that she does continue to experience discrimination in the community.

I mean, I can't tell you how many near injurious experiences that came along my way with just me being who I am. I give a lot of props to those who fought for me to be where I am now. And I walked those same lines before it was cool. Before you could fly a flag; before you could do anything. You know, I've had a gun in my face. (ST, Age 51)

While the majority of harassment, discrimination, and violence described by participants took place within predominantly cis-gender, heterosexual populations, most participants also described experiencing discrimination within the LGBTQ+ community. For some, discrimination was age related, yet others experienced rejection related to lacking acceptance for transgender identity or bisexual orientations. Although there is growing awareness for the spectrum of gender and sexual identities, stigma against bisexual or transgender individuals persists. For instance, HV, a bisexual transgender woman described often feeling the most community-related rejection due to her bisexual orientation. 


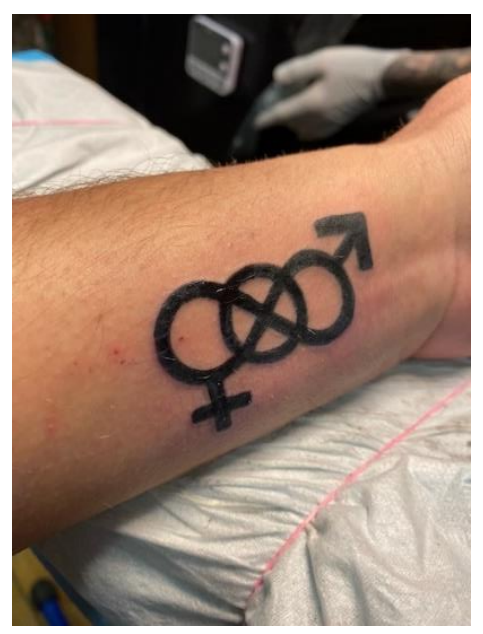

You're right, the bi community is the least represented. They're like the hidden part of the LGB community. We're [trans folks are] out there but bisexuals, we're like the hidden people.

(HV, age 63)

$\mathrm{B}$ and $\mathrm{K}$ also echoed these sentiments by describing rejection when existing within queer spaces due to having the outward appearance of being a heterosexual couple despite their bisexual status.

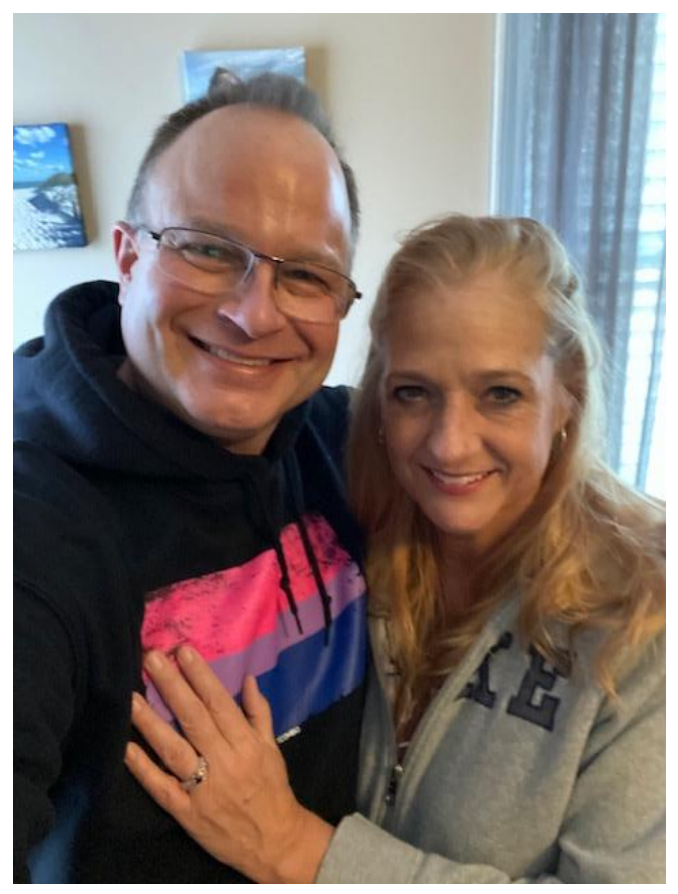

It's like, just because I'm committed to a female, monogamous, suddenly I don't fit in. We go down to [LGBTQ+ bars/clubs]or something like that and sometimes we do alright, 
but every now and then you get kind of a funny look when you're a M-F couple. I get it. On the outside it looks like we don't fit in. (B, Age 54; K, Age 53)

Finally, some participants described feeling rejection or discrimination within the LGBTQ+ community due to their age. MB, the oldest participant at the age of 83 described his long-time experiences of being treated poorly as an older gay man. In particular, MB described the lack of representation for older LGBTQ+ individuals within the broader queer community.

I think the attitude towards older gays is pretty crappy anyway in this country. There's nothing for us, and I feel that in my community. (MB, age 83)

Catalysts for relationships with others. Although participants noted significant challenges with their social support networks and broader community, they also frequently described feeling a great deal of support. Many participants equated the ability to partner and marry as success in later life, while others described the freedom to surround one's self with chosen family as the means by which they defined success. Liberation associated with coming out often promoted access to thriving support networks centered around identity support. For instance, DA articulated the feelings of success and thriving associated by no longer associating with her biological family and instead surrounding herself with family of choice. She states...

I no longer have to deal with toxic people anymore. I can choose my family and friends. Whereas before I was kind of stuck with what I was given. Now I'm pretty much free. There really haven't been any challenges that seem to be too difficult. I have an amazing group of friends that showed me how easy it was. They told me "this is much easier than you think." I'm now seeing how everything is much easier. I'm doing things I never thought were possible. I interviewed with the awesome job with incredible, overwhelming support. I didn't think any of this was possible. (DA, Age 52)

AW also described the process of adopting chosen family. While AW has grown children, she does not currently have biological grandchildren. She described the joy associated with the children of a close friend adopting her and her wife as grandma and 
grandpa. AW described these relationships while presenting this photo of herself that she took while with her chosen family. She noted "See how happy I look in this picture!? When I am with them [chosen family] I just feel so much joy!"

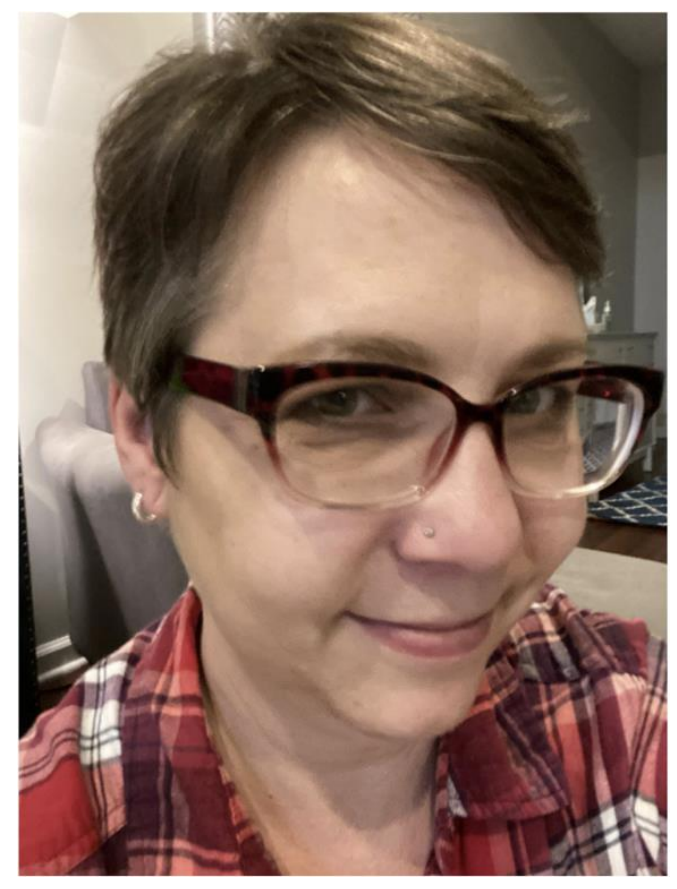

I'm grandma and my wife is grandpa. All the kids, maybe the second time we were at their house were like, we're going to call you grandpa. Grandpa stuck and so then, by default, I'm gramma. Our friend said, well, now that's interesting because you know I'm not in touch with my blood relatives, and I guess you're their grandparents now. So we're their chosen family and that's just me hanging out with the grandkids. (AW, age 52)

In addition to describing joy associated with being able to choose one's family, some noted the joy of being able to meet, and marry their partner as well. ML and AW both shared stories of meeting and marrying their spouses. ML, who described her love for Olivia Newton John as a way to better understand her sexual orientation earlier in the life course, presented this photo of her (now) wife, alongside Olivia Newton John. She described how their shared love of the music star was a catalyst for meeting her spouse, and described this photo as one of the happiest moments of her life. 


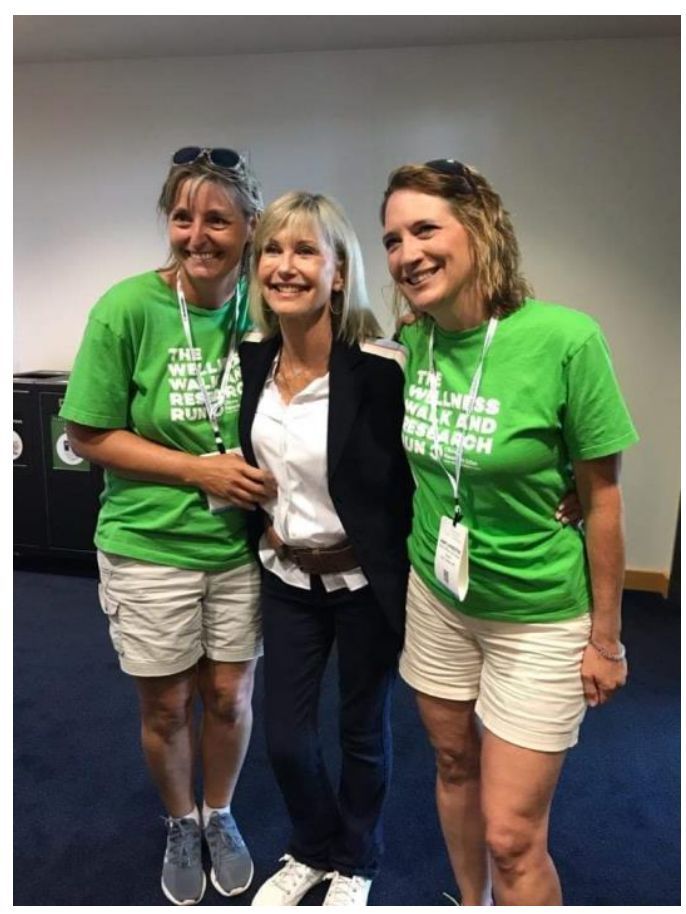

The day that I came out to my family, I had met my wife going to an Olivia Newton John concert. She had an extra ticket. We rode down to the Olivia concert and I had never met anyone like [my wife]. I was just so in love with her from the minute I met her. (ML, Age 52)

AW presented the photos of her proposing to her (now) wife alongside a photo of their wedding ceremony. She reflected upon the liberation she felt by being fully participatory in the choosing of her current marriage, in contrast to how she felt earlier on in her life.

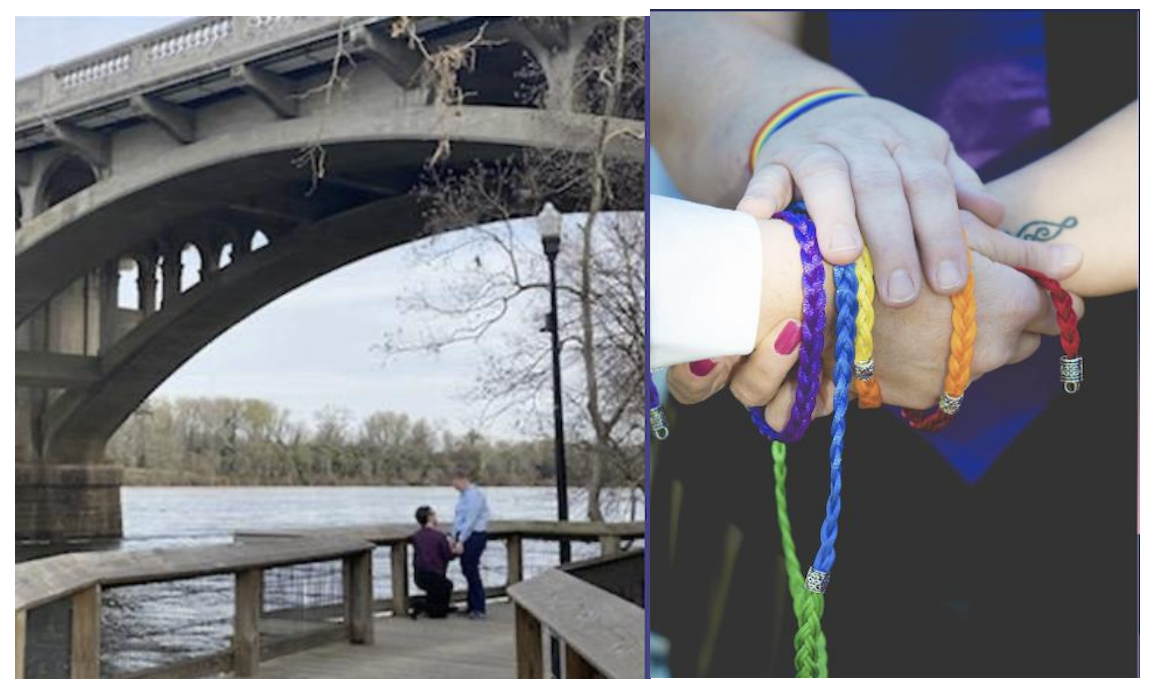


This is my real grown-up marriage, the one that I'm choosing, and I know exactly what I'm getting into and what I'm doing. She wanted a private proposal and that's a bridge on a river walk near where we live that we both really like. So, yeah, that's what it looks like for a 50-year-old to propose. I even got back up on my own! (AW, Age 52)

DA also described finding community support through her social support network and biking community.

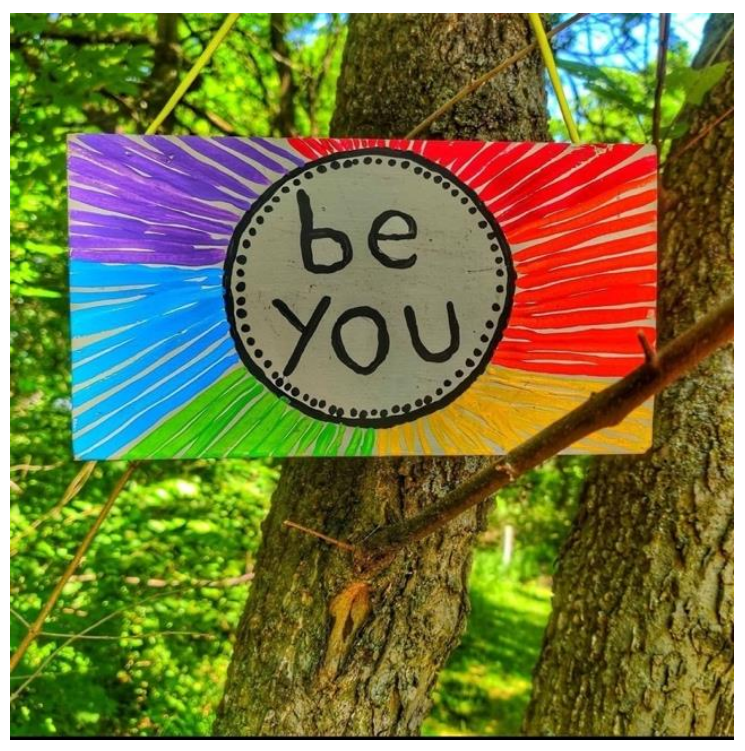

It's like the whole world just came together and it's like the people that decorated the trail, they put up these posters and signs and it's just so encouraging. There's so much love shown. There would just be rainbows and happy faces. It's very exciting, very euphoric. It's like the world comes alive when I'm out riding my bicycle on the trail. I see happy people and they always greet me with a smile. It just really makes my day. (DA, Age 52)

For nearly all participants, one of the most vital parts of their social support network consisted of pets, and were directly equated to feelings of success as they grew older, particularly with giving their lives meaning and companionship. For example, ST described the unconditional love her dogs offered: 


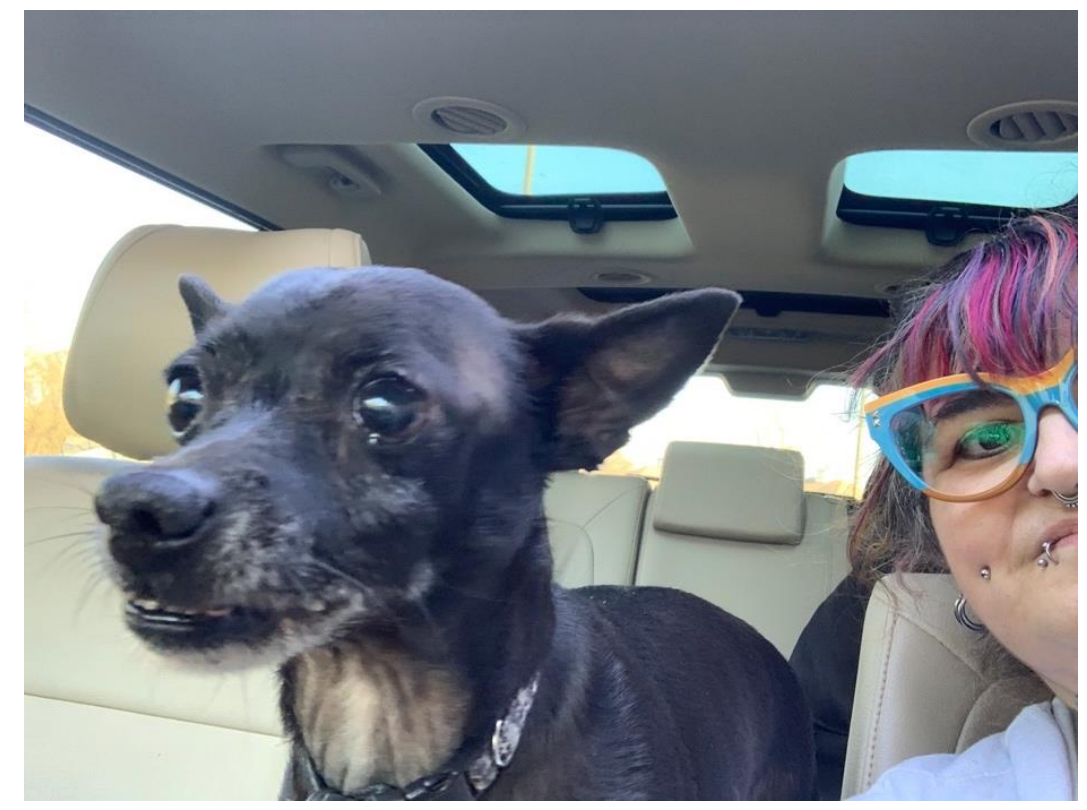

I owe my life to my dogs because every time I've ever gone through anything, very difficult, it's always been my dogs that I have leaned on for support. They've always been my constant, you know, relationships, fail, my dogs are still here you know if somebody doesn't like me for whatever reason, you know, my dogs still, they still love me, they don't care if I'm fat or skinny, my hair is a mess, I don't put my contacts in or I'm wearing a dirty shirt, you know, they, they don't care. They love me all the time.

She also went on to describe her dogs as her life's purpose, as her passion was to rescue older dogs in need of homes, and provide dogs near their end of life with hospice care. ST described that not only were her dogs a vital part of her support system, but also part of her post-retirement goal to expand her capacity for taking in older dogs in need of homes. ST exemplified the profound role that pets can play in achieving feelings of success in later life, as she was nearing the point of being able to retire and move on to make more space for her passions:

S: Yeah, so when you retire, like, What's your dream, part time job.

ST: Animal hospice - dog hospice. I think just because they're old doesn't mean that they don't need a lot of love and attention. I want them to leave this world the way I would hope to leave this world. Not scared and alone but knowing that I was loved. (ST, Age 51) 
Pets were also commonly mentioned as buffers for stress related to strife or difficulty within the social support network, as participants frequently described their animals as a consistent source of emotional support and unconditional love.

Further, participants often described their pets as participants in physical activity, and an avenue for staying healthy. For example, one participant experiencing health challenges related to COPD described the role his dog played in keeping him active:

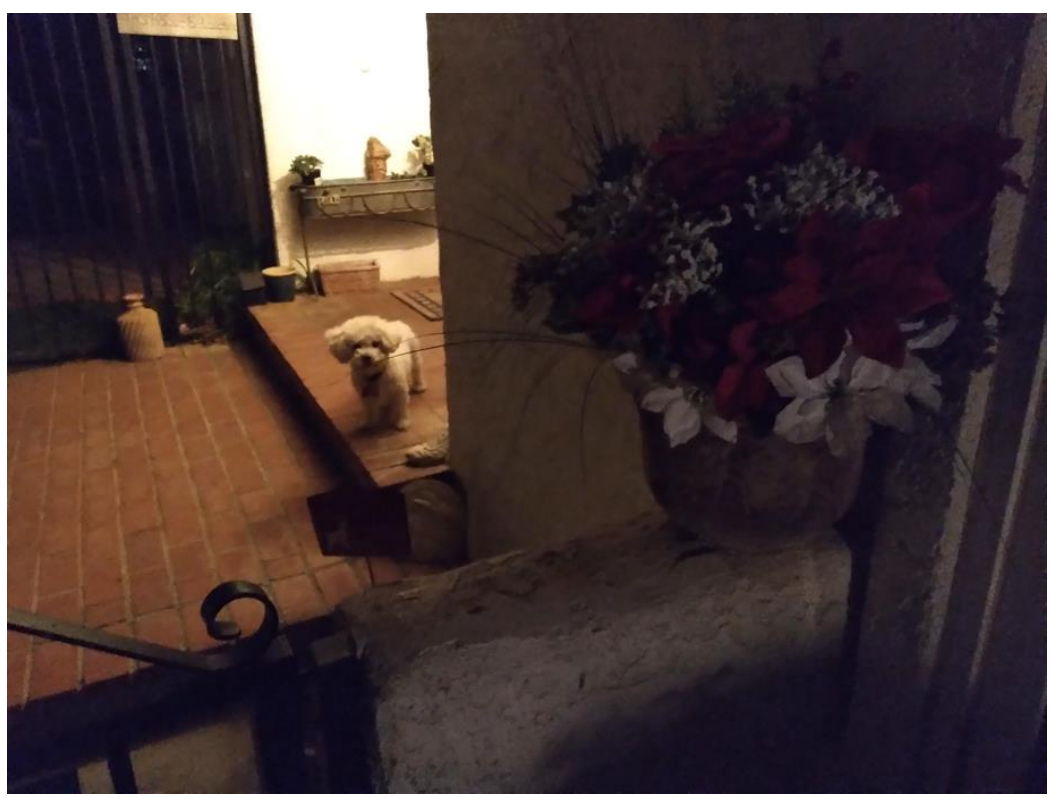

Especially this past year Coco was really good for me, you know. She's my companion. She kept me alive. She loves to play and for an old lady, she's keeping me young! (MB, Age 83)

After experiencing long-term impacts from Covid-19, AW mentioned that her dogs were part of her physical recovery, and a motivation to stay active. 


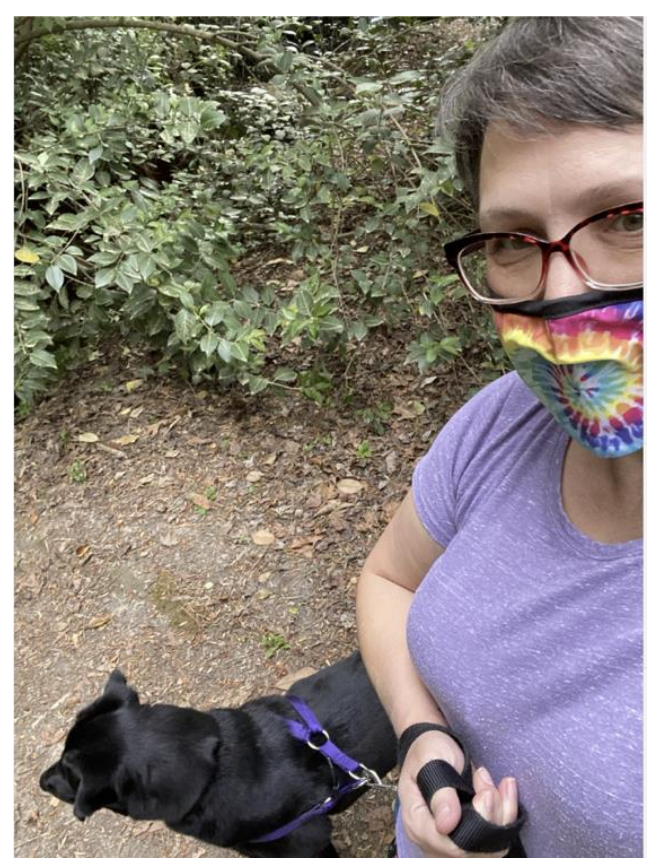

This is my dog with her weighted backpack because she is very energetic. She's my quarantine dog! I did not know how much dog I was getting! But I love dogs. This is my wife's dog just casually strolling - not pulling on the leash. and that was. I like being outside walking with the dogs. It's something I enjoy. They bring me joy even with the backpack and the high energy and the pulling! (AW, Age 52)

\section{Re-writing the Narrative (of Growing Older)}

The theme of Rewriting the Narrative emerged illustrating the ways in which participants discussed and described the notion of successful aging. In particular, this theme articulates the centrality of their LGBTQ+ identity to successful aging, legacy, and the mark they wish to leave on the world. Within this theme, sub-themes emerged in which LGBTQ+ older adults described successful aging for themselves: Our Stories Need to Be Heard, Beyond Outness, and Advocacy.

\section{Our Stories Need to Be Heard}

All participants described challenges related to 1) a lack of representation during their youth which suppressed the discovery of their LGBTQ+ identity earlier in the life 
course, 2) fit within the overall LGBTQ+ community due to identity stigma or ageism, and 3) a lack of societal representation that continues to exist as they navigate the world as an LGBTQ+ older adult. Notably, participants met these challenges with a desire to address it as part of their legacy and contribution to making the world a more welcoming and inclusive place for younger generations of LGBTQ+ individuals. As such, the subtheme of Our Stories Need to Be Heard emerged to articulate the representation gaps participants identified, and their work toward filling those gaps.

For participants who described difficulty discovering their LGBTQ+ identity due to a lack of representation, religion sometimes played a part. For AW, her religious upbringing in the South prevented her from exposure to the LGBTQ+ population altogether. She stated:

Somewhere in my early 40s I started to question everything. Religion, I started deconstructing. A friend of mine said, 'you did it in the right order!' I see what she means. For me I had to deconstruct from that version of Christianity in order to have any idea that gayness was me. (AE, Age 53)

ML, however, noted that while she knew many lesbians growing up, the lack of diversity represented within that population resulted in her denying her identity because she didn't fit the stereotype portrayed. ML described the challenges she faced as a more feminine Lesbian that was only exposed to those who were very masculine.

I didn't feel like I fit the profile of the lesbians working at my dad's company in his cabinet shop. And I didn't have anyone else to look at. There was no Ellen at that time or anyone else. (ML, Age 52)

In terms of participants' desire to fill the 'representation' gap, approaches varied. For instance, AW stated that she intentionally maintained friends on social media from her conservative social circles as a means to promote representation within the religious community for LGBTQ+ populations. As she presented this photo, she described that in 
her own coming out, her daughter (pictured along with AW) had also come out as transgender. AW discussed the importance of visibility:

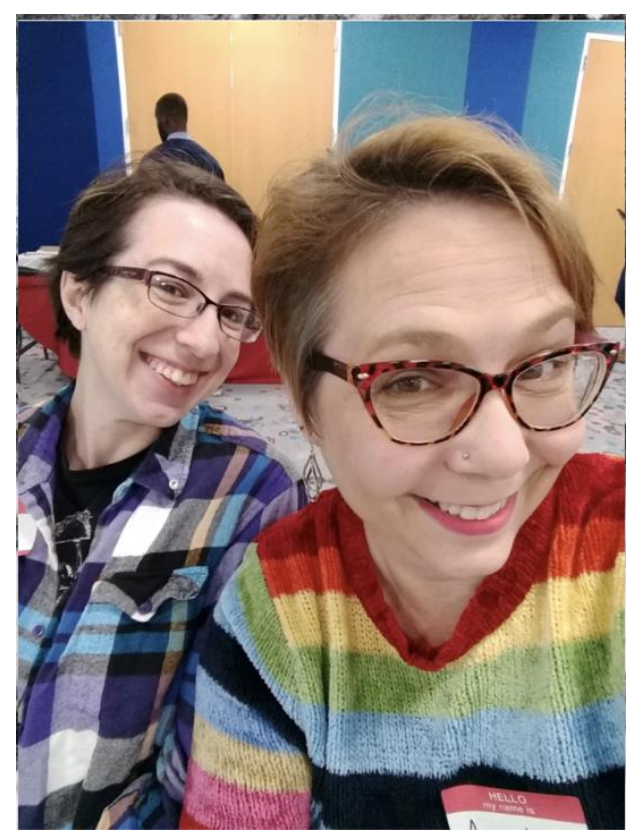

I want them to know that I am finally the person that I always was. Literally that's it. I left some people on my Facebook from my old old old church years. A lot of them I deleted but some saw my wedding pictures getting married to a woman. I was quiet about it on social media for a while and then by the time we got engaged I'm like, you know what, fuck it. And I've had a couple of the youth group kids from when I was married to the youth pastor reach out to me and say how happy they were for me. I had phone conversations with them. Yep I'm gay! I've had people come out to me as I've come out from way back in the day so I've kept some of them honestly to normalize it. (AW, age 52)

MB described getting a profile on Meet-Up_an app designed to connect local residents with common interests - to join a group intended for gay males as a means for him to represent older gay men and maintain open lines of communication with younger generations. B, on the other hand, described using his attire as a way to promote representation. He stated:

I bought a sweatshirt that said "Bi AF" and another one said "Bisexual and still not into you." I just thought they were funny and they can also raise awareness too. (B, Age 54) $\mathrm{MC}$ also articulated the need for LGBTQ+ stories to be heard for the purpose of promoting acceptance. 
We've all got our stories and experiences that we can share, and I think if we, if everybody had the opportunity to do that, I think we'd all figure out that we have a lot more in common with one another than we'd probably think. Which, hopefully that would go a long way towards fixing some of the things that are going on out there. (MC, Age $50)$

HV discussed the impact of being able to be a presence in the community, and available for others to learn from her experiences as a transgender woman, and specifically described the ways in which she speaks with people about being transgender to promote acceptance. She described one particular opportunity to share her story with a stranger, and the beneficial impact.

I've always encouraged people to ask me questions, even personal questions. One lady and I had a 45 minute conversation one day at the dentist's office. She asked this personal question. She would ask questions about what having sex was like and I would answer. Afew months later I was at the dentist office again, and she came in and thanked me. I said, for what? She said, for sharing with me. Long story short a relative of hers came out as a transgender woman. She said that me sharing with her made it easier to know what to say to her relative. (HV, Age 63)

ST also articulated the importance of being visible and sharing stories, and specifically the joy she receives from expressing her personal style, and helping eliminate stereotypes and fear of individuals that are heavily tattooed: 


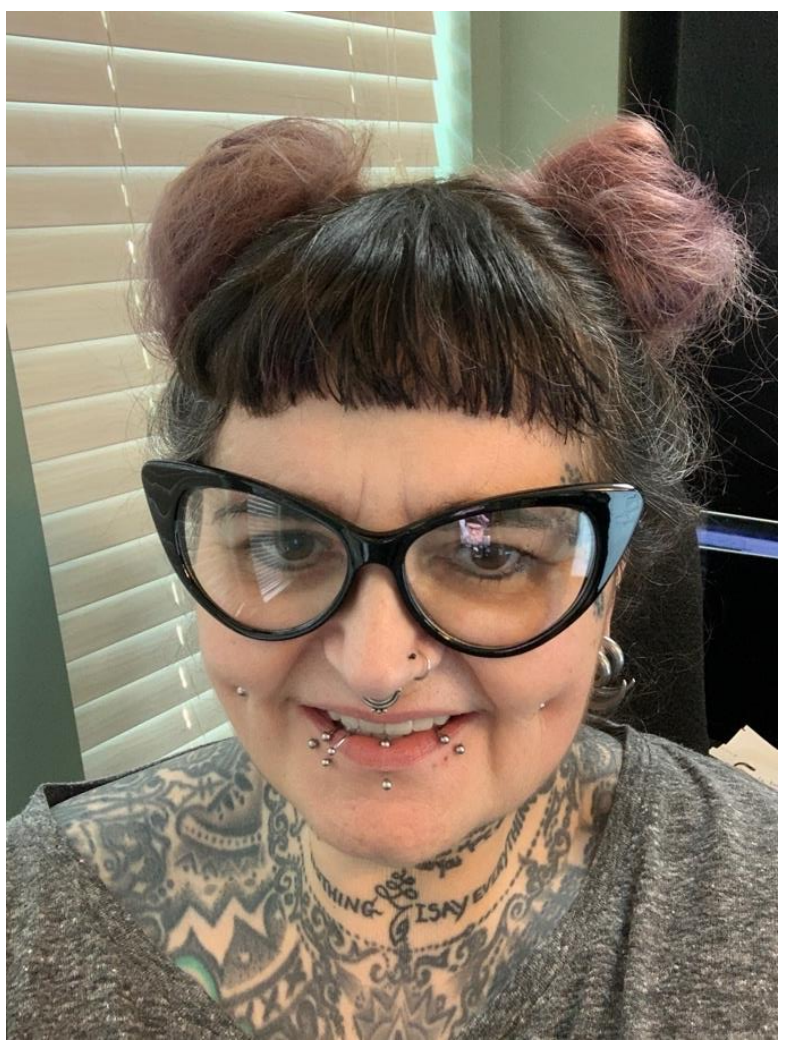

I will talk to anybody. I feel like we have so much to learn from each other. And even if it's just a random chance encounter at the line at Walgreens or whatever. People want to come up and talk to me. My tattoo artist, he always said that I'm one of the best ambassadors for heavily tattooed females that he's ever known because I'm so nice. (ST, Age 51)

Participants not only articulated the importance of visibility and societal representation for their own stories and the stories of other older LGBTQ+ individuals, but the need to elevate the stories of other high-profile LGBTQ+ individuals as well. MB described the emotional impact of seeing an openly gay man serving as a member of the President's cabinet: 


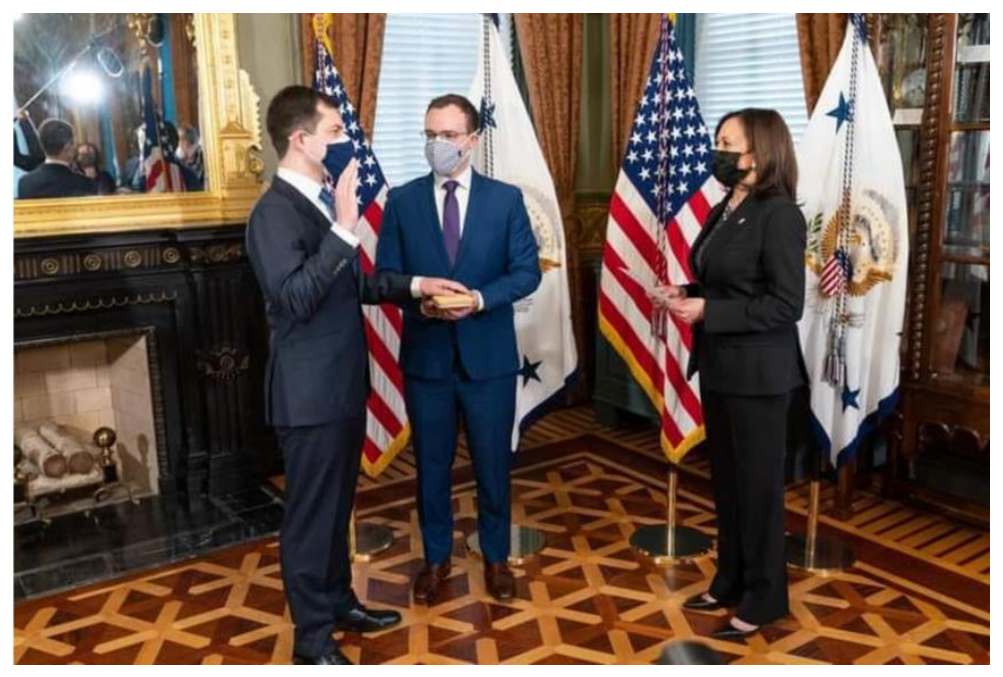

An openly gay man being sworn in as Secretary of Transportation by Kamala Harris and his husband holding the Bible as he's being sworn into the job. A gay kid from small city makes it to the big time to DC...It's just so powerful! it's so exciting! Holy catfish! It's from one extreme to the other hope it continues! (MB, Age 83)

ST also talked about the importance of elevating historical stories to help younger generations feel greater acceptance, while also recognizing those who paved the way:

As queer people we're never going to progress if we don't put ourselves out there, and definitely say thanks to those who fought for us. That's a that's a really big part of my identity. I'm always telling people - did you know how you know the Stonewall Riots got started?

When the younger generations now get older and they get to see younger generations. I think that's one very important part of my identity is giving back to the people who fought before me. And hopefully getting a little bit back for the fight I fought. Younger generations can be more open and free now. It's very important for me to recognize history, and the future. (ST, Age 51)

HV also mentioned the importance of hearing stories about historical LGBTQ+ figures:

I'm a trans woman and it's tough. We get screwed in a lot of things. A lot of the gays and lesbians are against us. LGBT rights actually started with two transgender women! It's important that we keep talking about that! (HV, Age 63)

\section{Success Beyond Outness}

The sub-theme of Success Beyond Outness emerged to encapsulate other parts of the self that were synonymous with successful aging for participants, such as being able 
to stay healthy and active, appreciating accomplishments and achievements across the life course, and relishing in their world perspective.

Staying Healthy and Active. Participants often noted that even through aches and pains related to growing older, they felt a sense of pride in their ability to stay active and healthy. Many participants described seeing prior generations of older adults in physical deterioration, and they desired to remain in physical shape, be able to participate in physical activity, and adopt an overall healthy lifestyle. Some participants discussed the need to prioritize health to counter discrimination and stigma they face in the healthcare system. One focus group in particular consisted of all geriatric healthcare providers, which resulted in the conversation turning to the consequences of stigma they witnessed LGBTQ+ older adult patients experience. K, a Geriatric Psychiatry nurse stated:

Two or three years ago is when we had the sensitivity training. A lot of the people at work think, I don't want to have to ask about that [sex assigned at birth]! It was explained that say it's a transgender man and all men can get breast cancer, but you say they have breast cancer and you don't know, or uterine cancer and you didn't ever know that they were a woman. You have to ask that. It's important for diagnoses. (K, Age 53)

HV, a hospice nurse, also described stigma she had experienced in the healthcare system as a transgender woman.

I know that transgender people, their doctor needs to know they're trans. A transgender woman did die from prostate cancer. She was misdiagnosed and they never assumed that. It's important. I know that some want to keep it secret so they don't have to deal with their doctor telling them to get the hell out of their office. Sometimes doctors don't know what to do with transgender people and they don't treat us well. That's why I got to take care of my body and my mind. Because if I don't maybe no one will. (HV, Age 63)

B, a psychologist, also added:

So we die with our identity! (B, Age 54) 
Although this conversation was unique to this particular focus group cohort, it illustrates the greater consequences LGBTQ+ older adults face in the healthcare system. Other participants

overall communicated acceptance around physical decline, they described the sense of purpose and enjoyment they got from being active. For instance, participants B and $\mathrm{K}$ described the joy they received from slowing down the pace of their work life to make more time for travel and going fishing. DA described great joy associated with riding several thousand miles on her bike during Covid-19 quarantine.
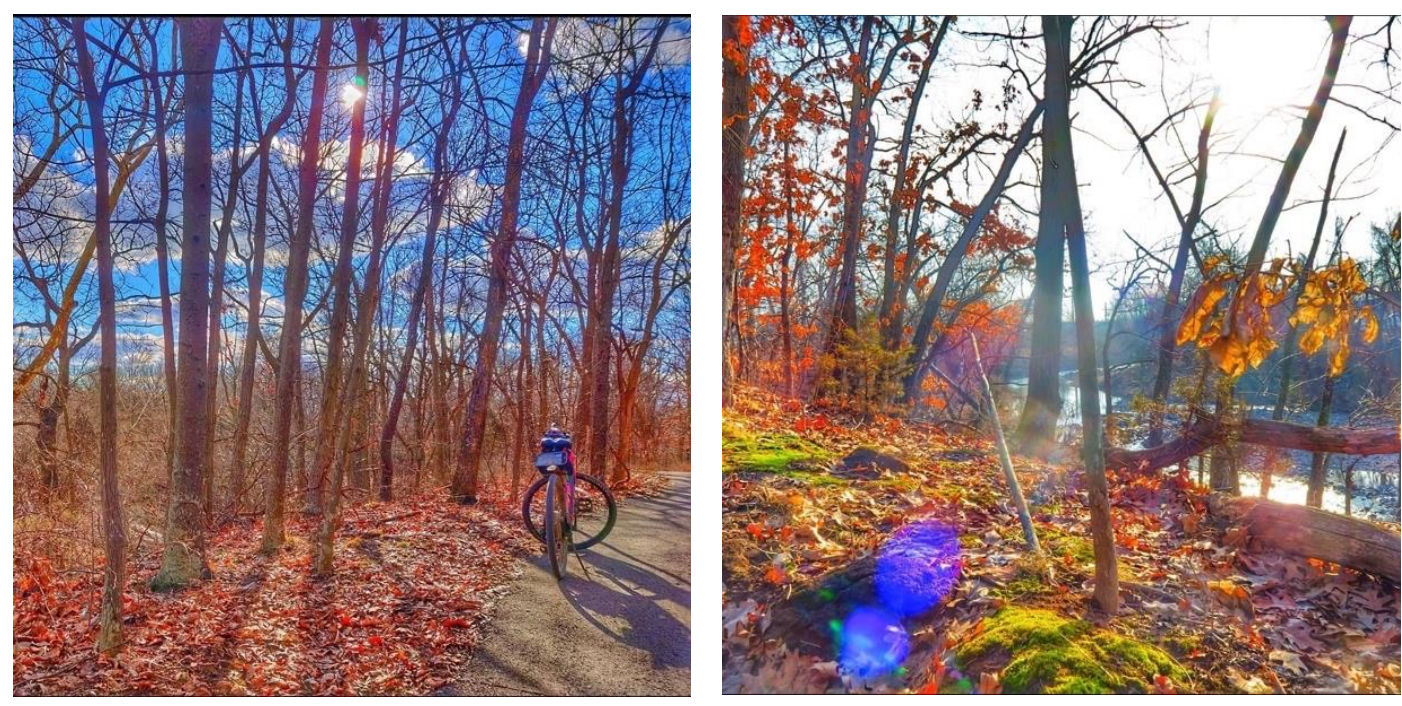

Staying physically active. It brings me great joy because my body just feels active and alive. You'd never really have any bad times when you're out exercising so we'd enjoy it. Last year we did about 2000 miles on this bicycle trail. (DA, Age 52)

AW described enjoyment associated with hiking and climbing trees, and felt a sense of pride and success associated with still being able to climb trees, even after struggling with long-term Covid-19 symptoms. 

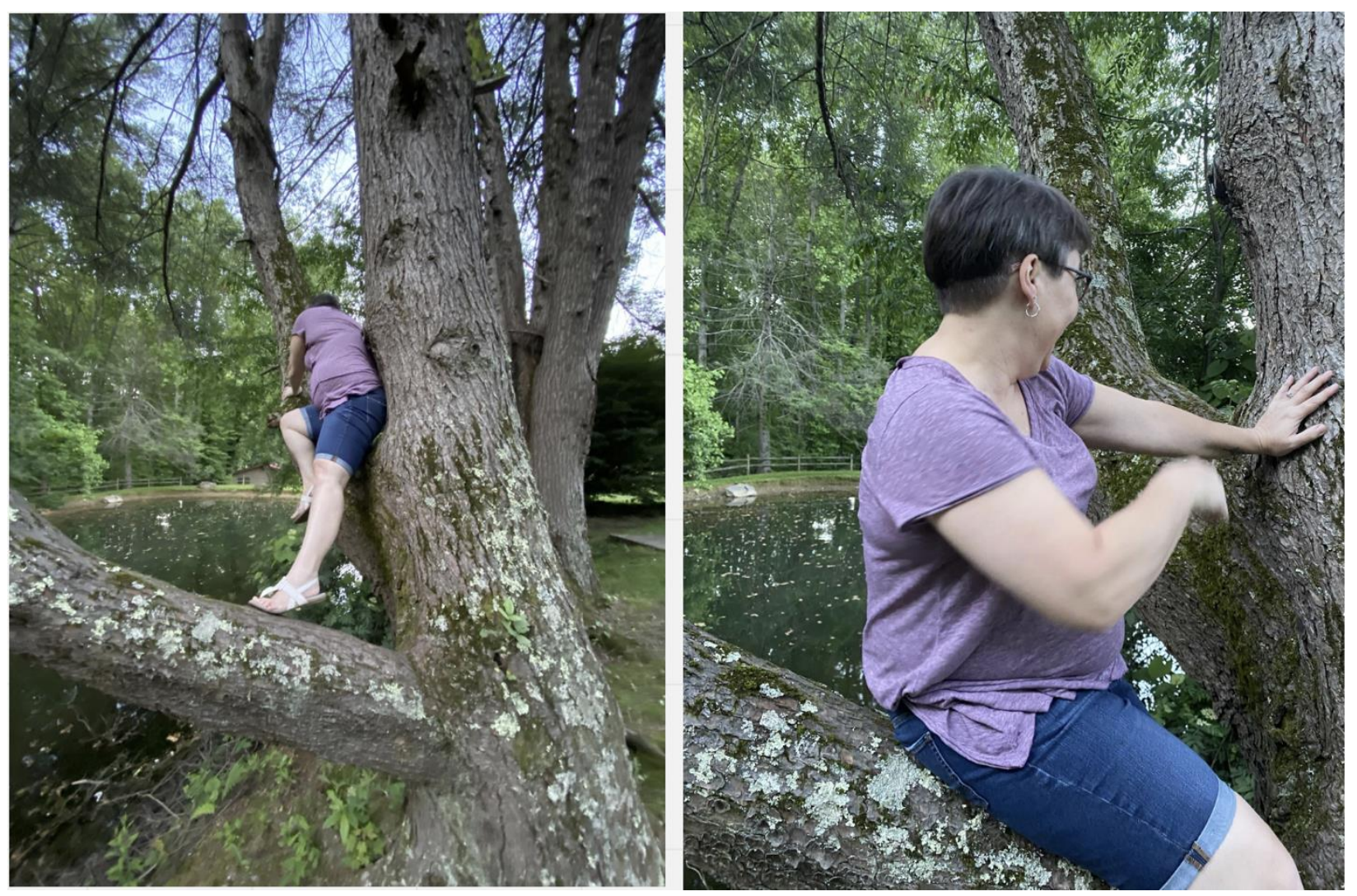

I like being outdoors, even if I'm not well enough to be really active. I can sit and, you know, climb around the rock. I have been known to climb trees. I'm 50 and I'm up in a frickin tree! (AW, Age 52)

B \& K also described their shift to a slower pace, but staying active. They also described that being able to engage in leisure activities has helped them enjoy a healthier pace of life. 


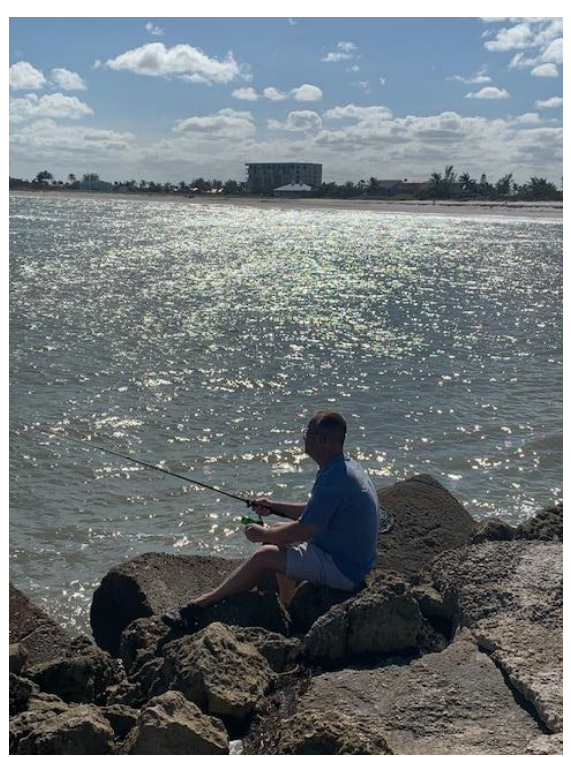

Some of the coolest times are when we go up to Atchison to go fishing, just sitting around in a little lake or something. Probably 20 years ago I would have thought no no no! That's not productive! That's not successful! Now it's like, that's what it's about! Enjoying the moment and staying active! (B, Age 54; K, Age 53)

Finally, ML discussed a shift in her overall lifestyle, with moving to a location that allowed for frequent kayaking, and less time in the car. She described the importance of staying active as salient to quality of life.

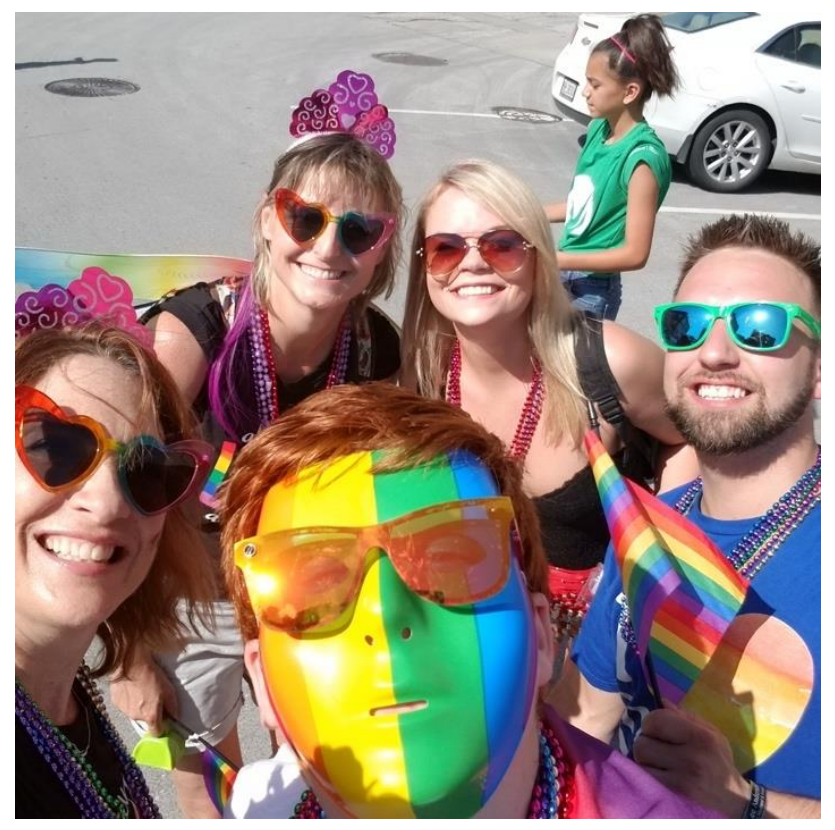

For me it's about being able to do things. But I've always been that way. Even before I came out I've always wanted to be the healthy one. I don't want to be the person who's 
just watching tv all day and doing nothing. Which is sort of what my life was turning into in my previous life. That's why I was running a lot, because at home, that's what I was faced with was a lot of tv watchers and doing nothing. - (ML, Age 52).

Reveling in Accomplishments. Participants frequently reflected upon personal accomplishments, which for many the biggest accomplishment described was that of being a parent and raising children who were accepting and supportive of their coming out. For example, HV (Age 63) teared up when discussing how open minded and supportive her children were when she came out to them as transgender.

I've been very lucky. I've been very fortunate. My kids are supportive. I called my daughter, she's in Maryland, and she said "I knew it mom!" The thing is she called me mom right away! I was so proud of the kids I raised!

ML, B, K, and AW all described feelings of success associated with being a grandparent. They expressed joy in spending time with younger children, and fostering a family culture of love and acceptance. Other accomplishments were less relational in nature, as ST described being able to buy a home for the first time.

Several participants described feeling pride associated with being a grandparent, and being able to reach that familial milestone. In particular, they expressed an enjoyment of spending time with younger children, and fostering a family culture of love and acceptance. For example, ML stated: 


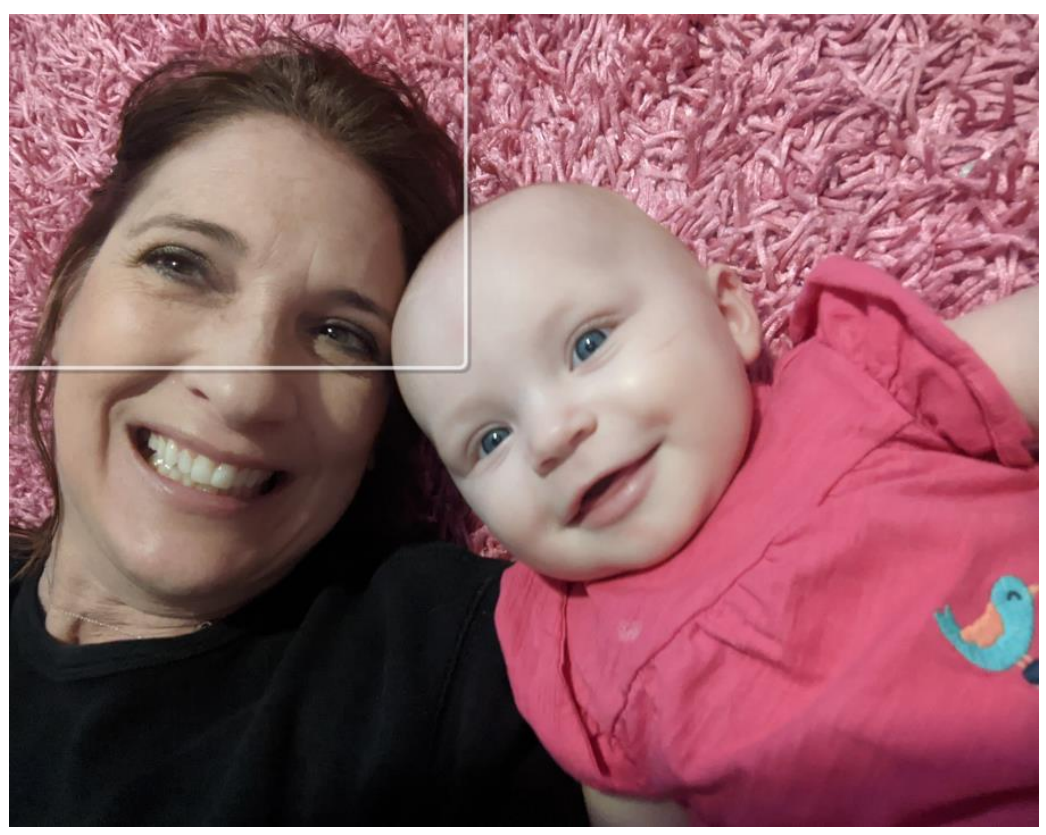

That little girl that's with me, that's my grandbaby, and I hope that she grows up in a world of happiness and love and acceptance. (ML, Age 52)

Other accomplishments were more tangible in nature, as ST described being able to buy a home for the first time.

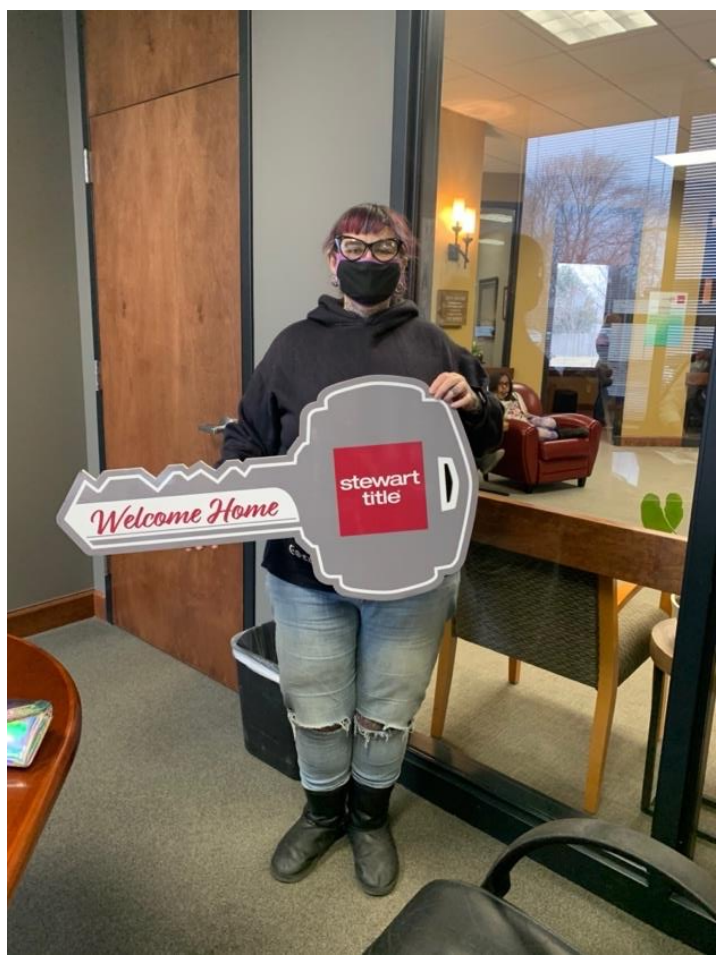


I just bought a house. I had the same job. I've worked for the state of Missouri since, 96, I think. I've been working for the same agency for almost 21 years. I'm actually 18 months from retirement, which is so bizarre. Now I'm definitely more into cleaning my house. I want my house to be tidy. I want it to look good. I want to have pride in it. (ST, Age 51)

MB also discussed receiving honors, awards, and recognition for his many years as a volunteer in the community, and also as a TV show host.

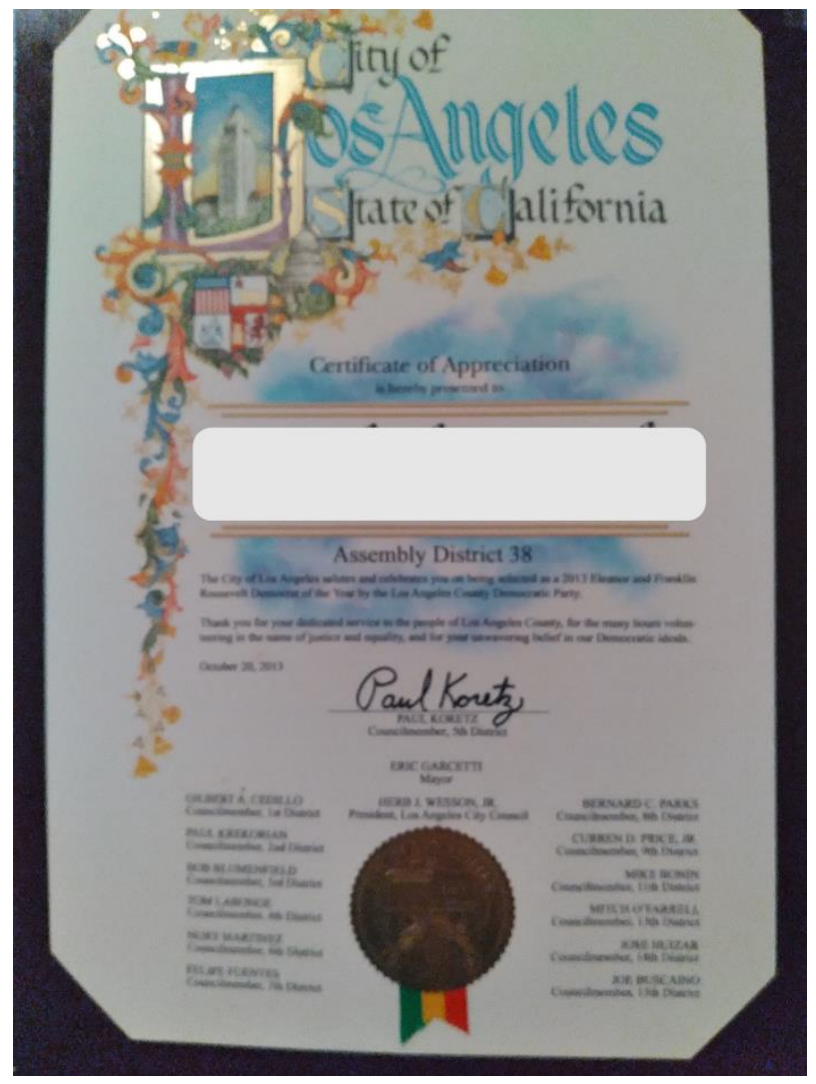

Because of my charitable work for 16 years, The Los Angeles County Democratic Party, which is the largest Democratic Party in the country... Somebody submitted my name unbeknownst to me. The LA County Democratic Party selects a democrat of the Year for each Assembly District, within LA County. I was awarded the, the Roosevelt Award. So with that came all these proclamations. One of them was that one from the city of Los Angeles and it's beautiful. It's absolutely gorgeous. It's you know, calligraphy and has the seal, plus a letter that was original signature by Barbara Boxer. It was a six-hour event that incorporated three cocktail parties. It was amazing. It was just, it was so nice. It was really, really, really special. (MB, Age 83)

New Way of Seeing the World. Finally, participants described feeling a sense of pride and success associated with their perspective on the world, achieved through years 
of navigating their identity, incurring life experience, and developing resilience. For instance, HV stated:

I think it's too bad you can't go backwards in time, but I think just the way that you see the world manage things today is a whole lot different. (HV, age 63)

In contrast, ST described a level of wisdom having resulted from coming out earlier in her life course, and successfully navigating challenges of being out when there was little social acceptance:

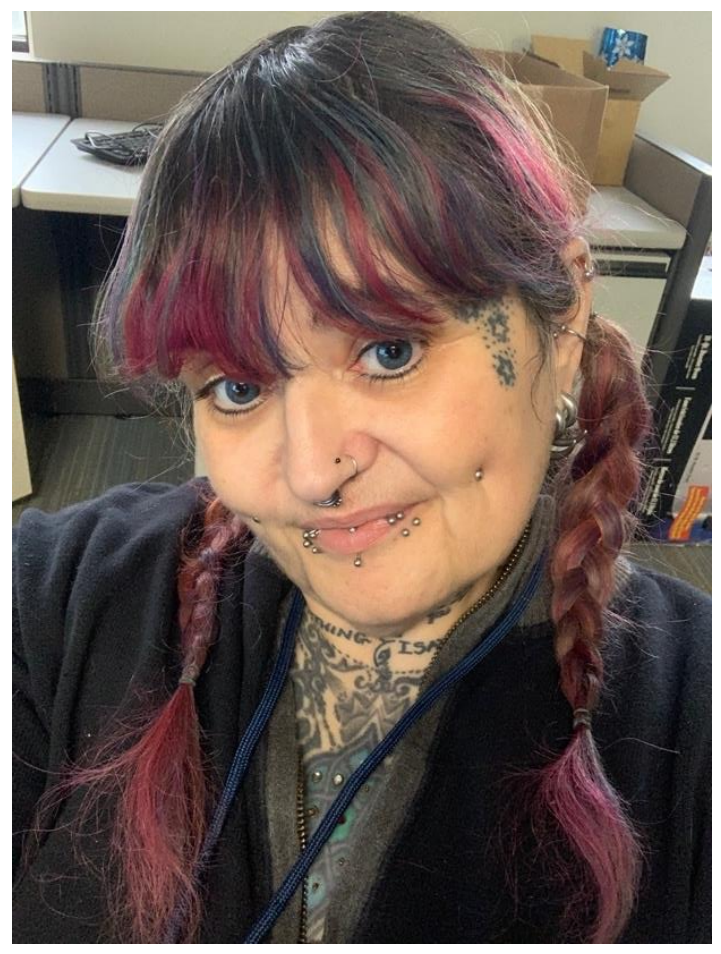

Everything that I have been through in my life has just allowed me to be unapologetically happy. Silly goofy dog mom...there's so many facets to me. I'm adaptable, and I think I learned that because of growing up and being out at an early age. (ST, Age 51)

Surprisingly, participants did not frequently describe resilience and perseverance when articulating their lived experience as an older LGBTQ+ person however, they did describe resilience as a component of their world view. For example, ST stated... My back is a wreck. My neck has been killing me. These are the things that you always hear your grandma say, like here's my arthritic hand. I actually wear hearing aids now. I 
had to get bifocals. It's like all these things started hitting me at one time. I have to go for regular injections in my elbow. My body is definitely, you know, feeling the effects but my mind isn't. And so if I want to do something and my body won't let me do it the way I used to be able to do it, I'm just going to change the way I do what I want so that I'm able to do it. (ST, age 51)

$\mathrm{HV}$ also described the desire to maintain a positive mindset as she grows older, even in the face of physical decline.

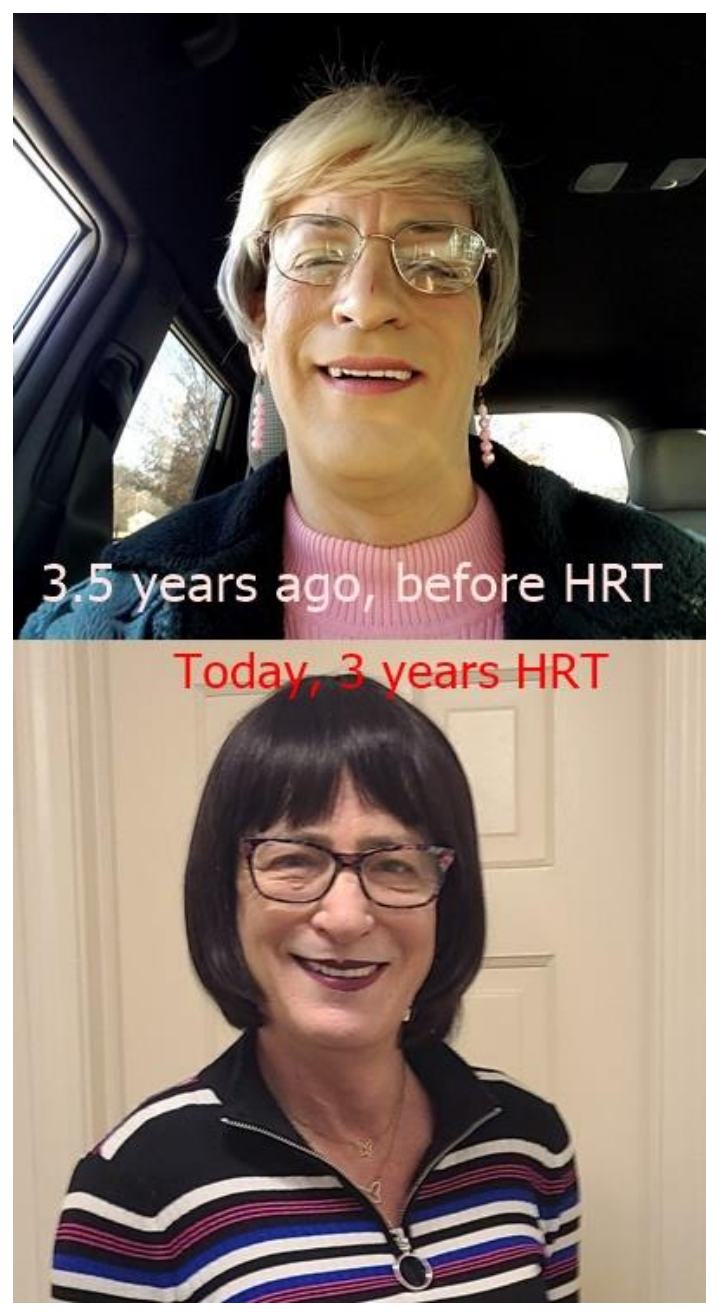

For me it's to just be happy. I mean, other people think of financial security and what not, but to me, continuing to be happy is successful. My dad always said it sucks getting old, but growing old is mandatory, but growing up is not! Growing up is optional! I try to keep my younger self in my mind. My brain says I'm 25, my body says the heck you are! (HV, Age 63) 
DA described feeling younger as she grows older, and especially due to her mindset shift after coming out, and how it's now in later life that she feels a sense of thriving:

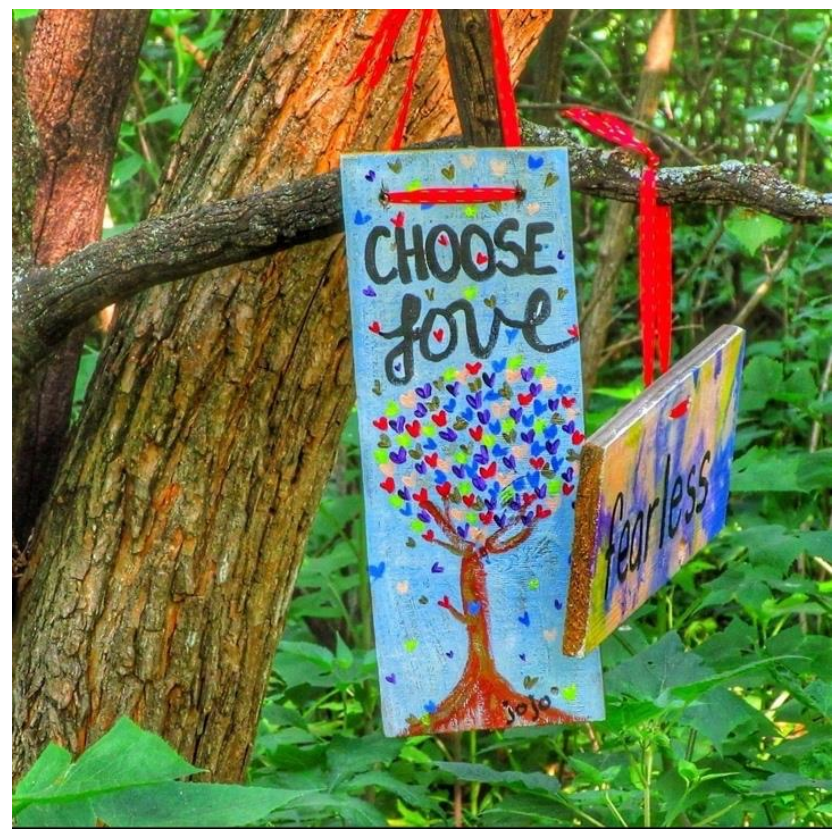

I just feel successful now, whereas before I didn't feel it or wasn't aware of it. I was just surviving. Now I'm thriving! When you think about age, it feels like I'm actually getting younger. I know my body is getting older. It takes longer for me to heal but I'm still fairly healthy. I can do pretty much everything, but now I AM doing everything I always wanted to. I am staying active. I'm living out the dream I've always wanted since I was a kid. I really feel that connection with my past where I was always dreaming. Now I'm actually LIVING. Before, all I had was dreams and real life. I feel successful the way I'm aging. I just see myself as happy. I have a good future now. I'm no longer living somebody else's narrative. I have my own life now and I'm not trying to figure out what other people have planned for me. Now I actually get it. I understand how everything connects together, where I'm supposed to go. Everything just comes together. Getting older, I think I've finally got my life together where I want it. (DA, Age 52)

ML described a newfound sense of empowerment that came from being out, which has helped her speak out more:

People need to be kind to one another! So I think it's like, this empowering thing that I've had. This is more empowerment than I've never had in my life! (ML, Age 52)

Finally, B (Age 54) described his shift in seeing the world and desire to give back as foundational to his feelings of success. 
Looking back a little more about that stuff. In your 20's you're looking at what you can get from the world. Then in the 50's you're starting to look back and see what have I given or what can I give? I think at least that's a big part of it (successful aging). It seems more and more important, even for $K$ too, to be able to do that with a partner by your side.

\section{Advocacy}

All participants described the importance of doing advocacy work as vital to feeling successful in later life. Even those who came out in later life had a history of serving the community as a volunteer, educator, or advocate in some capacity. After coming out, however, participants described feeling a sense of purpose as being a LGBTQ+ advocate. Participants articulated not only wanting to help the community at large, but also had a desire to instruct individuals on LGBTQ+ related issues, and wanting to pave the way for younger generations. Some participants discussed the desire to educate younger generations on the importance of LGBTQ+ history, mentioning the importance of the Stonewall Riots, LGBTQ+ art and media, and the need for establishing and maintaining intergenerational LGBTQ+ safe spaces. For example, AW described a great sense of purpose to educate youth, and after serving as a homeschool educator for over twenty years prior to coming out, she was now dedicated in later life to educating parents of LGBTQ+ youth. She described a shift in her education interests toward the LGBTQ+ community, in particular after coming out herself.

I just resigned after five years on the board of the secular inclusive homeschool support group here. My youngest is 21, but it's very important to me that we have that type of thing in our community and, you know, my chapter is done. Now I'm hosting virtual support groups for parents of queer kids, and also for queer parents. (AW, Age 52)

$\mathrm{HV}$ also described a desire and purpose to educate the broader community on transgender identity issues. She discussed not only being a volunteer at a local transgender clinic, but 
also talked about making herself available to others to ask questions and speak about more intimate and vulnerable topics related to being transgender. She stated:

I have a transgender flag sticker on the back of my car. I'm very open. I mean, I don't out myself hardly ever. I used to a lot but not anymore. I have a trans flag and a bisexual flag that I put in the back yard in a summer time. I'm very open. I encourage people... You talk about purpose in life. My purpose in life now is to educate people on transgender. I've always encouraged people to ask me questions, even personal questions. (HV, Age 63)

Further, HV also described using her position at work to advocate for LGBTQ+ supportive policies:

Before I came out, I must have emailed corporate to ask what the policy was for transgender people because I know lots of ladies that lost their jobs for being trans. They said that they give them the same protections as anyone else. Cool! They put it in their handbook two years ago that they couldn't discriminate based on color, race, and gender identity. Sexuality and gender identity are in there now. (HV, Age 63)

MB also discussed a long history of volunteering and serving as an advocate in the community. He worked to feed homeless populations, provide immigrant populations with infant and child items such as cribs and car seats, and also working across the nation as an AIDS advocate. He described successful aging as a result of his continued advocacy work with LGBTQ+ youth and families, and talked about accumulating pins on his church name tag to represent his many advocacy endeavors. 


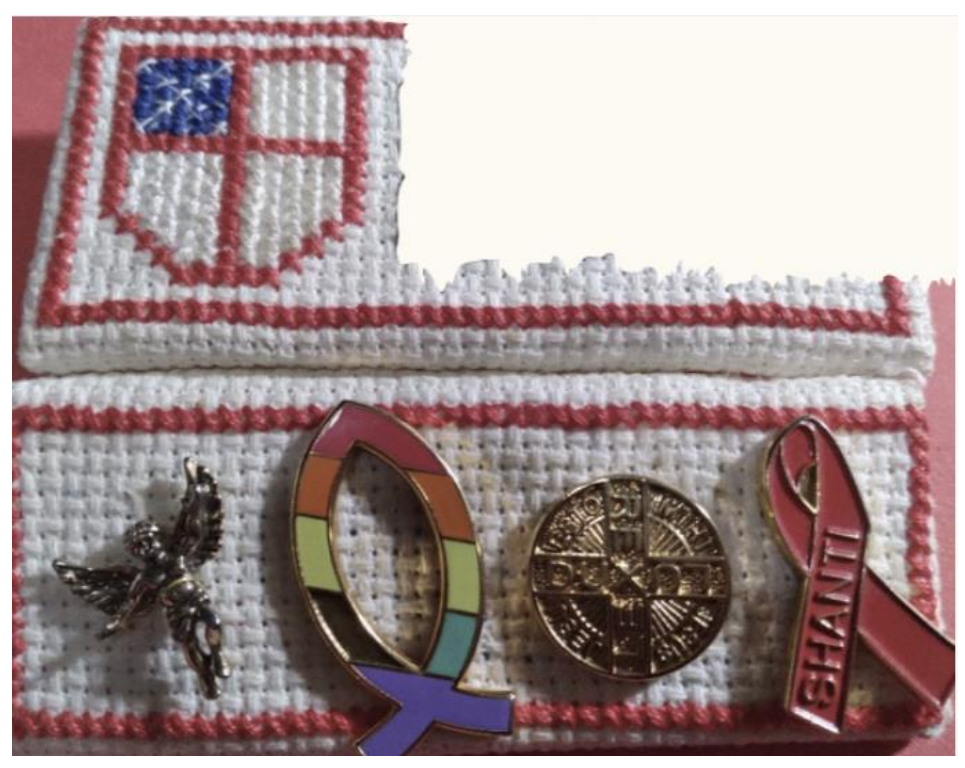

She made me a brand new name tag and collected all these little emblems and fixed it so that they can come off. On the right the pin represents being a volunteer for many years now in California. I've run an emotional support group for people with AIDS. We met in a church secretly. Because of that, firebombing, God knows what else. (MB, Age 83)

MB also shared the ways in which he continues to serve as an advocate in the LGBTQ+ older adult community:

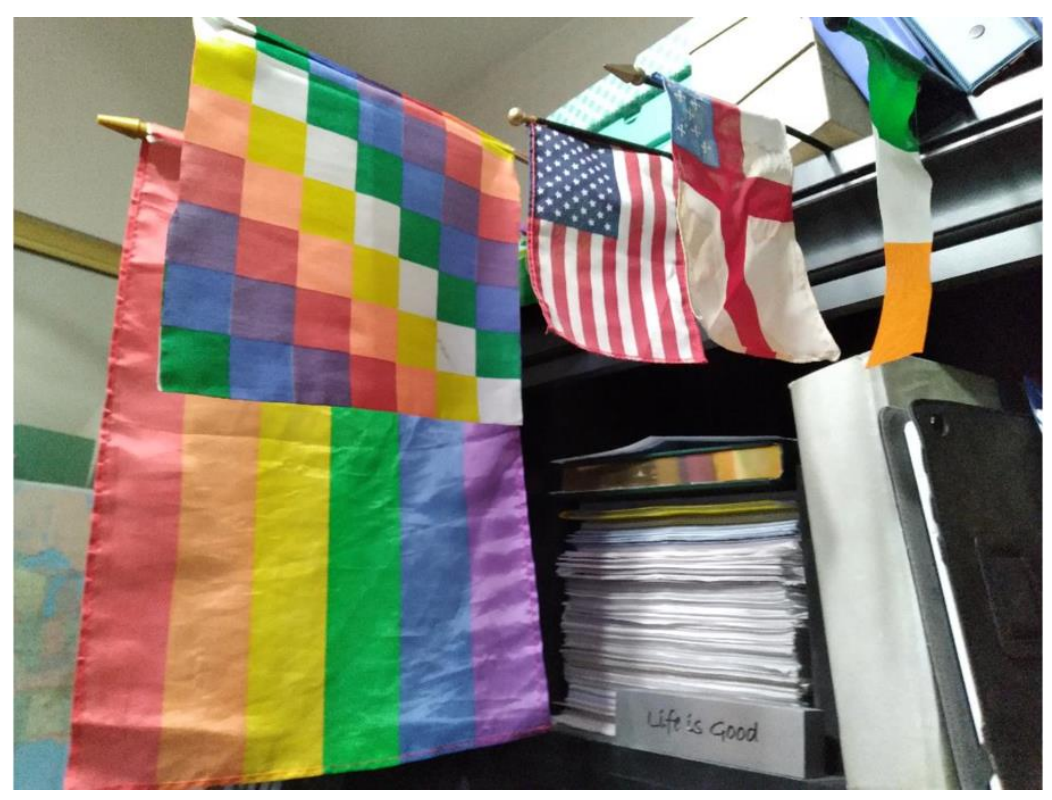

I run a little group on Facebook for older gays. I like to remind them that it's up to us. Whatever we do, it's up to us. We can't rely on anything anymore. We can't rely on the government. Social security used to be a guarantee. It's not. Medicare used to be a guarantee and it's not. We still have choices. We're still mobile. There's this national 
organization SAGE. I remember when it was founded. I was living in New York at the time, and it was just a small little group of people who were trying to encourage elderly gays and lesbians to come together and have meetings, do social stuff. Get off your ass and do things! That's my philosophy! Get off your ass! (MB, Age 83)

ST described the role queer spaces served in her own life, and the ways in which these spaces have died out. She talked about how she would like to support the LGBTQ+ community by helping re-create queer spaces, and build specific opportunities for middle age and older individuals.

You know, at that time, if there was something queer going on, every queer person was there. We finally got to be with our people, you know? Now it's like - we are very fragmented. It kind of bums me out that there's no place where I could just go and bring my laptop or my iPad or whatever and just like hang out, you know, drink a cup of coffee or whatever. I want to make these spaces happen again! We need them for us middle age and older queers! -(ST, Age 51)

\section{Educational Impact of the Photovoice Virtual Exhibit: Key Stakeholder Perspectives}

\section{Key Stakeholder Demographics}

A total of 38 service providers completed the survey to evaluate educational impact of the Photovoice Exhibit. Aside from profession, these participants were not asked any additional demographic questions. Key stakeholder participants represented a variety of service fields, including social or health service care coordination and referrals, adult education, social work, healthcare, financial service, legal services, advocacy, and non-profit services. A summary of the proportions of fields represented in the sample can be found in the table below.

\section{Table 2. Key Stakeholder Participant Demographics}

Service Field $\%$ of Total Sample

Care Coordination

$$
16 \%
$$

Education 
Social Work

Healthcare

Advocacy

Financial Services

Non-Profit

Legal Services
$23 \%$

$18 \%$

$7 \%$

$5 \%$

$13 \%$

$5 \%$

\section{Stakeholder Survey Results}

To evaluate the potential impact of using Photovoice as a community education tool key stakeholders of the LGBTQ+ community, multi-sector service providers were invited to view the virtual exhibit and respond to open-ended survey questions. For example, providers were asked questions such as, What surprised you?, What critical issues did you see portrayed in the exhibit?, and What did you learn that might apply to your profession? Thematic analysis of survey responses yielded two primary themes: Images Brought Stories to Light, and Nature of Identity.

\section{Images Brought Stories to Light}

Key stakeholder participants noted that while the stories were compelling, the images were effective at facilitating deeper meaning, allowing for deeper insight, and yielding a stronger emotional connection to the stories. The majority of respondents $(n=36)$ described the exhibit as compelling and a pathway for learning about LGBTQ+

older adults. Participants described how the images led to deeper insight that stories alone might not have facilitated. For instance, one participant stated, "The pictures helped me better understand the stories, so that I could be more prepared to work with the elderly 
LGBT. Without the pictures, the stories might not have affected me the same way and I might not have taken away as much." (Social Worker)

Many of the participants $(n=30)$ described an emotional response from the pairing of the images and stories. In particular, social work and healthcare professionals used the word "empathy" to describe their reactions to learning about the lived experiences of marginalized populations, stating the experience helped them feel empathy and connection with the clientele they serve. Some participants noted that the emotional reaction they had to the exhibit would be a powerful catalyst for doing a better job of addressing the needs of LGBTQ+ older adults. For instance, one healthcare professional stated, "The exhibit made me feel the empathy and understanding needed for doing this job. I feel more prepared to work with [LGBTQ+ older adults] in the ER now. My brain knows how to meet their health needs, but my heart needed to see this exhibit."

For some participants, however, the visual appeal potentially served as a distraction from the content. While most participants noted that the exhibit was visually compelling, not all participants described professional or educational insights apart from the visual appeal. Some participants solely provided comments such as "These people are so beautiful" (Non-profit Professional), or wrote, "[It is] such a gorgeous exhibit" (Education Professional), giving no response to the questions about professional insights about working with the LGBTQ+ population that were gained from viewing the exhibit.

\section{Nature of Identity}

Key stakeholders also described insights pertaining to the nature of LGBTQ+ identities expressed by those featured in the exhibit, which attended to aspects of LGBTQ+ identity such as timing of coming out, health challenges, and the importance of 
asking about identity. Specifically, professionals noticed the importance of the timing of coming out. When asked if anything in the exhibit surprised them, several participants ( $n$ $=13)$ commented on being surprised to learn that it was common to come out or transition in later life. For example, one participant stated, "I know lots of LGBTQ people professionally and personally. I had no idea that so many people didn't come out until later! This really surprised me!)" This newfound understanding led one social worker to consider this in future assessments of the life stressors of her LGBTQ+ clients, and to consider the health impact of hormone replacement therapy for the transgender population she serves. One health practitioner stated, "This helped me understand that it is important to ask about how long someone might be on HRT. The health effects are different and we should never assume!" Professionals commented that the exhibit helped them think of additional questions they should ask of their LGBTQ+ clients that they would not have thought of before. In response to the portion of the exhibit that illustrated the importance of screening for prostate or uterine cancer, one healthcare professional stated, "It would not occur to me to ask about whether a person has body parts that don't match the gender they present. I wonder how many providers miss that?"

In addition to learning the importance of asking about LGBTQ+ identity and the nature and timing of transition, practitioners described difficulty with approaching these topics. While respondents stated they were comfortable asking for pronouns and sex assigned at birth, they stated it was difficult to ask about sex organs, timing of transition, or sexual activity. Although the exhibit promoted awareness about the importance of discussing these topics with LGBTQ+ clients, more than half of all participants stated a need for training on how to best approach these discussions. This concern and desire for 
training was not limited to social service or healthcare professionals. For example, one legal service provider noted the difficulty of asking about the influence of LGBTQ+ identities as they pertain to end of life or estate planning. "The 'diet to die' part of the exhibit made me think about how I've had gay clients for estate planning that did not have kids. I know this is important to ask about, but I don't want to be rude. I don't know how to approach the subject."

When probed about populations served in their profession, many providers commented that they did not have much experience serving LGBTQ+ older adults. Some participants $(n=14)$ commented specifically on the role of sexuality in later life as a key takeaway from the exhibit. Although participants noted that sexuality might be an important topic of which to probe, especially for physical and mental health providers, they also shared feelings of discomfort about addressing this subject. For example, one social worker stated, "This project reminded me that sexuality is an important conversation that I need to be raising more often, especially with my older clients. I'm not sure how to do that if the client doesn't volunteer the information." 


\section{CHAPTER 4 -- DISCUSSION}

Photovoice methods were used to examine barriers and catalysts of successful aging for older LGBTQ+ individuals. Two primary themes emerged: The Relational Landscape and Rewriting the Narrative. The phenomena, relationships, and events that participants described as influential to their experience and conceptualization of successful aging were often identified as both barrier and catalyst. For instance, relationships that served as a barrier to successful aging in the LGBTQ+ community at one time point may have served as a catalyst at a later point. In addition, as echoed in the Photovoice exhibit (see Appendix A), whether participants viewed a particular situation as positive or negative was also heavily dependent on outness - the degree to which the individual discloses their LGBTQ+ identities to outside others.

Coming out—or being out—was a catalyst for successful aging for the majority of participants. While some barriers persisted after the coming out or transition process, the impact of these barriers was softened by newfound access to quality social support or buffered by joy associated with authentic expression. Some participants described fear or trepidation about coming out to family, yet they also described some members of their biological family as being part of their affirming support network. Within the sub-theme of Relationships with Others, participants articulated that coming out resulted in them gaining access to individuals that encouraged them to engage in meaningful experiences, while losing access to others. Notably, for many participants, the coming out process facilitated access to — and the shaping of — a supportive, affirming, and unconditional social support system consisting of biological and chosen family, friends, and pets. 
Participants described significantly more catalysts than barriers to successful aging, and often framing barriers as eventual catalysts, suggesting an appreciation for some of the challenges they faced as meaningful despite the intra- and interpersonal difficulties they represented. Commonly, participants articulated that many barriers were remedied by coming out, and that despite some newfound challenges associated with coming out, life as their authentic selves was much more worth living. The theme of Rewriting the Narrative emerged to encapsulate participants' cognitive reframing of barriers and catalysts into ways in which they were aging successfully. The experience of rewriting the narrative about one's identity illustrated what was particularly unique about aging as an LGBTQ+ person-queer identities were not only salient to the notion of successful aging, but they were also perceived to be impossible to separate from other aspects of their identity. In other words, a participant's LGBTQ+ identity was perceived to be the primary component of Self and the prism for which all other aspects of their identity were viewed. Indeed, when specifically probed for aspects of their identity unrelated to their LGBTQ+ identities, many had difficulty with identifying components of their identity that were outside of their queerness.

Although participants did describe some aspects of successful aging that overlap with the cis-gender, heterosexual older adults, LGBTQ+ successful aging was distinguished by the ways in which this population experiences and views such notions as inseparable from, and intrinsically tied to one's LGBTQ+ identity. For instance, participants described barriers to receiving quality healthcare due to stigma and discrimination, and the importance of maintaining a healthy and active lifestyle to prevent health decline and avoid unnecessary contact with the health system. Although 
successful aging studies using cisgender, heteronormative populations have also resulted in findings that maintaining a healthy and active lifestyle is important, they lack the additional layer of stigma that would result in fear or avoidance of the health system. Further, similar to cisgender, heterosexual populations, participants in this study also equated parenting and grandparenting as pertinent to successful aging. For the LGBTQ+ individuals in this study, however, they articulated that teaching acceptance of queer identities and promoting a family climate supportive of queer identities for future generations was of key importance.

In addition to exploring barriers and catalysts of successful aging for LGBTQ+ older adults, this study explored the use of the Photovoice exhibit to convey the lived experience of LGBTQ+ older adults to educate professionals in the community. Although all key stakeholders had some level of experience working within the LGBTQ+ population, there were still facets of the lived experience for LGBTQ+ older adults that these professionals indicated were previously unknown to them. Specifically, they described broadening awareness about life-saving health screenings and ongoing challenges experienced by this population that could impact mental health and social service needs. Moreover, key stakeholder participants were surprised to learn that it was common for LGBTQ+ individuals to come out or transition in later life. Professionals articulated being appreciative of learning about the importance of timing of coming out or transition, and expressed curiosity about how best to probe for further information that might impact service provision. For instance, health care and social work professionals expressed the desire to have more training about facilitating LGBTQ+ identity-related 
discussion with clients, and how to ask about matters that might have great implications for physical and/or mental health.

\section{Theoretical Implications}

\section{Life Course Perspective}

While I did not intentionally recruit participants who came out in later life, the majority of the sample described experiences of having come out later in the life course. The shift in mindset that took place after coming out altered these participants' lives in such a way that the quality of their relationship with one's self and others were considerably improved. Participants also described feeling a greater sense of joy after having come out, which carried through every aspect of their lives. Consistent with Fabbre's $(2014 ; 2015)$ qualitative work examining transgender individuals that waited until later life to come out, participants in this study described a process of addressing internalized stigma and fear as a pre-requisite for feeling they were successfully aging. The experiences of participants in this study did, however, deviate from prior studies on outness in later life. For instance, in Fabbre's prior studies on transgender older adults, later life was described as an opportune time to come out given a shift in responsibilities related to career and parenthood. Later life was leveraged as an opportunity to come out and begin gender transition. Although participants in this study described significant life course barriers to discovering and expressing their LGBTQ+ identity, they did not indicate that later life offered a unique opportunity to come out. Rather, they described the process of shedding religious upbringing and internalized stigma, and increased awareness of LGBTQ+ identities as the pathway toward coming out. Most participants in this study did not know they were not conscious of their LGBTQ+ identity earlier in their 
life course, which required a process of self-discovery over time in order to conclude that they were queer.

The finding related to shedding internalize stigma, in particular, contributes to an understanding of how life course perspective shapes the coming out process. In particular, sociocultural forces earlier in the life course, such as religion, geographic or community isolation, family of origin, and societal norms shaped participants' identity development and influenced the timing of coming out. Many participants noted that they were aware of their gender identity or sexual orientation earlier in the life course and were fearful of coming out due to stigma, violence, or ostracism from the church, community, and family. Others noted that they were unable to fully discern their own gender identity or sexual orientation earlier in the life course due to a lack of awareness or exposure to LGBTQ+ individuals. For all participants that came out in later life, there was a process of unraveling from internalized stigma that resulted from a lack of acceptance of queer identities. As noted within the Iridescent Life Course Perspective (Fredricksen-Goldsen, Jen, \& Muraco, 2019), sociocultural forces that impact queer identity development across the life course often translate into internalized psychological forces that pose challenges to the coming out process. This study further illuminates the diversity in how these forces might present across the life course, particularly with the shedding of internalized stigma.

\section{Queer Theory and Aging}

Queer theory served as a foundational lens through which to view the aging experiences of participants. Assumptions of queer theory suggest that gender identity and/or sexual orientation would be central to the aging experience, which was supported 
by the findings of this study. Participants consistently noted the salience of their LGBTQ+ identities in relation to describing successful aging, and frequently described coming out as central to aging successfully. This study also contributed to the understanding of how the rejection of heteronormativity specifically impacts notions of successful aging. Oswald et al. (2013) articulated the centrality of heteronormativity rejection when applying queer theory to better understand experiences of LGBTQ+ individuals:

"What we do need queer theory for is the examination of how heteronormativity is reproduced and resisted by everyone." (p. 15).

Participants in this study described participating in the reproduction of heteronormativity through religious upbringing and family culture, which was perpetuated by a lack of LGBTQ+ societal visibility. They also described the slow and arduous process of rejecting heteronormativity through their own processing of internalized stigma, and coming out in later life. Further, the theme of Our Voices Need to Be Heard, illustrates the resistance exhibited by participants to prevent the passive participation in heteronormativity, as representation and visibility can directly combat heteronormativity. Moreover, the use of the Photovoice exhibit to educate professionals and service providers also serves as a direct strategy for applying queer theory to decentralize heteronormativity in community services. Key stakeholder and focus group participants alike noted the impact of using the Photovoice exhibit as a means by which heteronormative assumptions can be combatted, and instead promote a more comprehensive spectrum of gender identities and sexual orientation. 
Notably, growing older in and of itself was not frequently mentioned as a barrier for focus group participants. Instead, most described feeling as though they were growing younger, being able to enjoy being active, and feeling an overall sense of enjoyment in life that was not available to them earlier in the life course. Transitioning or coming out promoted a feeling of youthfulness. While many participants described physical deterioration, mobility challenges, or health challenges, age was not frequently discussed as the primary reason for physical decline. Instead, participants most frequently described chronic illness as the source. While the study aims in many ways assumed that the intersection of queerness and aging would yield insights to the influence of compounding identities, participants most frequently noted their queerness in connection with successful aging while less frequently associating their age as pertinent. Some participants did note some agism within the LGBTQ+ community, most evident in the lack of queer spaces for individuals 50+, yet agism was not frequently discussed. While unexpected, the lack of emphasis on age and ageism for these participants highlights the importance of using a queer theory lens to further examine how coming out in later life, LGBTQ+ identity, and successful aging play out in the lives of older queer individuals.

\section{Successful Aging}

A primary aim of this study was to explore the ways in which LGBTQ+ older adults self-defined successful aging. Despite the existence of a wide range of definitions (Rowe \& Kahn, 2015), I chose not to anchor this study in a preconceived definition of successful aging. This decision did yield some difficulty for articulating a definition that attended to the intersection of aging and queer identity, particularly in a way that translates to the successful aging body of literature in existence. Without anchoring this 
study in some general, basic tenants of successful aging, such as the influence of biological, sociological, and psychological forces, there was some difficulty in translating findings into one particular definition.

There were, however, some unique findings that contribute to the understanding of successful aging from the LGBTQ+ perspective. For instance, this study highlighted that although there might be some overlap with heterosexual, cis-gendered populations, the lived experience of growing older is impacted by and inseparable from LGBTQ+ identity. The notion of successful aging did resonate with study participants, yet aspects of the lived experience that either positively or negatively impacted one's ability to feel a sense of success in the aging process were different for LGBTQ+ older adults in comparison to the cis-gendered, heterosexual population. For example, studies drawing from cisgender, heterosexual populations describe successful aging through accomplishments such as financial security (Chen, 2015; Tate et al., 2013), spirituality (Amin, 2017; Tate et al., 2013), and planning for having a good death (Chen 2015). Other dominant gerontological perspectives such as the Bio-Psycho-Social models have yet to fully recognize and incorporate LGBTQ+ identity as salient to understanding successful aging for queer populations. Participants in this study, however, did not mention or identify with these depictions of successful aging. Further research is needed to determine fit of common aging theories for the LGBTQ+ older adult population, and in particular, whether LGBTQ+ specific theories and models are necessary or whether existing scholarly frameworks can be adapted to include this population. Most importantly, successful aging literature should ensure adequate representation of LGBTQ+ individuals. For instance, in a recent scoping review of definitions of 
successful aging (Teater \& Chonody, 2020), of the 22 studies presented, none of the studies included an LGBTQ+ population despite the existence of studies that address the concept of successful aging with queer populations (Fredricksen-Goldsen, Jen, \& Muraco, 2019).

\section{Photovoice}

For this study, Photovoice was used as a means to yield deeper insight about the experiences of LGBTQ+ older adults, and generating photo artifacts in addition to focus group data to address the research questions. For historically excluded or marginalized populations, Photovoice can promote a sense of empowerment, and also serve as an opportunity to describe experiences that are not easily articulated by dominant discourse (Mitchell, 2011; Wang \& Burris, 1997). Photo artifacts provided by participants in this study greatly influenced the understanding of what it means to age successfully for this population, and provided deeper insight to the impact of LGBTQ+ identity and coming out and successful aging. In some instances, photos served as a visual metaphor for the coming out experience as evident by photos focusing on nature. Some participants used photos to articulate a shift in the ways they viewed the world after coming out. For example, one participant described their use of bright colors within their photos in contrast to how they saw the world as void of color prior to coming out. In other instances, photos elicited deeper reflection, particularly when considering earlier points of the life course, as participants provided images of their pre-transition selves or childhood idols. For other participants, photos demonstrated the ways in which participants rectified their relationship with self and identity with the external world that was often a hostile place. The use of photo data was especially useful for articulating the 
ways in which LGBTQ+ older adults see and experience themselves, their relationships, and the broader communities, and how successful aging is shaped by the broader queer experience.

Photovoice, in and of itself, is a method utilized to promote advocacy at the community-level (Mitchell, 2011; Wang \& Burris, 1997). For this study population, in particular, a primary theme that emerged was the importance of advocacy to feeling as though they were aging successfully. Through the creation of the Photovoice exhibit, participants were able to engage firsthand in community advocacy and increasing the representation of older LGBTQ+ individuals. While this study did not probe for participant experiences of creating the Photovoice exhibit specifically, all participants described advocacy as salient to successfully aging, and described the mark they wish to leave on the world as an out and proud older adult. Given that advocacy emerged as a primary theme related to what successful aging means to LGBTQ+ older adult participants, the use of Photovoice not only provided those insights but allowed participants to actively engage in the process as well.

Further, Photovoice methods were used in this study to examine the application of the exhibit as a community education tool. The Photovoice exhibit created by participants was then used to educate a variety of professionals and service providers. Key stakeholder participants viewed the exhibit and provided their reactions, which included the power of using photos along with words to help facilitate emotional impact. Key stakeholder participants not only described learning a great deal about the LGBTQ+ older population, but articulated a desire to learn more. This study demonstrated the potential 
use of the Photovoice exhibit as a community education tool, and also as a seed for promoting future education and advocacy.

\section{Implications for Professionals}

As the general LGBTQ+ population grows, more individuals are coming out as queer in later life, leading to a growing population of aging LGBTQ+ persons as a whole. Professionals across health, social, economic, and legal sectors are likely serving this population, yet unaware of important aspects of the queer aging experience. Findings of this study highlight the fact that LGBTQ+ identity cannot be disentangled from the overall lived experience. Therefore, service providers must be prepared to attend to aspects of the LGBTQ+ identity regardless of whether or not the matter is directly related to gender identity or sexuality. In some circumstances, ignoring aspects of LGBTQ+ identity can be life threatening, such as with cancer or mental health screenings. In other circumstances, seemingly benign details can have significant effects on quality of life for LGBTQ+ older adults. Moreover, findings from this study demonstrate the importance of viewing LGBTQ+ older adults through a queer theory lens. Participants frequently noted that their LGBTQ+ identity was incredibly significant to the notion of successful aging. In order to comprehensively understand the aging needs of LGBTQ+ individuals, gender identity and sexual orientation should remain in the forefront for service provision.

Future work is needed to prepare professionals across a variety of domains to better understand which aspects of the LGBTQ+ aging experience to probe for, and how professionals can approach probing for identity-related attributes. As a means to use the lived experience as a starting point for instruction, the Photovoice exhibit can be an effective avenue for educating cross-sector professionals on a variety of aspects that 
might affect service provision for the LGBTQ+ population. Further work is needed to systematically investigate the efficacy of using Photovoice as a community education tool, however, this study provides a first step in demonstrating the potential of using the Photovoice exhibit for these purposes.

\section{Future Research}

While gender and sexual minorities are more frequently represented in family science and gerontology research, both fields would benefit considerably from further exploration. First, while this study contributed to the understanding of what successful aging means to LGBTQ+ older adults, more work is needed to consider whether existing definitions of successful aging can be adapted to include a queer lens, or whether separate queer-specific conceptualizations are necessary. While the idea of successful aging did resonate with participants in this study, future work should also probe for alternative constructs preferred by older LGBTQ+ populations to articulate priorities in later life. Moreover, further research is needed to examine the relationship between timing of coming out and aging experiences. This study was unique in that the majority of participants had come out in later life, however, future studies could be useful for determining the degree to which timing of coming out might influence notions of successful aging. In addition, future work is needed to examine life course factors that impact the timing of coming out, particularly pertaining to barriers such as religion, geographic isolation, societal visibility, and the influence of shifting societal norms.

While findings of this study highlighted the importance of social networks and social support in relation to aging successfully, further research is needed to examine the broader relational landscape. Participants who were partnered at the time of coming out 
or transitioning described the difficult process of navigating those partnerships. Although some relationships ended, some participants described remaining in the relationship and grappling with implications for the partner. Considerable inquiry is needed to examine the ways in which relationships are negotiated after coming out or transitioning, particularly with couples who are able to successfully navigate shifts in identity or orientation. Moreover, relationships with adult children during and after transition or coming out would benefit further exploration. Notably, participants in this study did not describe conflict with children pertaining to coming out or transitioning. Instead, all participants who were parents of adult children described receiving support and acceptance. Future work is needed to consider the experiences and relational processes of adult children when a parent comes out or transitions in later life specifically.

Finally, while the method of Photovoice is growing in its application within gerontology and family science research, future work is needed to continue to improve applications of the method. Traditionally Photovoice methods are applied using in-person focus groups, however, due to Covid-19 restrictions, the method was adapted for a virtual approach. As such, Photovoice methods applied to this study deviated from typical approaches, including use of Zoom for conducting focus groups, using a web-based exhibit, and using programs such as Miro to guide discussion and navigate through photos. Future work is needed to explore the use of Photovoice methods in a virtual setting, in particular regarding the ways in which focus group dialogue might be impacted. Moreover, future directions should also focus on ways of engaging older adults in Photovoice studies, especially those who might not possess necessary photo-taking technology or skills. It is necessary to explore ways to mitigate the tech divide with older 
adult populations to ensure proper engagement and representation of older generations across Photovoice studies.

\section{Limitations}

While rigorous methods and procedures were used to conduct this study, some limitations must be acknowledged. Participants of the Photovoice portion of the study were overwhelmingly white, lacking perspective from Black, Indigenous, and other populations of color. Although one participant identified as Hispanic, they also noted that they were white-presenting, and thus not a reliable representative of the more significantly marginalized experience of the BIPOC LGBTQ+ population. Given the level of violence and discrimination aimed at LGBTQ+ populations of color, specifically toward Black transgender populations, significant work would need to be done to partner with racially marginalized communities for targeted recruitment and culturally competent adaptations to the research.

Additionally, more intentional recruitment within the LGBTQ+ older adult community is needed to include participants that came out earlier in the life course. Given that the majority $(n=8)$ of the population for this study described coming out in later life, findings disproportionately reflected the experience of coming out in later life. Some evidence suggests that those of the Baby Boomer generation that came out earlier in one's life course, have the greatest number of violent experiences of all older adult age cohorts (Morales et al., 2011). Thus, including more participants who came out earlier in the life course would allow future researchers the ability to conduct a more in depth, comparative analysis pertaining to timing of coming out and experiences of successful aging. 
Additional limitations are recognized when considering the impact of Photovoice as a community education tool. Although the open-ended survey questions were useful for gleaning insight and impressions from professionals who viewed the exhibit, more work is needed to validate measures of impact, and to assess for differences in profession and personal demographics. Further research is needed to determine the use and quality of Photovoice exhibits as an impactful community education or professional development tool.

\section{Conclusion}

This study utilized Photovoice to explore barriers and catalysts for successful aging for LGBTQ+ individuals. Further, this study also aimed to assess the impact of using the Photovoice exhibit as a community education tool. Findings indicated that for LGBTQ+ older adults, discovering and celebrating LGBTQ+ identity was salient to the ways in which queer older adults experienced feelings of success in later life. Data demonstrated that identifying barriers and catalysts for successful aging was dependent upon whether one was out. They were also often intertwined, indicating that challenge and resilience were experienced simultaneously. Preliminary evidence from this study showed promising potential with using the Photovoice exhibit as a community education tool, as professionals described learning important and potentially life-saving strategies for serving the LGBTQ+ older adult population. Moreover, those who viewed the exhibit described a desire to receive further education for how to probe for LGBTQ+ identityspecific details. In sum, this study highlighted the connection between being out and celebrating one's identity, and successful aging. 


\section{References}

Amin, I. (2017). Perceptions of successful aging among older adults in Bangladesh: An exploratory study. Journal of Cross Cultural Gerontology, 32, 191-207.

Braun, V., \& Clarke, V. (2013). Successful qualitative research: A practical guide for beginners. Sage Publishing.

Brennan-Ing, M., Seidel, L., Larson, B., \& Karpiak, S. E. (2014). Social care networks and older LGBT adults: Challenges for the future. Journal of Homosexuality, 61, 21-52. doi: 10.1080/00918369.2013.835235

Brown, M. T. (2009). LGBT aging and rhetorical silence. Sexuality Research \& Social Policy, 6(4), 65-78.

Burles, M., \& Thomas, R. (2014). "I just don't think there's any other image that tells the story like [this] picture does": Researcher and participant reflections on the use of participant-employed photography in social research. International Journal of Qualitative Methods, 185-205.

Butler, J. (1993). Critically queer. GLQ:A Journal of Lesbian and Gay Studies, 1, 17-32.

Carlson, E. D., Engebretson, J., \& Chamberlain, R. M. (2006). Photovoice as a social process of critical consciousness. Qualitative Health Research, 16(6), 836-852. doi: $10.1177 / 1049732306287525$

Chen, L. (2015). Rethinking successful aging. Asian Journal of Women's Studies, 21, 215-231.

De Vries, B., \& Croghan, C. F. (2014). LGBT aging: The contributions of communitybased research. Journal of Homosexuality, 61(1), 1-20. doi:10.1080/00918369.2013.834794

Elder, G. H. (1994). Time, human agency, and social change: Perspectives on the life course. Social Psychology Quarterly, 57(1), 4-15.

Erosheva, E. A., Kim, H., Emlet, C., \& Fredricksen-Goldsen, K. I. (2016). Social networks of lesbian, gay, bisexual, and transgender older adults. Research on Aging, 38(1), 98-123. doi: 10.1177/0164027515581859

Fabbre, V. D. (2014). Gender transitions in later life: The significance of time in queer aging. Journal of Gerontological Social Work, 57(0), 161-175. doi:10.1080/01634372.2013.855287 
Fabbre, V. D. (2017). Agency and social forces in the life course: The case of gender transitions in later life. Journals of Gerontology: Social Sciences, 72(3), 479-487. doi:10.1093/geronb/gbw109

Fine, M. (2006). Bearing witness: Methods for researching oppression and resistance - A textbook for critical research. Social Justice Research, 19(1), 83-108. doi: $10.1007 / \mathrm{s} 11211-006-0001-0$

Finkenauer, S., Sherratt, J., Marlow, J., \& Brodey, A. (2012). When injustice gets old: A systematic review of trans aging. Journal of Gay \& Lesbian Social Services, 24, 311-330. DOI: 10.1080/10538720.2012.722497

Fredricksen-Goldsen, K. I, \& Muraco, A. (2010). Aging and sexual orientation: A 25year review of the literature. Research on Aging, 32(3), 372-413. doi: $10.1177 / 0164027509360355$

Fredriksen Goldsen, K. I., Kim, H., Emlet, C. A., Muraco, A., Erosheva, E. A., Hoy-Ellis, C. P...Petry, H. (2011, November). The aging and health report: Disparities and resilience among lesbian, gay, bisexual, and transgender older adults. [report]. Seattle: WA: Institute for Multigenerational Health. Retrieved from https://digitalcommons.tacoma.uw.edu/socialwork_pub/117

Fredricksen-Goldsen, K. I., Cook-Daniels, L., Kim, H., Erosheva, E. A., Emlet, C., HoyEllis, C. P., Goldsen, J., \& Muraco, A. (2013). Physical and mental health of transgender older adults: A at-risk and underserved population. The Gerontologist, 54(3), 488-500. doi:10.1093/geront/gnt021

Fredricksen-Goldsen, K. I., Kim, H., Shiu, C., Goldsen, J., \& Emlet, C. A. (2015). Successful aging among LGBT older adults: Physical and mental health-related quality of life by age group. The Gerontologist, 55(1), 154-168. doi:10.1093/geront/gnu081

Fredricksen-Goldsen, K. I., Jen, S., \& Muraco, A. (2019). Iridescent life course: LGBTQ aging research and blueprint for the future - A systematic review. Gerontology, 65, 253-274. doi: 10.1159/000493559

Fredricksen-Golsen, K., Kim, H., Jung, H., \& Goldsen, J. (2019). The evolution of Aging with Pride - National Health, Aging, and Sexuality/Gender Study: Illuminating the iridescent life course of LGBTQ adults aged 80 years and older in the United States. The International Journal of Aging and Human Development, 88(4), 380404. doi: $10.1177 / 0091415019837591$

Halperin, D. M. (2003). The normalization of queer theory. Journal of Homosexuality, 45(2-4), 339-343. doi: 10.1300/J082v45n02_17 
Hughes, A. K., Luz, C., Hall, D., Gardner, P., Hennessey, C. W., \& Lammers, L. (2016). Transformative theater: A promising educational tool for improving health encounters for LGBT older adults. Gerontology \& Geriatrics Education, 37(3), 292-306. doi: 10.1080/02701960.2015.1127812

King, A., \& Cronin, A. (2010). Queer methods and queer practices: Re-examining the identities of older lesbian, gay, and bisexual adults. In. K. Browne \& C.J. Nash (Eds.), Queer methods and methodologies: Intersecting queer theories and social science research. Ashgate Publishing, 85-96.

Jablonski, R. A., Vance, D. E., \& Beattie, E. (2013). The invisible elderly: Lesbian, gay, bisexual, and transgender older adults. Journal of Gerontological Nursing, 39(11), 47-52. doi:10.3928/00989134-20130916-02

Jacob, M., \& Cox, S. R. (2017). Examining transgender health through the International Classification of Functioning, Disability, and Health's (ICF) contextual factors. Qual Life Res, 26, 3177-3185. doi.org/10.1007/s11136-017-1656-8

Jenkins Morales, M., King, M. D., Hiler, H., Coopwood, M. S., \& Wayland, S. (2014). The greater St. Louis LGBT health and human services needs assessment: An examination of the silent and baby boom generations. Journal of Homosexuality, 61(1), 103-128. doi: 10.1080/00918369.2013.835239

Joffe, H. (2007). The power of visual material: Persuasion, emotion and identification. Diogenes, 217, 84-93. doi: 10.1177/0392192107087919

Leach, F. (2006). Researching gender violence in schools: Methodological and ethical considerations. World Development, 34(6), 1129-1147.

Lincoln, Y.S. \& Guba, E. G. (1985). Naturalistic Inquiry. Sage Publications.

Merriam, S. B. \& Tisdell, E. J. (2016). Qualitative Research: A Guide to Design and Implementation (4E). Wiley \& Sons, Inc.

Mitchell, C. (2011). Doing visual research. Sage Publications.

Muhammad, M., Wallerstein, N., Sussman, A. L., Avila, M., Belone, L., \& Duran, B. (2015). Reflections on researcher identity and power: The impact of positionality on community based participatory research (CBPR) processes and outcomes. Critical Sociology, 41(7-8) 1045-1063. doi: 10.1177/0896920513516025

Oswald, R. F., Kuvalanka, K. A., Balter Blume, L., \& Berkowitz, D. (2013). Handbook of Feminist Family Studies: Queering the Family. (Ed., Lloyd, S. A., \& Few, A. L.). Sage Publications, Inc. 
Porter, K. E., \& Krinsky, L. (2014). Do LGBT aging trainings effectuate positive change in mainstream elder service providers? Journal of Homosexuality, 61, 21-52. doi: $10.1080 / 00918369.2013 .835235$

Sandelowski, M. \& Barroso, J. (2007). Handbook for synthesizing qualitative research. Springer Publishing.

Stoudt, B. G., Fox, M., \& Fine, M. (2012). Contesting privilege with critical participatory action research. Journal of Social Issues, 68(1), 178-193.

Tate, R. B., Swift, A. U., \& Bayomi, D. (2013). Older men's lay definitions of successful aging over time: The Manitoba follow-up study. The International Journal of Aging and Human Development, 76, 297-322.

Teater, B., \& Chonody, J. M. (2020). How do older adults define successful aging? A scoping review. The International Journal of Aging and Human Development, 91(4), 599-625.

Testa, R. J., Habarth, J., Peta, J., \& Balsam, K. (2015). Development of the gender minority stress and resilience measure. Psychology of Sexual Orientation and Gender Diversity, 2(1), 65-77.

Teti, M., Koegler, E., Conserve, D. F., Handler, L., \& Bedford, M. (2018). A scoping review of photovoice research among people with HIV. Journal of the Association of Nurses in AIDS Care, 29(4), 504-527. doi: 10.1016/j.jana.2018.02.010

Teti, M., Pichon, L., Kabel, A., Farnan, R., \& Binson, D. (2013). Taking pictures to take control: Photovoice as a tool to facilitate empowerment among poor and racial/ethnic minority women with HIV. Journal of the Association of Nurses in AIDS Care, 24(6), 539-553. doi.org/10.1016/j.jana.2013.05.001

Walker, R. V., Powers, S. M., \& Witten, T. M. (2017). Impact of anticipated bias from healthcare professionals of perceived successful aging among transgender and gender nonconforming adults. LGBT Health, 4(6), 427-433. doi. 10.1089/lgbt.2016.0165

Wang, C. (1999). Photovoice: A participatory action research strategy applied to women's health. Journal of Women's Health, 8(2), 185-192. doi.org/10.1089/jwh.1999.8.185

Wang, C., \& Burris, M. A. (1997). Photovoice: Concept, methodology, and use for participatory needs assessment. Health Education \& Behavior, 3, 369-387. 
Wang, C. C., Yi, W. K., Tao, Z. W., \& Carvano, K. (1998). Photovoice as a participatory health promotion strategy. Health PromotionInternational, 13(1), 75-86.

Zelle, A., \& Arms, T. (2015). Psychosocial effects of health disparities of lesbian, gay, bisexual, and transgender older adults. Journal of Psychological Nursing, 53(7), 25-30. doi:10.3928/02793695-20150623-04 
APPENDIX A

Final Exhibit Images

Figure 1.1. Virtual Exhibit Homepage

LGBTQIA+ EXPERIENCES OF GROWING OLDER

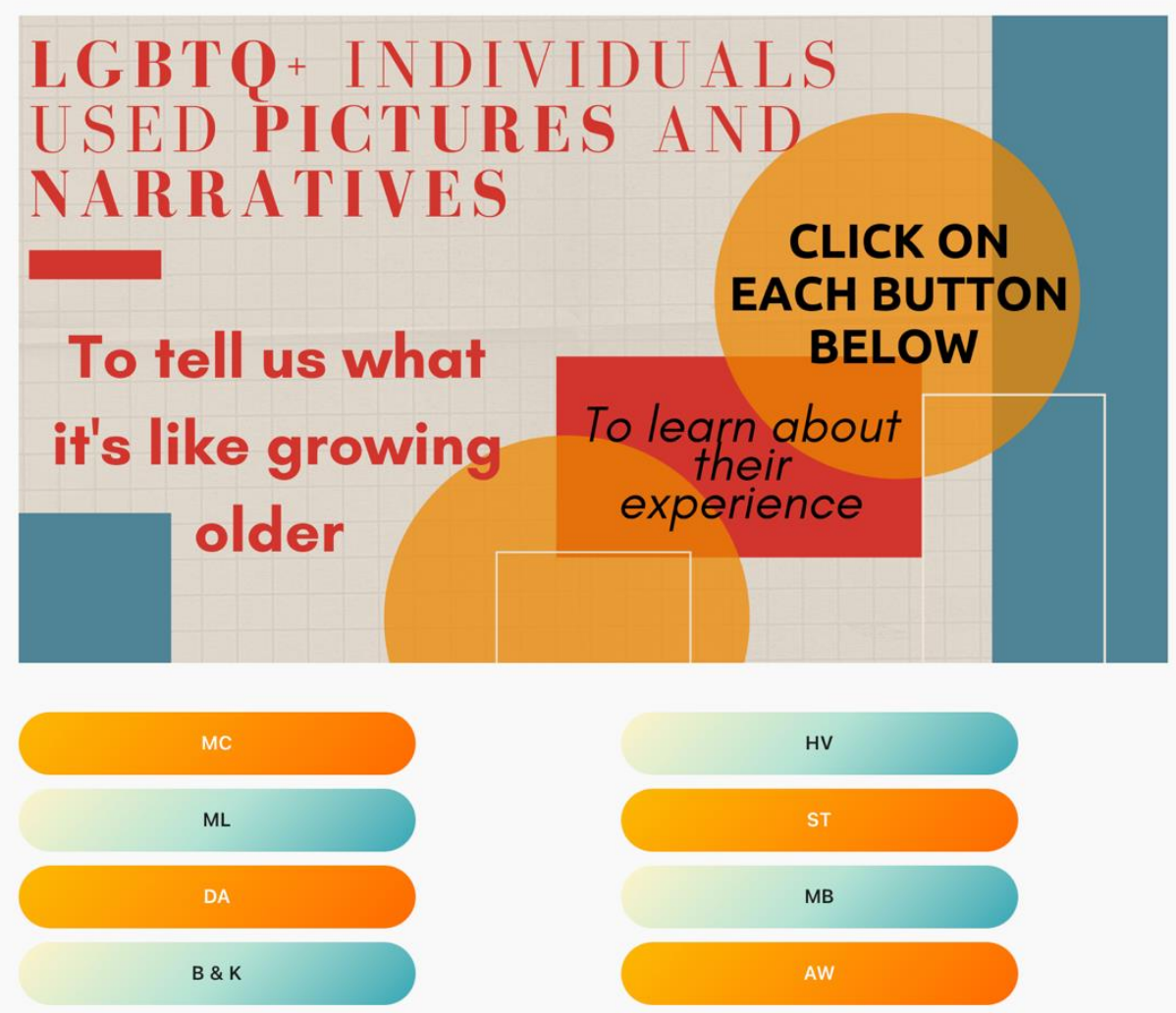




\section{Figure 1.2. AW Exhibit 1}

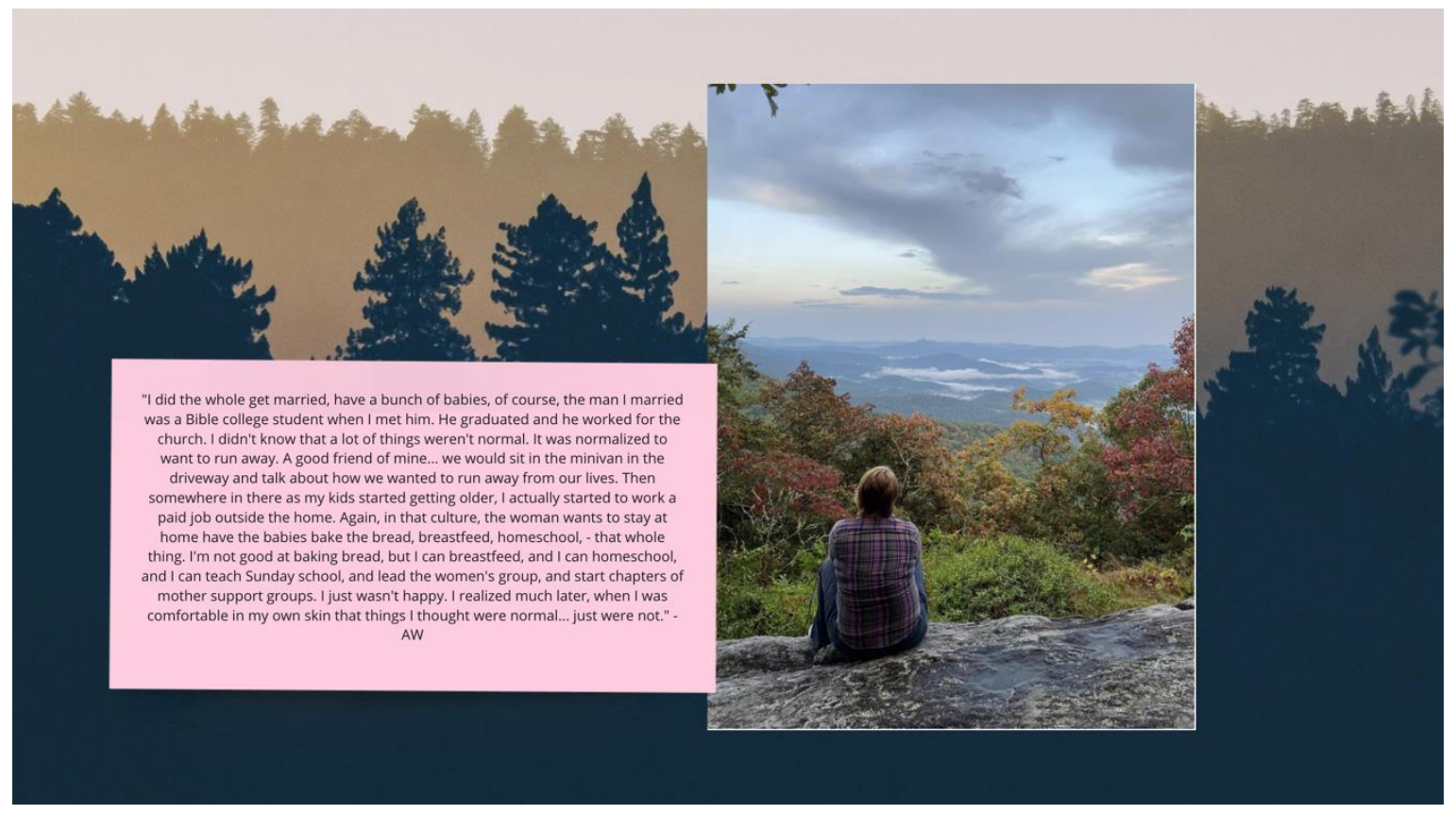

\section{Figure 1.3. AW Exhibit 2}

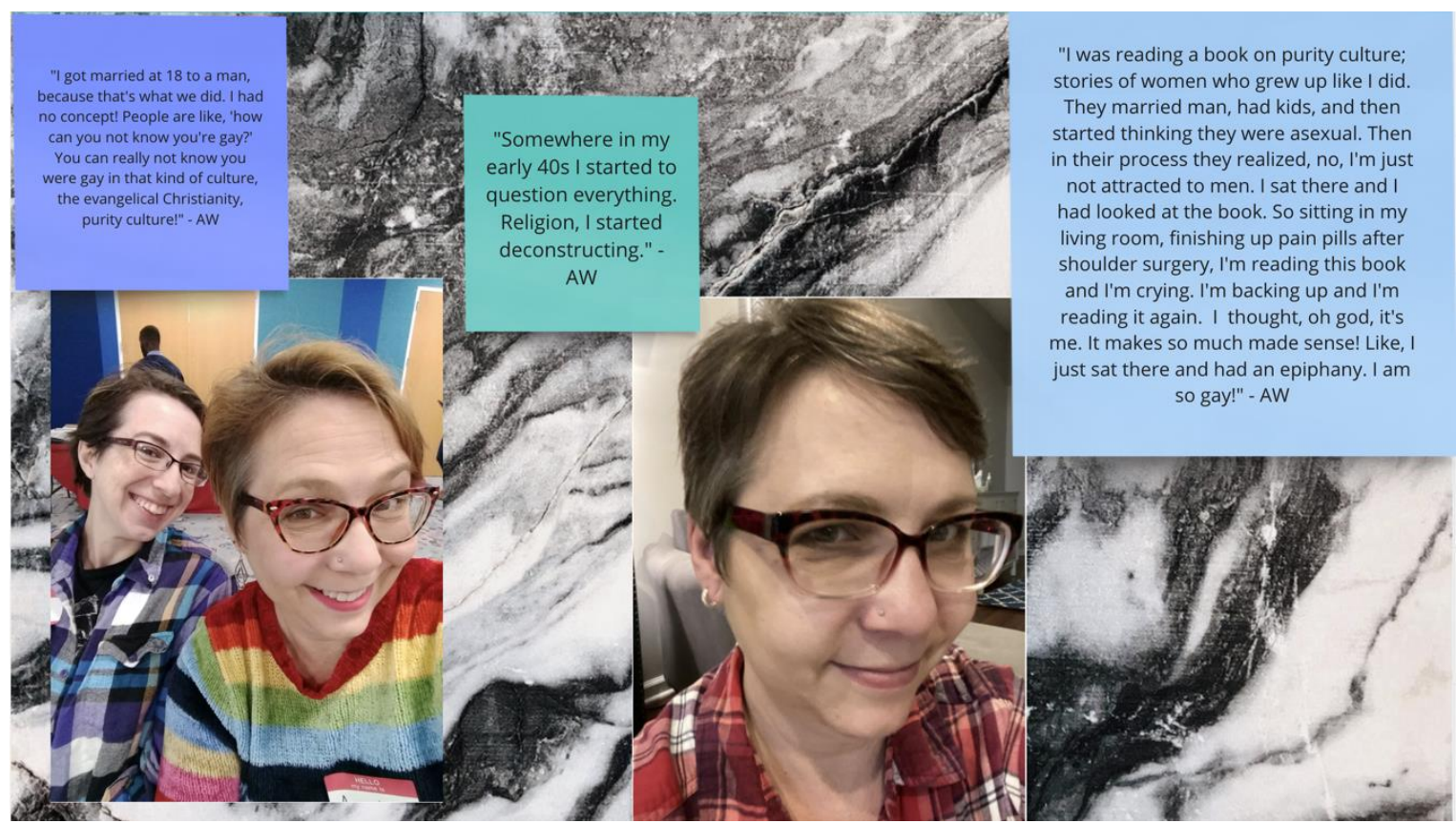


Figure 1.4. AW Exhibit 3

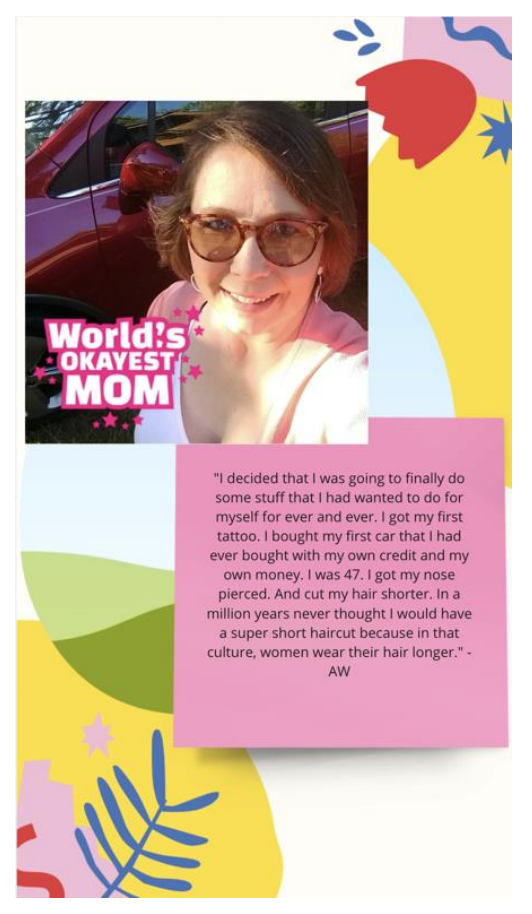

Figure 1.5. AW Exhibit 4

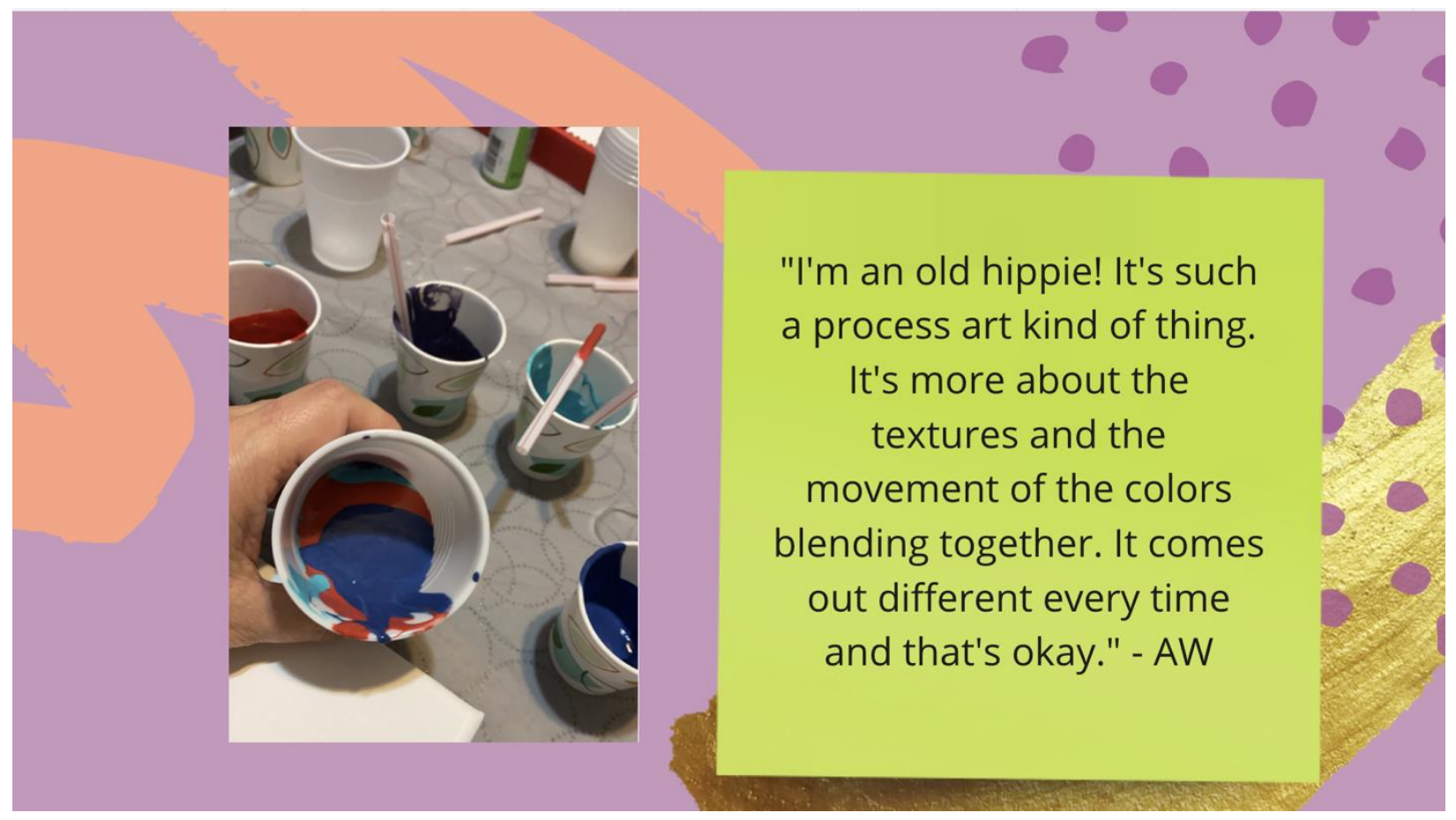


Figure 1.6. AW Exhibit 5

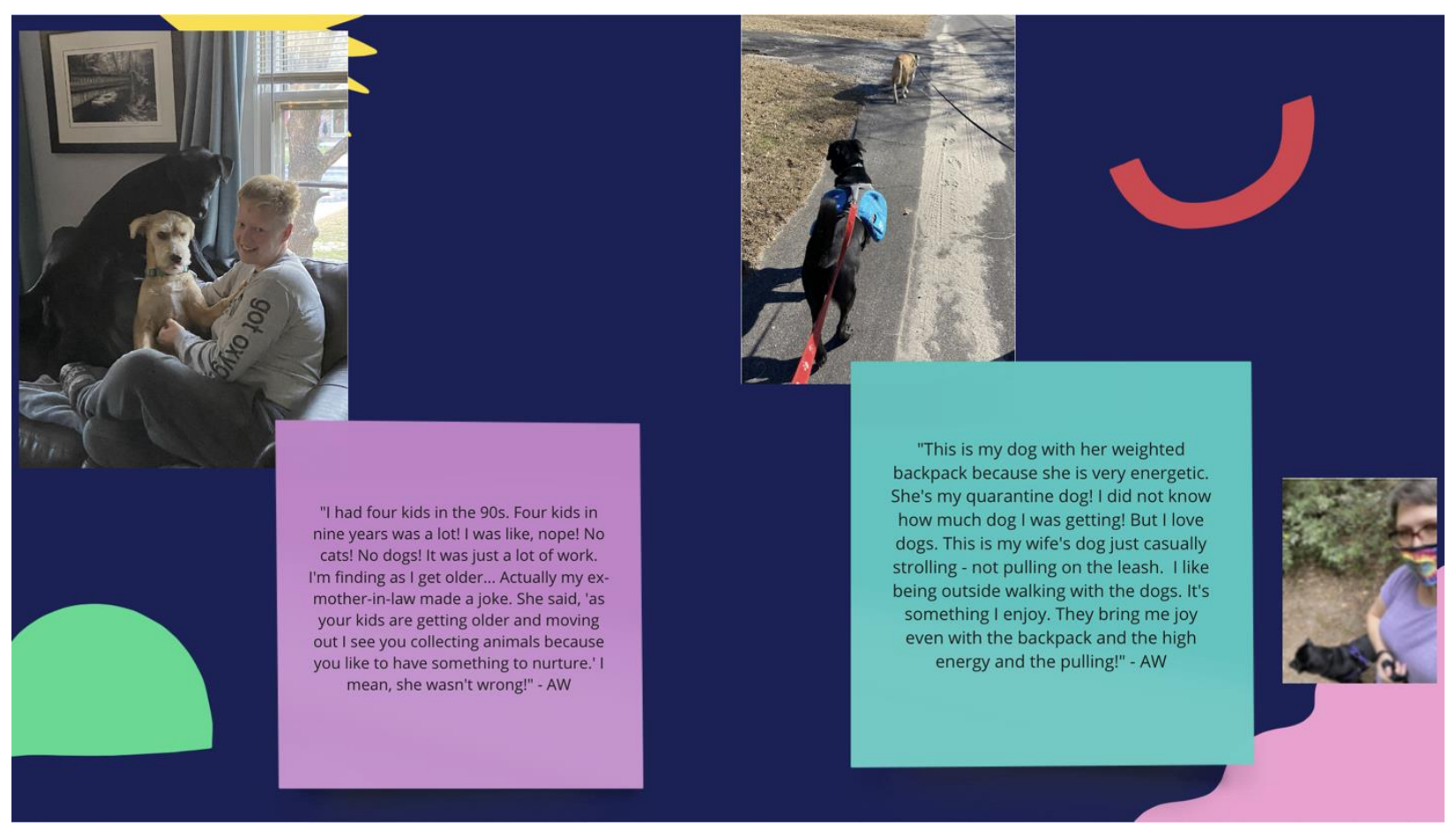

Figure 1.7. AW Exhibit 6

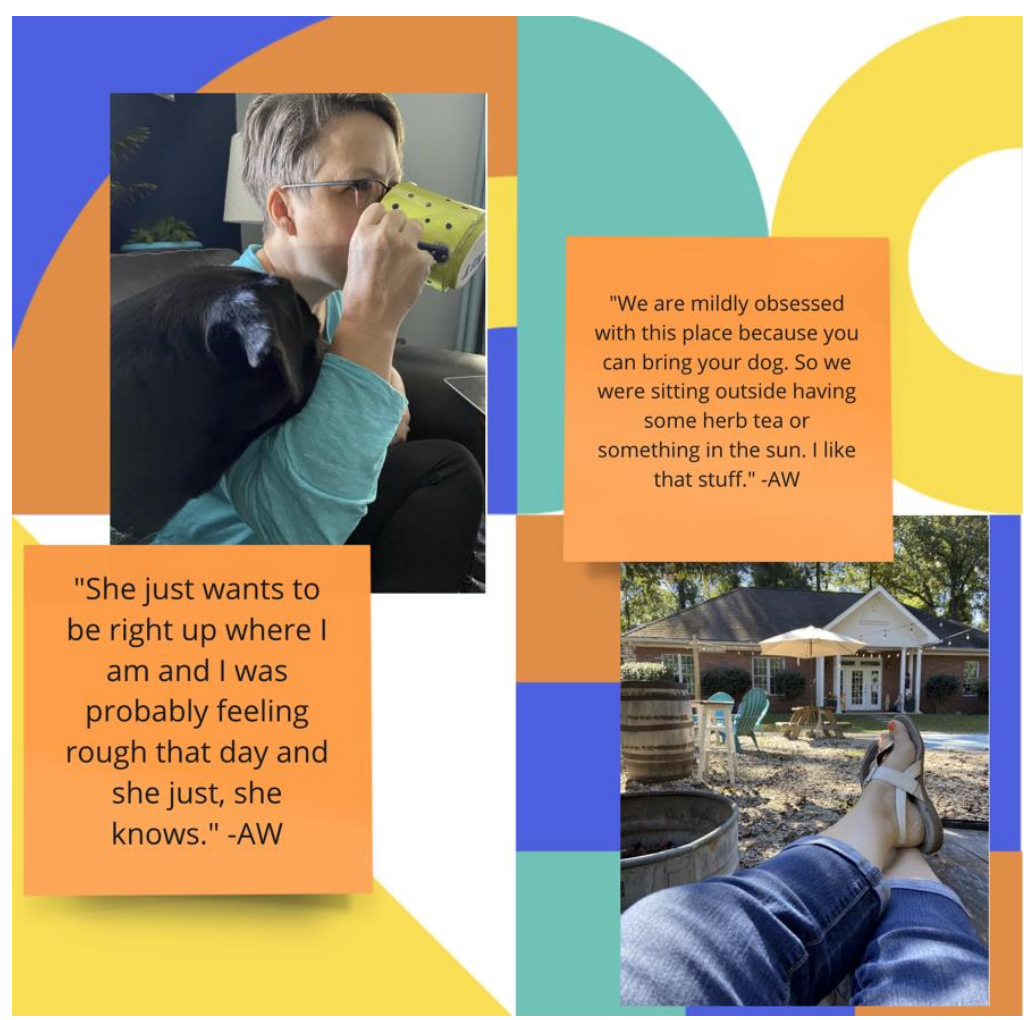


Figure 1.8. AW Exhibit 7

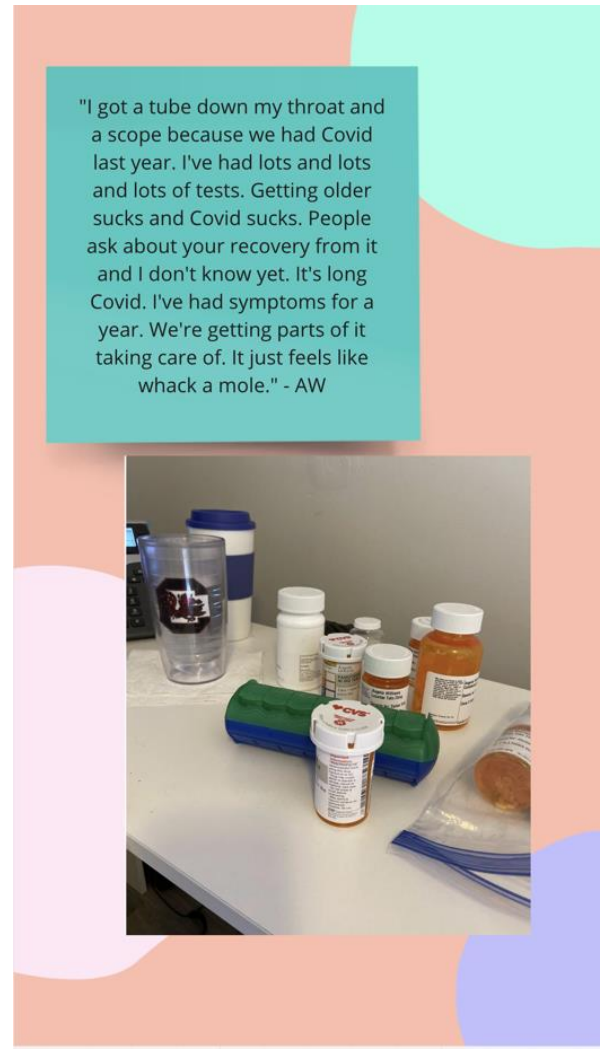

Figure 1.9. AW Exhibit 8

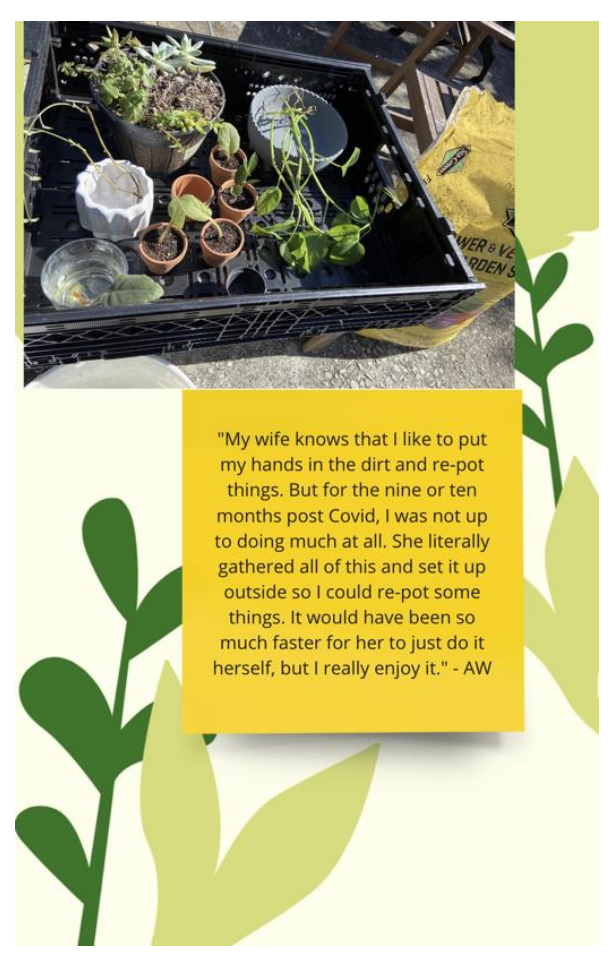


Figure 1.10. AW Exhibit 9
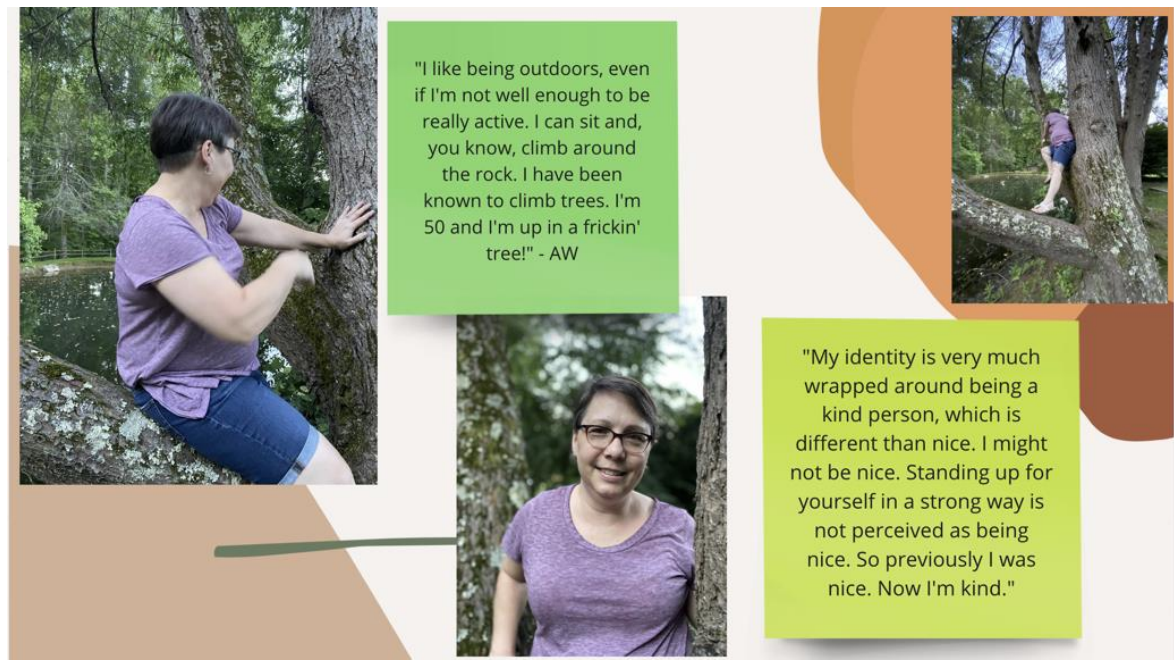

"My identity is very much wrapped around being a

kind person, which is

different than nice. I might

not be nice. Standing up for

yourself in a strong way is

not perceived as being

nice. So previously I was

nice. Now I'm kind."

Figure 1.11. AW Exhibit 10

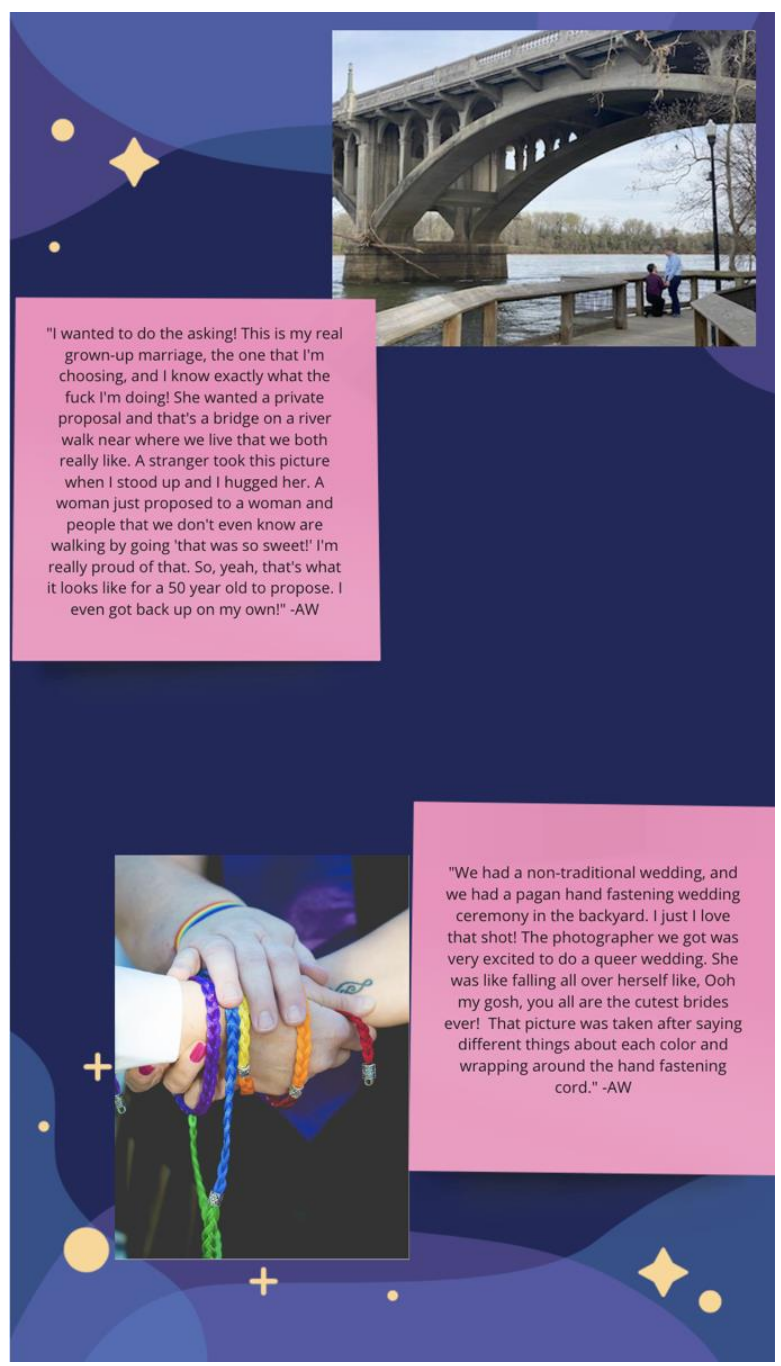


Figure 1.12. AW Exhibit 11

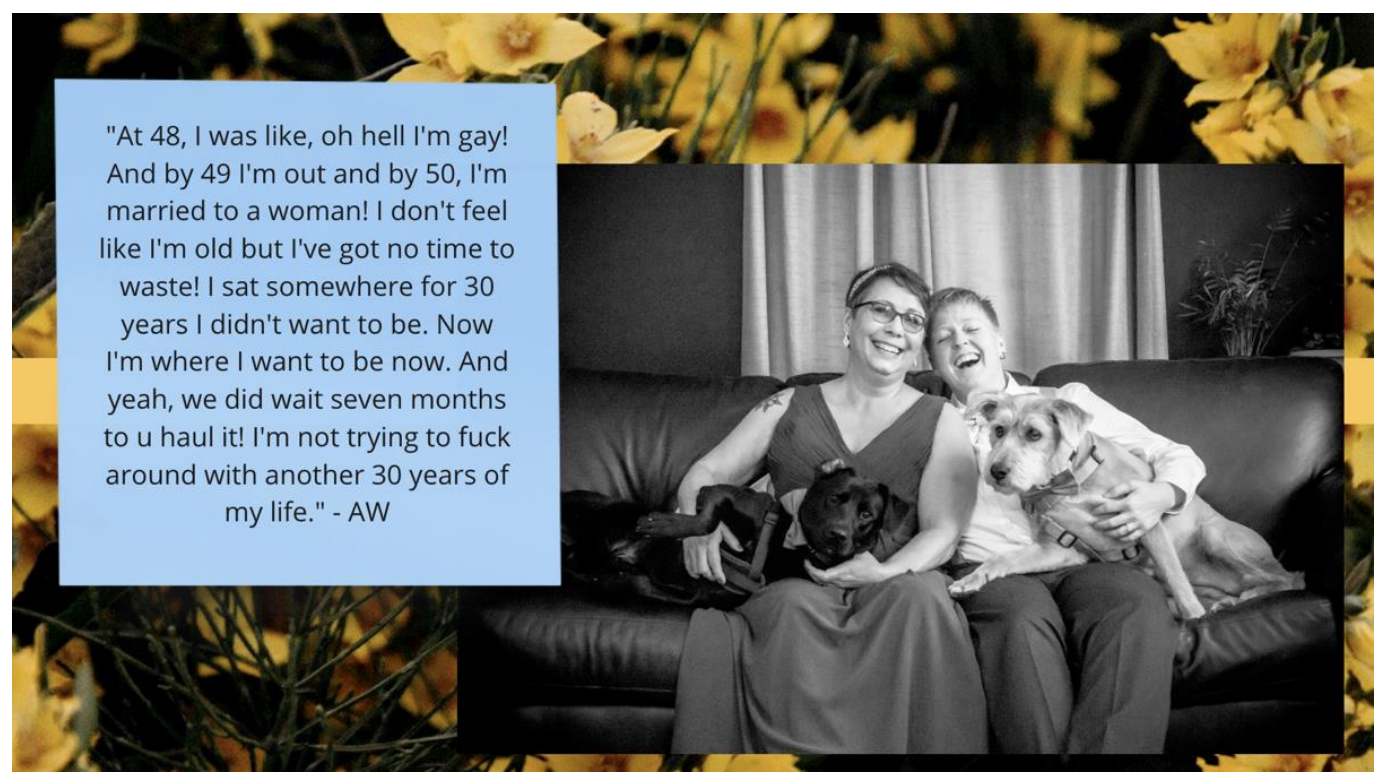

Figure 1.13. BK Exhibit 1

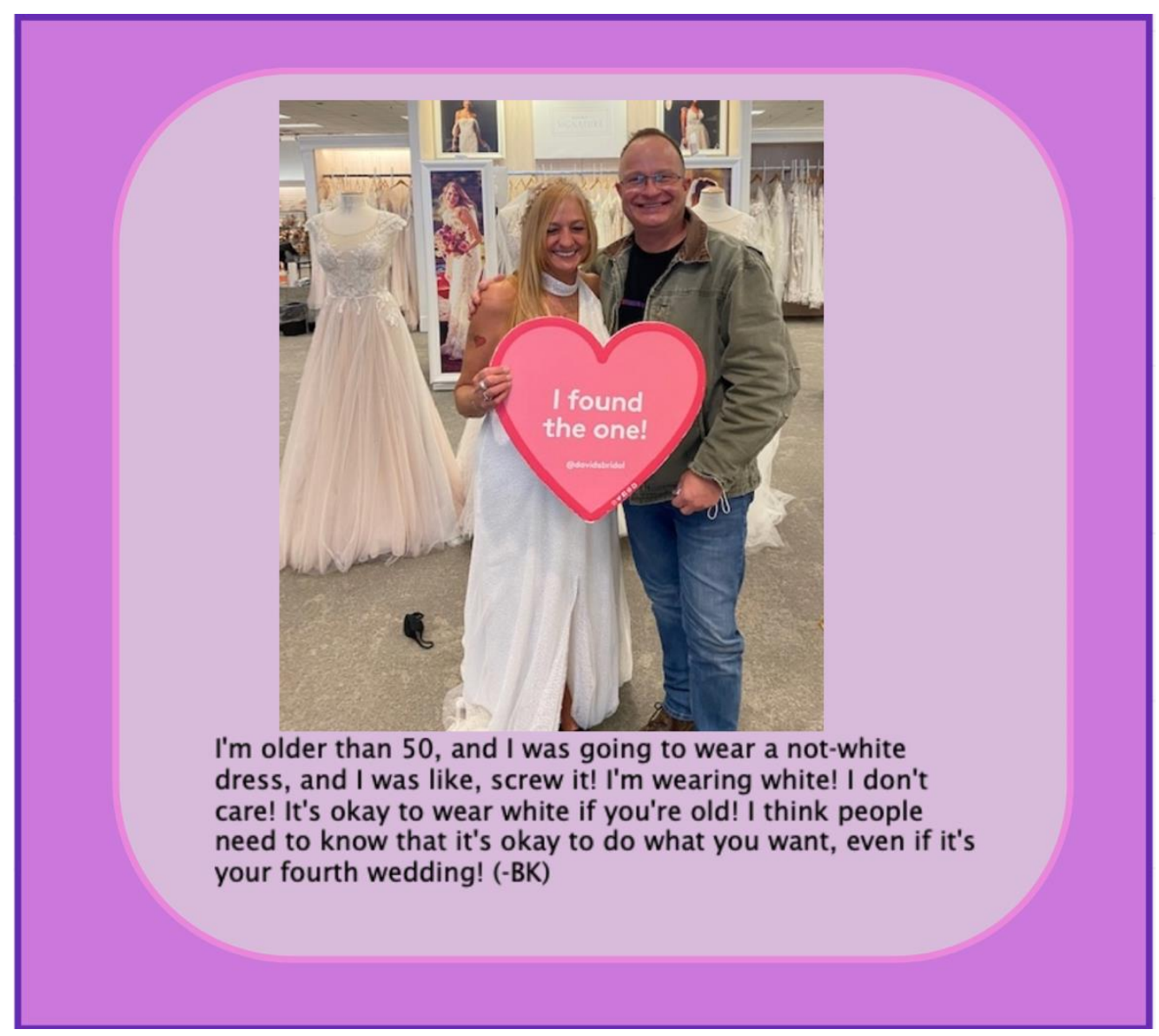


Figure 1.14. BK Exhibit 2

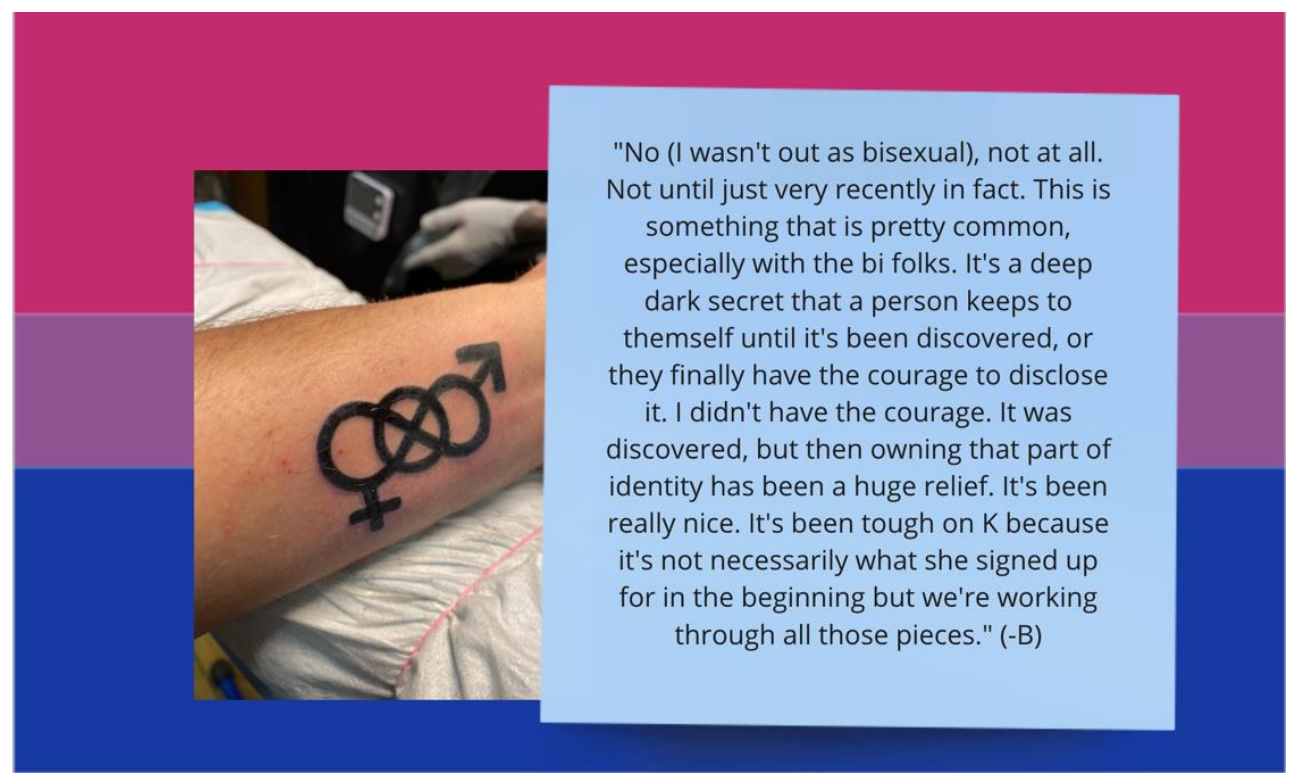

Figure 1.15. BK Exhibit 3

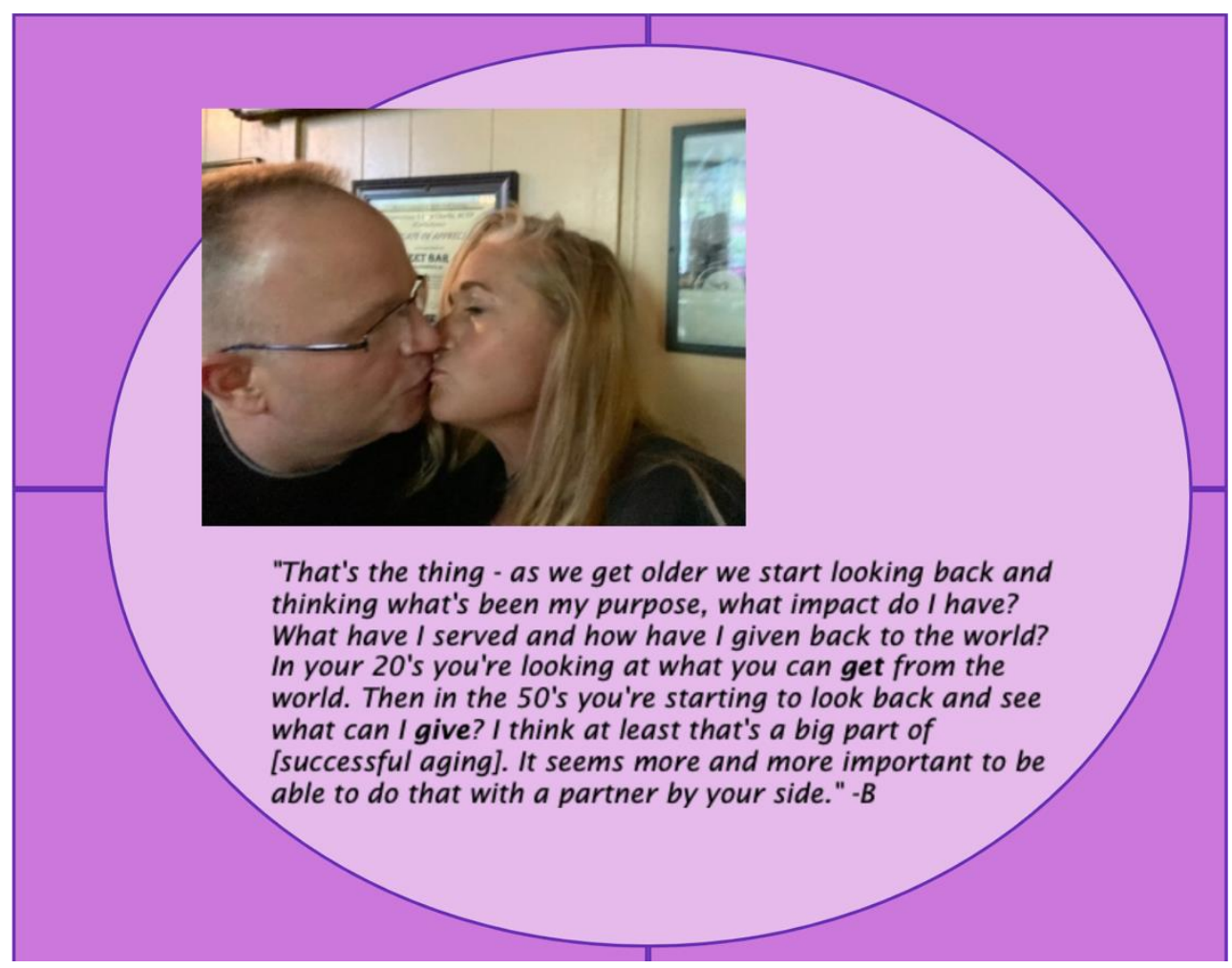




\section{Figure 1.16. BK Exhibit 4}

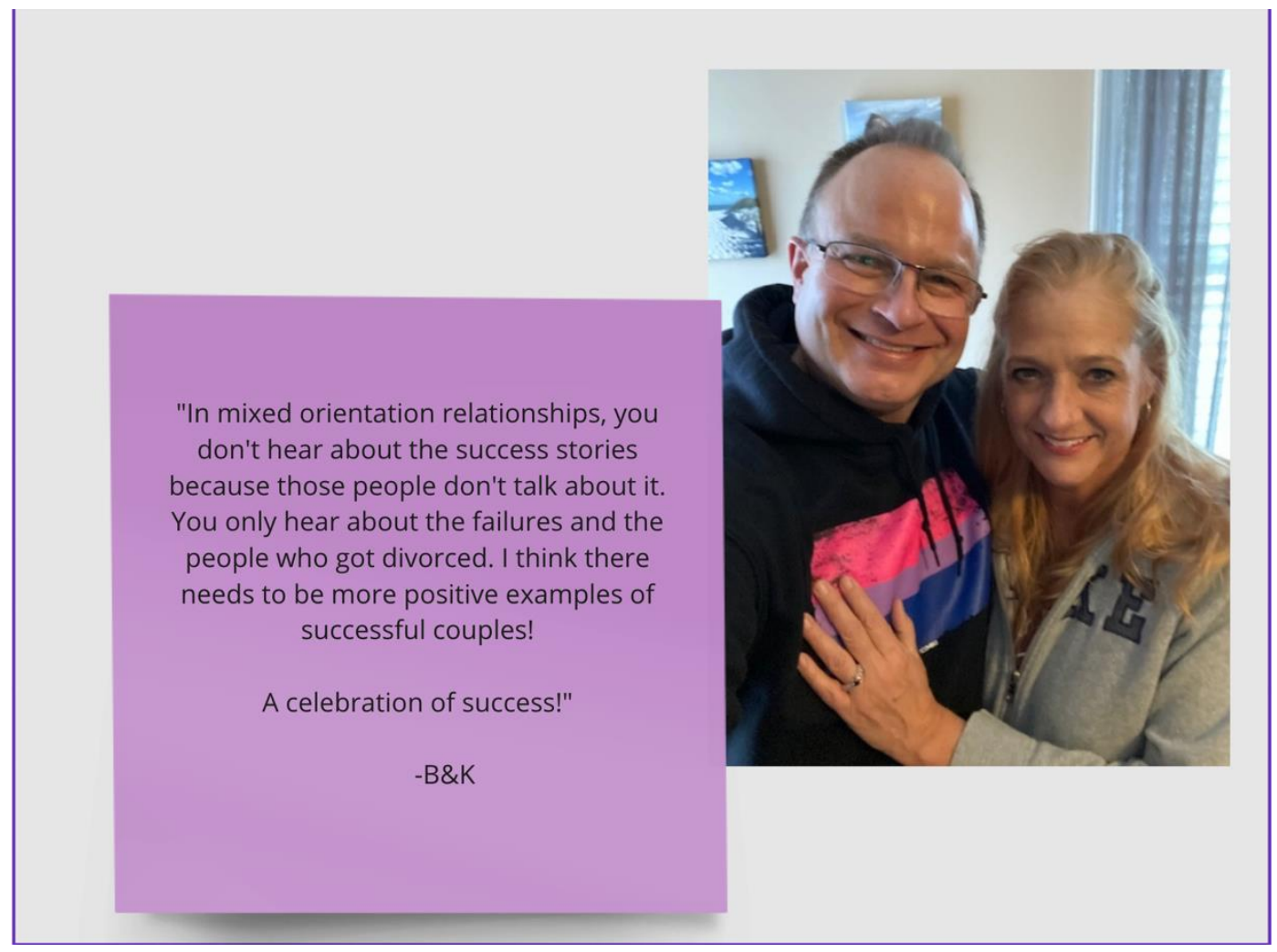

Figure 1.17. BK Exhibit 5

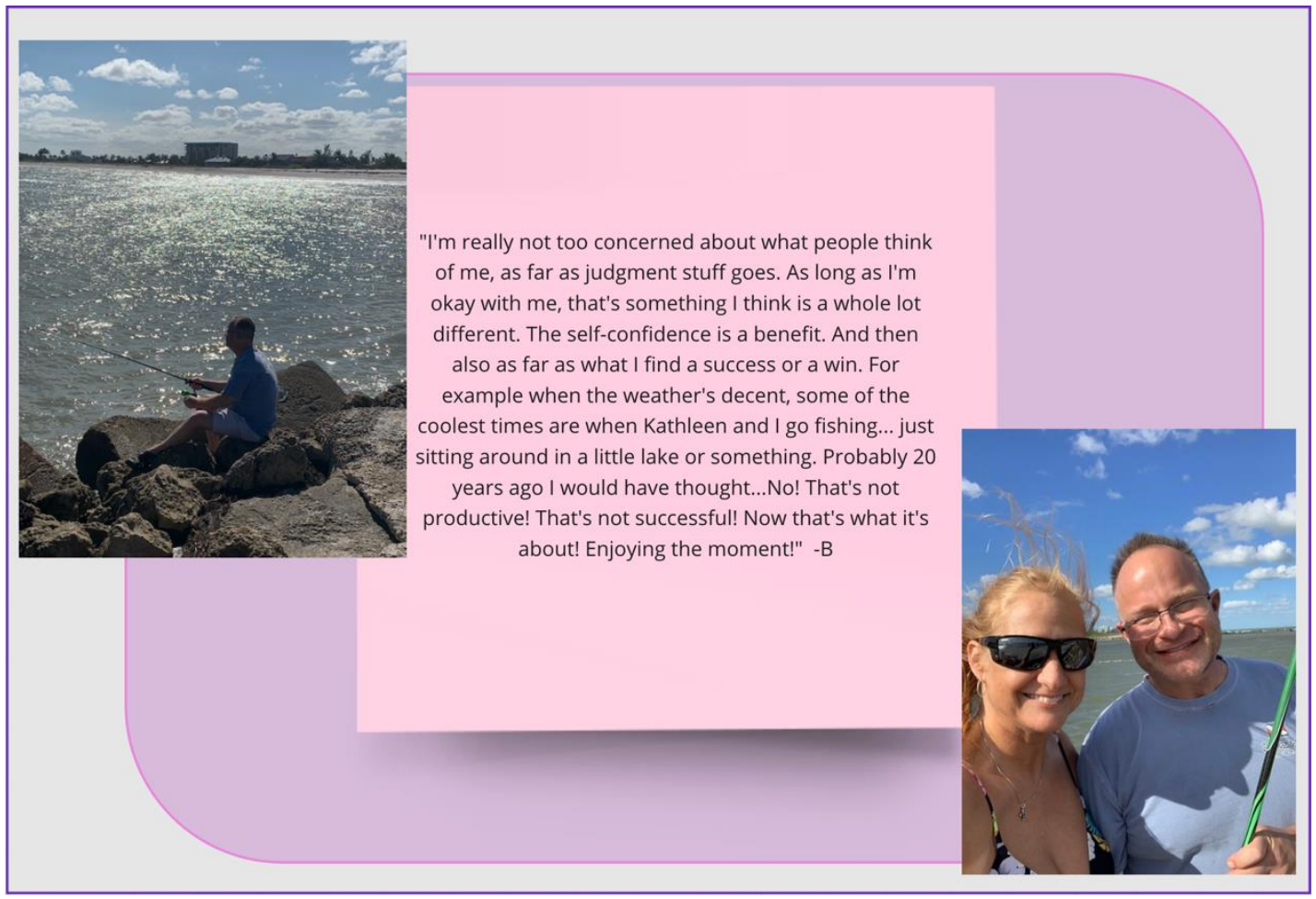


Figure 1.18. BK Exhibit 6

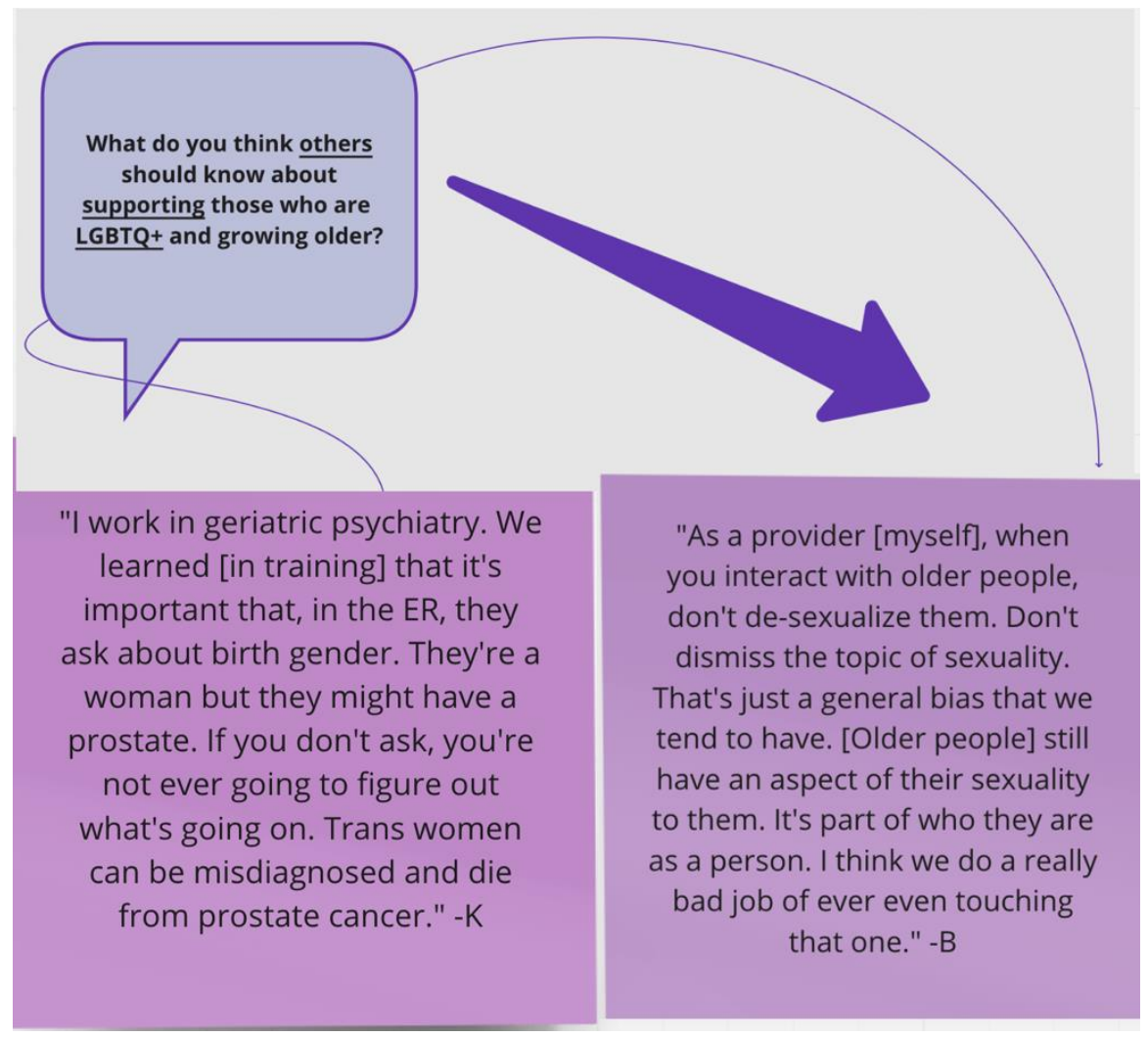

Figure 1.19. DA Exhibit 1

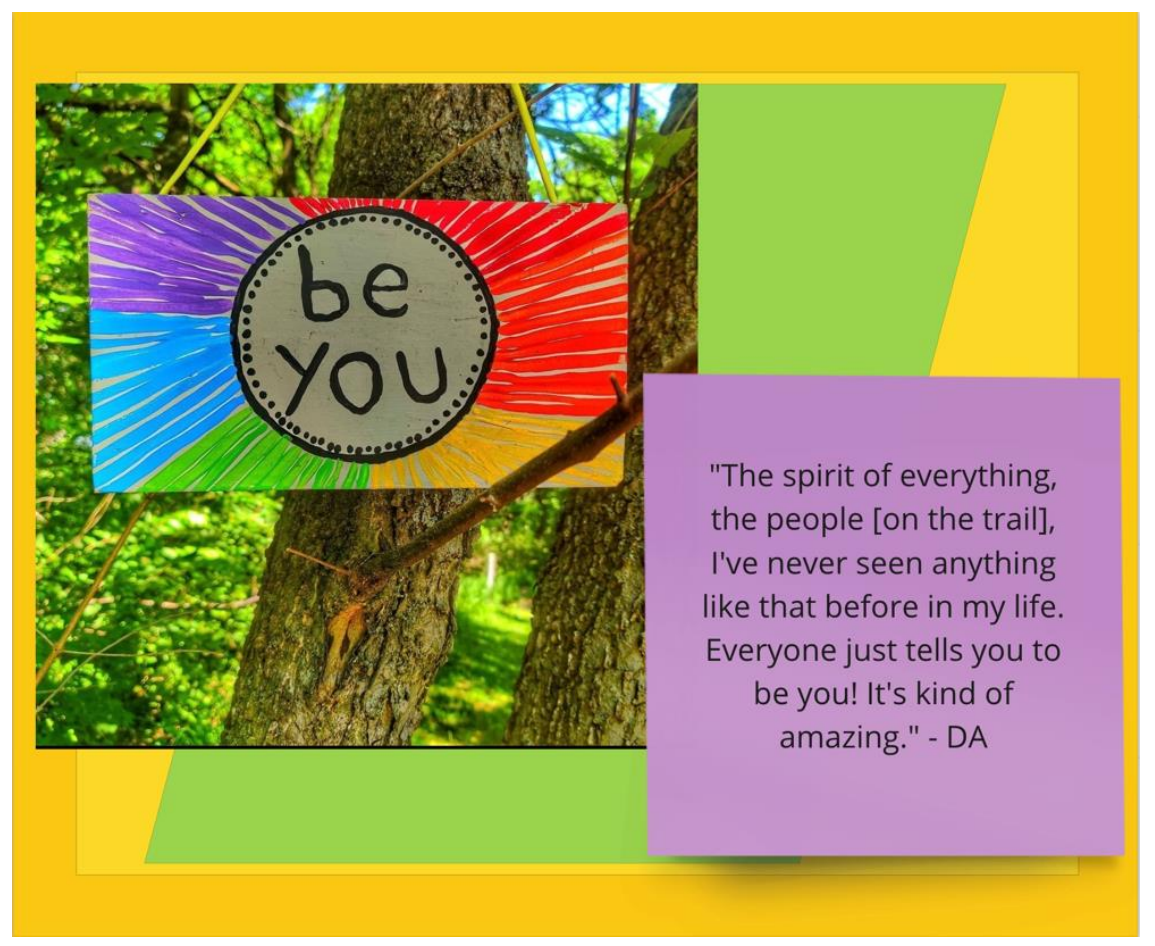


Figure 1.20. DA Exhibit 2

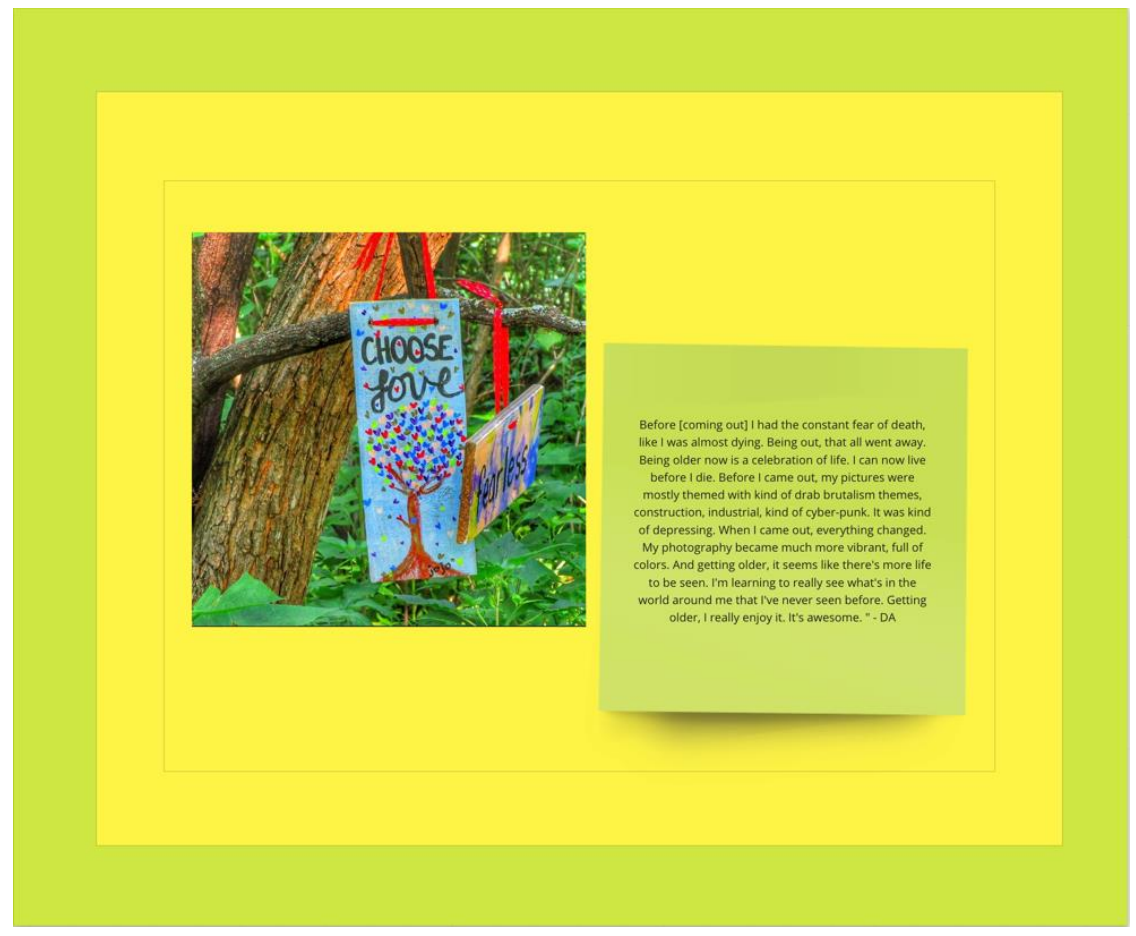

Figure 1.21. DA Exhibit 3

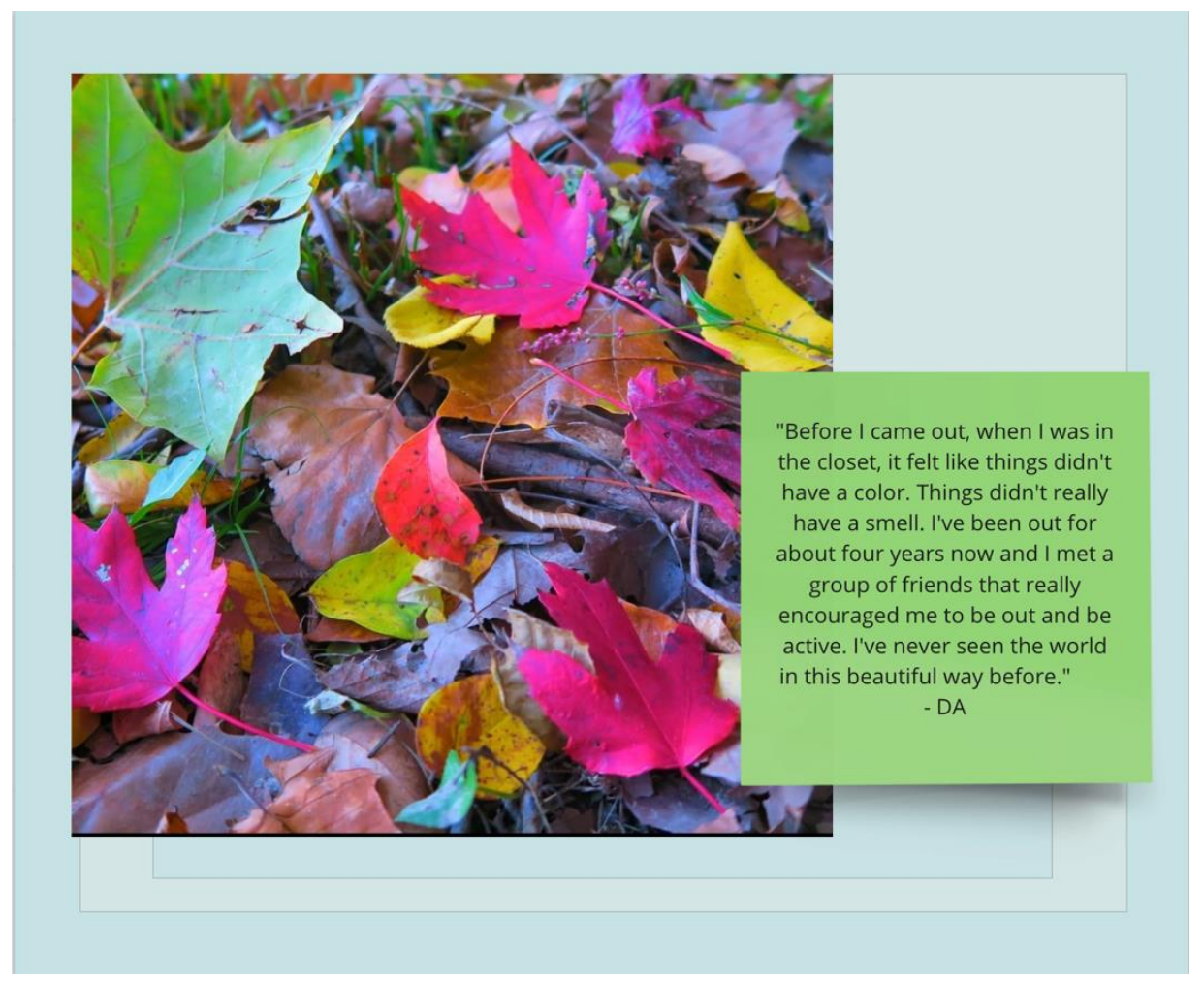


Figure 1.22. DA Exhibit 4

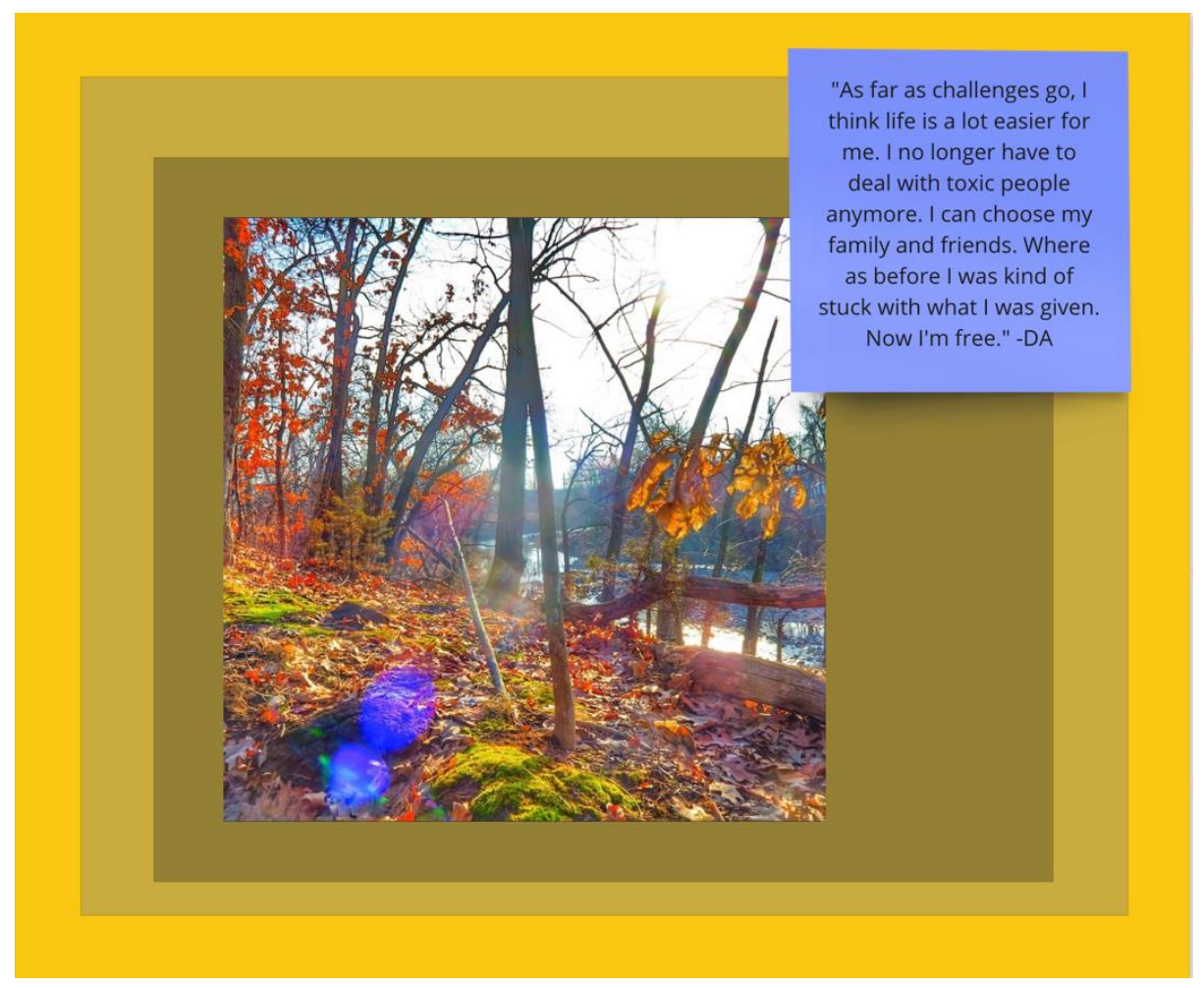

Figure 1.23. DA Exhibit 5

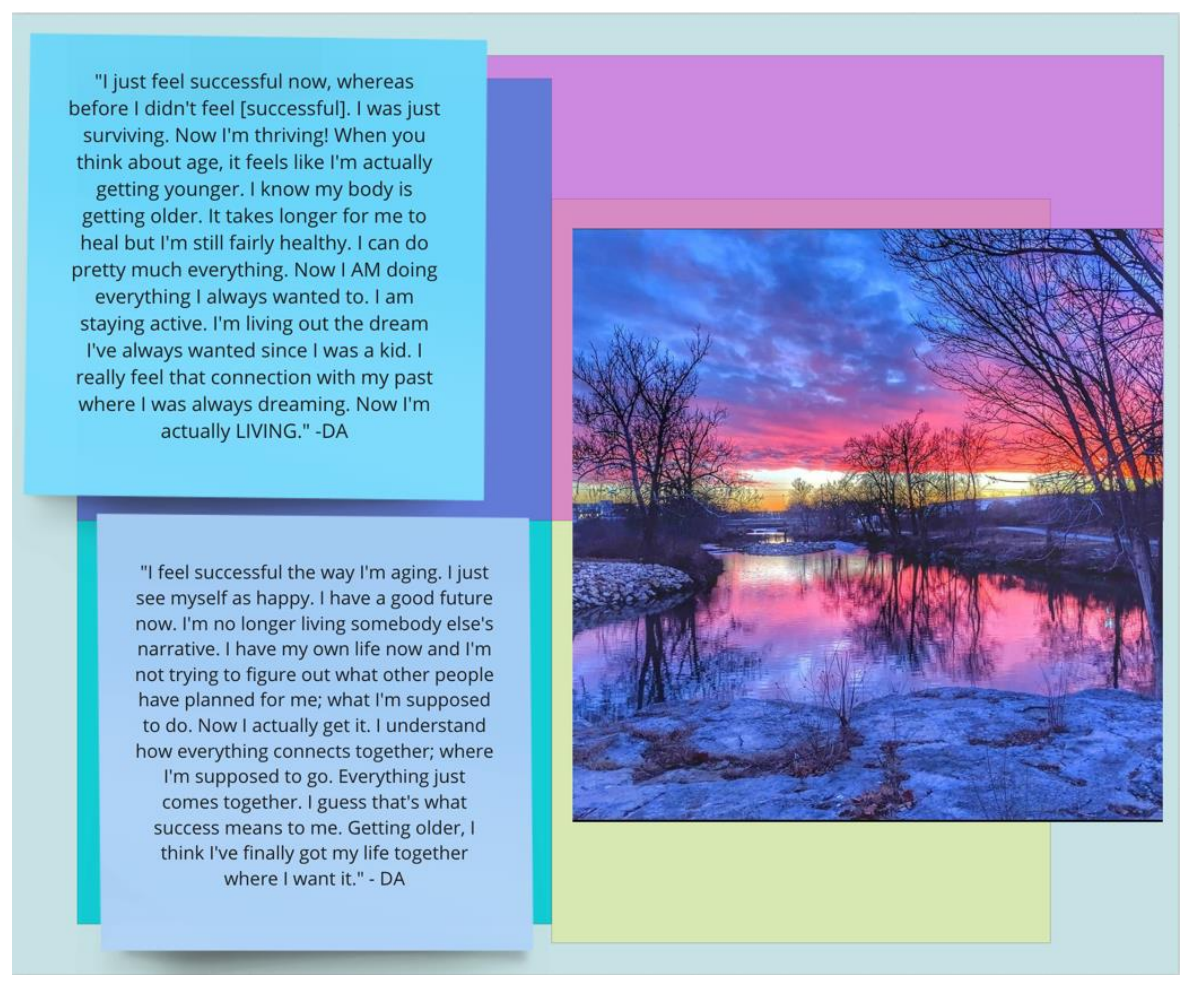


Figure 1.24. DA Exhibit 6

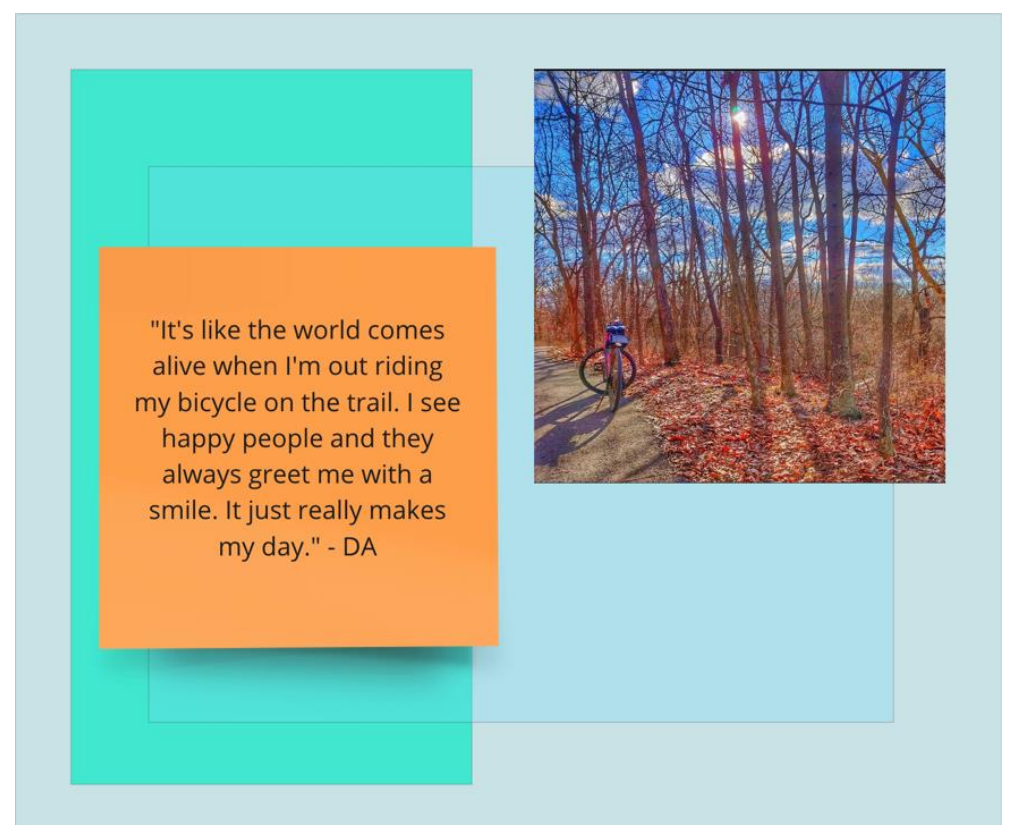

Figure 1.25. DA Exhibit 7

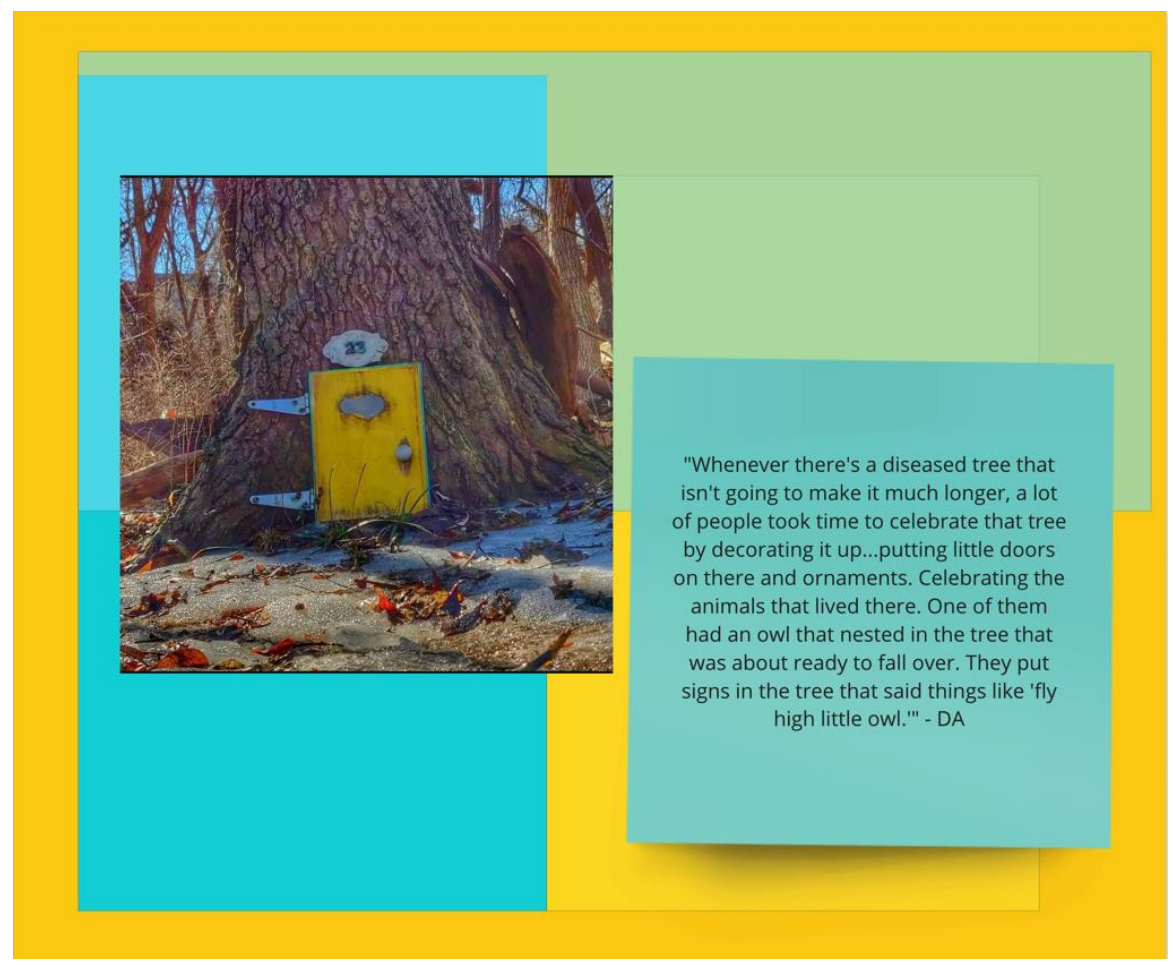




\section{Figure 1.26. DA Exhibit 8}

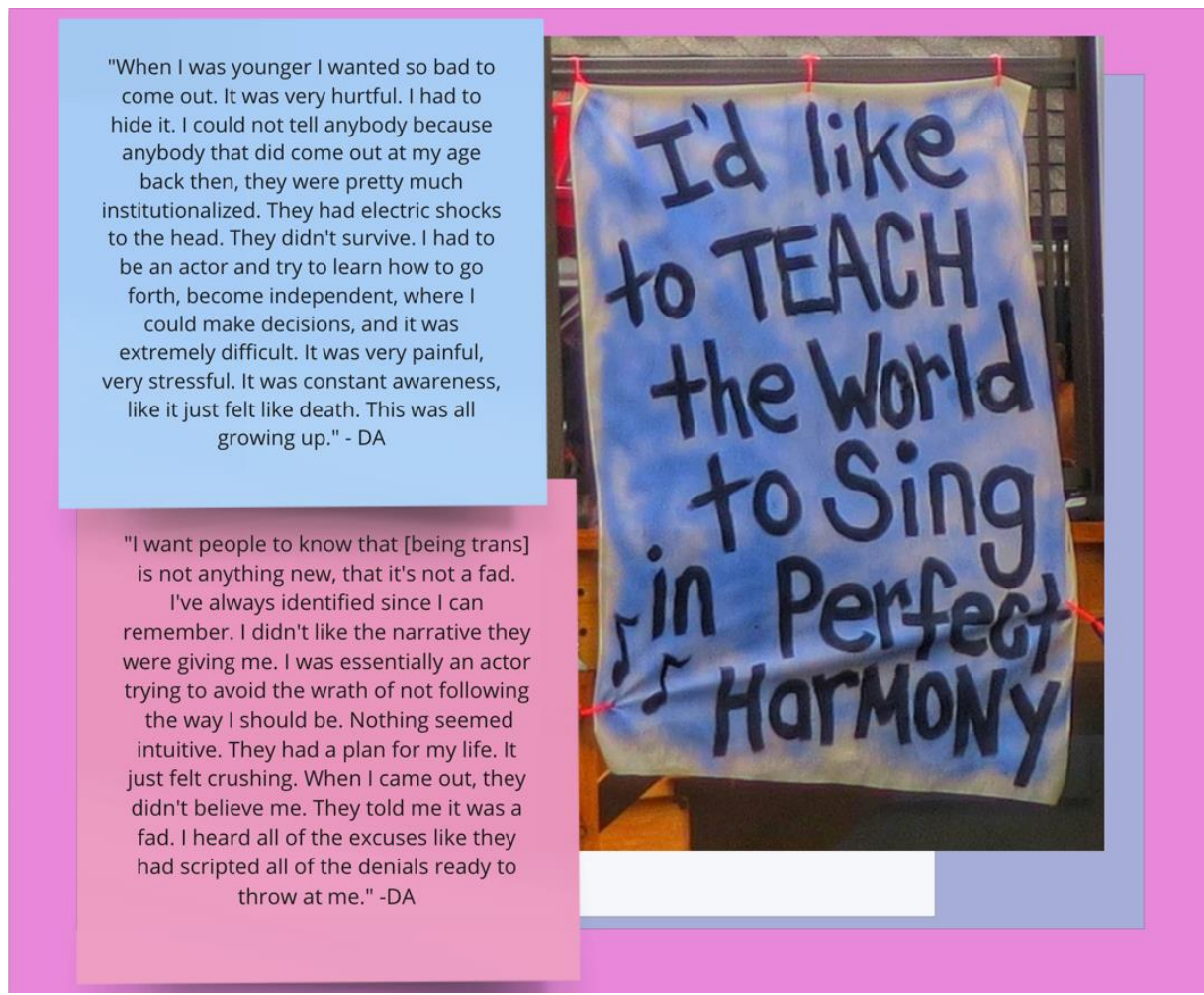

Figure 1.27. HV Exhibit 1

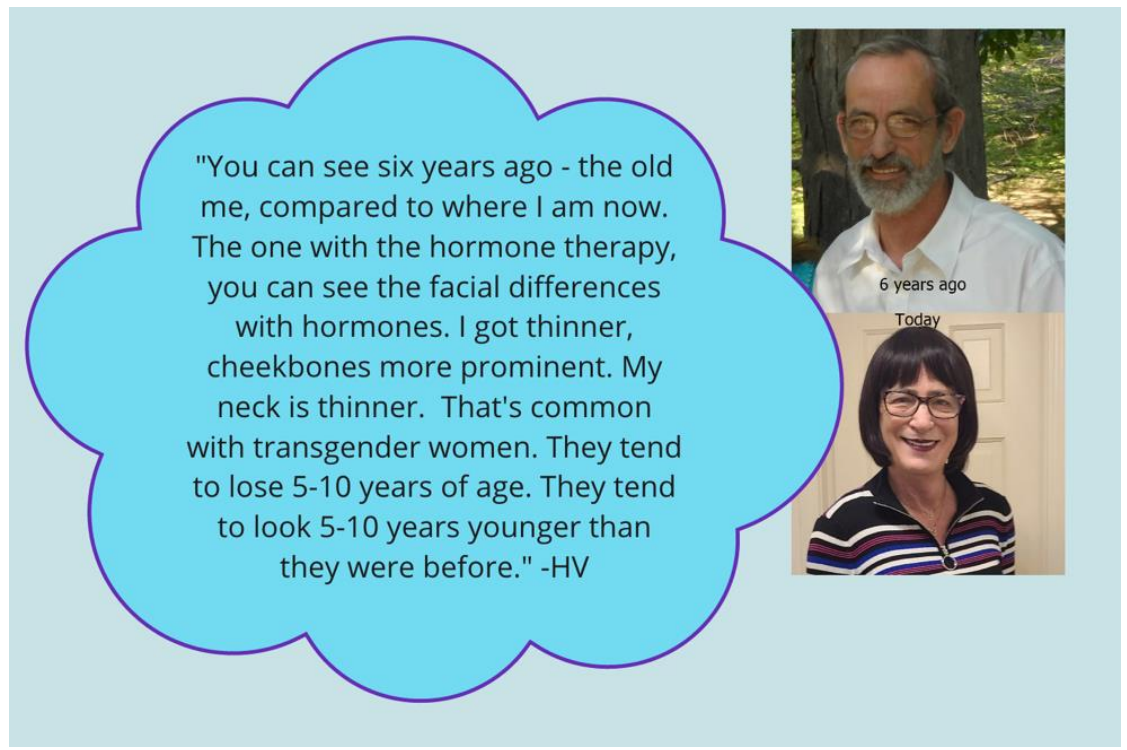


Figure 1.28. HV Exhibit 2

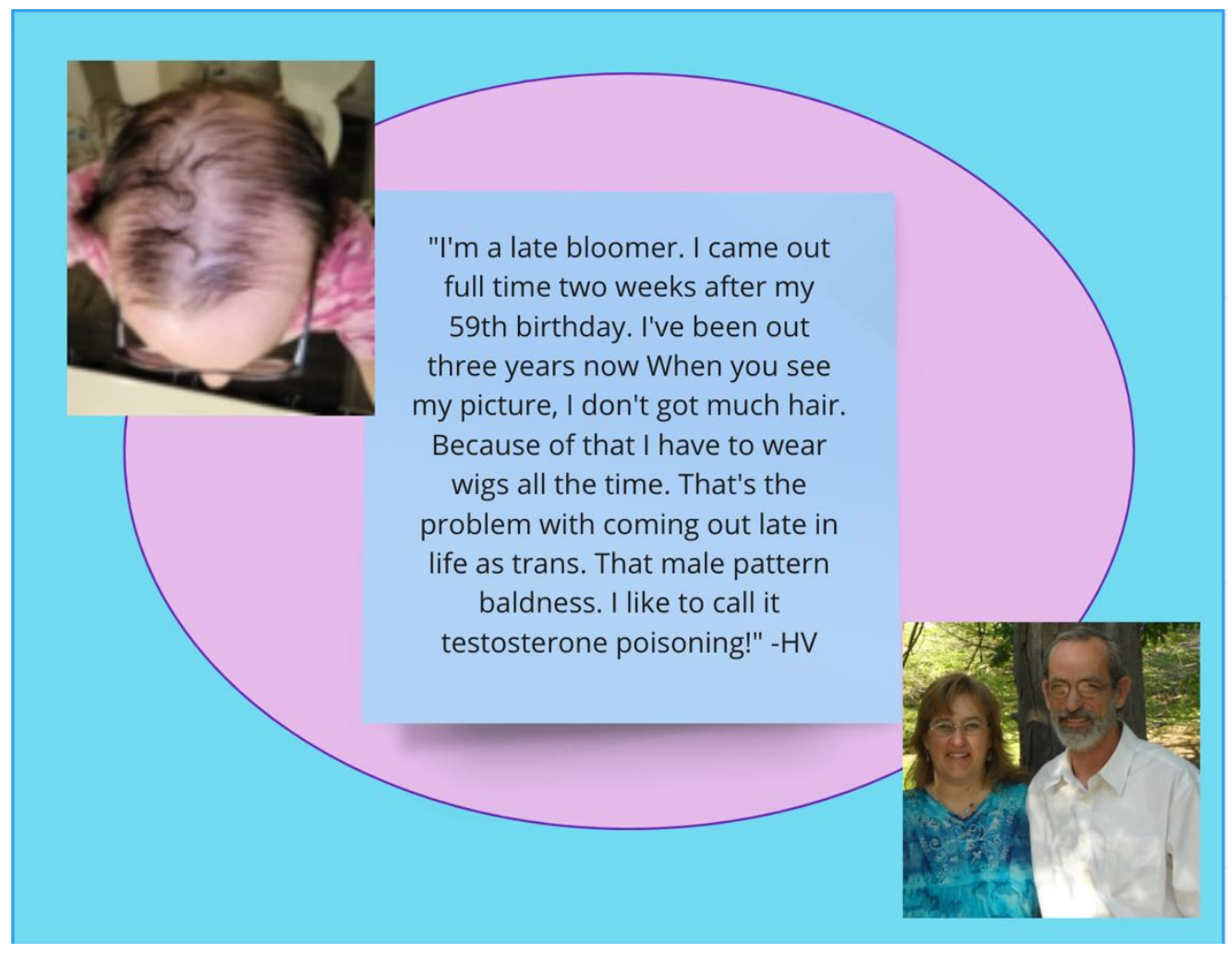

Figure 1.29. HV Exhibit 3

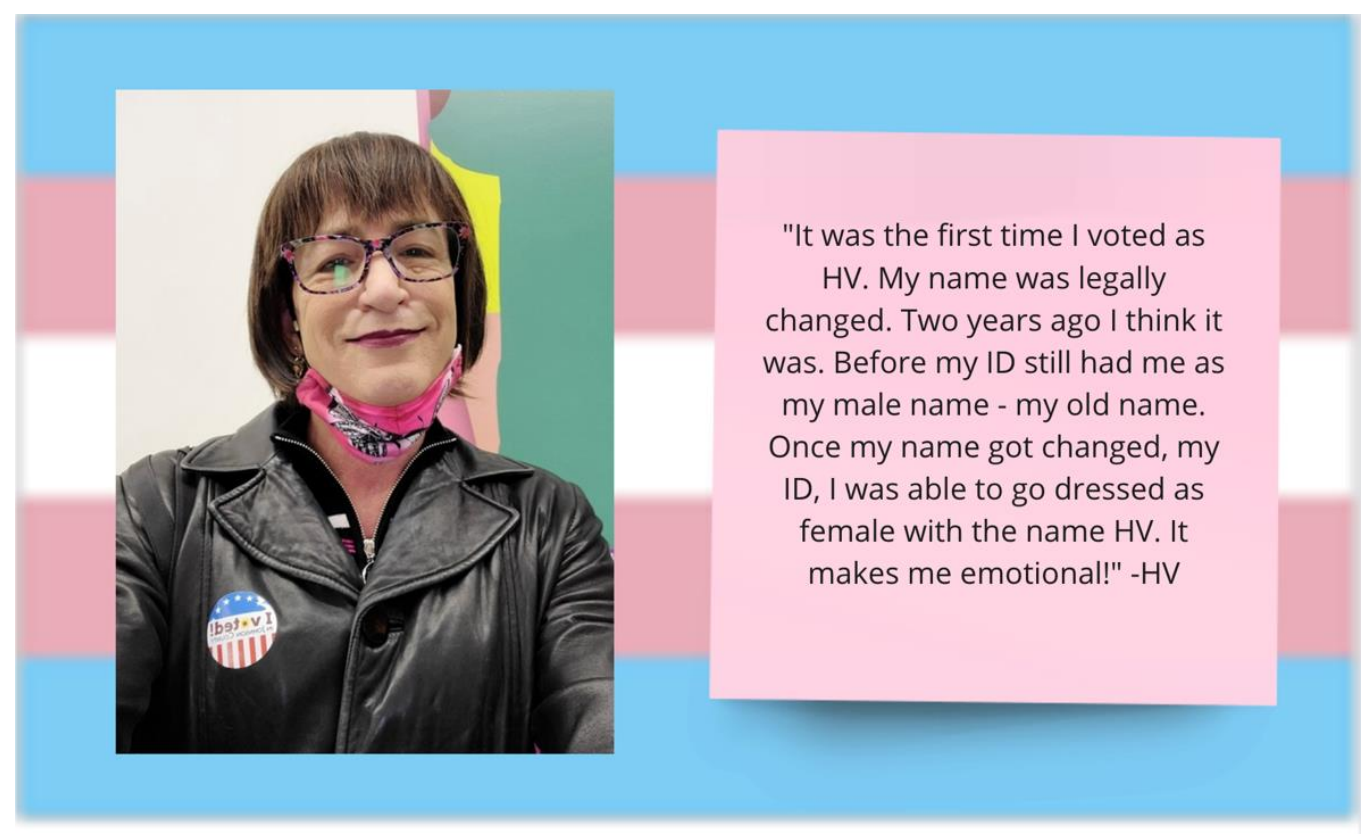




\section{Figure 1.30. HV Exhibit 4}

"It's difficult to come out as trans, bi-, gay, or lesbian. It's difficult coming out. Different levels of difficulty of course. But come out if at all possible to be your true self! You cannot have true happiness until you discover your true self and you're able to live as your true self. don't want to have to hide being trans. say you can't find true happiness until you witness your true self, whatever your true self is. The earlier the better. Do it as early as you can!" -HV

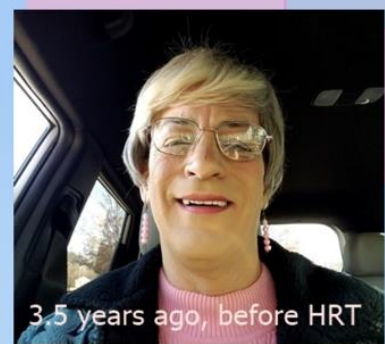

"[Successful aging] for me means to just be happy. Other people think of financial security and what not, but to me continuing to be happy is successful. Growing old is mandatory, but growing up is not! Growing up is optional! I try to keep my younger self in my mind. My brain says I'm 25 , my body says the heck you are!" -HV

\section{Figure 1.31. HV Exhibit 5}

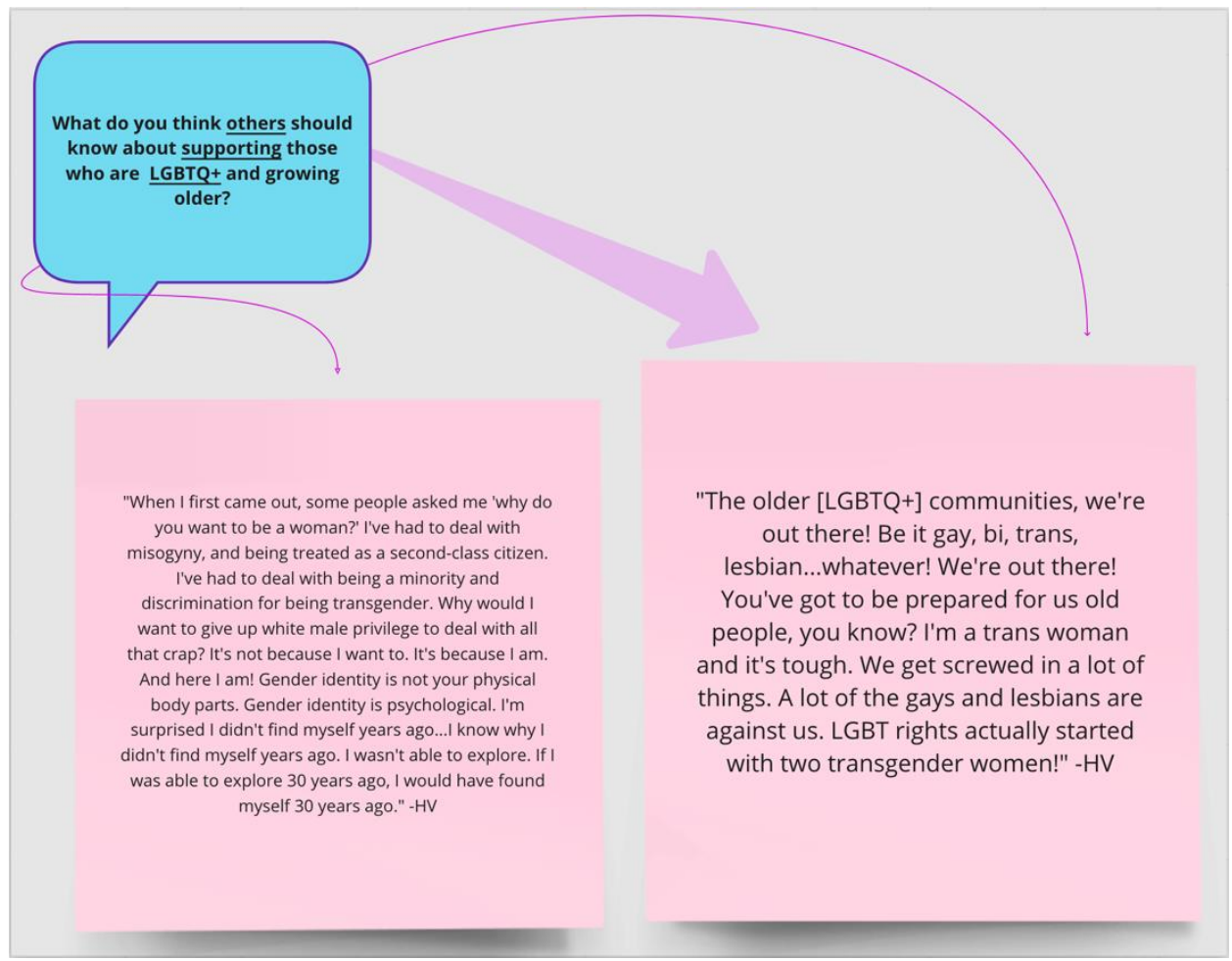


Figure 1.32. MB Exhibit 1

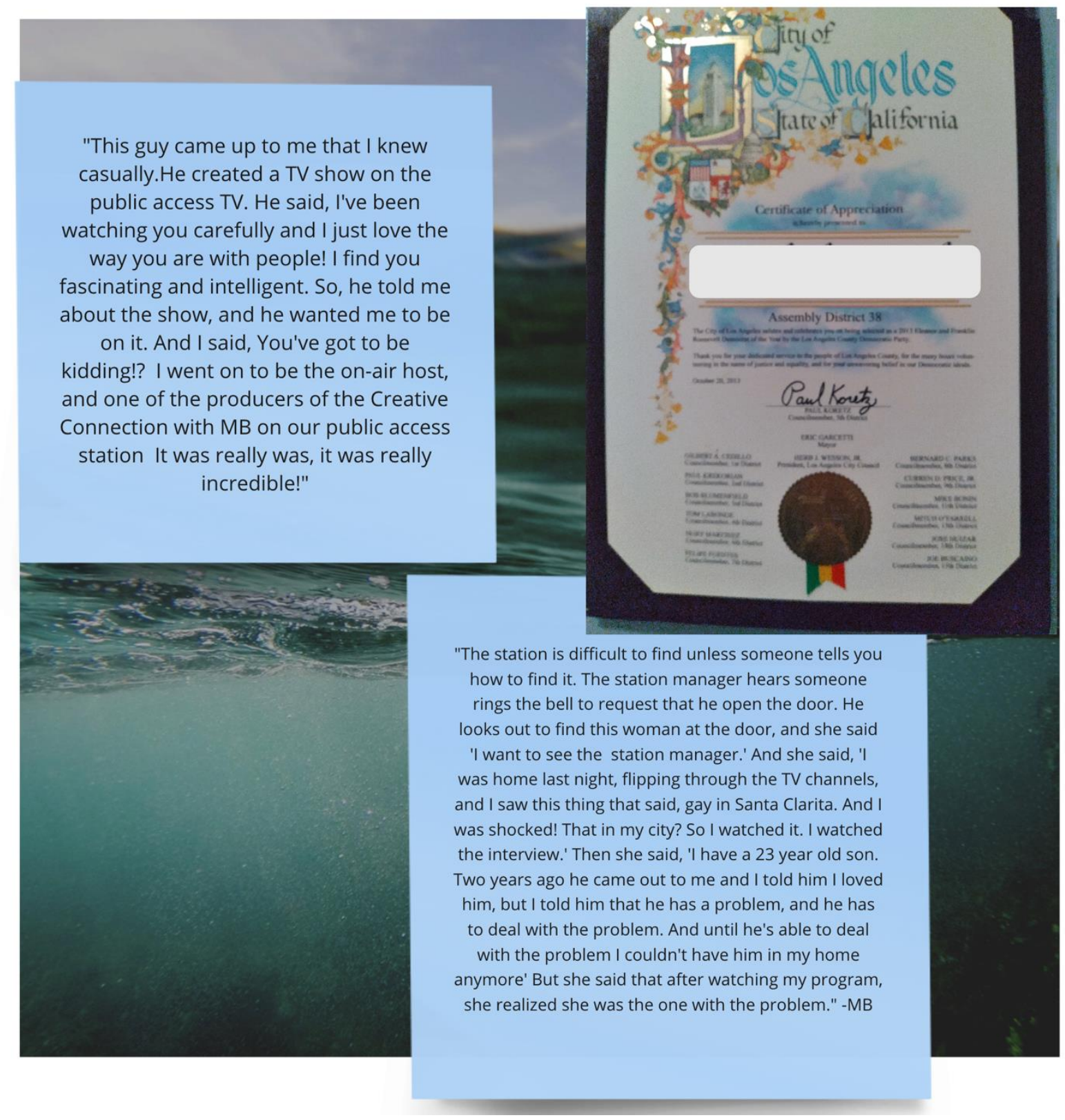


Figure 1.33. MB Exhibit 2

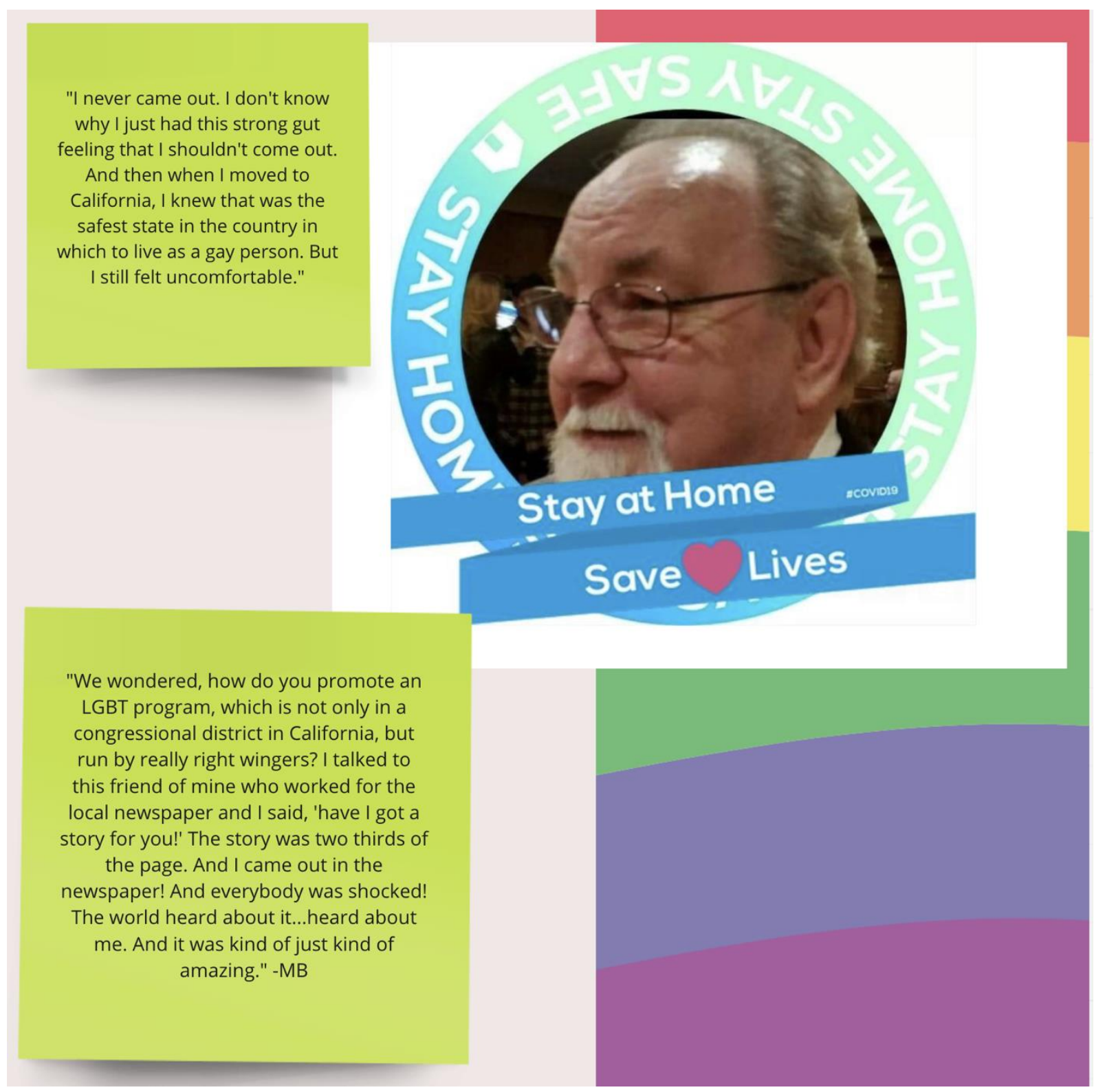


Figure 1.34. MB Exhibit 3

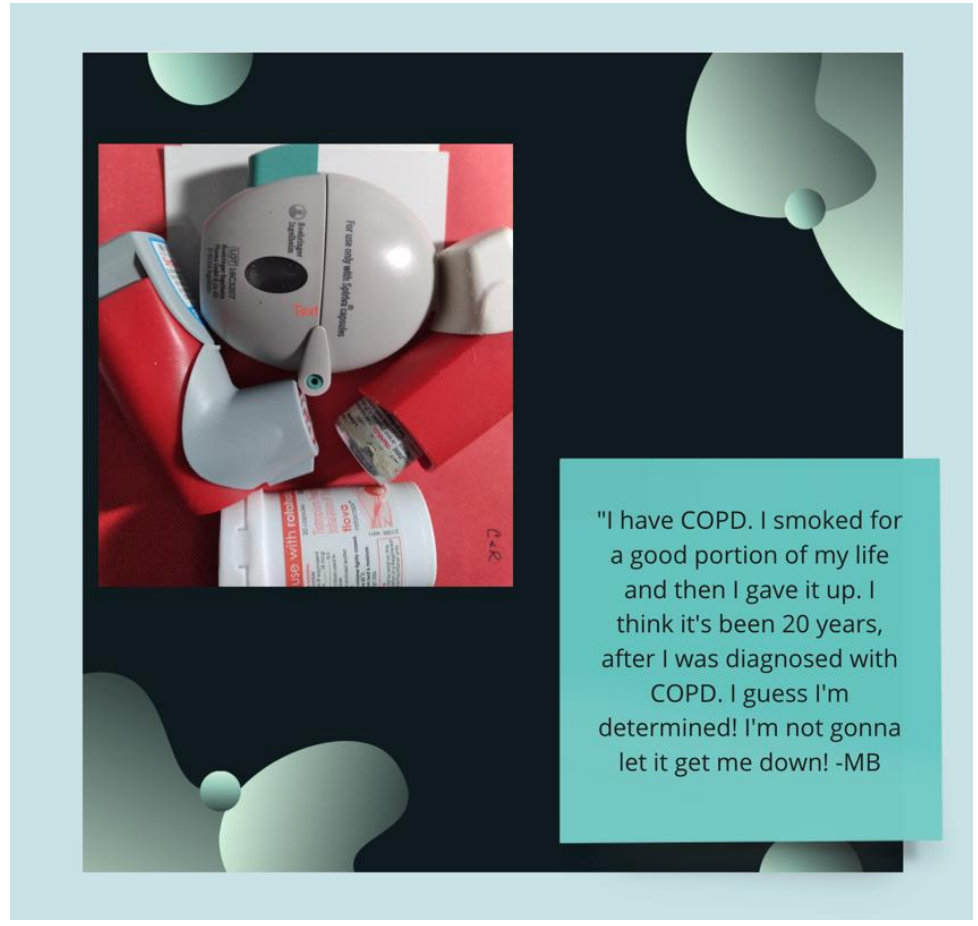

Figure 1.35. MB Exhibit 4

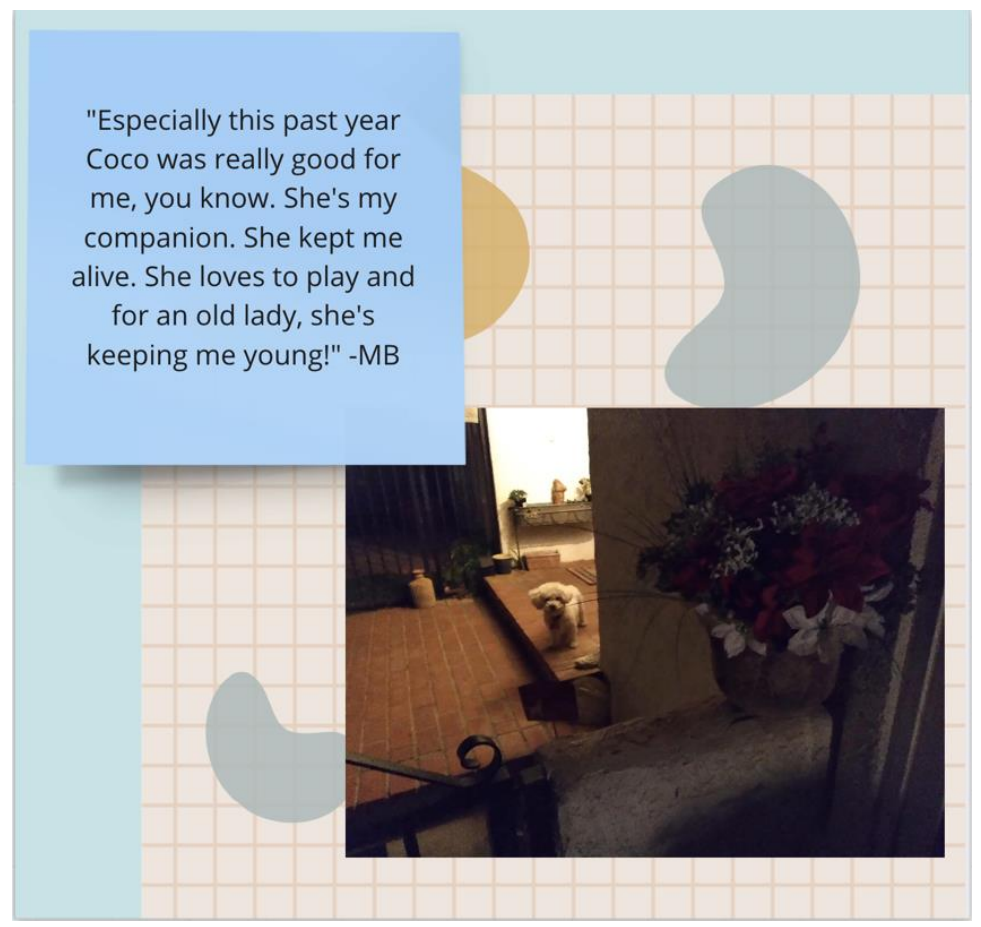


Figure 1.36. MB Exhibit 5

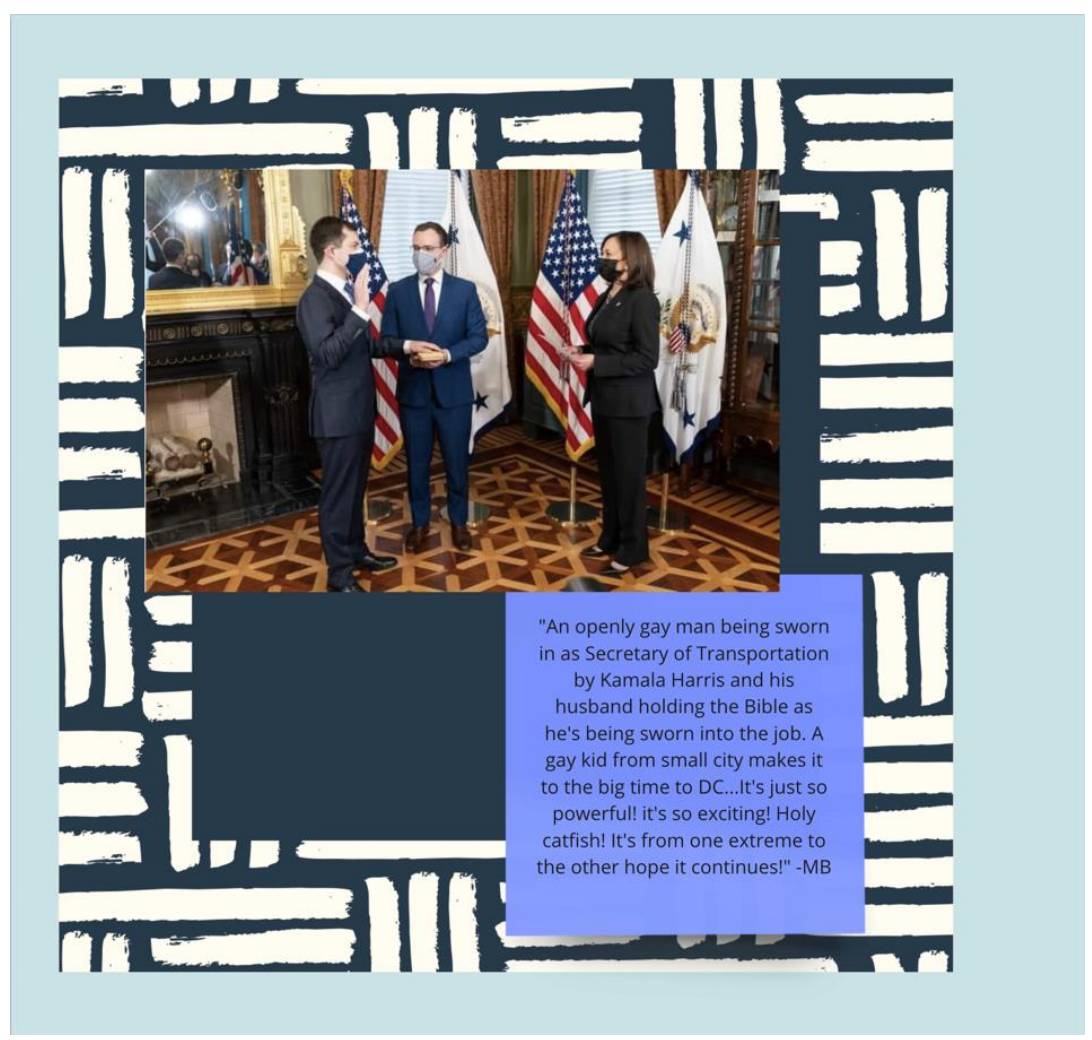

Figure 1.37. MB Exhibit 6

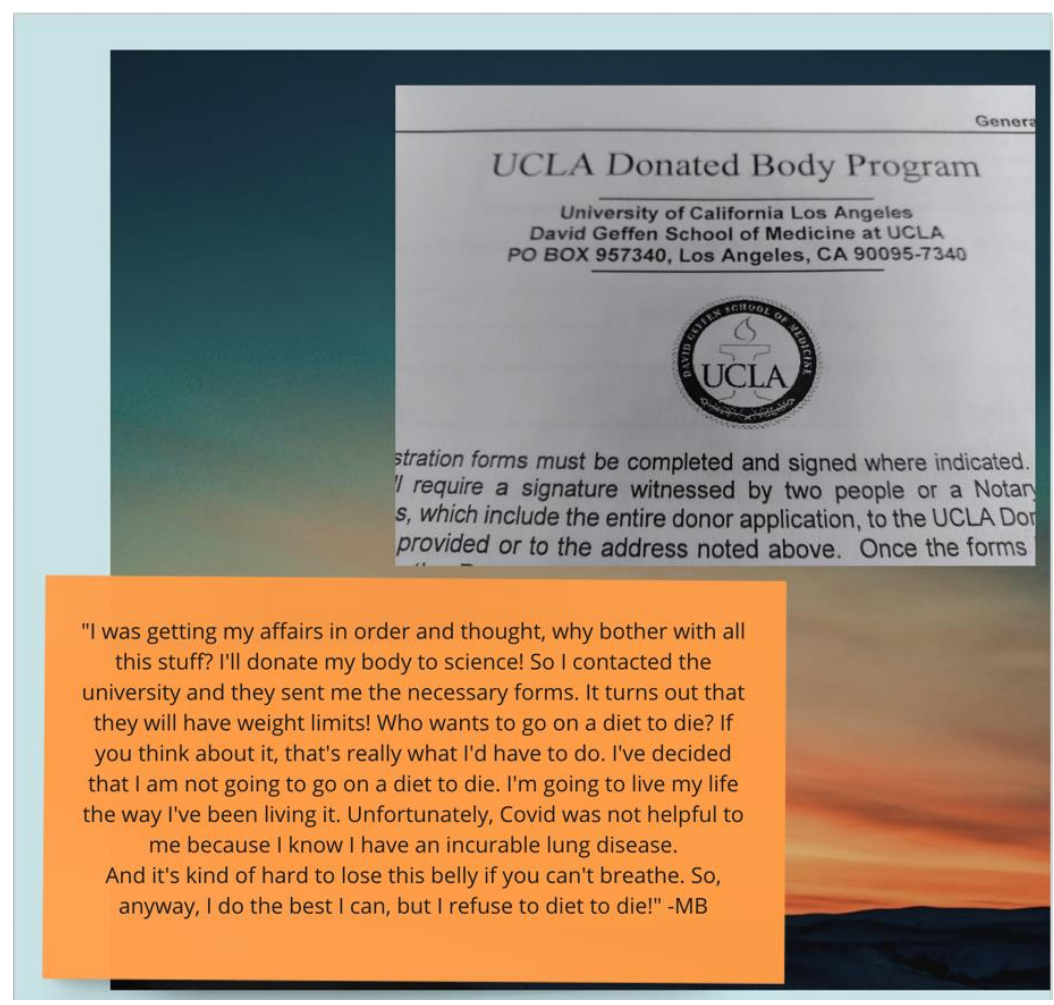


Figure 1.38. MB Exhibit 7

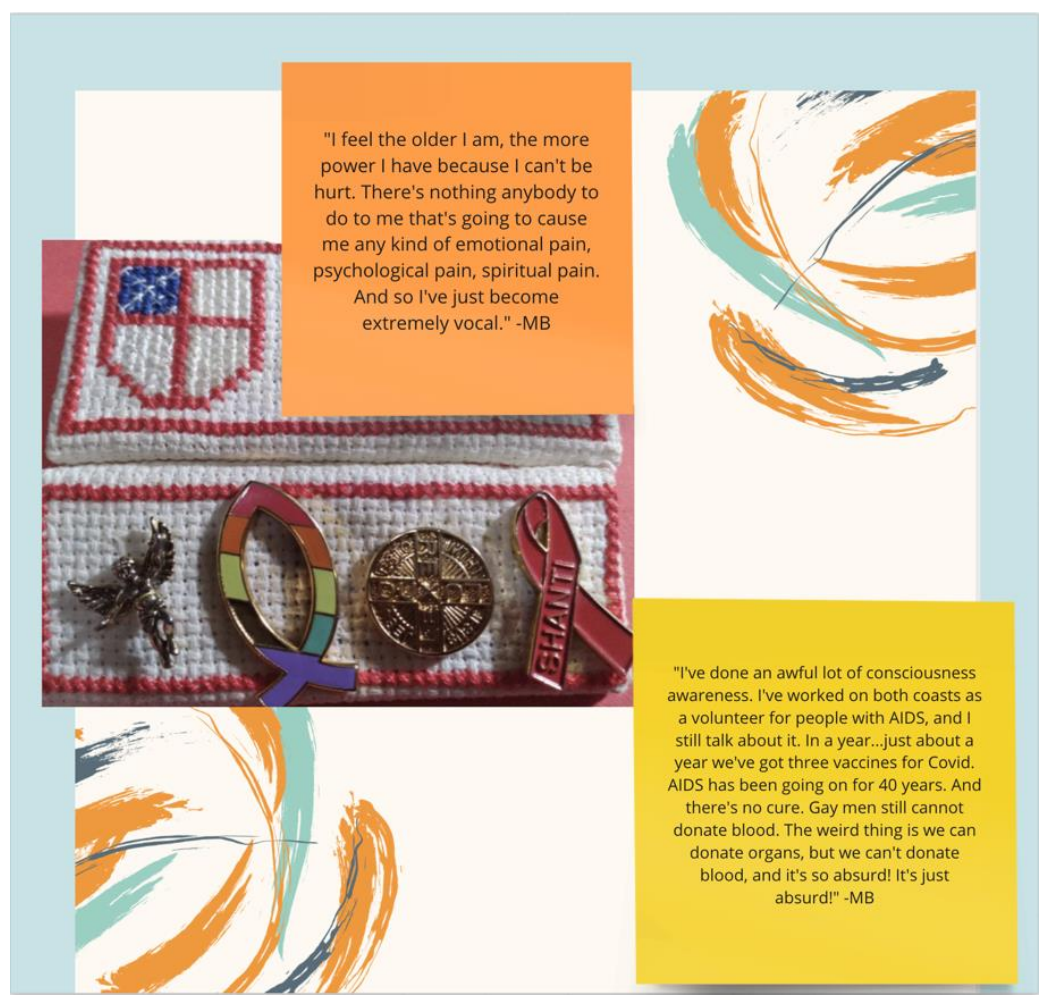

Figure 1.39. MB Exhibit 8

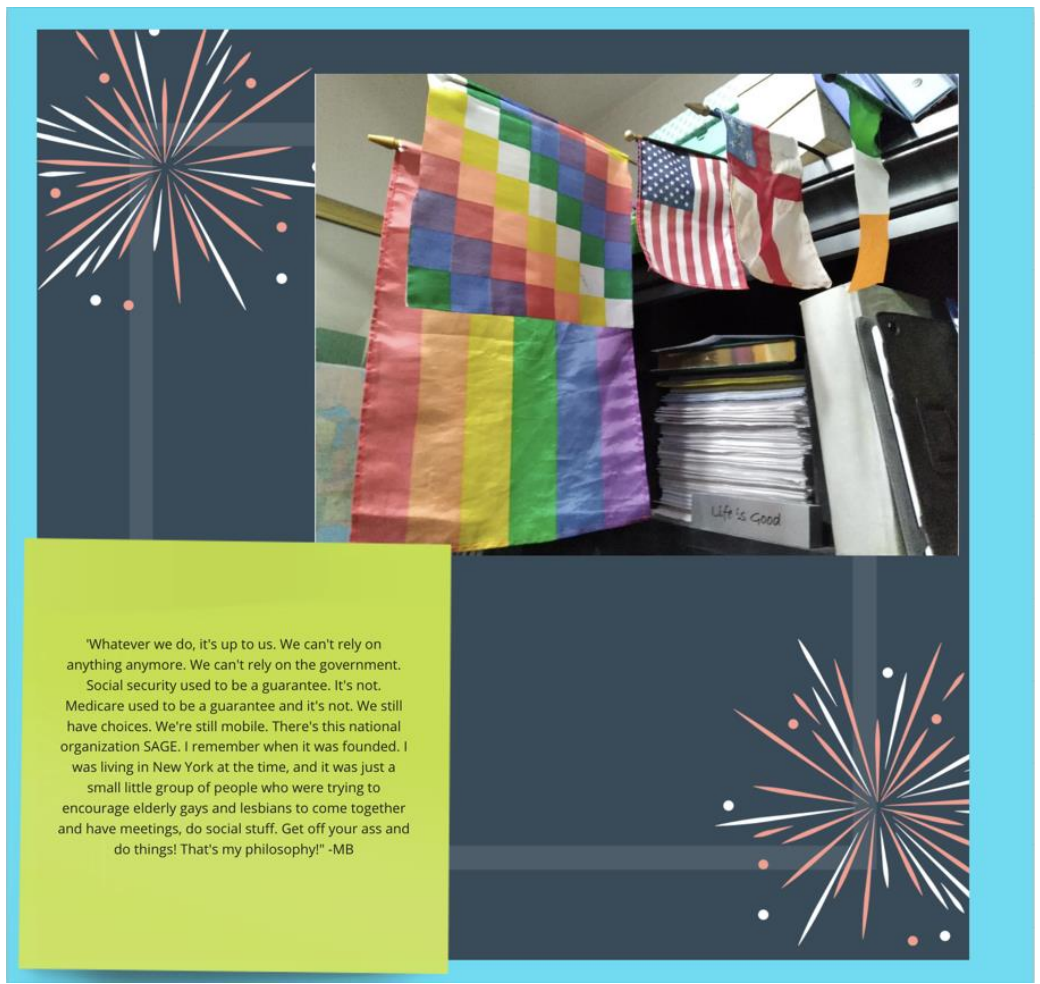


Figure 1.39. MC Exhibit 1

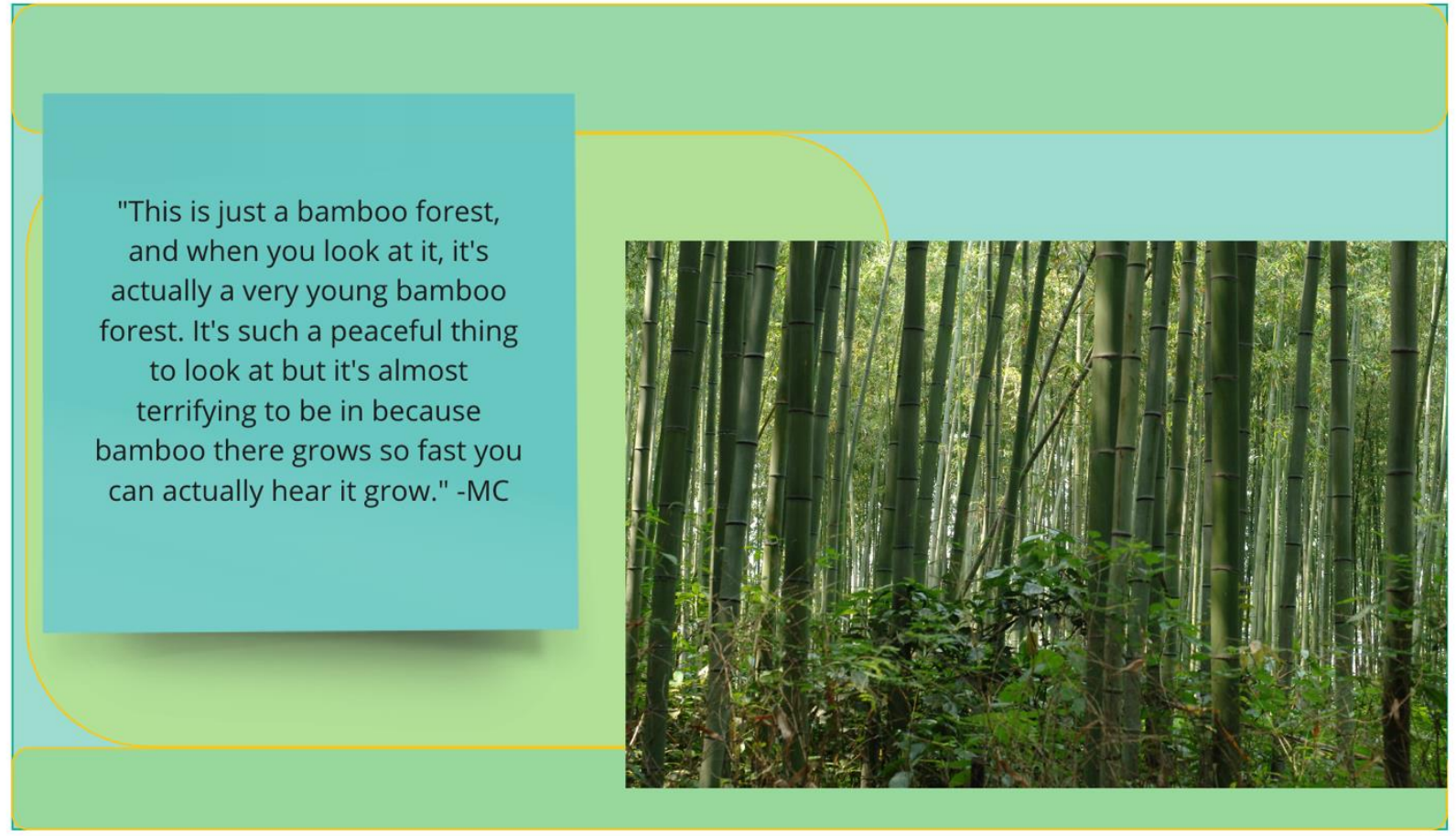

Figure 1.40. MC Exhibit 2

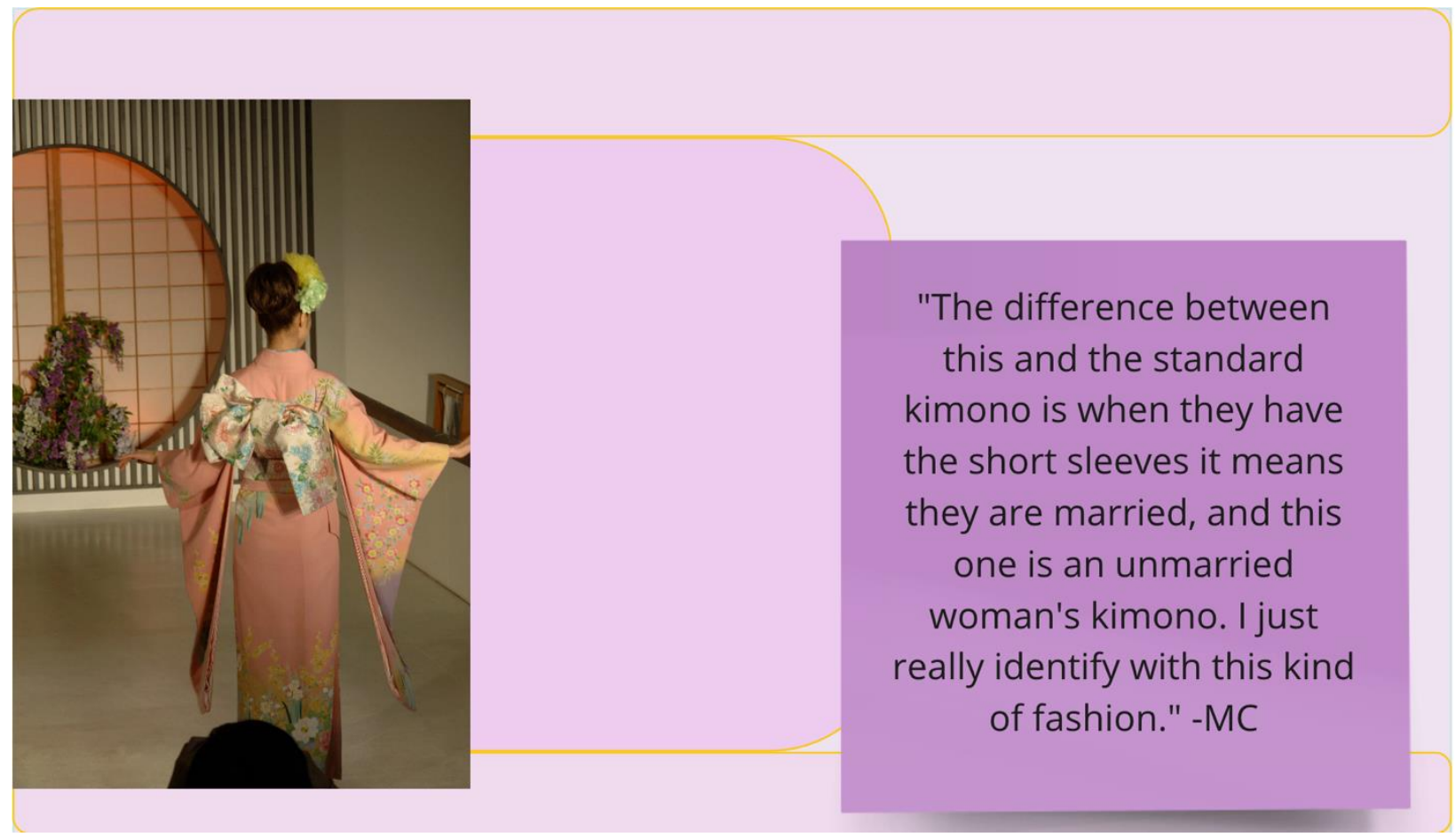




\section{Figure 1.41. MC Exhibit 3}

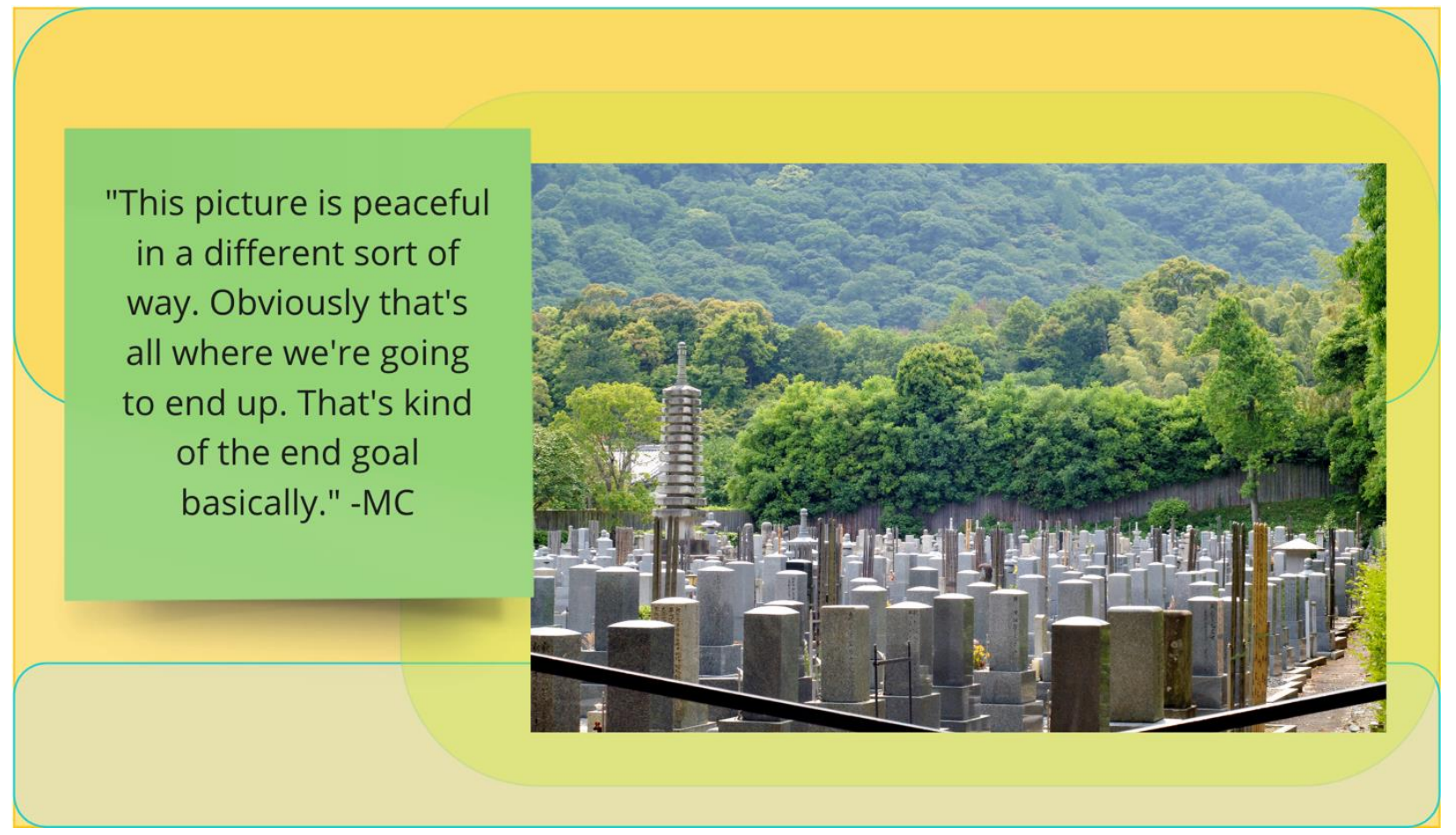

\section{Figure 1.42. MC Exhibit 4}

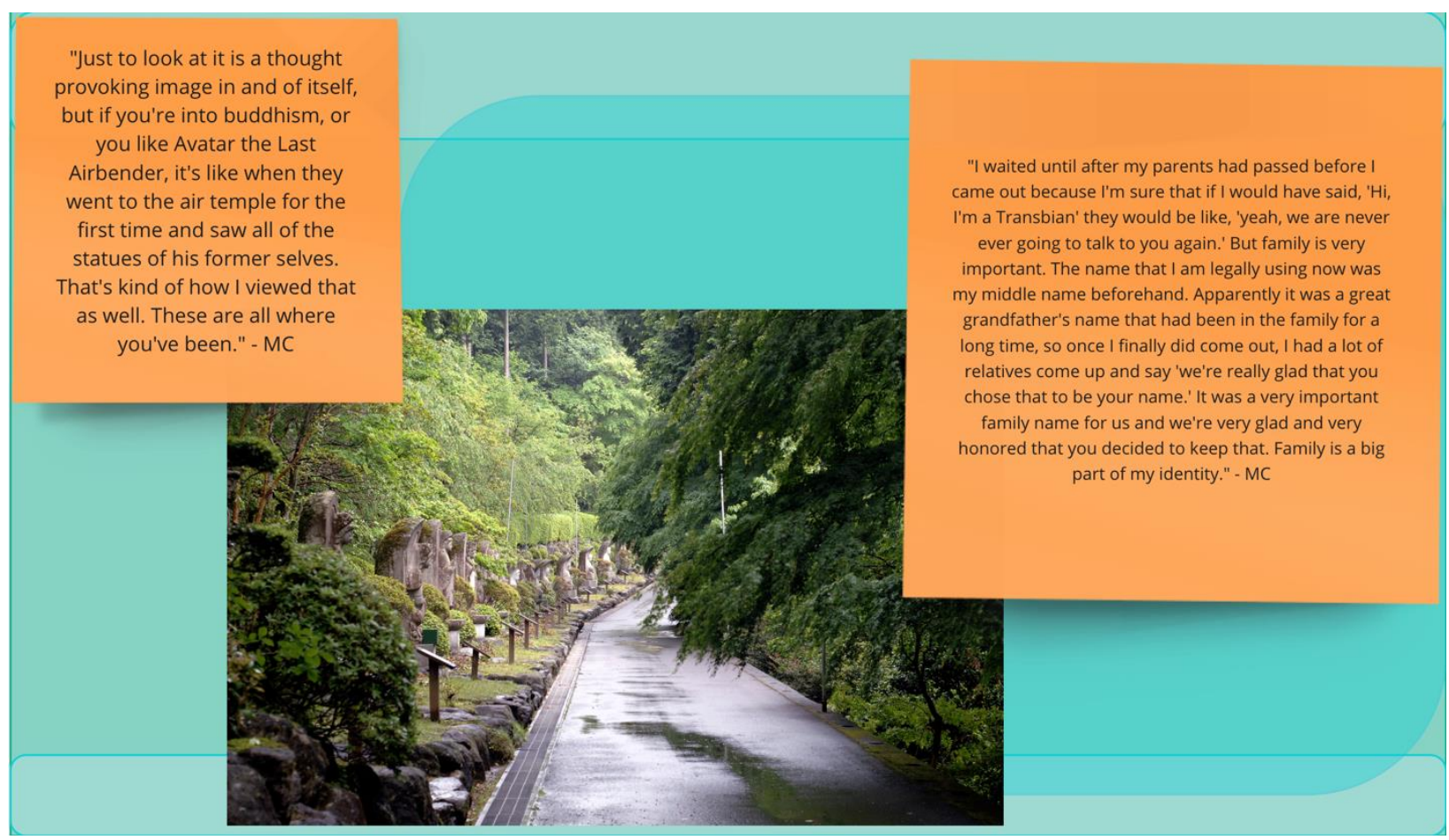




\section{Figure 1.43. MC Exhibit 5}

"We're the rock that you see there - in the middle. And time is

the water. No matter how resilient, no matter how long we have, that water's gonna win. Just looking at the effect of the water on the rock is an absolutely beautiful thing. That's kind of how life is for the most part." -MC

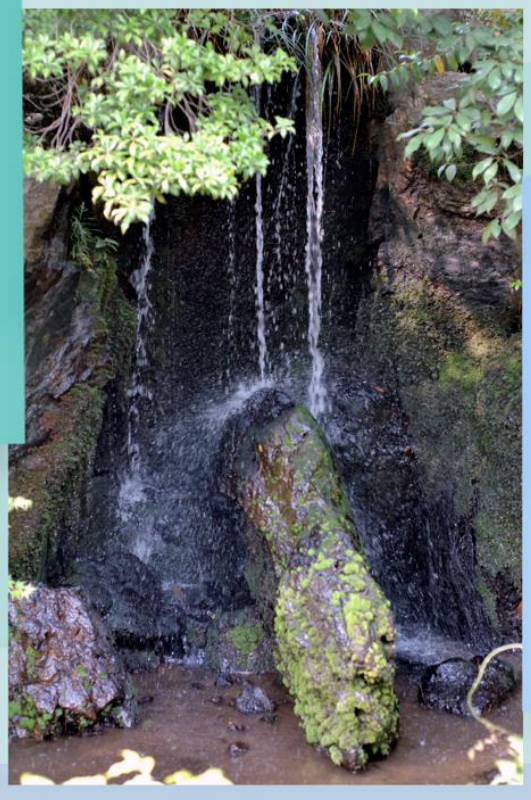

"[The water] stripped a lot of things away, including the boy facade that I wore for many many years. I knew at age 6 that something wasn't right, but because I grew up in a fairly strict household and anything that wasn't going on in the church was evil. So I had to pretend for a long long long long time that everything was normal. Which it absolutely wasn't. The normal that I was presenting was not normal for me whatsoever." - MC

\section{Figure 1.44. ML Exhibit 1}

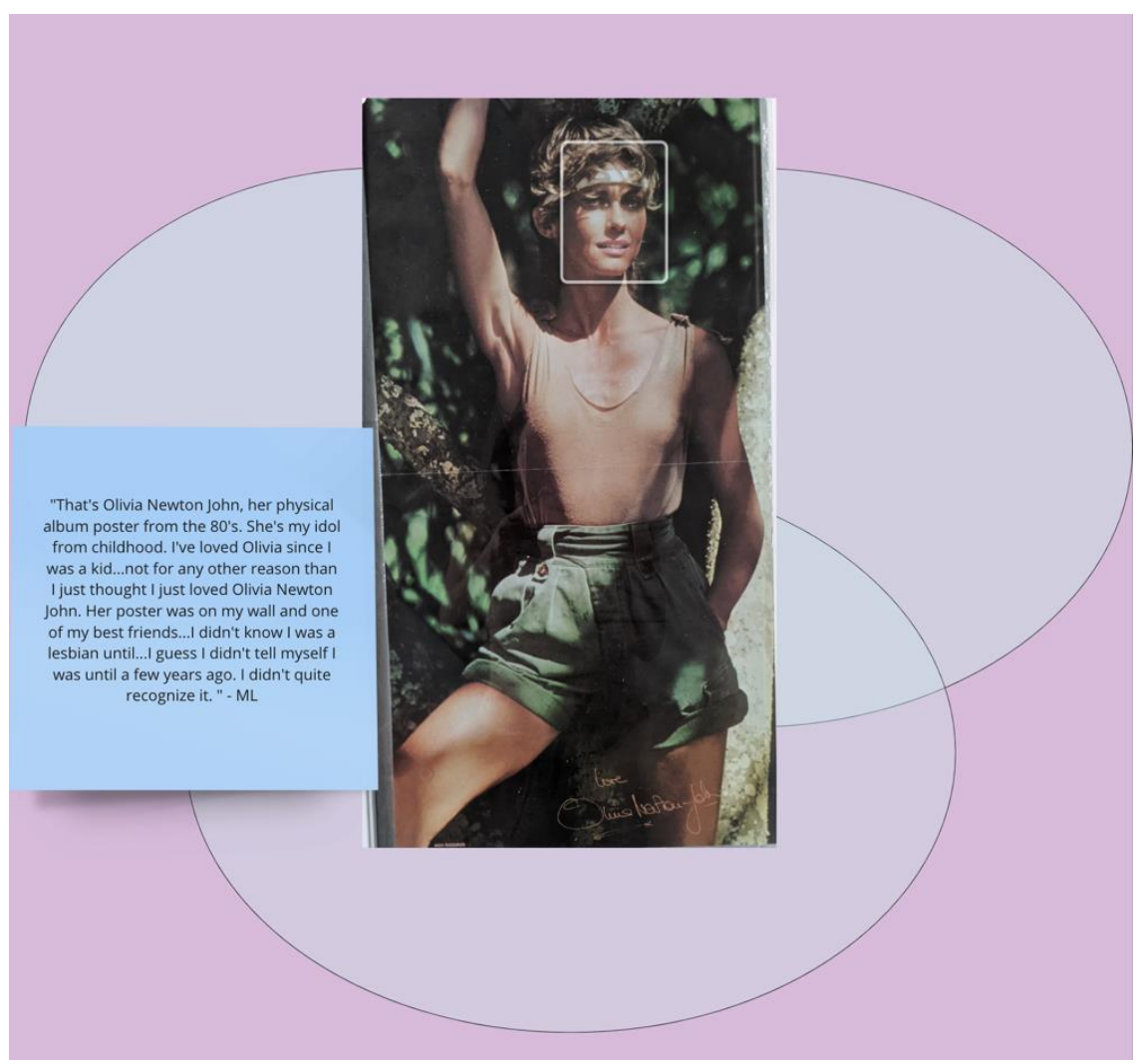


Figure 1.45. ML Exhibit 2

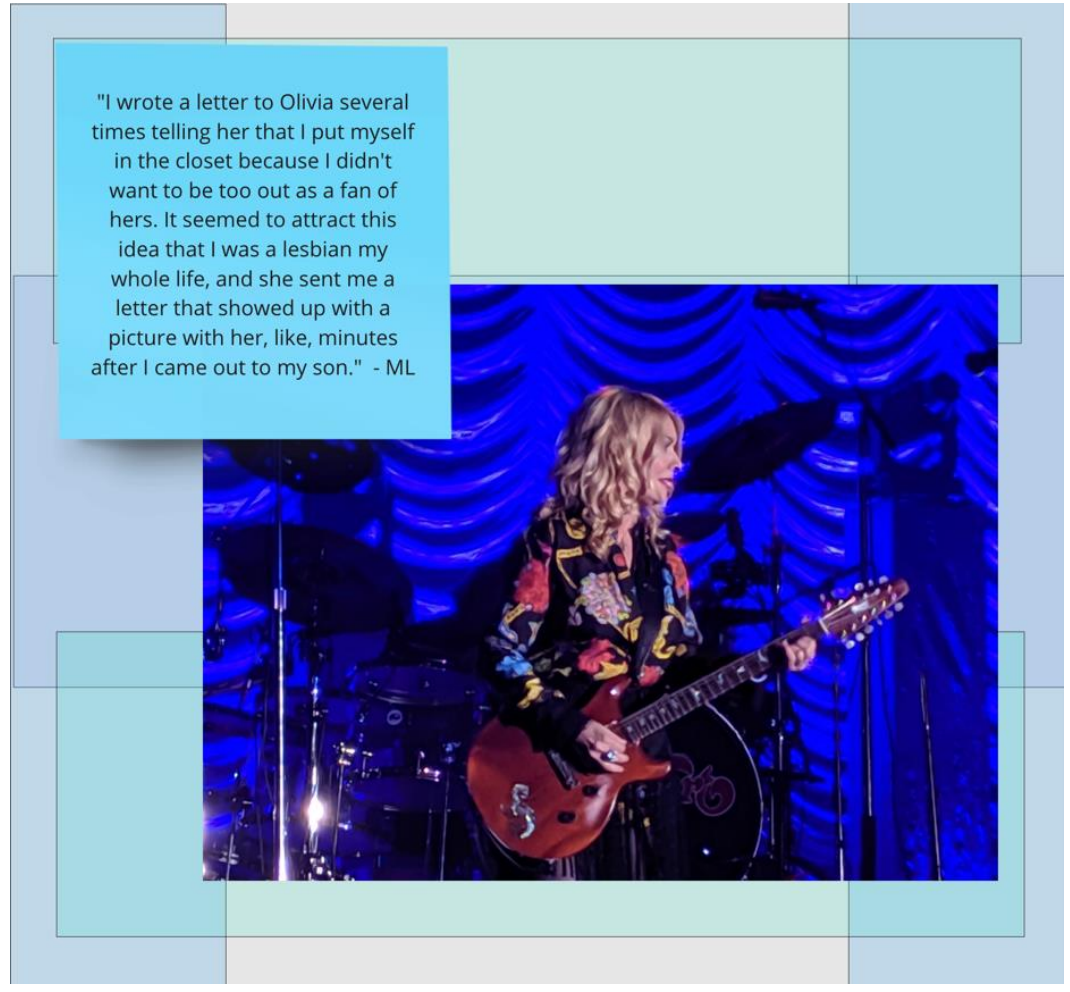

Figure 1.46. ML Exhibit 3

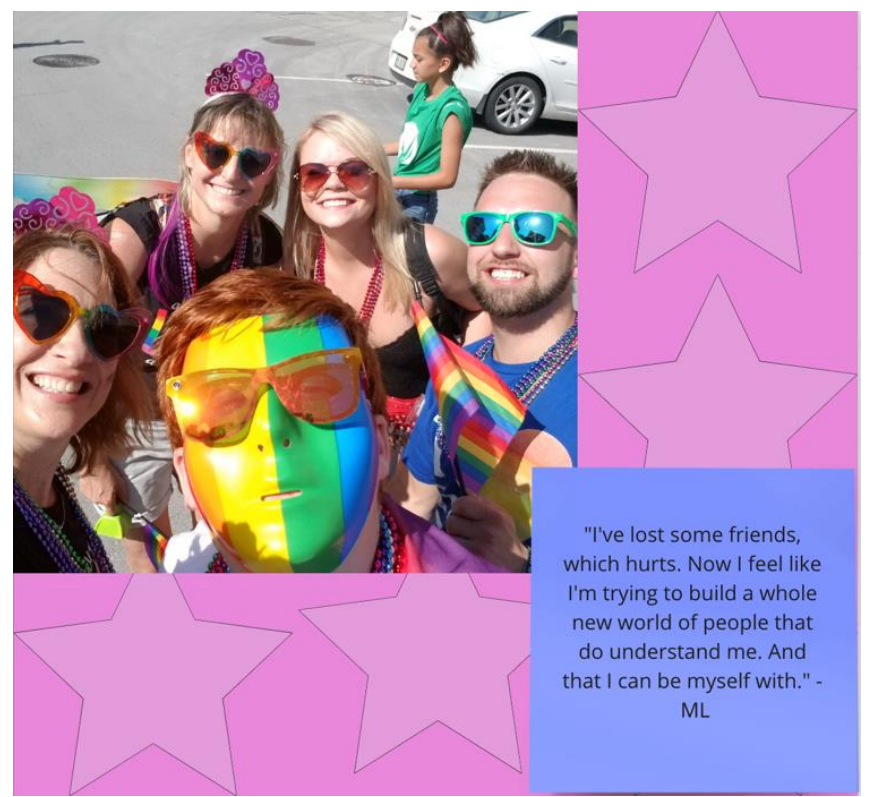


Figure 1.47. ML Exhibit 4

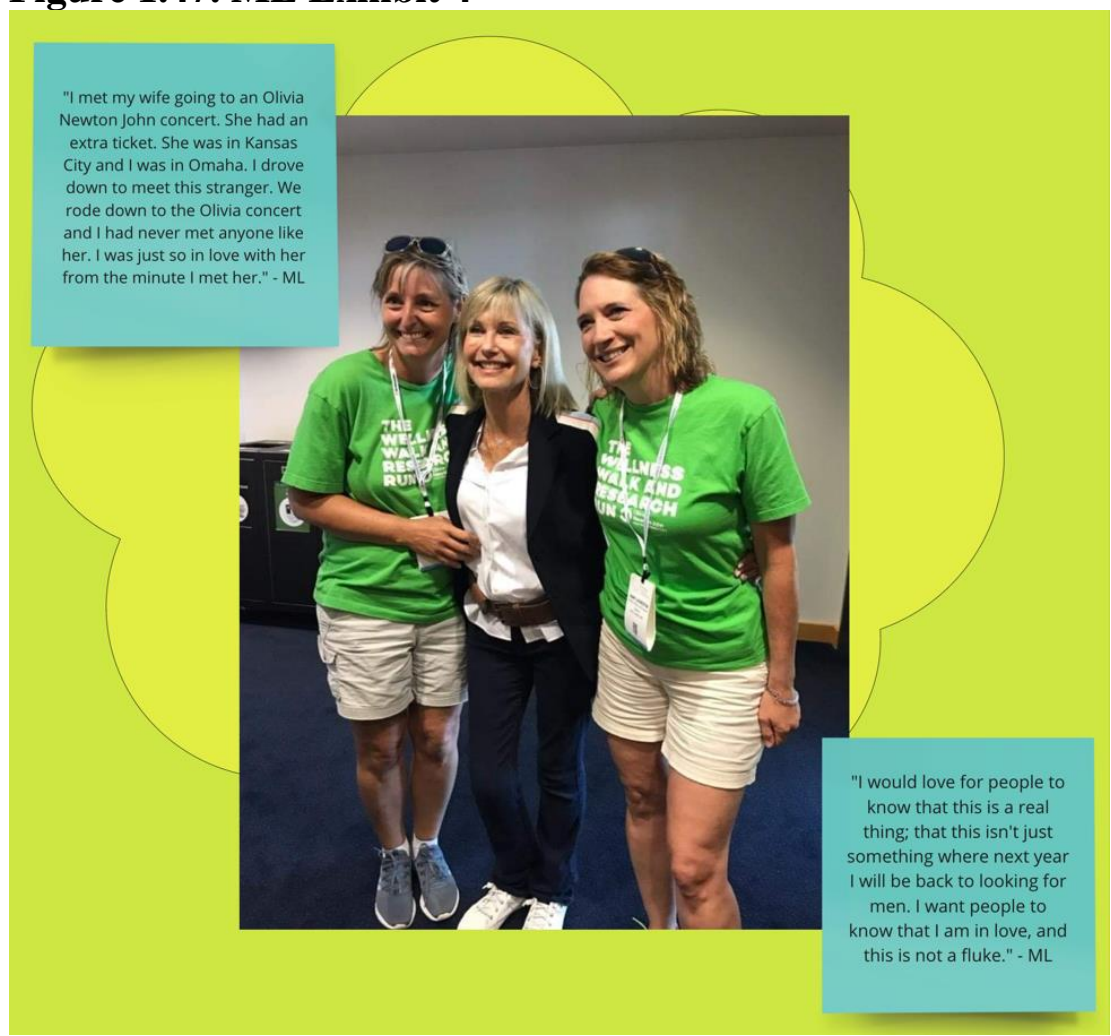

Figure 1.48. ML Exhibit 5

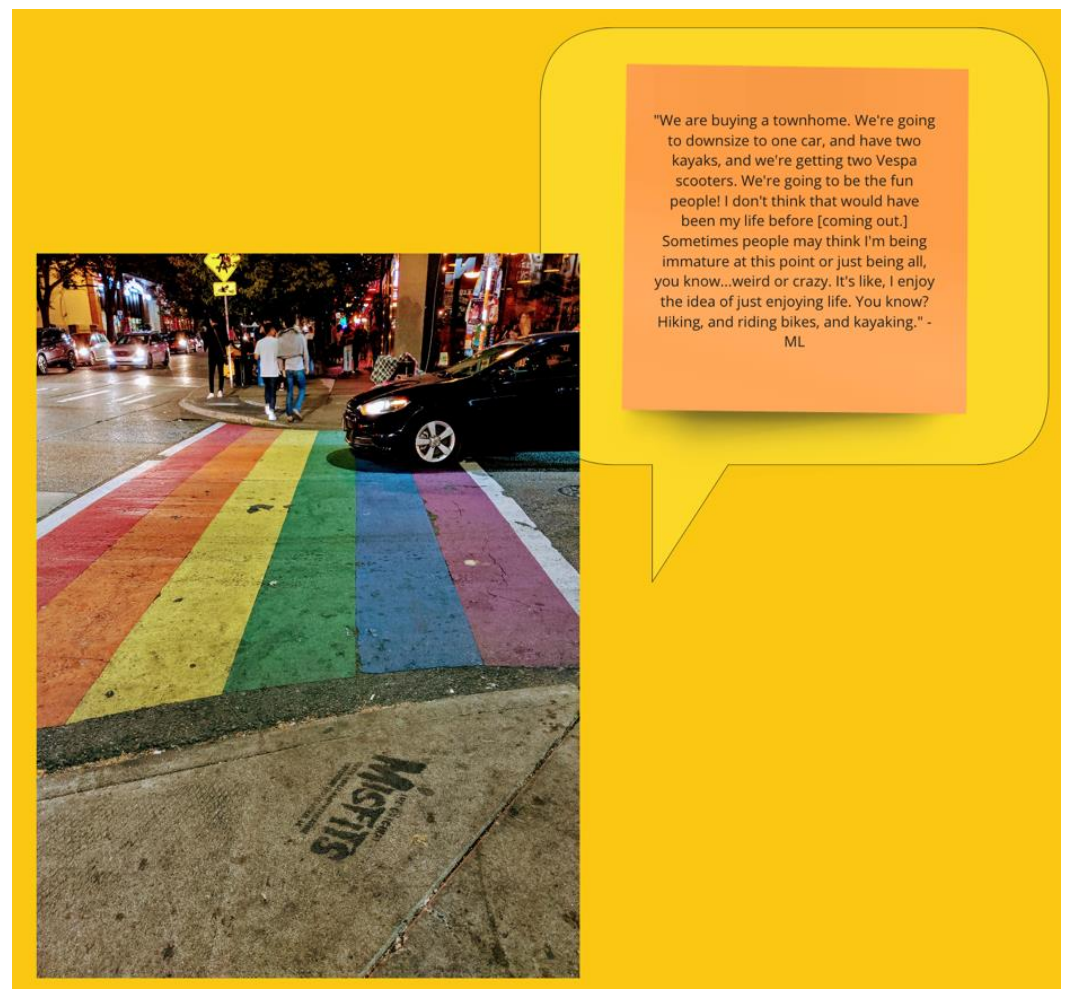


Figure 1.49. ML Exhibit 5

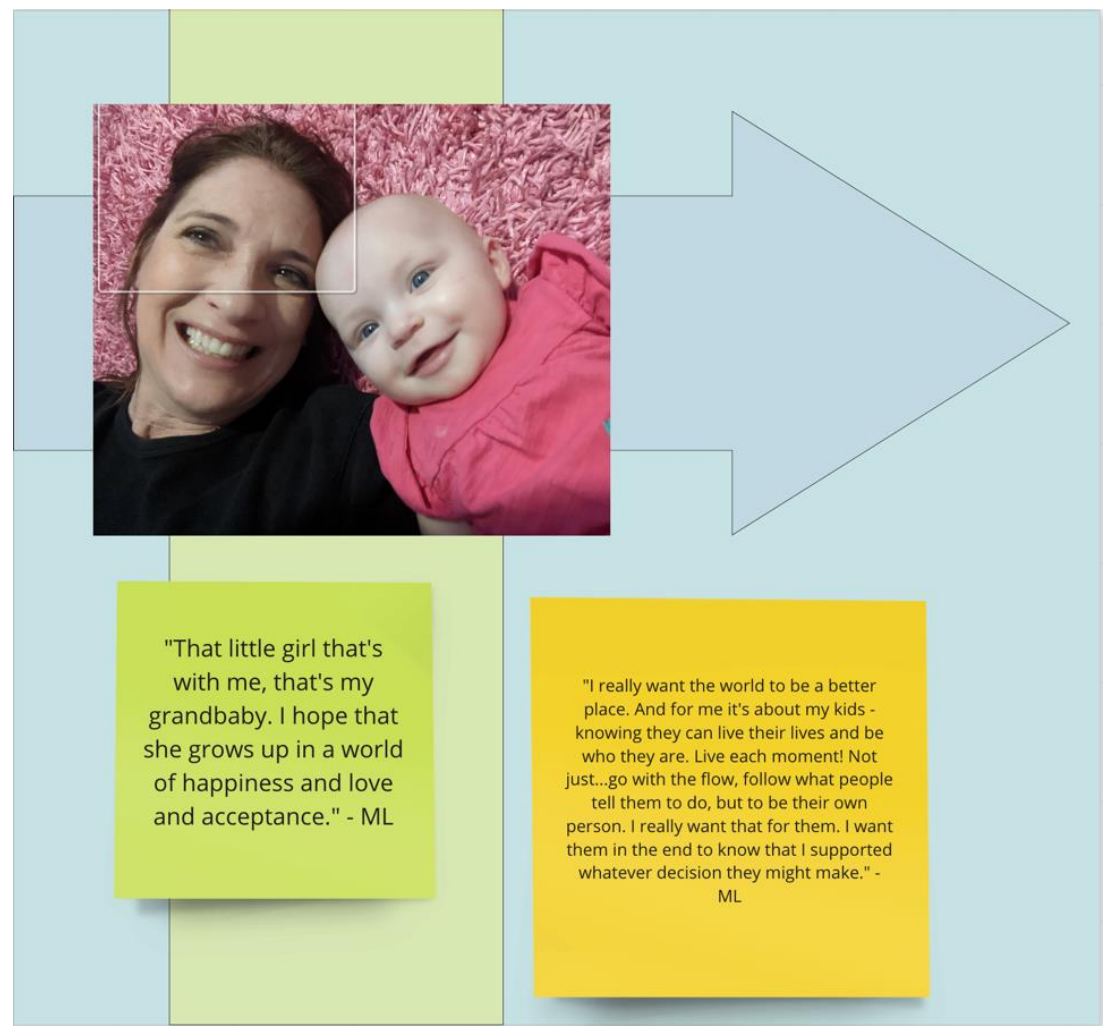

Figure 1.50. ST Exhibit 1

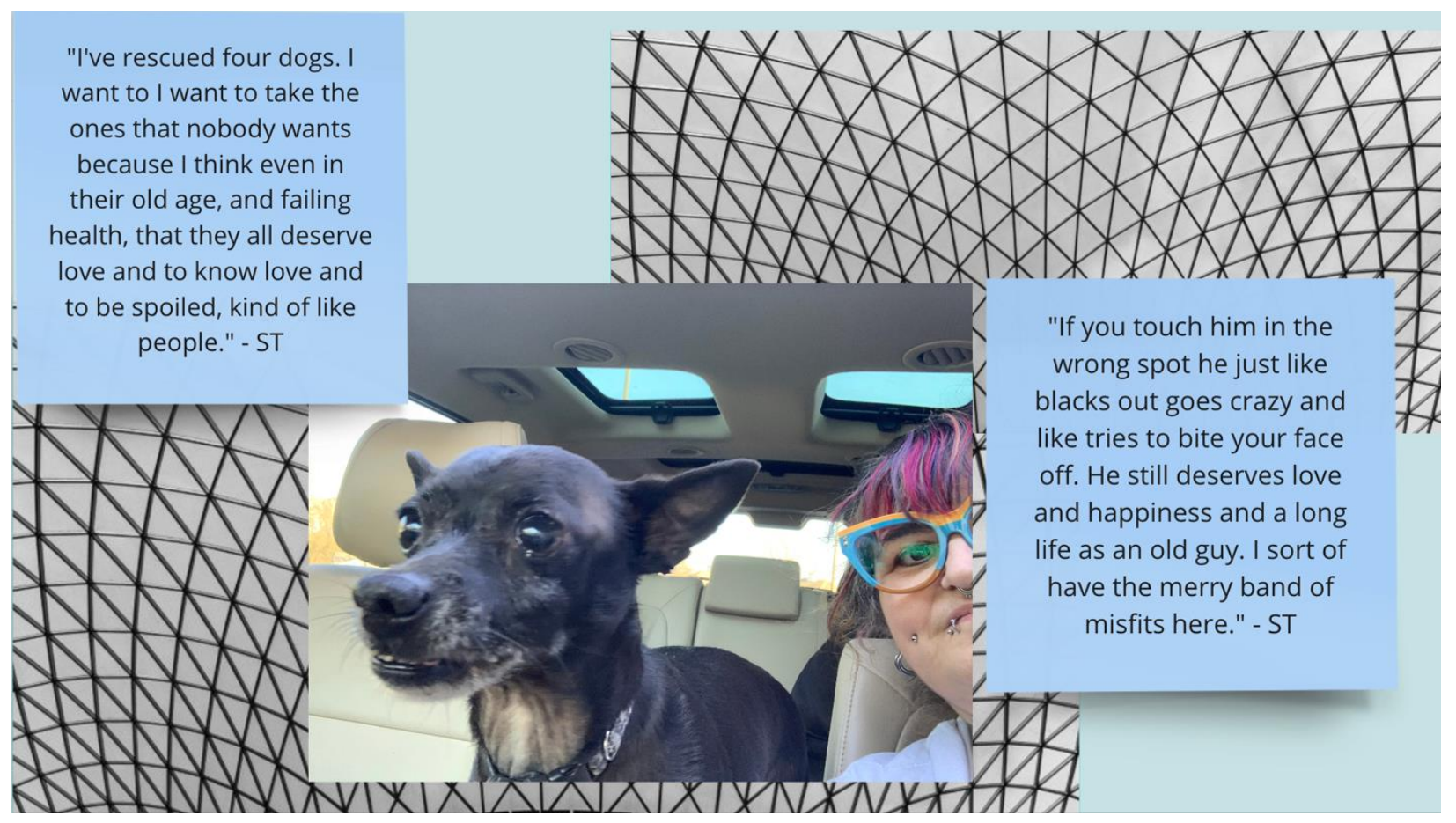




\section{Figure 1.51. ST Exhibit 2}

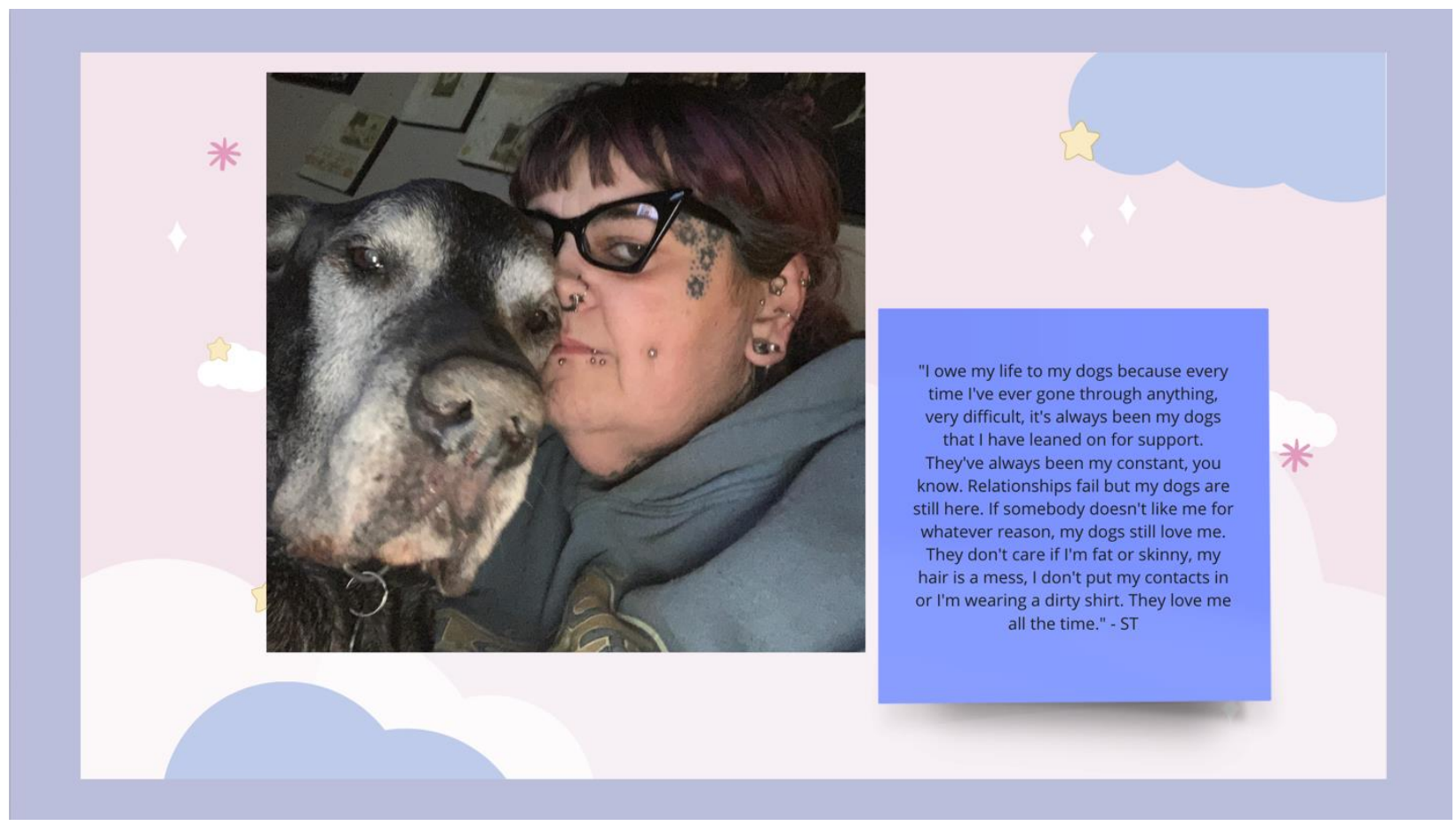

\section{Figure 1.52. ST Exhibit 3}

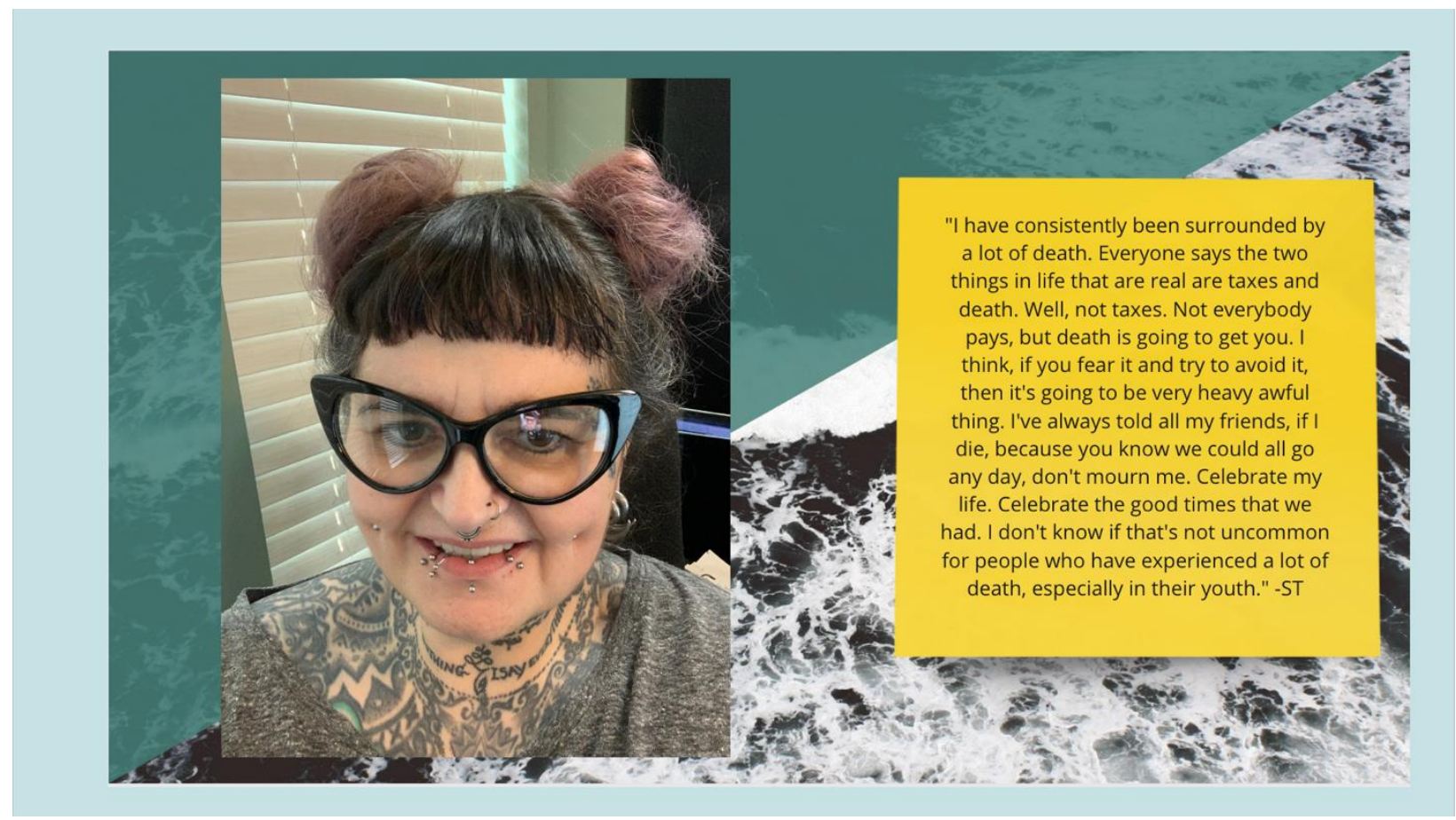


Figure 1.53. ST Exhibit 4

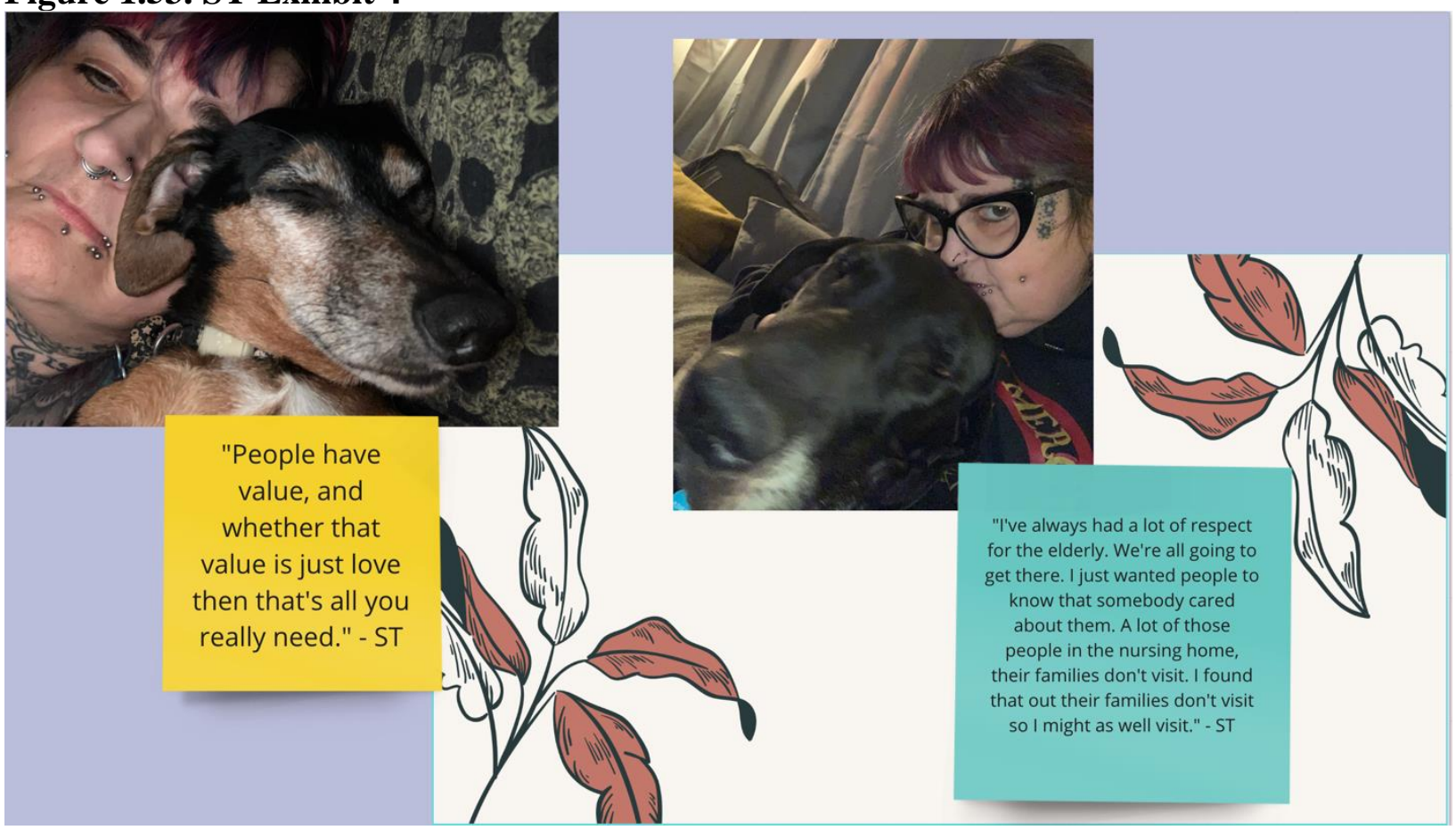

Figure 1.54. ST Exhibit 5

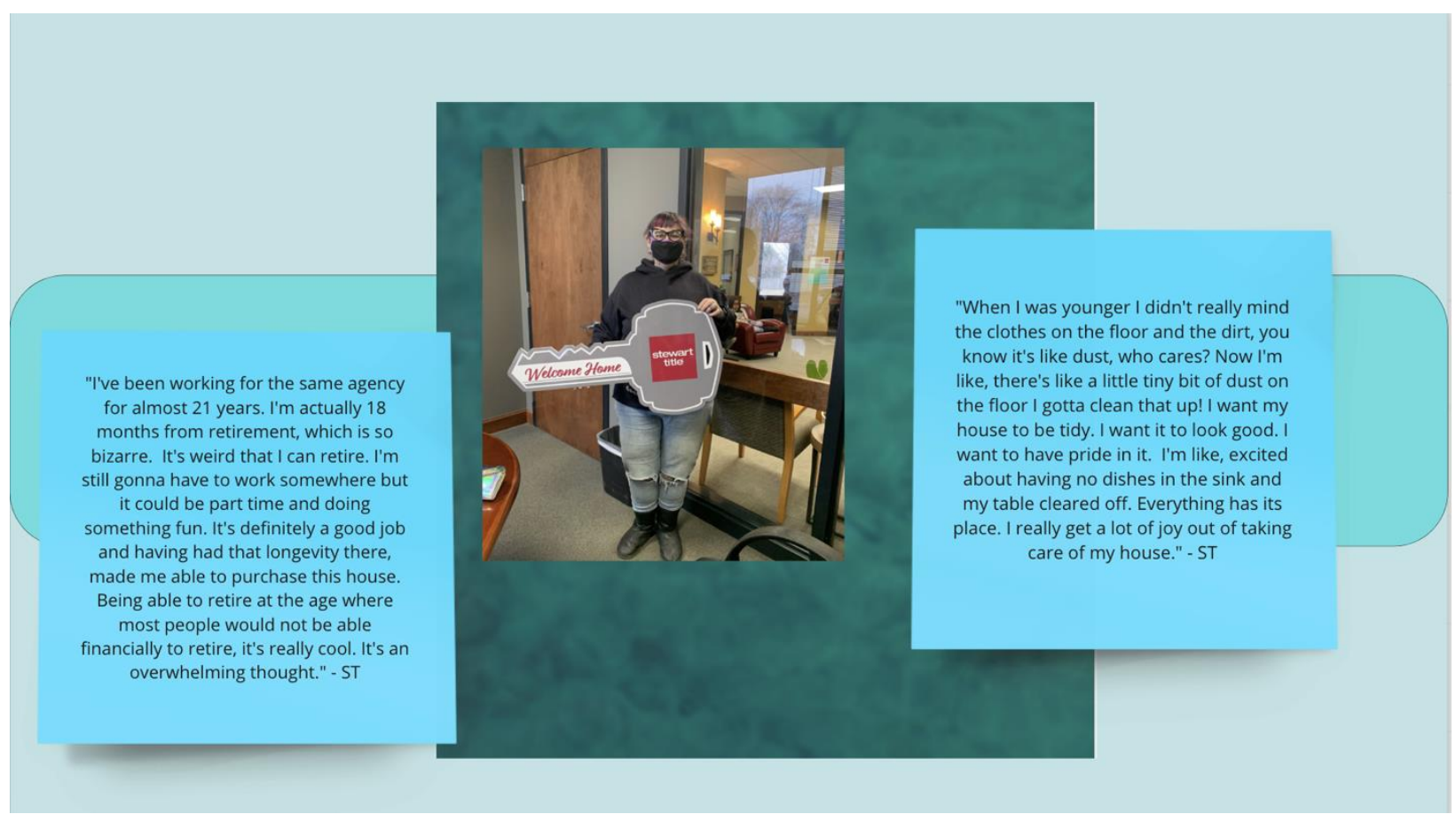




\section{Figure 1.55. ST Exhibit 6}

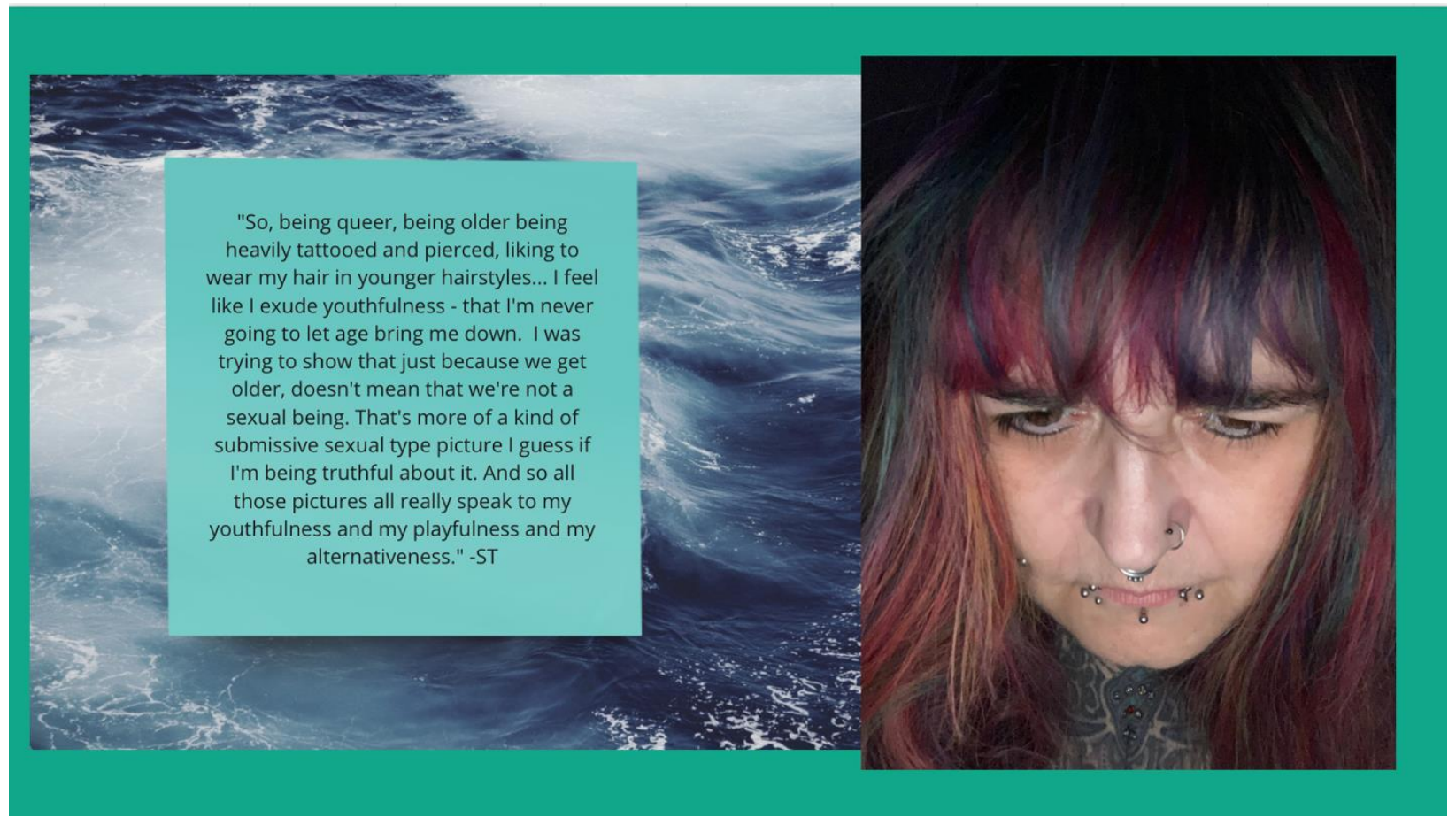

\section{Figure 1.56. ST Exhibit 7}

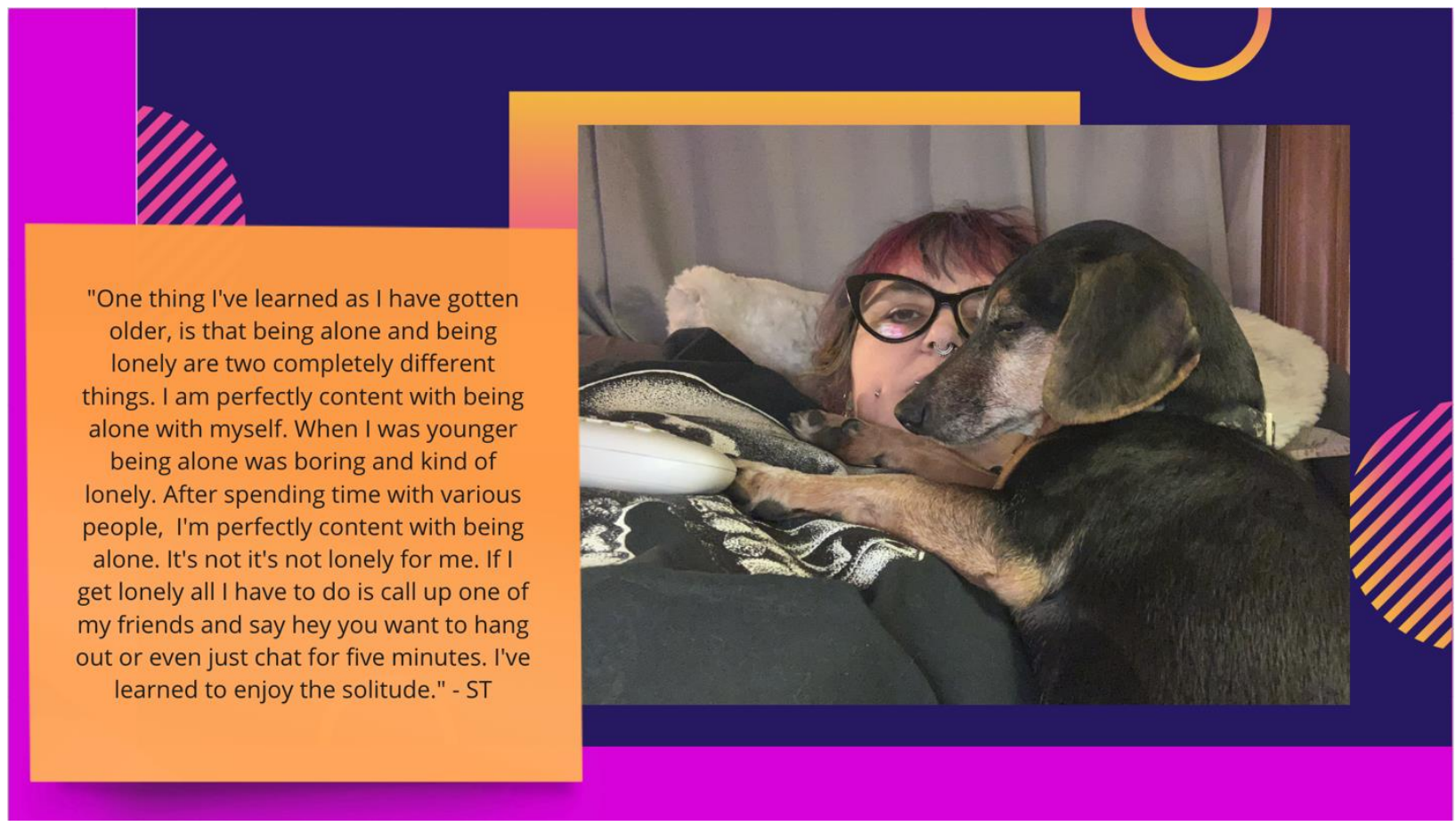




\section{Figure 1.57. ST Exhibit 8}

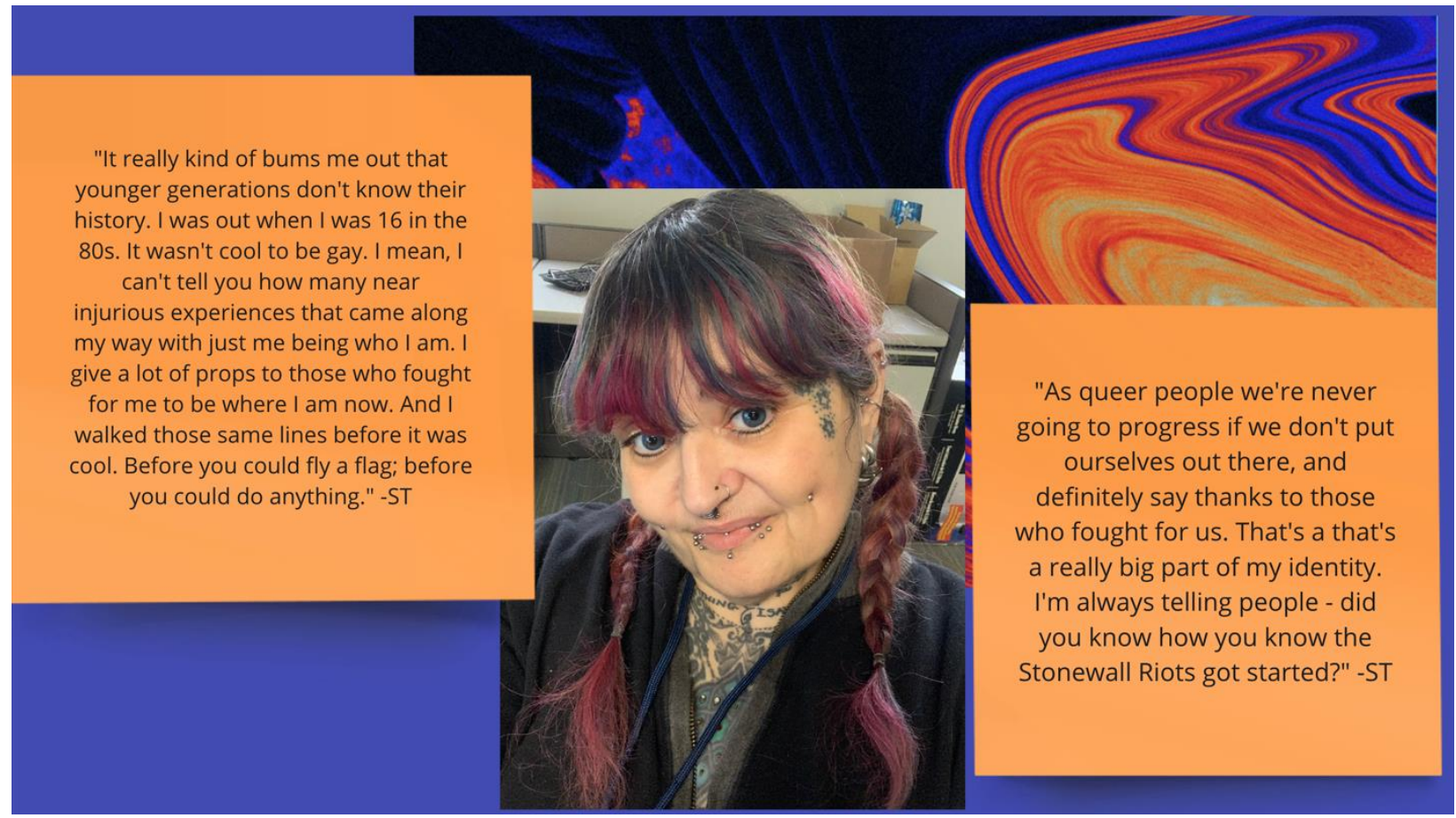




\section{APPENDIX B}

\section{Terms and Definitions}

\begin{tabular}{|c|c|}
\hline Term & Definition \\
\hline Sexual Orientation & $\begin{array}{l}\text { Refers to one's inherent attraction to other people, expressed through } \\
\text { emotional, romantic, and/or sexual intimate relationships (Foglia \& } \\
\text { Fredriksen-Goldsen, 2014). }\end{array}$ \\
\hline Lesbian & $\begin{array}{l}\text { Refers to a female that experiences sexual and/or romantic attraction } \\
\text { to other females (Foglia \& Fredriksen-Goldsen, 2014). }\end{array}$ \\
\hline Gay & $\begin{array}{l}\text { Refers to individuals that experience same-sex sexual or romantic } \\
\text { attraction. This term is commonly used to describe homosexual } \\
\text { males; however, the term can also be used to describe lesbians } \\
\text { (Foglia \& Fredriksen-Goldsen, 2014). }\end{array}$ \\
\hline Bisexual & $\begin{array}{l}\text { Refers to sexual or romantic attraction toward both males and } \\
\text { females (Foglia \& Fredriksen-Goldsen, 2014). }\end{array}$ \\
\hline Queer & $\begin{array}{l}\text { Refers to sexual and/or gender minorities that are not heterosexual or } \\
\text { cisgender. The term was historically used as a slur against } \\
\text { transgender, lesbian, and/or gay individuals, but has been reclaimed } \\
\text { by LGBTQ+ activists over the last } 40 \text { years. The term is often } \\
\text { applied as an umbrella to encompass the scope of LGBTQ+ } \\
\text { identities (Foglia \& Fredriksen-Goldsen, 2014). }\end{array}$ \\
\hline Transgender & $\begin{array}{l}\text { Gender identity and/or expression that does not match the biological } \\
\text { sex at birth (Fredricksen-Goldsen et al., 2011). }\end{array}$ \\
\hline Gender transition & $\begin{array}{l}\text { The process by which an individual begins to transition into living } \\
\text { their lives according to their gender identity, as opposed to the sex } \\
\text { assigned at birth. Transition is unique to each individual and might } \\
\text { include clothing, appearances, changing one's name, or medical } \\
\text { treatments such as hormone therapy or surgery (Fredricksen-Goldsen } \\
\text { et al., 2011). }\end{array}$ \\
\hline Homosexual & $\begin{array}{l}\text { Refers to individuals with romantic and/or sexual attraction to same- } \\
\text { sex individuals (Fredricksen-Goldsen et al., 2011). }\end{array}$ \\
\hline Heterosexual & $\begin{array}{l}\text { Refers to individuals with romantic and/or sexual attraction to the } \\
\text { opposite sex (Fredricksen-Goldsen et al., 2011). }\end{array}$ \\
\hline Cis-Gender & $\begin{array}{l}\text { Refers to an individual that identifies as the gender matching } \\
\text { biological sex at birth, and is typically used to distinguish } \\
\text { transgender/gender nonconforming populations from non- } \\
\text { transgender (Fredricksen-Goldsen et al., 2011). }\end{array}$ \\
\hline
\end{tabular}




\section{APPENDIX C \\ Focus Group Semi-Structured Protocol}

\section{Pre-Session Brief}

The facilitator will contact each participant individually prior to their scheduled focus group to provide an overview and introduction to the project, and also discuss photo taking ethics.

Photovoice: The facilitator will describe the concept of Photovoice and how the method is used.

Ethics, Risk, and Privacy: The facilitator will describe ethical issues such as obtaining informed consent, and avoiding personal information (i.e., addresses, last names, etc.) in photographs. Participants will be provided with a consent form to use if needed, and will receive instruction on how and when to get consent from others.

Project: Facilitator will describe the project and provide questions to guide the photo taking process:

What is it like getting older/aging?

What identities (gender identity or sexual orientation) influence what it is like to get older?

How do these identities influence getting older/aging?

What are some challenges you have experienced?

How have these challenges influenced experiences related to aging?

What are some examples of things that have kept you going or give you joy?

How do these influence experiences relate to aging?

What do you wish service providers (such as healthcare providers, LGBTQ+ advocates, social workers, policy makers, etc.) better understood about you?

The facilitator will then ask the participants to take the next week to take their pictures. The facilitator will ask the participants to select 2-3 of their favorites to email by X date (prior to session 2). 


\section{Focus Group Session 1 \\ Semi-Structured Protocol}

The facilitator will guide each participant through discussing their photos. Conversation will be guided by the following questions:

What is it like getting older/aging?

What identities (gender identity or sexual orientation) influence what it is like to get older?

How do these identities influence getting older/aging?

What are some challenges you have experienced?

How have these challenges influenced experiences related to aging?

What are some examples of things that have kept you going or give you joy?

How do these influence experiences relate to aging?

What do you wish service providers (such as healthcare providers, LGBTQ+ advocates, social workers, policy makers, etc.) better understood about you?

After the discussion, participants will be asked to write narratives for the photos they will be submitting to the exhibit and email to the facilitator by $\mathrm{X}$ date (prior to Session 3 ).

\section{Focus Group Session 2 (Exhibit Semi-Structured Protocol}

Participants will be shown a the exhibit via private web page, and the facilitator will use the following questions to guide discussion:

What critical issues do you see displayed here?

When you look at the photos and read the narratives, what challenges stand out to you?

How does it help us better understand about what it is like to get older/age?

When you look at the photos and read the narratives, what are some joyful examples that stand out to you?

How does it help us better understand about what it is like to get older/age? 
Do you see anything that surprises you?

What are some perspective/representation gaps that you see reflected in the photos/narratives? Who is missing from the photos/narratives that should be represented?

What were your experiences with participating in this project? 


\section{APPENDIX D}

\section{Key Stakeholder Survey}

What is your title/role/employment field?

What kind of work do you do in this position? What populations do you serve?

\section{View the exhibit website and answer the following open-ended survey questions:}

What critical issues do you see displayed in the images?

When you look at the photos and read the narratives, what challenges stand out to you? How does it help us better understand about what it is like to get older/age?

When you look at the photos and read the narratives, what are some joyful examples that stand out to you?

How does it help us better understand about what it is like to get older/age?

Do you see anything that surprises you?

What are some perspective/representation gaps that you see reflected in the photos/narratives? Who is missing from the photos/narratives that should be represented?

What were your experiences with viewing this project?

How might you apply what you learned from the photos/narratives to the work that you do?

How, if at all, do these photos/narratives help prepare you to interact/communicate with this population?

What else would you like to share? 
APPENDIX E

\section{Participant Consent Form}

\section{Consent Form to Participate in a Research Study}

\section{Name(s) Of Researcher(s): $\quad$ Steffany sloan, Jacquelyn benson, and Michelle Teti PROJECT IRB \#:}

\section{STUDY TITLE: BARRIERS AND CATALYSTS OF SUCCESSFUL AGING FOR LGBTQ+ INDIVIDUALS: A PHOTOVOICE STUDY}

This research study is about successful aging for LGBTQ+ older adults. We are doing this study to better understand challenges and resilience inherent to the aging process for LGBTQ+ individuals.

We invite you to take part in this research study, because you identify as LGBTQ+ and are age 50 or older. This consent form tells you why we are doing the study, and what will happen if you join the study.

Please take as much time as you need to read this consent form. You can discuss it with your family, friends, or anyone you choose. If there is anything you do not understand, please ask us to explain. Then you can decide if you want to take part in the study or not.

Research studies help us to answer questions that may improve our understanding of human behavior, attitudes, beliefs, and interactions. Taking part in a research study is voluntary. You are free to say yes or no. We will only include you in this study if you give us your permission first by signing this consent form. Participation in this study is voluntary. 


\section{Why Is This Study Being Done?}

The purpose of this research is to use "photo narratives" (the process of taking pictures, discussing pictures, and sharing pictures) to better understand aging as a LGBTQ+ individual. The photo narratives will be transformed into a virtual exhibit to help educate and inform service providers and LGBTQ+ community members.

\section{How Many People Will Be In This Study?}

About 16 LGBTQ+ individuals and 30 service providers will take part in this study. LGBTQ+ participants will be assigned to a focus group consisting of 3-4 individuals each.

\section{What Will Happen If I TAKe Part In This Study?}

If you agree, you will take and discuss pictures about growing older as an LGBTQ+ person. In addition to taking pictures you will attend three virtual focus groups. 1. At the first visit you will learn about the study and discuss taking pictures with your mobile device or digital camera. We will discuss ideas for taking pictures if you want us to, but there are no wrong answers. You are simply going to tell your story with pictures. 2. You will then have one week to take pictures that capture your story of growing older as an LGBTQ+ person.

3. Then you will attend a recorded virtual focus group meeting, and in that meeting you will present 2-3 photos of your choice. You will show and discuss your photos and the photos of other group members.

4. We will then meet a third time in a recorded virtual focus group. The group will discuss and organize the photo narratives into a virtual exhibit.

\section{How Long WiLl I Be IN The Study?}

We will ask you to attend a 1-2 hour focus group once per week for three weeks.

\section{Can I Stop Being In The Study?}


Yes, you can stop being in the study at any time without giving a reason. Just tell the researcher or study staff right away if you wish to stop taking part.

Also, the researcher may decide to take you off this study at any time, even if you want to stay in the study. The researcher will tell you the reason why you need to stop being in the study.

\section{Are There Any Benefits To Taking Part In This Study?}

There might be no direct benefit to you from taking part in this study. However, the information we learn from you during this study may help us better understand growing older as an LGBTQ+ person.

\section{Are There Any Risks From Being In This Study?}

You may feel uncomfortable talking about personal issues, such as your experience with stigma, marginalization, discrimination, body image, health challenges, etc. You do not have to talk about anything that you do not want to discuss. Depending on what you take pictures of, you may risk your privacy with your images. Remember that you decide which pictures you will take to tell your story.

\section{What Other Choices Do I have If I Don't Take Part?}

Instead of being in this study, your choices may include:

Attending support or networking groups for LGBTQ+ individuals offered by various community organizations in the Kansas City area. An alternative is to not participate in this research study.

\section{Will Information About Me Be Kept Private?}

The information we collect about you will be stored in the researcher's electronic/computer or paper files. Computer files are protected with a password and 
the computer is in a locked office that only study team members can open. Paper files are kept in a locked drawer in a locked office that only study team members can open.

We will give your records a code number and they will not contain your name or other information that could identify you. The code number that connects your name to your information will be kept in a separate, secure location. Information that may identify you may not be given to anyone who is not working on this study without your written consent, or if required by law.

We will do our best to make sure that your personal information from this study is kept private, but we cannot guarantee total privacy. We may give out your personal information if the law requires it. If we publish the results of this study or present them at scientific meetings, we will not use your name or other personal information.

The information we collect from you for this study will not be used or shared with other investigators for future research studies. This applies even if we remove all information that could identify you from your information.

You must give us permission to use the photographs, audio/video recordings we take of you during the study. You will be able to view them before you give your permission for us to use them.

\section{WiLl I Be PAID For TAKING PART In ThIS Study?}

You will not be paid for taking part in this study.

\section{What Are My Rights as a Study Participant?}

Taking part in this study is voluntary. If you do decide to take part, you have the right to change your mind and drop out of the study at any time. Whatever your decision, there will be no penalty to you in any way. 
We will tell you about any new information discovered during this study that might affect your health, welfare, or change your mind about taking part.

\section{Who Can I Call If I Have Questions, Concerns, Or Complaints?}

If you have more questions about this study at any time, you can call Dr. Michelle Teti at 573-884-6705 or Dr. Jaquelyn Benson at 573-882-4399.

You may contact the University of Missouri Institutional Review Board (IRB if you:

- Have any questions about your rights as a study participant;

- Want to report any problems or complaints; or

- Feel under any pressure to take part or stay in this study.

- The IRB is a group of people who review research studies to make sure the rights of participants are protected. Their phone number is $573-882-3181$.

If you want to talk privately about your rights or any issues related to your participation in this study, you can contact University of Missouri Research Participant Advocacy by calling 888-280-5002 (a free call), or emailing MUResearchRPA@missouri.edu.

We will give you a copy of this consent form. Please keep it where you can find it easily. It will help you to remember what we discussed today.

\section{Signature of Participant}

\section{Consent to Participate in Research}

By signing my name below, I confirm the following:

- I have read/had read to me this entire consent form.

- All of my questions were answered to my satisfaction. 
- The study's purpose, procedures/activities, potential risks and possible benefits were explained to me.

- I voluntarily agree to take part in this research study. I have been told that I can stop at any time.

\begin{abstract}
APPENDIX F
Oral Script

This research study is about successful aging for LGBTQ+ older adults. We are doing this study to better understand challenges and resilience inherent to the aging process for LGBTQ+ individuals. This project involves research. These focus groups will be audio recorded. you will take and discuss pictures about growing older as an LGBTQ+ person. Your participation in this study is completely voluntary.

\section{You will be taking pictures to show your experience of growing older and attend three} virtual focus groups. The focus groups will be 1-2 hours, once a week, for three weeks total. You will select 2-3 photos that you would like to display in a virtual exhibit at the end of our time together.
\end{abstract}

1. At the first visit you will learn about the study and discuss taking pictures with your mobile device or digital camera. We will discuss ideas for taking pictures if you want us to, but there are no wrong answers. You are simply going to tell your story with pictures. 2. You will then have one week to take pictures that capture your story of growing older as an LGBTQ+ person.

3. Then you will attend a recorded virtual focus group meeting, and in that meeting you will present select photos of your choice. You will show and discuss your photos and the photos of other group members. 
4. We will then meet a third time in a recorded virtual focus group. The group will discuss and organize the photo narratives into a virtual exhibit.

During these focus group sessions, you might discuss some things about personal issues that might result in minor discomfort. You may feel uncomfortable talking about personal issues, such as your experience with stigma, marginalization, discrimination, body image, health challenges, etc. You do not have to talk about anything that you do not want to discuss. Remember that you decide which pictures you will take to tell your story.

You can stop being in the study at any time.

Just a reminder, my name is Steffany Sloan. I am a Doctoral Candidate at the University of Missouri-Columbia. My contact information is sms5ef@umsystem.edu. I can also be reached by phone at 816-328-6829. You can also contact my supervisor, Dr. Jaquelyn Benson. She can be reached at 573-882-4399 or by email at bensonjj@missouri.edu. If you want to talk privately about your rights or any issues related to your participation in this study, you can contact University of Missouri Research Participant Advocacy by calling 888-280-5002 (a free call), or emailing MUResearchRPA@missouri.edu. 
APPENDIX G

Photovoice Recruitment Ad

\section{Do you identify as LGBTQIAt? Are you 50 years or older? \\ Do you like to take photos?}

Researchers at the University of Missouri are conducting a study using photo narratives to understand the experience of growing older as a LGBTQIA+ person.

\section{Participation includes:}

- Taking and sharing pictures with a small group

- Creating a virtual exhibit to share with the community

- Participation includes:

- One (2 hour) virtual focus group

- One (2 hour) virtual exhibit presentation

\section{Sounds fun!}

\section{How do I Participate?}

Email kcphotonarrativeproject@gmail.com

Text or call 816-328-6829

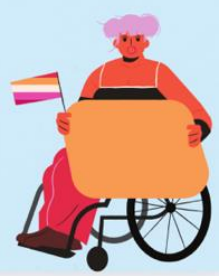


APPENDIX H

Stakeholder Survey Informed Consent

\section{Photo Narrative Exhibit Viewer Survey}

Q1 You are invited to take a survey about the photo narrative exhibit about growing older as an LGBTQ individual. You have been invited to participate in this study because you are a service provider (e.g. case manager, healthcare provider, social worker, educator, etc.) in the greater Kansas City area. We hope to learn about your experiences viewing this exhibit to help us understand ways to improve services, programs, and policies for LGBTQ individuals.

If you decide to participate, please complete the questions that start on the next page. You will be asked to describe your role as a service provider, about the type of work that you do, and the populations that you serve. Finally, you will be asked to describe your experiences viewing the exhibit and the impact of the images and narratives.

You may not directly benefit from this research. However, we hope that this research will result in finding ways to support the well-being of the LGBTQ population.

If you decide to participate, you can choose to stop at any time. If you are not comfortable answering certain questions, they can be skipped. There are no anticipated risks to participating in this survey, however, if discomfort arises, please know that you can stop at any time.

Data will be collected using the Internet. There are no guarantees of the security of data sent on the Internet. Confidentiality will be kept to the degree permitted by the technology used.

This study has been approved by the Institutional Review Board at the University of Missouri-Columbia.

Please feel free to ask questions regarding this study. You may contact Steffany Sloan at KCPhotoNarrativeProject@gmail.com if you have any questions.

Thank you for your time. 
By clicking the link below, I confirm that I have read this form and will participate in the project described. Its general purposes, the particulars of involvement, and the possible risks and inconveniences have been explained to my satisfaction. I understand that I can discontinue participation at any time. My consent also indicates that I am at least 18 years of age.

[Please feel free to print a copy of this consent.]

I agree to participate, begin the Study. (1)

I decline, I do not wish to participate (2)

\section{Display This Question:}

If You are invited to take a survey about the photo narrative exhibit about growing older as an LGBT... = I agree to participate, begin the Study. 
VITA

Steffany Sloan is from Kansas City, Missouri. In 2002 she earned a Bachelor of Science with a major in Computer Science from DeVry University. She then went on to earn a Master of Elementary Education in 2005. She earned a certificate in English Language Learning and Language Acquisition in 2007. Steffany taught in the Kansas City Public School District from 2003-2008. She then worked as a case manager and parent educator in the non-profit sector from 2008-2016. Steffany earned a Ph.D in Human Development and Family Science and a Certificate in Participatory Health Research in 2021. Her research interests focus on LGBTQ+ populations, older adults, and the application of community-based participatory methods. Steffany currently works as an Associate Researcher at the University of Kansas Center for Public Partnerships and Research. She resides in Kansas City, MO with her partner Lara, and her four children, Lilah, Miles, Violet, and August. 